UNIVERSIDADE DE SÃO PAULO

INSTITUTO DE GEOCIÊNCIAS

\title{
RECONSTITUIÇÃO DA PLUVIOSIDADE DA CHAPADA DIAMANTINA (BA) DURANTE O QUATERNÁRIO TARDIO ATRAVÉS DE REGISTROS ISOTÓPICOS (O E C) EM ESTALAGMITES
}

Eline Alves de Souza Barreto

Orientador: Prof. Dr. Francisco William da Cruz Júnior

\author{
DISSERTAÇÃO DE MESTRADO \\ Programa de Pós-Graduação em Geoquímica e Geotectônica
}

São Paulo

2010 
UNIVERSIDADE DE SÃO PAULO

INSTITUTO DE GEOCIÊNCIAS

\section{RECONSTITUIÇÃO DA PLUVIOSIDADE DA CHAPADA DIAMANTINA (BA) DURANTE O QUATERNÁRIO TARDIO ATRAVÉS DE REGISTROS ISOTÓPICOS (O E C) EM ESTALAGMITES}

Eline Alves de Souza Barreto

Dissertação de mestrado apresentada junto ao Instituto de Geociências da Universidade de São Paulo na Área de Geoquímica dos Processos Exógenos para a obtenção do título de Mestre em Geociências.

São Paulo

2010 
Autorizo a reprodução e divulgação total ou parcial deste trabalho, por qualquer meio convencional ou eletrônico, para fins de estudo e pesquisa, desde que citada a fonte

Ficha catalográfica preparada pelo Serviço de Biblioteca e Documentação do Instituto de Geociências da Universidade de São Paulo

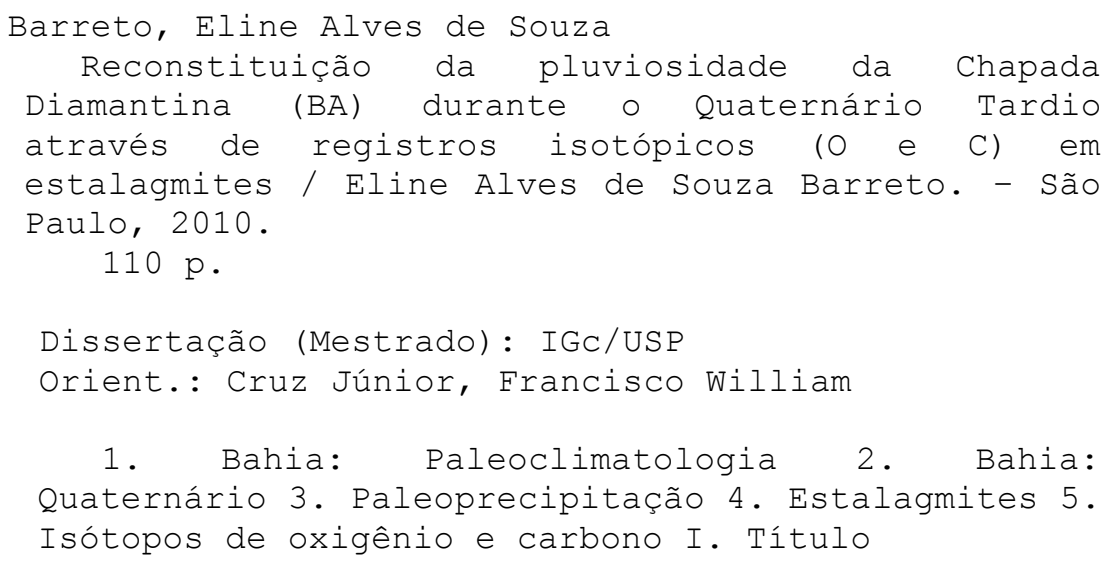


Ventana sobre la utopía

"Ella está en el horizonte [...].

Me acerco dos pasos, ella se aleja dos pasos.

Camino diez pasos y el horizonte se corre diez pasos más allá.

Por mucho que yo camine, nunca la alcanzaré.

¿Para qué sirve la utopía? Para eso sirve: para caminar”

\section{Eduardo Galeano}

Las palabras andantes 


\section{AGRADECIMENTOS}

Ao professor Dr. Francisco William da Cruz Jr. pelo forte apoio como orientador e amigo em todas as etapas do mestrado, por dispensar o esforço possível para a concretização deste trabalho.

Ao professor Dr. Ivo Karmann por apoiar e acreditar no trabalho desde o início, contribuindo por meio de discussões e atividades práticas imprescindíveis.

Ao Dr. Xianfeng Wang, Dr. Hai Cheng e ao Prof. Dr. Lawrence Edwards da Universidade de Minnesota (Estados Unidos) pela importante cooperação laboratorial possibilitando a realização das análises geocronológicas.

À Prof ${ }^{a}$. Dra. Maria Helena Hollanda, Dr. Luis Mancine e Alyne B. da Silva pelas análises realizadas no laboratório de isótopos estáveis do Centro de Pesquisas Geocronológicas (LIECPGEO) do IGc/USP.

Ao Prof. Dr. Stephen Burns da Universidade de Massachusetts (Estados Unidos) pela disponibilização dos dados isotópicos da estalagmite DV2.

Ao Prof. Dr. Mathias Vuille da Universidade de Albany (Estados Unidos) pelas imprescindíveis discussões, pela confecção do mapa climático e pela disponibilização das imagens obtidas através das simulações do modelo climático ECHAM-4.

Especialmente ao amigo e colega de laboratório Nicolás Strikis pela amizade e pela imensa contribuição na realização deste trabalho, tanto com atividades práticas como por meio de importantes discussões.

Também agradeço de modo especial ao colega Marcos Saito de Paula pelo apoio imprescindível na conclusão deste trabalho.

À Sheila S. do Carmo pela grande contribuição na realização das atividades laboratoriais como também pela amizade. Agradeço também aos colegas de laboratório Maria Carolina Catunda, Valdir Novello e Thaize Baroni pelo apoio nas atividades do laboratório de Sistemas Cársticos do IGc/USP e pela ajuda direta e indireta neste trabalho.

Ao Dr. Augusto Auler pelas dicas e discussões e à Prof a . Dr. Sônia Barros de Oliveira pela compreensão e pelas valiosas sugestões durante a disciplina Seminários Gerais.

Ao Manoel Souza pela paciência e por confeccionar os suportes para estalagmites necessários para a realização das análises isotópicas.

À Paula Andrea P. Espitia pela contribuição com o texto final da dissertação.

À Ericson Igual pelo importante apoio nas viagens de campo e pela sincera amizade. Agradeço também a Roger S. Soares pela ajuda no trabalho de campo na Chapada Diamantina. 
Ao Grupo Pierre Martin de Espeleologia (GPME) e a União Paulista de Espeleologia (UPE) pela cooperação e auxílio nas atividades de campo e ao Grupo Bambuí de Pesquisas Espeleológicas pela disponibilização do mapa da caverna Ioiô.

Ao Centro da Terra - Grupo Espeleológico de Sergipe pelo apoio às saídas de campo no Estado de Sergipe como também pelo incentivo e motivação para a realização deste trabalho.

Especialmente à minha mãe, Maria José A. Simões, a qual com todo amor não mediu esforços para tornar possível a realização do mestrado. A ela também sou imensamente grata pelo grande exemplo de perseverança e por ensinar que tudo deve ser feito com determinação.

Aos meus tios, Maria Simões e Antônio Silva, por fornecerem sem precedentes o amor e o apoio incondicional para a morada em São Paulo. A eles sou infinitamente grata.

Ao meu irmão, Erick A. S. Barreto e a minha tia Vania A.S. Dantas, pelo amor e por acreditar desde o início que tudo daria certo. Agradeço ao meu pai Antônio Eduardo S. Barreto por apoiar-me. Também agradeço ao meu padrasto Antônio Carlos Brito pelo carinho.

À minha grande amiga, Elaine Cristina Bornancin, pela profunda amizade e por tornar a morada em São Paulo algo verdadeiramente bom. A ela sou muito grata por todo o carinho, pela paciência nos momentos difíceis e pela contagiante alegria.

Ao meu companheiro, Marcelo Rojas, sou grata pelo amor, pela dedicação e pelo exemplo de determinação. Agradeço especialmente por ajudar-me na conclusão deste trabalho e pelo intenso apoio nos momentos mais difíceis na reta final deste caminho.

Especialmente à Gisele Utida pelo imprescindível apoio para o ingresso do mestrado, pelo companheirismo durante toda esta jornada e pela sincera amizade. Também agradeço aos meus colegas de sala Felipe van Enky Meira e Mírian Liza A. F. Pacheco pelo carinho, pelas boas conversas e brincadeiras.

Aos amigos Claúdia Salata, Ayanne Maciel, Karin Luitz, Sarah Alencar, Camila Yumi, Fábio Pimentel, Yasmin Poe, Alba Marina Suarez, Karol Suescun, Maria Glória Motta, Estêvão Sumburane e a todos os colegas; agradeço pelas conversas e pelos bons momentos divididos em São Paulo. Sou grata enfim por compartilharmos simplesmente a amizade.

Agradecimentos especiais aos amigos de Aracaju Christiane R. Donato, Ericka Alexandra B. de Almeida, Mário André T. Dantas e Elias José Silva, os quais acompanham-me a muito tempo e que mesmo longe estiveram presentes durante este ciclo.

A toda a minha grande família, exatamente a todos, sou grata por todo o amor e carinho. A todos os meus amigos que apoiaram-me com a amizade mais sincera. Enfim agradeço a todos que contribuíram direta e indiretamente nesta trilha.

À FAFESP (Fundação de Amparo à pesquisa de São Paulo) pelo auxílio financeiro através bolsa de estudo (2008/01997-0). Agradeço também ao financiamento inicial fornecido pelo $\mathrm{CNPq}$ (Conselho Nacional de Desenvolvimento Científico e Tecnológico). 


\section{RESUMO}

BARRETO, E. A. de S. Reconstituição da pluviosidade da Chapada Diamantina (BA) durante o Quaternário Tardio através de registros isotópicos $(O$ e $C)$ em estalagmites. 2010. 110. f. Dissertação (mestrado) - Instituto de Geociências, Universidade de São Paulo, São Paulo.

Registros das razões isotópicas do oxigênio $\left(\delta^{18} \mathrm{O}\right)$ e do carbono $\left(\delta^{13} \mathrm{C}\right)$, juntamente com as taxas de crescimento de espeleotemas, precisamente datados pelo método U/Th, foram utilizados para reconstituição das variações de pluviosidade dos últimos 93 mil anos A.P. na região da Chapada Diamantina, porção central do Estado da Bahia. A reconstituição paleoclimática foi apoiada por estudo de calibração realizado em duas cavernas da região estudada, através do qual se obteve boa relação entre a assinatura isotópica da chuva e do $\delta^{18} \mathrm{O}$ dos gotejamentos e evidências de condições ambientais propícias para deposição de espeleotemas em equilíbrio isotópico com a água de gotejamento. A interpretação climática dos dados de $\delta^{18} \mathrm{O}$ dos espeleotemas considera também a análise da composição isotópica da água da chuva em face da pluviometria, a partir de dados de estações do IAEA-GNIP no Brasil e de simulações das variações do $\delta^{18} \mathrm{O}$ da chuva através do modelo climático ECHAM-4. Esses dados indicam o fator "amount effect", como relação preponderante na discussão de pluviosidade através dos registros de espeleotemas, a qual é caracterizada pela diminuição dos valores de $\delta^{18} \mathrm{O}$ com o aumento do volume de chuvas. A partir dos registros de $\delta^{18} \mathrm{O}$ dos espeleotemas foi possível reconstituir os padrões regionais de pluviosidade segundo o ciclo de insolação, como também identificar eventos de mudança abrupta de pluviosidade em escala milenar ocorridos durante o último período glacial e Holoceno. Em escala orbital, foi observado aumento (diminuição) da paleoprecipitação na Bahia durante fases de baixa (alta) insolação de verão $\left(10^{\circ} \mathrm{S}\right)$. Essa relação é evidente na maior parte do registro baiano com exceção do período entre 40 e 20 ky A.P., quando houve predomínio de clima seco, mesmo em fases de insolação baixa. No entanto, tal é relação inversa a que foi descrita em estudos paleoclimáticos do Sul/Sudeste do Brasil e dos Andes. Além disso, variações de paleopluviosidade da Chapada Diamantina estão em fase com as registradas nos trópicos do Hemisfério Norte, na China e Venezuela. Esses resultados indicam influência direta do sistema de Monções Sul-americana (MSA) sobre o regime de chuvas do Nordeste em longa escala de tempo, a qual é primariamente modulada pela intensidade da insolação de verão. Aumentos abruptos da paleopluviosidade em escala milenar, indicados por baixos valores de $\delta^{18} \mathrm{O}$ e $\delta^{13} \mathrm{C}$, como pelas altas taxas de crescimento de espeleotemas, ocorreram durante predomínio de condições frias no Atlântico Norte, em períodos de grandes mudanças nas condições oceânicas, e são concomitantes com os eventos Heinrich e Younger Dryas. Já fortes diminuições foram observadas durante alguns eventos Dansgaard-Oeschger e Bølling-Allerød. Ao contrário do que foi observado durante os ciclos orbitais, o impacto no clima da Bahia atribuído a esses eventos é semelhante em todo país e também nos Andes, de acordo com estudo comparativo entre testemunhos marinhos/lacustres e espeleotemas. Esses eventos produz efeito na pluviosidade de regiões (sub)tropicais do Hemisfério Norte, assim como registrados em arquivos paleoclimáticos da China e Venezuela. O mecanismo mais provável para geração desses eventos está relacionado com mudanças na Atlantic Meridional Overturning Circulation (AMOC). Com a AMOC desintensificada durante eventos Heinrich no Hemisfério Norte, existe predomínio de um gradiente da temperatura da superfície do Atlântico tropical que favorece posicionamento da Zona de Convergência Intertropical mais a sul durante os eventos úmidos na Bahia.

Palavras-chave: Bahia, Chapada Diamantina, espeleotemas, cavernas, isótopos estáveis, paleoclima, insolação, Quaternário. 


\begin{abstract}
BARRETO, E. A. de S. Reconstituição da pluviosidade da Chapada Diamantina (BA) durante o Quaternário Tardio através de registros isotópicos $(O$ e $C)$ em estalagmites. 2010. $110 \mathrm{f}$. Dissertação (mestrado) - Instituto de Geociências, Universidade de São Paulo, São Paulo.
\end{abstract}

Speleothem records of stable oxygen $\left(\delta^{18} \mathrm{O}\right)$ and carbon isotope ratios $\left(\delta^{13} \mathrm{C}\right)$ and speleothem growth rates, precisely dated by U/Th method, were used to reconstruct past changes in precipitation in the last 93,000 years B.P. from Chapada Diamantina region, Bahia State. The paleoclimatic reconstruction takes into account results from a calibration study performed in two caves in the Chapada Diamantina region. It was found a robust relationship between isotope signature in precipitation and cave drip water and also evidenced adequate environmental conditions for speleothem deposition in isotopic equilibrium with drip water. The interpretation of the speleothem $\delta^{18} \mathrm{O}$ records is based on the relationship between isotope composition of precipitation and rainfall amount from IAEA-GNIP stations in Brazil and also results from climate experiments coupled with $\delta^{18} \mathrm{O}$ in precipitation using ECHAM-4. These data indicate the "amount effect" as the dominant isotope fractionation factor controlling the $\delta^{18} \mathrm{O}$ variations in meteoric water forming speleothems, which is characterized by a decrease in the $\delta^{18} \mathrm{O}$ values with an increase in rainfall amount. Speleothem $\delta^{18} \mathrm{O}$ records allow reconstructing the regional paleoprecipitation patterns on both orbital and millennial timescales during last glacial period and Holocene. These records indicate an increase (decrease) in paleoprecipitation over central Bahia during low (high) summer insolation $\left(10^{\circ} \mathrm{S}\right)$ phases. This relationship is evident is most of this new speleothem record, except in the period between 40 and 20 ka B.P., when dry climate conditions predominate in the region even during the low insolation phases. However, this relationship is exactly the contrary of the one reported from southern/southeastern Brazil and Central Andes paleoclimate studies. Furthermore, the precipitation variations in Chapada Diamantina are in phase with records from Northern Hemisphere on orbital time-scales, particularly from China and Venezuela. These results suggest a direct influence of the South American Monsoon System (SAMS) on long-term changes in precipitation over northeastern Brazil, which is primarily controlled by gradual changes in summer insolation. Abrupt wet events are defined on millennial time-scales in the Chapada Diamantina records by low values of $\delta^{18} \mathrm{O}$ e $\delta^{13} \mathrm{C}$ and high speleothem growth rates. They occurred under prevalence of cold conditions in Northern Hemisphere, triggered by major changes in oceanic circulation in Atlantic Ocean, during Heinrich and Younger Dryas (YD) events. On the other hand, abrupt decreases in regional precipitation are coincident with some of the Dansgaard-Oeschger (D-O) e Bølling-Allerød (B-A), which are typical warm events in Northern Hemisphere. However, differently from the isotope-climate relationship established on orbital times, the impact of these millennial events on the precipitation variations of Bahia is similar to what is documented in speleothem, lake and marine records from Brazil and Central Andes and opposite to changes described in China and Venezuela, among many other records from Northern Hemisphere. The climate mechanism behind the origin of these millennial events is associated with changes in the Atlantic Meridional Overturning Circulation (AMOC). The Heinrich events are linked to periods of weaker AMOC and sea surface temperature gradients that favor a mean southern position of Intertropical Convergence Zone, which results in very wet conditions in Bahia.

Key words: Bahia, Chapada Diamantina, speleothems, caves, stable isotopes, paleoclimate, insolation, Quaternary, last glacial period. 


\section{LISTA DE FIGURAS}

Figura 2.1 - Localização das principais unidades carbonáticas do Brasil ................................9

Figura 2.2 - Localização no mapa geológico da Bahia das cavernas Paixão, Ioio e Diva de

Maura.

Figura 2.3 - Distribuições pluviométricas mensais nas estações meteorológicas nos municípios Andaraí, Wagner, Iraquara e Seabra

Figura 2.4 - Mapa climático representando a média da quantidade total sazonal de precipitação

Figura 2.5 - Gráficos de quantidade de chuvas, temperatura e umidade relativa externa por semana da caverna Fumaça, Iraquara - BA.

Figura 2.6 - Dados de $\delta^{18} \mathrm{O}$ e $\delta \mathrm{D}$ de gotejamentos das cavernas Paixão e Fumaça, localizadas nas áreas de Andaraí-BA e Iraquara-BA 23

Figura 2.7 - Variação de $\delta^{18} \mathrm{O}$ versus vazão de gotejamento e pluviosidade na área da caverna Fumaça.

Figura 2.8 - Variação de $\delta^{18} \mathrm{O}$ versus vazão de gotejamento e pluviosidade na área da caverna Paixão 25

Figura 2.9 - Dados da média mensal de $\delta^{18} \mathrm{O}_{\text {chuva }}$, pluviometria e temperatura das estações da IAEA em Salvador, Brasília, Ceará Mirim e Fortaleza.

Figura 2.10 - Relação entre a média pluviométrica mensal e o $\delta^{18} \mathrm{O}_{\text {chuva }}$ nas estações da IAEA em Salvador, Brasília, Ceará Mirim e Fortaleza

Figura 2.11 - Relação entre a média pluviométrica trimestral e os valores de $\delta^{18} \mathrm{O}_{\text {chuva }}$ nas estações da IAEA em Salvador, Brasília, Ceará Mirim e Fortaleza.

Figura 2.12 - Contribuição média anual das diferentes áreas fontes de umidade para a precipitação regional obtidas pela simulação através do modelo ECHAM-4 33

Figura 2.13 - Composição isotópica média das chuvas que afetam a América do Sul simulada através do ECHAM-4 com dados obtidos por estações da IAEA

Figura 3.1 - Face polida e digitalizada da estalagmite DV2.

Figura 4.1- Intervalos de deposição de todas as estalagmites coletadas nas cavernas da

Chapada Diamantina, situadas em Iraquara e Andaraí,

Figura 4.2 - Distribuição de idades U/Th versus profundidade $(\mathrm{mm})$ das estalagmites DV2, PX5, PX7, IO2 e PX9.... 45

Figura 4.3 - Taxas de crescimento das estalagmites DV2, PX5, PX7, IO2, PX9 e DV1 ........ 48

Figura 4.4 - Face da estalagmite PX5 amostrada para geocronologia U/Th 
Figura 4.5 - Comparação entre as razões isotópicas de carbono e oxigênio das doze estalagmites utilizadas na pesquisa.

Figura 4.6 - Comparação entre taxa de crescimento das estalagmites PX16 e DV1 e as razões isotópicas de carbono e oxigênio das estalagmites IO1, PX14, DV1, PX16, PX8 e PX13; e a curva de insolação de verão $\left(10^{\circ} \mathrm{S}\right)$

Figura 4.7 - Comparação entre a taxa de crescimento das estalagmites PX9, IO4 e IO2 com as razões isotópicas de carbono e oxigênio; e a curva de insolação de verão $\left(10^{\circ} \mathrm{S}\right)$ 56

Figura 4.8 - Comparação entre taxa de crescimento das estalagmites PX5 e PX7 com as razões isotópicas de carbono e oxigênio, e a curva de insolação de verão $\left(10^{\circ} \mathrm{S}\right)$.

Figura 4.9 - Comparação entre a taxa de crescimento das estalagmites PX5 e DV2 com as razões isotópicas de carbono e oxigênio, e a curva de insolação de verão ( $\left.10^{\circ} \mathrm{S}\right)$.

Figura 5.1 - Comparação entre registros paleoclimáticos de $\delta^{18} \mathrm{O}$ de espeleotema entre 93 e 47 mil anos A.P., com os registros da China, das cavernas Santana (SP) e Botuverá (SC), da Chapada Diamantina e a curva de insolação de verão $\left(10^{\circ} \mathrm{S}\right)$.

Figura 5.2 - Comparação entre registros de $\delta^{18} \mathrm{O}$ de espeleotemas durante os últimos 45 mil anos A.P. da China, das cavernas Santana (SP) e Botuverá (SC) e das cavernas Ioiô, Paixão, Diva de Maura da Chapada Diamantina; e a curva de insolação de fevereiro $\left(10^{\circ} \mathrm{S}\right)$.

Figura 5.3 - Como na comparação da figura anterior, mas com utilização dos valores de anomalias de $\delta^{18} \mathrm{O}$ dos espeleotemas

Figura 5.4 - Comparação entre registros paleoclimáticos durante os últimos 45 mil anos A.P. da Venezuela, do Rio Grande do Norte, da Chapada Diamantina e a curva de insolação de verão $\left(10^{\circ} \mathrm{S}\right)$.

Figura 5.5 - Comparação entre registros paleoclimáticos da China, das cavernas Santana (SP) e Botuverá (SC), da Venezuela, da Chapada Diamantina e do norte da Bahia

Figura 5.6 - Comparação entre as razões isotópicas de $\delta^{18} \mathrm{O}$ dos espeleotemas da China, das cavernas Santana (SP) e Botuverá (SC) e das cavernas Paixão e Ioiô (BA)

Figura 5.7 - Comparação entre os registros paleoclimáticos da Venezuela, da costa nordestina e das estalagmites da caverna Paixão e Ioio - BA e do Rio Grande do Norte 89

Figura 5.8 - Comparação entre os registros de espeleotemas da China, de Santa Catarina, do Rio Grande do Norte, da Chapada Diamantina e do norte da Bahia

Figura 5.9 - Comparação entre os registros da Venezuela, da costa nordestina e da Chapada Diamantina. 


\section{LISTA DE TABELAS}

Tabela 2.1 - Média trimestral da quantidade de chuva nos municípios de Iraquara, Wagner,

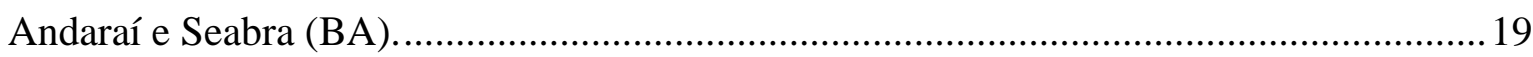

Tabela 3.1 - Exemplo de planilha de cálculo da resolução temporal da amostra IO2 para amostragem de pó destinada as análises isotópicas de $\mathrm{O}$ e $\mathrm{C}$. 38 


\section{LISTA DE ABREVIATURAS}

\begin{tabular}{|c|c|}
\hline$\delta_{18} \mathrm{O}-$ & Razão isotópica de Oxigênio \\
\hline$\delta_{13} \mathrm{C}-$ & Razão isotópica de Carbono \\
\hline $\mathrm{CaCO}_{3-}^{-}$ & Carbonato de cálcio \\
\hline NEB - & Nordeste brasileiro \\
\hline MAM - & Março, Abril e Maio \\
\hline DJF - & Dezembro, Janeiro e Fevereiro \\
\hline JJA - & Junho, Julho e Agosto \\
\hline NDJF- & Novembro, Dezembro, Janeiro e Fevereiro \\
\hline MSA - & Monção Sul-Americana \\
\hline ZCAS- & Zona de Convergência do Atlântico Sul \\
\hline ZCIT - & Zona de Convergência Intertropical \\
\hline ZCA - & Zona de Convergência dos Alísios \\
\hline ASAS - & Alta Subtropical do Atlântico Sul \\
\hline TSM - & Temperatura da Superfície Marinha \\
\hline PNM - & Pressão ao Nível do Mar \\
\hline GMWL- & Global Meteoric Water Line \\
\hline CD - & Chapada Diamantina \\
\hline IO - & Estalagmite da caverna Ioiô \\
\hline PX - & Estalagmite da caverna Paixão \\
\hline DV - & Estalagmite da caverna Diva de Maura \\
\hline St8 - & Estalagmite da caverna Santana \\
\hline $\mathrm{Bt} 2-$ & Estalagmite da caverna Botuverá \\
\hline TBV- & Toca da Boa Vista \\
\hline $\mathrm{R}-$ & Coeficiente de correlação \\
\hline$R^{2}-$ & Coeficiente de determinação \\
\hline ICP-MS - & Inductively coupled plasma mass spectrometry \\
\hline U/Th - & Urânio-Tório \\
\hline $\mathrm{Sr} / \mathrm{Ca}-$ & Razões Estrôncio e Cálcio \\
\hline $\mathrm{Mg} / \mathrm{Ca}-$ & Razões Magnésio e Cálcio \\
\hline $\mathrm{Ti} / \mathrm{Ca}-$ & Razões Titânio e Cálcio \\
\hline $\mathrm{Fe} / \mathrm{Ca}-$ & Razões Ferro e Cálcio \\
\hline$[\mathrm{Ti}]-$ & Concentração de Titânio \\
\hline $\mathrm{CO}_{2}-$ & Dióxido de carbono \\
\hline$k y-$ & Thousands of years \\
\hline A.P. - & Antes do Presente \\
\hline UMG - & Último Máximo Glacial \\
\hline MIS- & Marine Isotope Stage \\
\hline $\mathrm{H}-$ & Heinrich event \\
\hline YD - & Younger Dryas \\
\hline B-A- & Bølling-Allerød \\
\hline D-O - & Dansgaard-Oeschger \\
\hline IRD - & Ice-rafted debris \\
\hline
\end{tabular}


NGRIP-

GRIP -

THC -

NADW-

AMOC-

ANA -

IAEA- GNIP -
North Greenland Ice Core Project

Greenland Ice Core Project

Thermohaline Circulation

North Atlantic Deep Water

Atlantic Meridional Overturning Circulation

Agência Nacional de Águas

International Agency Energy Agency - Global Network of Isotopes in Precipitation 


\section{SUMÁRIO}

1. Introdução

1.1. Objetivos da pesquisa

2.1. Localização e caracterização geológico-geomorfológica............................................... 8

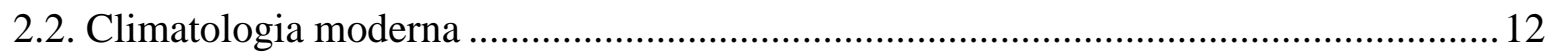

2.2.1. Relação entre os valores de $\delta \mathrm{D}$ e $\delta^{18} \mathrm{O}$ em águas de gotejamento de cavernas e precipitação na Chapada Diamantina

2.2.2. Monitoramento pluviométrico da IAEA-GRIP: Análise da composição isotópica da chuva e controle isotópicos

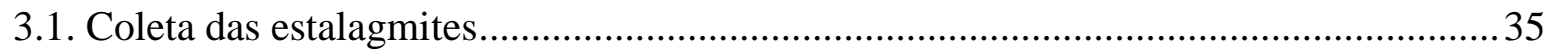

3.2. Preparação de estalagmites para estudo paleoclimático .............................................. 35

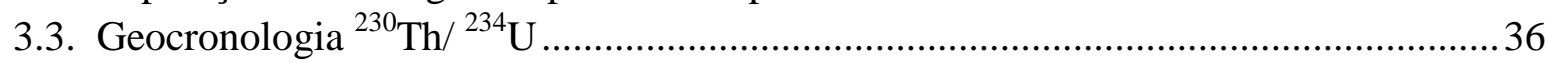

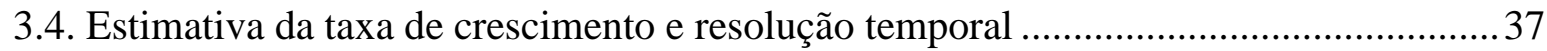

3.5. Amostragem de calcita para análises das razões isotópicas de oxigênio e carbono ...... 38

3.6. Interpolação de idades e cálculo de anomalias das razões isotópicas de $\delta^{18} \mathrm{O} \ldots \ldots \ldots \ldots . . .40$

4. Registros paleoclimáticos

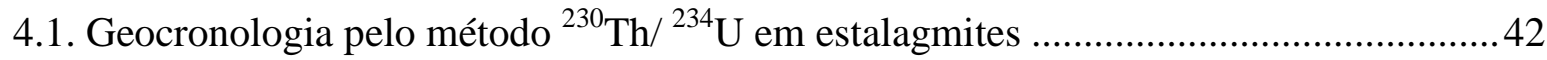

4.2. Registros isotópicos de $\delta^{18} \mathrm{O}$ e $\delta^{13} \mathrm{C}$ em estalagmites .............................................. 48

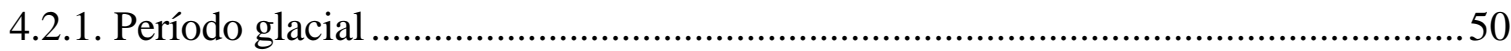

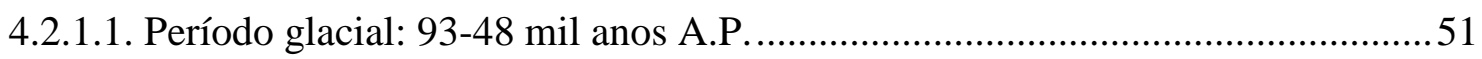

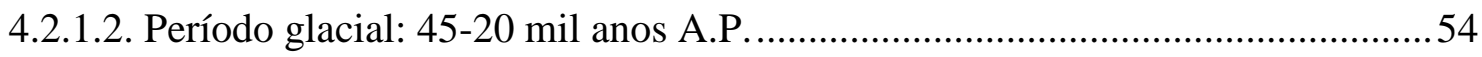

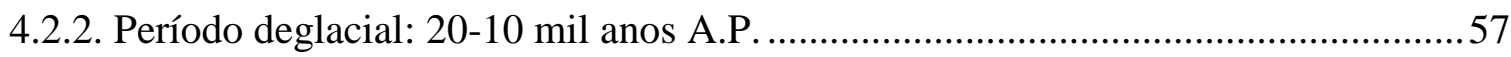

4.2.3. Período Holoceno: a partir de 10 mil anos até a atualidade ......................................60 
5. Reconstituição paleoclimática a partir dos registros isotópicos de $\delta^{18} \mathrm{O}$ de

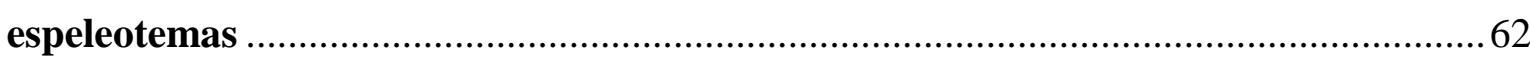

5.1. Significado paleoclimático das razões isotópicas do oxigênio em estalagmites da

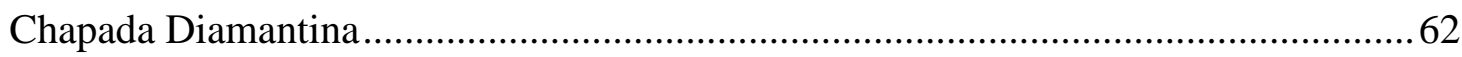

5.2. Variações paleoclimáticas em longas escalas temporais ...........................................64

5.2.1. Variações climáticas ocorridas entre 93 e 47 mil anos A.P. ..................................66

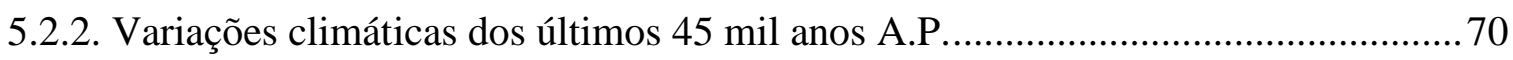

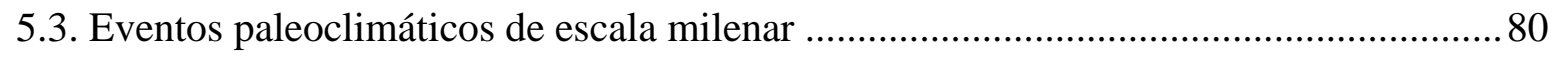

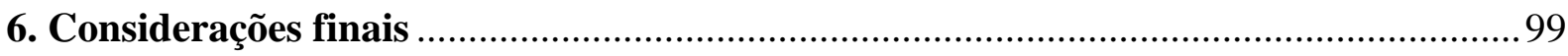

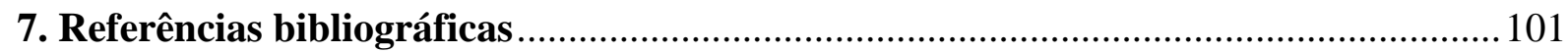

ANEXOS 


\section{INTRODUÇÃO}

Espeleotemas são depósitos secundários de carbonato de cálcio $\left(\mathrm{CaCO}_{3}\right)$ precipitados em cavernas, considerados um dos melhores indicadores de variações paleoclimáticas continentais (Henderson, 2006). Dentre os métodos mais aplicados para as reconstituições ambientais, estão as razões isotópicas de Oxigênio $\left(\delta^{18} \mathrm{O}\right)$ e Carbono $\left(\delta^{13} \mathrm{C}\right)($ Lachniet, 2009; McDermott, 2004), razões elementares (Sr/Ca e Mg/Ca) (Fairchild et al. 2009; 2006a) e taxas de crescimento (Baker et al. 2007; Genty et al. 2001). Uma reconstituição mais completa das condições ambientais é realizada a partir da multicomparação de métodos em um mesmo espeleotema.

Precisamente datados pelo método urânio-tório (U-Th), cujo limite alcança 600 mil anos, com precisão em torno de $~ 0,5-1 \%$, estimativa $2 \sigma$ (Edwards, 1987; Richards e Dorale, 2003), os espeleotemas por meio de seus registros paleoclimáticos vêm sendo largamente utilizados para o estudo da paleopluviosidade em regiões (sub)tropicais. Através deles foi possível estabelecer uma precisa cronologia para as variações das chuvas associadas às atividades das monções de verão no Hemisfério Norte (Wang et al. 2001; Wang et al. 2008; Cheng et al. 2009) e Hemisfério Sul (Cruz et al. 2005b; Wang et al. 2007a), as quais seguem perfeitamente os longos ciclos de variação de insolação, segundo o ciclo de precessão de Milankovitch.

Outro atributo dos estudos com espeleotemas a ser ressaltado é a possibilidade de discutir a influência de eventos ou ciclos de variações paleoclimáticas, através de arquivos isotópicos em alta resolução. Um dos melhores exemplos disso foi o reconhecimento de flutuações abruptas de chuvas nas regiões afetadas pelas monções asiáticas (Wang et al. 2001) e indiana (Fleitmann et al. 2003; Burns et al. 2002), as quais são coincidentes com os eventos Heirinch $(\mathrm{H})$ e Dansgaard-Oeschger (D-O) registrados em regiões de alta latitude (Bond et al. 1992; 1993; Dansgaard et al. 1993; Andersen et al. 2004).

No caso das regiões (sub)tropicais, interpretações baseadas nos valores de $\delta^{18} \mathrm{O}$ em espeleotemas (Wang et al. 2001; Wang et al. 2006; Lachniet et al. 2004; van Breukelen, 2008) são fortemente direcionadas às reconstituições da paleopluviosidade, devido a forte relação entre a composição isotópica da chuva e as variações pluviométricas, associada aos condicionantes isotópicos amount effect (efeito quantidade) e/ou regime de chuva. Esse primeiro efeito é responsável por correlações negativas entre valores de $\delta^{18} \mathrm{O}_{\text {chuva }} \mathrm{e}$ a quantidade de precipitação (Vuille et al. 2003; Rise et al. 2009), e são relacionados com 
processos de profunda convecção vertical ocorrida nos trópicos. O segundo fator é importante em regiões com regime de chuva tipicamente bimodal, como o Sul e parte do Sudeste do Brasil (Cruz et al. 2005a). Nessas regiões as chuvas que recebem contribuição maior de umidade amazônica durante as monções de verão apresentam valores de $\delta^{18} \mathrm{O}_{\text {chuva }}$ de $-7 \%$ em média, que são bem inferiores aos das chuvas extratropicais de inverno -3\%o. Portanto, foi possível reconstituir a variação no regime de chuva ao longo do tempo, com base em registros isotópicos de $\delta^{18} \mathrm{O}$ de espeleotemas nos subtrópicos do Brasil que, por sua vez, responderam à variação da insolação de verão (Cruz et al. 2005a).

Já a aplicação das razões isotópicas de $\delta^{13} \mathrm{C}$ dos espeleotemas tem sido direcionada principalmente para as reconstituições de mudanças de vegetação no passado (Dorale et al. 1998), muito embora estas interpretações ocorram de forma mais limitada. Isso ocorre porque o processo de fracionamento isotópico é mais complexo, pois envolve a interação entre o carbono orgânico, originado a partir do $\mathrm{CO}_{2}$ do solo dissolvido na água de percolação, e o carbono inorgânico, que provém da rocha carbonática encaixante da caverna $(\mathrm{McDermott}$ et al. 2004). De todo modo, registros de $\delta^{13} \mathrm{C}$ em espeleotemas são aplicados como indicadores da expansão de florestas sobre campos e vice-versa, os quais são descriminados a partir de valores mais negativos de $\delta^{13} \mathrm{C}$, devido a predominância de plantas com metabolismo $\mathrm{C}_{3}$ (maioria árvores) sobre plantas $\mathrm{C} 4$ (maioria gramínias), assim como interpretado em registros de solos (Pessenda et al. 2004; 2009)

Por ser menos complexo, o foco dos estudos paleoclimáticos com espeleotemas tem-se direcionado principalmente ao uso dos registros de $\delta^{18} \mathrm{O}$, contudo as razões isotópicas de $\delta^{13} \mathrm{C}$ também têm auxiliado nas interpretações paleoclimáticas (McDermott et al. 2004). Os valores de $\delta^{13} \mathrm{C}$ também podem trazer informações importantes sobre as variações das taxas de crescimento das estalagmites, a exemplo do trabalho realizado por Cruz et al. (2006a), através de registros em espeleotemas do Sul brasileiro. Para essa região, sugeriu-se que o crescimento dos espeleotemas responde mais diretamente às variações na produção de $\mathrm{CO}_{2}$ do solo devido a mudanças de temperatura, do que propriamente a abundância relativa de água. Isso porque, durante o período glacial, todas as fases de alta taxa de crescimento foram correlacionadas com valores mais negativos de $\delta^{13} \mathrm{C}$ nos espeleotemas. Consideradas as limitações da aplicação das razões isotópicas de $\delta^{13} \mathrm{C}$ em espeleotemas, no presente trabalho utilizou-se destas com a finalidade de reforçar as interpretações de paleopluviosidade realizadas a partir dos valores de $\delta^{18} \mathrm{O}$.

As reconstituições climáticas, principalmente de variações da paleoprecipitação 
através dos valores de $\delta^{18} \mathrm{O}$ em espeleotemas de regiões (sub)tropicais, têm permitido observar claramente mudanças climáticas segundo ciclos em escala orbital, com destaque para o ciclo de precessão, cuja periodicidade é de 23 mil anos, e dos eventos em escala milenar, que ocorrem numa sequência quasi-periódica devido variação de frequência em média de 1.5 a 3 mil anos. As variações climáticas moduladas por meio de forçantes orbitais, tais como os ciclos de Milankovitch, são condicionadas principalmente pela quantidade de radiação solar que atinge o topo da atmosfera terrestre, distribuída diferentemente de acordo com as latitudes e as estações climáticas ao longo do ano (Imbrie e Imbrie, 1980; Ruddiman, 2008). Dentre esses ciclos, os de precessão dos equinócios (ciclos de insolação), são mais frequentemente relacionados a mudanças paleoclimáticas nas pesquisas através de registros isotópicos em espeleotemas, devido a sua periodicidade mais curta e pelo significativo impacto responsáveis por condições climáticas nas regiões diretamente afetadas pelas monções tropicais durante os últimos quatro períodos glaciais (Wang et al. 2008; Cheng et al. 2009).

Nas variações climáticas geradas por eventos de escala milenar tem-se atribuído mudanças ocorridas na circulação oceânica do Atlântico como principal forçante da pluviosidade de regiões continentais situadas nos trópicos (Baker et al. 2001b; Seltzer et al. 2002; Ledru et al. 2005), as quais, por meio de um processo de interação oceano-atmosfera proporcionaram mudanças globais no clima (Broecker, 2000). Nesse aspecto, destacam-se os eventos Heinrich e Dansgaard-Oeschger, como responsáveis por variações climáticas abruptas para condições, respectivamente, mais frias e quentes no Hemisfério Norte, respectivamente (Bond et al. 1992; Dansgaard et al. 1993).

Nesse sentido, trabalhos clássicos, a exemplo dos realizados através dos registros de $\delta^{18} \mathrm{O}$ de espeleotemas da caverna Hulu (Wang et al. 2001), e mais recentemente das cavernas Sanbao e Dongee (Wang et al. 2008) na China, possibilitaram sugerir que variações da paleopluviosidade estiveram associadas a alterações do sistema monçônico, ocorridas em escala orbital e milenar. Essas condições, segundo os autores, teriam sido provocadas por variações dos padrões de circulação atmosférica em ampla escala geográfica, relacionadas com condições climáticas em altas latitudes do Hemisfério Norte.

Do mesmo modo, vários outros trabalhos conseguiram reconstituir variações de paleoprecipitação em distintas escalas temporais e associá-las a ocorrência de eventos climáticos. Dentre eles destacam-se os realizados na península arábica (Burns et al. 2002; Fleitmann et al. 2004), em Israel (Bar-Matthews e Ayalor, 1997; 2000), e no continente 
africano (Gasse, 2000).

Foi a partir dos estudos isotópicos em estalagmites que interpretações acerca das variações da paleopluviosidade no Brasil em escala de ciclos mais longos e, por conseguinte, da circulação atmosférica, envolvendo o Pleistoceno Tardio e o Holoceno, tornaram-se mais claras (Cruz et al. 2005a; 2006b; Wang et al. 2006; 2007a). Através deles foi possível observar que o aumento (diminuição) relativo das chuvas no Sul/Sudeste brasileiro, associado ao regime das Monções Sul-Americana de verão (MSA), ocorre durante as fases de insolação máxima (mínima) de verão (fevereiro) no Hemisfério Sul $\left(30^{\circ} \mathrm{S}\right)$, em ciclos de $\sim 23$ mil anos. Nesse caso, variações dos valores de $\delta^{18} \mathrm{O}$ de espeleotemas, teriam estado associadas às mudanças na localização média e intensidade da MSA, feição que por sua vez reflete mudanças globais da circulação atmosférica.

Reconstituições da paleopluviosidade e da circulação atmosférica no Nordeste brasileiro associadas ao ciclo de insolação, já foram esboçadas por Wang et al. (2004) para a Bahia, através de registros geocronológicos pelo método U/Th em espeleotemas e travertinos depositados nos últimos 210 mil anos A.P. Contudo, devido a descontinuidades temporais nesse registro, não foi possível obter uma relação muito evidente entre controle climático da insolação de verão sobre variações de umidade na Bahia.

A relação entre a forçante insolação e oscilações da paleoprecipitação e da circulação atmosférica foi mais recentemente investigada no norte da região Nordeste do Brasil por Cruz et al. (2009a). Análises de registros isotópicos dos últimos 26 mil anos em espeleotemas do Rio Grande do Norte realizadas por estes autores sugerem que as variações da paleoprecipitação seguiram também as fases de máxima e mínima da insolação de verão de fevereiro $\left(10^{\circ} \mathrm{S}\right)$. No entanto, o aumento das chuvas ocorreu em fases de insolação mínima de verão, ao contrário do que foi observado no Sul e Sudeste do Brasil. Essas reconstituições, obtidas através de registros de alta resolução de $\delta^{18} \mathrm{O}$ em estalagmites potiguares, permitiram indicar que a insolação foi a principal forçante das longas variações da precipitação do passado, no entanto elas possuem uma relação antifásica com o regime de chuva das monções observado nas regiões Sul e Sudeste do país e também na região dos Andes Centrais (Seltzer et al. 2000; Baker et al. 2001a; Fritz et al. 2007).

Registros isotópicos de espeleotemas também revelaram importantes variações paleoclimáticas em escala milenar no Sul/Sudeste brasileiro (Cruz et al. 2006b; Wang et al. 2007a; 2007b), que mesmo secundariamente superimposta ao ciclo dominante de $\sim 23$ mil anos, constituíram uma das raras evidências dos eventos Heinrich e Younger Dryas (YD) no 
Hemisfério Sul. A partir desses trabalhos, estabeleceu-se que fases de clima mais frio no Hemisfério Norte, durante os eventos Heinrich e YD, coincidem com oscilações abruptas para valores mais baixos de $\delta^{18} \mathrm{O}$ nos espeleotemas do Brasil, devido as chuvas de verão mais abundantes na faixa que envolve deste o sul de São Paulo até Santa Catarina. Essas variações de pluviosidade, por sua vez, estariam associadas à maior atividade da Zona de Convergência do Atlântico Sul (ZCAS), uma das feições mais importantes do sistema das Monções SulAmericanas (Vera et al. 2006).

Variações da paleoprecipitação segundo eventos milenares, foram primeiramente descritas no Brasil por Wang et al. (2004), que interpretaram intenso aumento na pluviosidade na região Nordeste do país, através das fases de crescimento de espeleotemas na Caverna Toca da Boa Vista, situada numa área no norte da Bahia, onde a aridez do clima impede a deposição dessas formações nos dias atuais. Todos esses eventos úmidos foram registrados nos últimos 210 ky A.P. na Bahia e definem, com boa precisão temporal definido pelo método U/Th, o impacto positivo dos eventos Heinrich e de outros eventos frios registrados no Hemisfério Norte, na pluviosidade da Bahia. Mais recentemente, os eventos úmidos milenares foram também descritos no oeste da Bahia, através de baixos valores de $\delta^{18} \mathrm{O}$ de estalagmites da Gruta do Padre (Wang et al. 2007b) e também pelos registros isotópicos dos espeleotemas do Rio Grande do Norte (Cruz et al. 2009).

Durante os eventos Heinrich, condições climáticas mais severas no Hemisfério Norte favoreceram o deslocamento da ZCIT mais para sul em relação a sua posição atual (Chiang et al. 2003), o que provavelmente ocasionou as fases úmidas pioneiramente descritas por Wang et al. (2004), para região onde hoje está localizado o semi-árido nordestino. Por conseguinte, o aumento do volume do gelo e redução nas temperaturas no Hemisfério Norte, teria também impulsionado o suprimento de umidade do Atlântico para a Bacia amazônica e desta forma teria intensificado a ZCAS. Esse último mecanismo climático explicaria o aumento de chuva de verão na região subtropical do Brasil, justificando, deste modo, o aumento sincrônico da paleoprecipitação tanto ao Sul/Sudeste como no Nordeste ou em todo território brasileiro (Cruz et al. 2005a; Cruz et al. 2006b, Wang et al. 2007a; 2007b).

Outros tipos de registros paleoclimáticos importantes no norte do Nordeste brasileiro, tais como os obtidos em sedimentos lacustres, de solo e marinhos, confirmam as fortes variações de umidade sucedidas em escala milenar (Sifeddine et al. 2004; Jacob et al. 2006; Ledru et al. 2006), associadas principalmente a mudanças do gradiente de temperatura entre o Atlântico tropical Norte e Sul, devido mudanças nos padrões de circulação oceânica e dos 
ventos alíseos de sudeste e nordeste (Arz et al. 1998; 1999; Weldeab et al. 2006; Jaeschke et al. 2007). Tais variações teriam implicado em alterações nos padrões de circulação atmosférica regional que estão diretamente ligados à atuação passada da ZCIT na região Nordeste (Jennerjahn et al. 2004; Jaeschke et al. 2007). Esses indicadores, juntamente com outros registros paleoclimáticos da América do Sul, a exemplo dos registros obtidos em sedimentos marinhos da costa venezuelana (Peterson et al. 2000; Haug et al. 2001; Lea et al. 2004), permitiram estabelecer um padrão das variações da paleopluviosidade no continente sul-americano que está fortemente condicionado pela interação oceano-atmosfera, principal chave das mudanças climáticas registradas durante os eventos milenares (Broecker. 2006).

A ampliação dos estudos paleoclimáticos na região Nordeste, realizados no presente trabalho através dos registros de $\delta^{18} \mathrm{O}$ e $\delta^{13} \mathrm{C}$ de doze estalagmites, coletadas em três cavernas da Chapada Diamantina, Bahia, irá contribuir de forma muito importante tanto para as reconstituições paleoambientais locais e regionais, como também no cenário de interação paleoclimática das regiões tropicais com aquelas situadas em altas latitudes do globo. Precisamente datados pelo método Th-U, os registros isotópicos de Oxigênio e Carbono de espeleotemas da Chapada Diamantina, possibilitaram reconstituir as variações de paleopluviosidade tanto em escala mais longas, segundo ciclos orbitais, quanto durante eventos milenares, ocorridos nos últimos 93 mil anos A.P. Por fim, as variações da pluviosidade durante a maior parte do último período glacial e Holoceno foram associadas a mudanças nos padrões de circulação atmosférica meridional e zonal, tópico da climatologia tropical que está em pleno debate científico.

\subsection{Objetivos da pesquisa}

- Realizar levantamento paleoclimático e paleoambiental, com base em perfis isotópicos de $\delta^{18} \mathrm{O}$ e $\delta^{13} \mathrm{C}$ em estalagmites depositadas em cavernas da região da Chapada Diamantina, Bahia, durante o Pleistoceno Tardio e o Holoceno.

- Identificar e descrever padrões das variações de paleopluviosidade da região central da Bahia em diferentes escalas de tempo, de acordo com o ciclo de precessão (periodicidade de aproximadamente 23 mil anos), durante a ocorrência remota dos eventos milenares tipo Heinrich, Younger Dryas e Dansgaard-Oeschger (de aproximadamente 1500 a 3000 anos). 
- Discutir os mecanismos responsáveis por mudanças da intensidade e posicionamento geográfico dos sistemas climáticos que afetaram a paleopluviosidade do interior do Nordeste, hoje situado numa faixa de clima semi-árido. Atenção especial será dada aos mecanismos associados à atividade da zona de convergência intertropical e das monções sul-americanas, os quais consistem nos principais sistemas climáticos atuantes na região central da Bahia. 


\section{2. ÁREA DE ESTUDO E CLIMATOLOGIA}

\subsection{Localização e caracterização geológico-geomorfológica}

A área de estudo está localizada nos municípios de Iraquara e Andaraí, situados na região da Chapada Diamantina, porção central do estado da Bahia (Fig. 2.1; Fig. 2.2). A Chapada Diamantina está inserida dentre as províncias cársticas mais relevantes do Brasil (Fig. 2.1) e abriga muitas cavernas de grandes dimensões (desenvolvimento em planta maior que $1 \mathrm{~km}$ ), que são caracterizadas pela exposição de grande variedade e quantidade de espeleotemas ou depósitos secundários de carbonato de cálcio e outros minerais, os quais são descritos de forma geral por Auler et al. (2004). Neste trabalho, foram estudadas especificamente as formações tipo estalagmites, de três cavernas que estão situadas em duas áreas distintas da região da Chapada Diamantina. As duas áreas são divididas geograficamente pela Serra do Sincorá, que consiste numa feição relevante para a climatologia local, pois atua como barreira orográfica da umidade proveniente do Atlântico Sul.

Situadas a oeste da Serra do Sincorá estão as cavernas Ioiô e Diva de Maura, ambas desenvolvidas na Bacia de Irecê, localizadas no município de Iraquara. Ao leste da Serra e próximo a localidade de Ubiraitá, município de Andaraí, está situada a caverna Paixão, desenvolvida nas formações carbonáticas da Bacia Una-Utinga (Fig. 2.2). O acesso aos dois municípios ocorre através da BR 324 e BR 242 a partir da capital Salvador sentido Brasília.

As Bacias de Irecê e Una-Utinga estão localizadas na porção central do Cráton do São Francisco. As rochas carbonáticas que compõem essas bacias fazem parte do Grupo Una, que foram depositadas no Proterozóico Superior (Inda e Barbosa, 1978). De acordo com Souza et al. (1993) o Grupo Una depositou-se em uma planície de maré sob condições climáticas áridas, numa bacia restrita intermontana, tectonicamente estável e com rampa de declividade moderada. As litofácies carbonáticas do Grupo Una estão em discordância angular ou em desconformidade sobre as rochas do Grupo Chapada Diamantina, Supergrupo Espinhaço (Pedreira da Silva, 1994).

As formações geológicas características do Proterozóico Superior em ambas as bacias descritas acima são denominadas de Formações Bebedouro (basal) e Salitre (superior). A Formação Bebedouro é formada principalmente por diamictitos de natureza essencialmente glacial (Misi e Silva, 1996). 


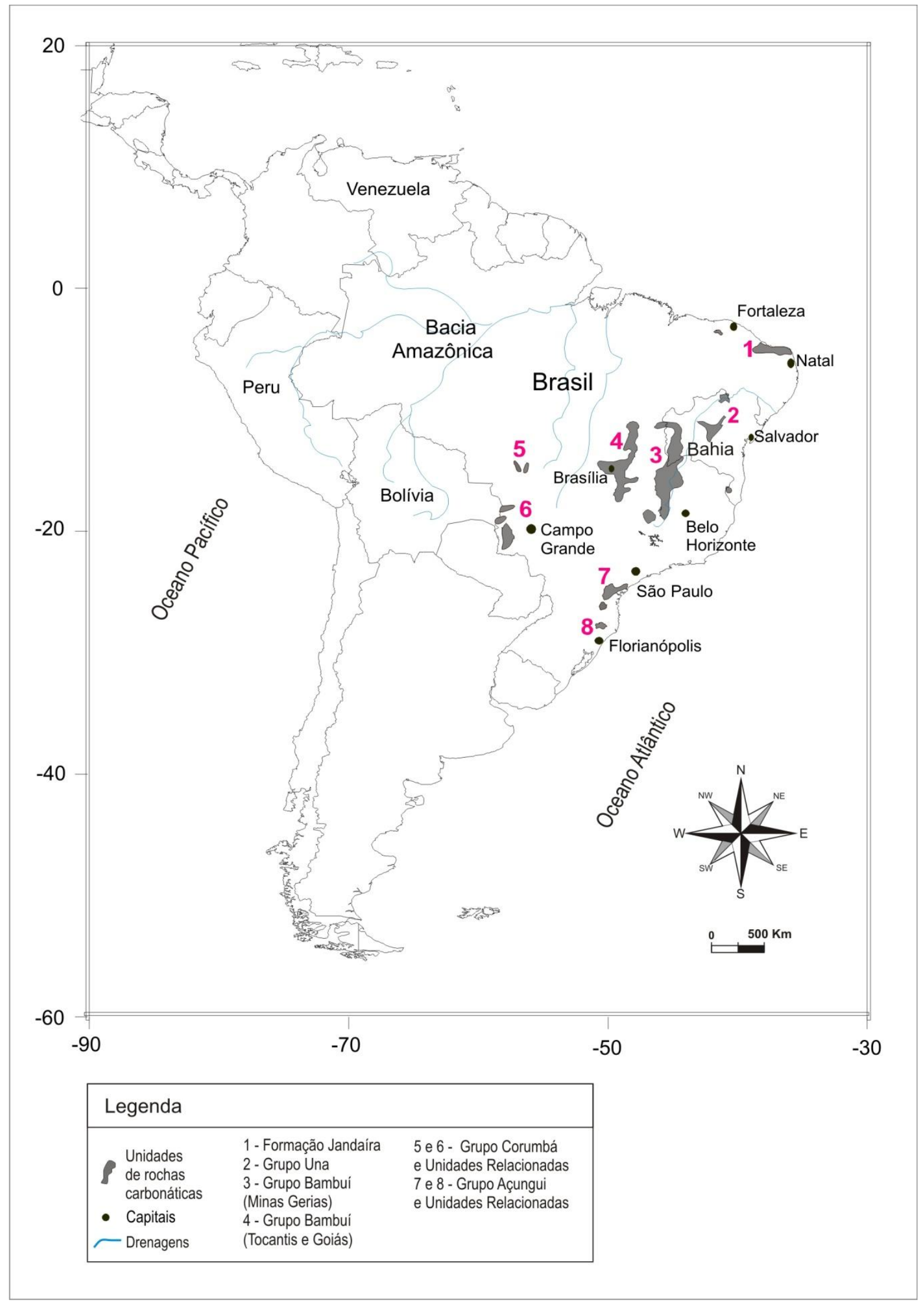

Figura 2.1 - Mapa representativo da localização das unidades carbonáticas brasileiras. O destaque corresponde ao Estado da Bahia, onde está localizada a Chapada Diamantina (Modificado de Karmann e Sánchez, 1979). 


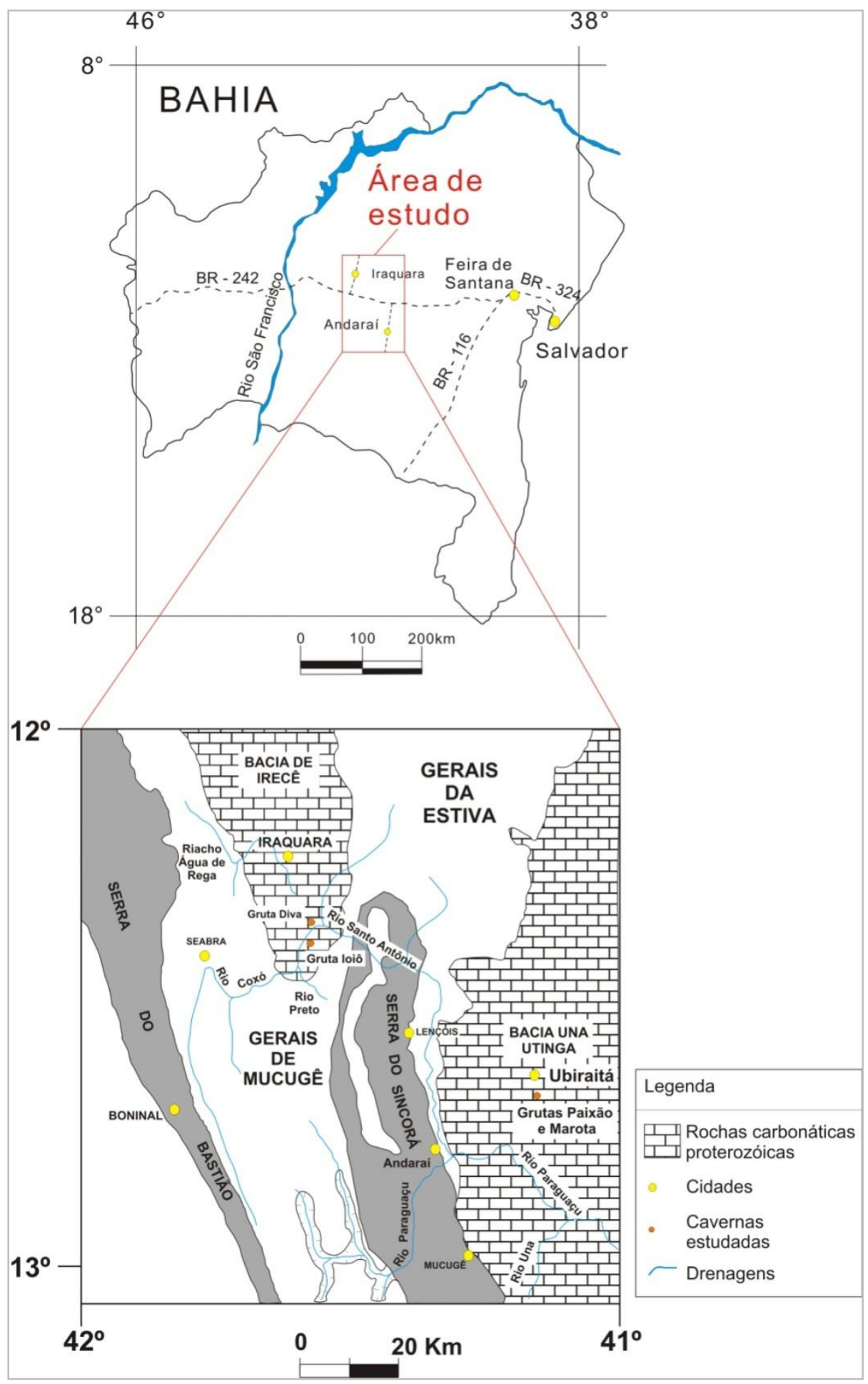

Figura 2.2 - Localização no mapa geológico da Bahia das cavernas Paixão, Ioiô e Diva de Maura, de onde foram coletadas as estalagmites para estudo paleoclimático. (Modificado de Laureano, 1998)

Já a Formação Salitre, é constituída por várias litofácies carbonáticas depositadas em ambiente marinho raso (Barbosa e Dominguez, 1996). São característicos desta Formação calcilutitos, calcissiltitos, calcarenitos, laminitos algais e margas, as quais consistem nas rochas encaixantes das cavernas do presente estudo. 
A geomorfologia da Chapada Diamantina é marcada principalmente por dois domínios: por planaltos e serras compostas por rochas siliclásticas, também denominados regionalmente de Gerais, e por planaltos cársticos compostos por rochas carbonáticas. De acordo com Laureano (1998), os planaltos cársticos são caracterizados por possuírem baixas altitudes em relação às Gerais, que varia entre 650 e $800 \mathrm{~m}$ na bacia carbonática de Irecê e 350 e 600m na bacia Una Utinga. As Gerais apresentam, por sua vez, intervalos de altitude que variam entre 800 a $1100 \mathrm{~m}$.

A distribuição das cavernas na Bacia de Irecê ocorre preferencialmente numa faixa de relevo com altitude variando entre 650 e 750m (Cruz, 1998) e está associada ao gradiente hidráulico produzido pela Serra do Sincorá, um dos principais divisores de água da região. Os gradientes de fluxo são maiores nas proximidades das encostas das serras areníticas, sendo as drenagens formadoras das cavernas preferencialmente capturadas para subsuperficie nas proximidades do contato com as rochas carbonáticas do planalto cárstico. Um dos motivos para o grande desenvolvimento de condutos na região é a presença dessas drenagens que nascem em áreas de rochas carbonáticas ou drenagens alogênicas, pois suas águas menos saturadas em carbonato produzem maior desenvolvimento de condutos de grandes dimensões. As cavernas Diva de Maura e Ioiô, situadas nas proximidades das margens do Rio Preto, para onde são drenadas toda água do aquífero cárstico da área de Iraquara, são bons exemplos de sistemas de condutos associados com drenagens alogênicas.

Laureano (1998) e Pereira (1998) discutiram feições remanescentes do ciclo de denudação ocorrido no Terciário Inferior, para as Bacias de Irecê e Una-Utinga, originalmente descritas por King (1956). O planalto da Bacia de Irecê é caracterizado por relevo suavemente ondulado e pela presença de vales encaixados com vertentes escarpadas. Guerra (1986), Cruz (1998) e Laureano e Cruz (2003) descreveram feições morfológicas típicas de relevo cárstico, como áreas com restrita rede de drenagem superficial, substituída pela drenagem subterrânea e o aparecimento de estruturas de desabamento e acomodação como os vales cegos, etc.

Essa morfologia é mais típica da porção ao sul da bacia, onde estão localizadas as cavernas Ioiô e Diva de Maura, e na proximidade dos contatos entre os carbonatos com os quartzitos. As depressões cársticas consistem na feição mais abundante da paisagem, onde se destacam dolinas de abatimento com profundidade e diâmetro que ultrapassam 50 metros, que marcam as entradas das cavernas estudadas. Os condutos com grandes dimensões que caracterizam essas cavernas são formados por recargas alogênicas no aquífero cárstico da Bacia de Irecê, de drenagem originada a partir das serras areníticas adjacentes. 
A bacia Una-Utinga é caracterizada por possuir relevo mais dissecado quando comparada com a bacia de Irecê. De acordo com Pereira (1998), as feições cársticas nesta região são mais incipientes e restritas a alinhamentos mais esparsos de depressões cársticas, que variam de dolinas a úvalas dispostas no centro de bacias poligonais. Além dessas feições típicas de terrenos cársticos, são comuns também a presença de sumidouros autogênicos, ou que nascem na área dos próprios carbonatos e morros testemunhos carbonáticos.

A recarga hídrica na bacia Una-Utinga ocorre de forma mista, ou seja, através de drenagens tanto de origem autogênica como alogênica. $O$ principal curso fluvial de superfície desta região é o Rio Una, que também é um tributário da margem direita da Bacia do Rio Paraguaçu. De acordo com Pereira (1998) a margem esquerda do rio Una é caracterizada por uma recarga hídrica alogênica oriunda dos metarenitos da Chapada Diamantina e das rochas da Formação Bebedouro. A recarga autogênica, que ocorre através das rochas carbonáticas da Formação Salitre ocorre em ambas às margens do Rio do Una.

\subsection{Climatologia moderna}

A área estudada está localizada ao sul da região do Nordeste brasileiro (NEB), que de modo geral, apresenta aspectos climáticos atípicos das áreas equatoriais caracterizados por médias pluviométricas anuais muito inferiores às outras regiões brasileiras. O NEB é marcado pela existência de longos períodos de estiagem, época que há diminuição considerável da quantidade de precipitação ou completa parada nos eventos de chuva. A região apresenta três regimes pluviométricos, cujos picos de atuação ocorrem em épocas distintas no ano (Kousky, 1979), proporcionando uma precipitação anual que varia entre 300 a 2.000 mm (Kayano e Andreoli, 2009).

Os picos de alta pluviosidade no NEB, principalmente ao norte, são alcançados durante o outono austral, nos meses de março, abril e maio (MAM), correspondendo a 70\% da precipitação anual em algumas áreas (Rao et al. 1996; Rao et al. 1990). Ao sul do NEB, onde está localizada a Bahia, as precipitações ocorrem principalmente durante a estação de verão, nos meses de Dezembro, Janeiro e Fevereiro (DJF) (Rao et al. 1993). As precipitações das estações de verão e outono, ou seja, durante seis meses do ano, correspondem a $80 \%$ da precipitação anual ocorrida na porção continental do NEB, enquanto durante os outros meses restantes registra-se $20 \%$ da precipitação total (Rao et al. 1996). As chuvas que ocorrem no inverno, nos meses de Junho, julho e Agosto (JJA), são muito relevantes na região costeira 
entre a Bahia e o Rio Grande do Norte, mas pouco significantes na porção continental do NEB.

Na Chapada Diamantina o regime climático varia entre sub-úmido e semi-árido de acordo com a classificação de Köppen-Geiger adotada no mapa pluviométrico do Estado da Bahia do ano de 2005 (www.sei.ba.gov.br). Localmente, os valores pluviométricos nos municípios de Andaraí e Iraquara são bastante distintos, fator que pode estar associado à barreira orográfica representada pela Serra do Sincorá (Fig. 2.2). Devido sua localização, a região de Andaraí encontra-se sob maior influência das precipitações das estações de outono e inverno e por isso apresenta valores pluviométricos anuais mais elevados.

Esse cenário foi bem constatado através do tratamento de dados de estações metereológicas, obtidos através da Agência Nacional de Águas (ANA, fonte: www2.ana.gov.br). Foram utilizados dados das estações localizados nos municípios de Andaraí e Wagner (Fig. 2.3a, Fig. 2.3b), a fim de representar as médias acumuladas na borda leste da Chapada Diamantina, a partir 60 e 51 anos de amostragens mensais de precipitação, respectivamente. Para análise da distribuição de chuvas na borda oeste da Chapada Diamantina, foram utilizados dados de monitoramento nas estações de Iraquara e Seabra (Fig. 2.3c; Fig. 2.3d), no qual foram obtidas médias pluviométricas de 22 e 25 anos, respectivamente.

Através da análise dos acumulados médios anuais de precipitação entre os quatro municípios analisados, foi possível observar contrastes significativos na distribuição de chuvas entre as bordas leste e oeste da Chapada Diamantina. Em Andaraí e Wagner, esses valores corresponderam a 1125.5 e 687.2 mm/ano e em Iraquara e Seabra a 460 e 367.3 $\mathrm{mm} / \mathrm{ano}$, respectivamente.

Observou-se nesses dois primeiros municípios que os meses chuvosos ocorrem no verão. Percentualmente, as chuvas nos meses de NDJF representam 57.5 e $56 \%$ da precipitação total anual. Do mesmo modo, as precipitações de verão, em NDJF, também foram as mais significativas nos municípios de Iraquara e Seabra e representam assim 65.3 e $68.1 \%$ da precipitação anual, respectivamente. Essas estimativas estão de acordo com o cálculo das variações anuais de precipitação no Brasil, segundo Rao et al. (1996). A esse período estão associadas às chuvas ocasionadas a partir das atividades monçônicas sulamericana de verão (MSA) (Bombardi e Carvalho, 2008). 

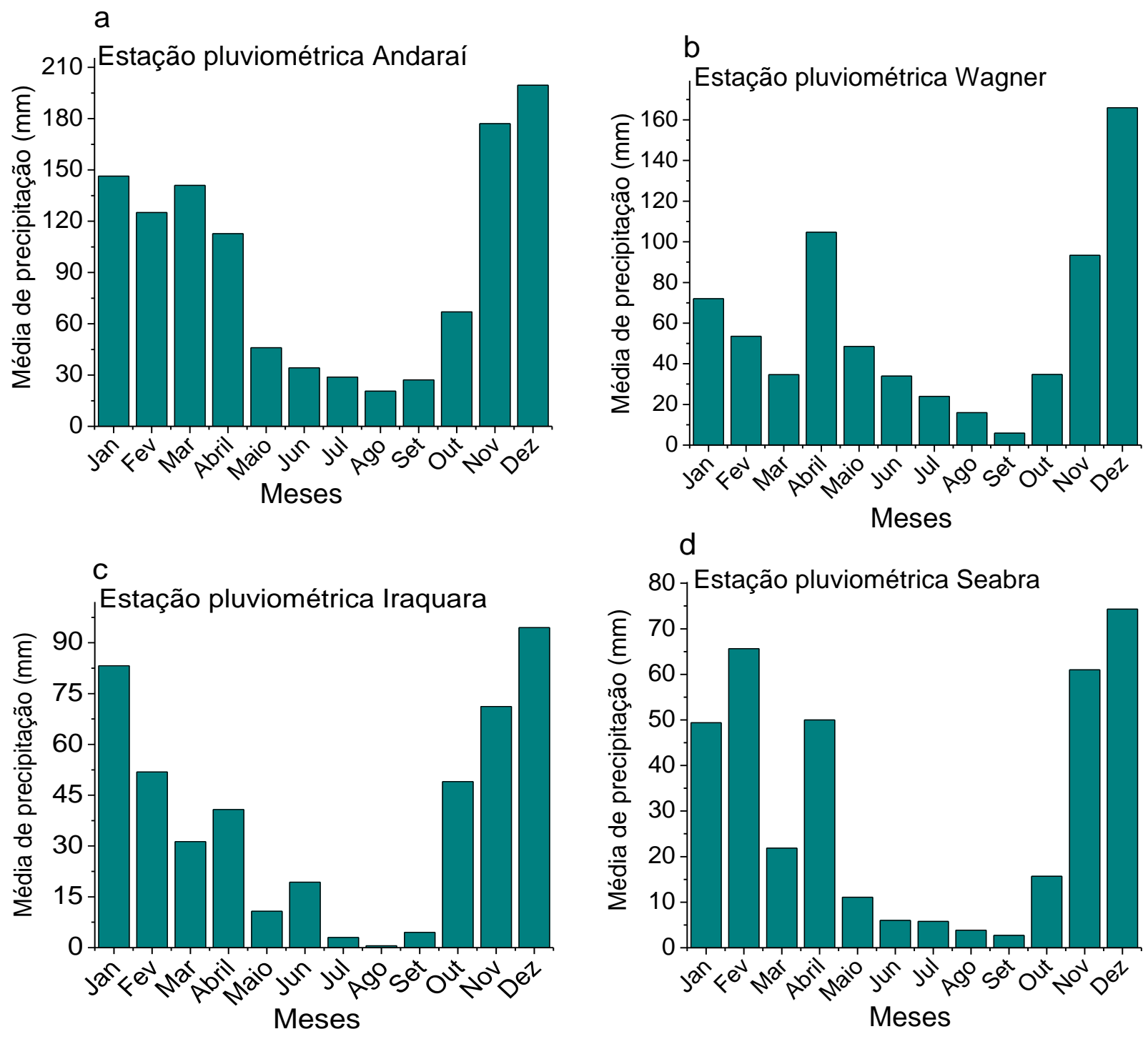

Figura 2.3 - Distribuições pluviométricas mensais nas estações meteorológicas nos municípios Andaraí (a), Wagner (b), Iraquara (c) e Seabra (d). Dados pluviométricos obtidos pela ANA (www2.ana.gov.br).

A precipitação monçônica tem sua origem na bacia amazônica e distribuição caracterizada por contornos de máxima precipitação segundo a direção noroeste-sudeste, cujo eixo alcança o Oceano Atlântico na região do sudeste brasileiro em dezembro (Fig. 2.4). As chuvas monçônicas afetam grande parte das regiões brasileiras, sendo os valores mais altos observados na região amazônica e do centro-oeste do Brasil. No entanto, os índices pluviométricos diminuem perpendicularmente ao eixo de máxima precipitação da MSA, com valores gradativamente menores em direção a costa nordestina. Dessa forma, as chuvas de verão são mais intensas em Brasília e oeste da Bahia do que na Chapada Diamantina. Mesmo que em intensidade mais fraca, essas são muito importantes tanto no município de Andaraí como de Iraquara, uma vez que as médias máximas de precipitação corresponderam a 199.5 e 
94.5 mm/ano (Tab. 2.1; Fig. 2.3a; Fig. 2.3c) e indicam, portanto, a principal estação chuvosa em ambas as áreas.

De modo geral, o início da circulação monçônica da América do Sul está relacionado ao aumento da convergência de umidade do Atlântico equatorial para região amazônica, favorecida pelo maior aquecimento do continente em relação à superfície marinha (TSM) da região oceânica adjacente (Vera et al. 2006). A circulação atmosférica é tipicamente anticiclônica, divergente em altos níveis e convergente em baixos níveis, com células ascendentes no interior continental e descendentes no oceano (Mechoso et al. 2005; Vera et al. 2006).

O início dessa circulação ocorre durante a primavera austral com níveis máximos de precipitação no sul da Amazônia associados ao ciclo de variação sazonal de insolação (Vera et al. 2006). A fase madura das monções ocorre nos meses DJF, quando uma zona de baixa pressão próximo a superfície e um anticiclone em altos níveis se estabelecem entre a Bolívia e o Peru, conhecida climatologicamente com o Alto da Bolívia. De acordo com Zhou e Lau (1998), os ventos alísios de nordeste, responsáveis por transportar umidade a baixos níveis do Atlântico Sul, estão fortalecidos durante a maturidade monçônica e prolongam-se até o leste da região tropical andina, onde são desviados para a costa sudeste do Brasil, através dos jatos de baixos níveis.

Essa banda de nebulosidade e de chuvas, denominada de Zona de Convergência do Atlântico Sul (ZCAS), desloca-se no sentido NW-SE desde a zona de profunda atividade convectiva na Amazônia, atravessa o Centro-Oeste e alcança o Sudeste brasileiro, atingindo frequentemente, o oceano Atlântico Subtropical (Carvalho e Jones, 2009). No entanto, o sistema ainda afeta de forma significativa a porção oeste e central da Bahia.

As precipitações que ocorrem durante o outono austral no NEB, consistem na principal estação chuvosa na porção norte da região e estão associadas à influência da Zona de Convergência Intertropical (ZCIT) do Atlântico (Kayano e Andreoli, 2009) (Fig. 2.4). Segundo Melo et al. (2009), a ZCIT é a conjunção de variáveis metereológicas que atuam na faixa equatorial dos oceanos, sendo elas: a Zona de Confluência dos Alísios (ZCA), a região do cavado ${ }^{1}$ equatorial, as áreas de máxima TSM e de máxima convergência de massa, e a banda de máxima cobertura de nuvens convectivas. De modo geral, essas condições

\footnotetext{
${ }^{1}$ Região da atmosfera em que a pressão é baixa, relativa às regiões circunvizinhas do mesmo nível. Na carta sinótica é representado pelo sistema de isóbaras paralelas que apresentam uma forma semelhante a um V. (Fonte: INMET)
} 
caracterizam a ZCIT como um sistema metereológico de grande zona de baixa pressão convergente a baixos níveis (divergente em altos).

Durante os meses de março-abril a banda de umidade encontra-se posicionada mais ao sul do Atlântico equatorial. Esse posicionamento da ZCIT está associado à predominância dos padrões de ventos, que por sua vez, são condicionados a partir de mudanças da TSM no Atlântico equatorial, quando passa a predominar os ventos alísios de nordeste (Xie e Carton, 2004).

A predominância dos ventos é condicionada, principalmente, por alterações da pressão ao nível do mar (PNM) geradas pela posição da termoclina ao leste do Atlântico, quando este se encontra menos aquecido (Xie e Carton, 2004). Sob essas condições, variações no padrão de circulação dos alísios de nordeste e sudeste seriam responsáveis pela intensidade e posicionamento da ZCIT (Namias, 1972, apud Molion e Bernardo, 2000).

A análise dos dados das quatro estações na região de estudo mostrou que as chuvas nos meses MAM, estação de outono, são também muito significantes. Contudo, as chuvas do período foram um pouco mais significativas nos municípios de Andaraí e Wagner, onde correspondem respectivamente a 26.6 e $27.3 \%$ do acumulado total de precipitação (Tab. 2.1). Já nas estações de Andaraí e Wagner a quantidade total das chuvas de outono corresponde a 18 e $22.5 \%$ (Tab. 2.1).

Em médias acumuladas, os valores são mais significativos na borda leste da Chapada Diamantina, variando entre 229.6 e 187.8 mm/ano em Andaraí e Wagner (Tab.2.1), enquanto que na borda oeste, em Iraquara e Seabra, os valores totais médios de precipitação acumulados em MAM foram de 82.8 e 82.9 mm/ano, respectivamente (Tab.2.1). Esses estão de acordo com o estudo de Rao et al. (1996), que estimaram que as chuvas de outono compõem 25 a $30 \%$ do acumulado anual na porção sul do NEB.

As precipitações ocorridas em MAM, que consiste assim na segunda estação mais chuvosa na região, estão associadas à atuação da ZCIT, que corresponde a uma área de nebulosidade localizada sob a região equatorial oceânica e continental (Melo et al. 2009). As chuvas ocasionadas a partir da atuação desse sistema metereológico estão associadas à mudança de seu posicionamento, que se encontra mais a sul equador nos meses de marçoabril (Moura e Shukla, 1981) e impulsionam aumento de precipitação nas regiões principalmente ao norte no NEB (Hastenrath e Heller, 1977). 

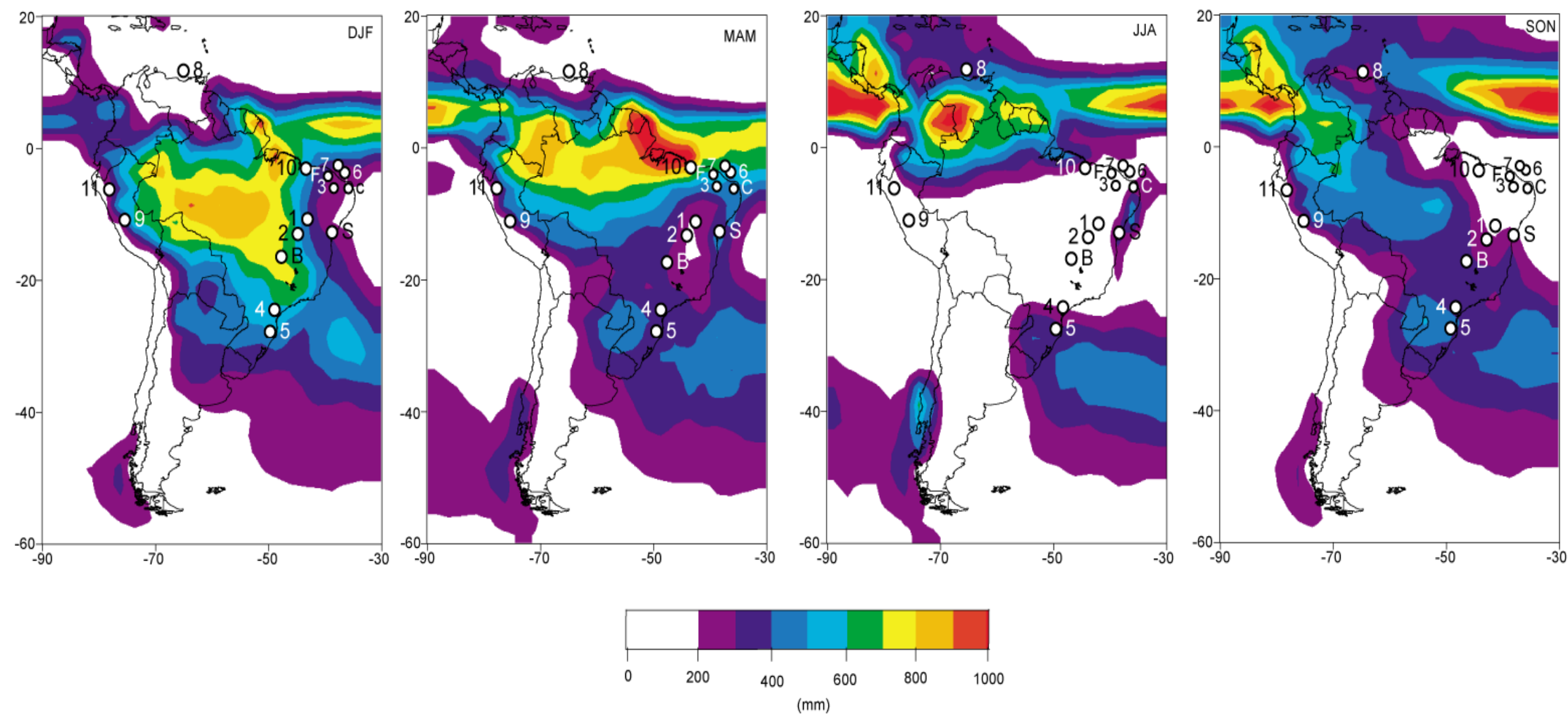

Figura 2.4 - Mapa climático representando a média da quantidade total sazonal de precipitação, obtida entre 1979-2000, proveniente do Climate Prediction Center Merged Analysis. Para a região da Chapada Diamantina, Bahia, observa-se a ocorrência de maiores médias de precipitação em DJF e MAM (estações de verão e outono), o que indica a atuação de mecanismos climáticos associados à MSA e a ZCIT. Os números indicados no mapa correspondem às seguintes localidades: 1 - Chapada Diamantina, 2 - Gruta do Padre, Bahia (Wang et al. 2007b; 2009), 3 - Cavernas do Rio Grande do Norte (Cruz et al. 2009), 4 - Caverna Santana (Cruz et al. 2005; 2006), 5 - Caverna Botuverá (Wang et al. 2006; Cruz et al. 2005), 6 e 7 - Testemunhos marinhos GeoB 3911-3 e GeoB 3104 (Arz et al. 1998), 8 - Bacia do Cariaco, Venezuela (Peterson et al, 2000, Haug et al. 2003), 9 - Lago Junin, Peru (Seltzer et al. 2000), 10 - Lago Caçó, Maranhão (Sifeddine et al. 2003), 11 - Cueva del Tigre Perdido, Peru (van Breukelen, 2008). As letras indicam as localidades das estações de monitoramento da IAEA-GNIP: S - Salvador, B - Brasília, C - Ceará Mirim e, F - Fortaleza. 
As chuvas associadas à atividade da ZCIT durante outono influem significativamente no acumulado total de precipitação anual na Chapada Diamantina, sendo sua contribuição maior em Andaraí do que em Iraquara. Em ambas as áreas, as chuvas de MAM juntamente com a precipitação dos meses de verão, constituem os principais períodos úmidos que se prolonga durante, aproximadamente, 5 e 6 meses no ano, como verificado por Rao et al. (1996) ao tratar da climatologia do NEB.

De forma resumida, a estação chuvosa no NEB associada aos meses MAM, está diretamente relacionada à migração sazonal e latitudinal para sul do eixo de confluência a baixos níveis adjacente ao leste tropical Atlântico (Hastenrath e Heller, 1977) que durante o mês de Março encontra-se localizado aproximadamente a $4^{\circ} \mathrm{S}$ (Molion e Bernardes, 2000), mas que também influencia na porção sul da região nordeste no estado da Bahia.

Mudanças no gradiente de TSM entre Atlântico tropical norte e sul são consideradas as principais causas dos padrões de variação decadal de chuva no Nordeste, sendo que os períodos mais chuvosos na região ocorrem durante anomalias positivas de TSM no Atlântico logo a sul do equador (Nobre e Shukla, 1996). Anomalias do gradiente meridional da TSM no Atlântico equatorial afetam o posicionamento da ZCIT, forçando um ajuste hidrostático no limite com as camadas atmosféricas, que impacta o posicionamento da ZCIT sobre o oceano (Nobre e Shukla, 1996; Biassuti et al. 2004; Hastenrath et al. 2006).

Em escala interanual, as anomalias de TSM no Pacifico tropical repercutem nas condições pluviométricas no NEB, estando associado à alta variação das médias pluviométricas principalmente em MAM (Kayano e Andreoli, 2009). Essa condicionante também afeta o posicionamento da ZCIT na região e conduz a períodos de longa estiagem durante os fenômenos El Niño e cheias durante La Niña no interior do Nordeste. As anomalias interanuais de precipitações em MAM são mais importantes no norte da região Nordeste, mas também são significativas na distribuição de chuvas na Chapada Diamantina (Ambrizi et al. 2004).

Após outono, ocorre um decréscimo contínuo na média de precipitação nos quatro municípios mencionados, sendo os valores mínimos registrados em agosto e setembro (Fig. 2.3). No entanto, as chuvas dos meses de inverno, responsáveis pelos maiores índices pluviométricos na costa sul baiana, ainda chega a atingir a borda leste da Chapada, como registrado nas estações pluviométricas de Wagner e Andaraí, com valores correspondentes a 10.7 e $7.4 \%$ do acumulado total anual, o que equivale a 74 e 83.7 mm/ano (Tab.2.1), respectivamente. Já na borda oeste, as chuvas de JJA são pouco importantes, visto totais 
acumulados de 22.9 e 15.6 mm/ano em Iraquara e Seabra, o que representa 4.9 e $4.2 \%$ do acumulado anual.

Tabela 2.1 - Média trimestral da quantidade de chuva (acumulado em mm/ano e também expresso em porcentagem) nos municípios de Iraquara, Wagner, Andaraí e Seabra.

Município de Andaraí

\begin{tabular}{ccccc}
\hline Trimestres & DJF & MAM & JJA & SON \\
\hline \multirow{2}{*}{ Média (mm/ano) } & 199.5 & 140.9 & 34.2 & 27.1 \\
& 146.3 & 112.7 & 28.8 & 66.9 \\
\cline { 1 - 1 } Acumulado (mm/ano) & 125.0 & 45.9 & 20.6 & 177.0 \\
$(\%)$ & 41.8 & 299.6 & 83.7 & 271.1 \\
& & & 7.4 & 24.0 \\
\hline
\end{tabular}

Município de Wagner

\begin{tabular}{ccccc}
\hline Trimestres & DJF & MAM & JJA & SON \\
\hline \multirow{2}{*}{ Média (mm/ano) } & 166.0 & 34.6 & 34.0 & 5.8 \\
& 72.0 & 104.6 & 24.0 & 34.7 \\
\cline { 1 - 3 } Acumulado (mm/ano) & 53.5 & 48.5 & 16.0 & 93.3 \\
$(\%)$ & 291.5 & 187.8 & 74.0 & 133.9 \\
& 42.4 & 27.3 & 10.7 & 19.4 \\
\hline
\end{tabular}

Município de Iraquara

\begin{tabular}{ccccc}
\hline Trimestres & DJF & MAM & JJA & SON \\
\hline \multirow{2}{*}{ Média (mm/ano) } & 83.2 & 31.3 & 19.3 & 4.7 \\
& 51.8 & 40.8 & 3.0 & 49.0 \\
\cline { 1 - 1 } Acumulado (mm/ano) & 94.5 & 10.7 & 0.5 & 71.1 \\
$(\%)$ & 229.6 & 82.8 & 22.9 & 124.6 \\
& 49.9 & 18.0 & 4.9 & 27.0 \\
\hline
\end{tabular}

Município de Seabra

\begin{tabular}{ccccc}
\hline Trimestres & DJF & MAM & JJA & SON \\
\hline \multirow{3}{*}{ Média (mm/ano) } & 49.4 & 21.8 & 6.0 & 2.7 \\
& 65.6 & 50.0 & 5.7 & 15.6 \\
\cline { 1 - 1 } Acumulado (mm/ano) & 74.3 & 11.1 & 3.8 & 61.0 \\
$(\%)$ & 189.3 & 82.9 & 15.6 & 79.3 \\
\hline
\end{tabular}


Os menores valores de chuvas de inverno, observados na borda oeste da Chapada, são atribuídos ao barramento da umidade de leste proveniente do litoral baiano, pelas montanhas mais altas que compõem a Serra do Sincorá, as quais possuem orientação aproximadamente norte-sul (Fig.2.2).

Essas porcentagens pluviométricas durante os meses de inverno estão concordância com os valores verificados por Rao et al. (1996), cujo acumulado a partir do mapa de isolinhas oscilou entre 5 e $10 \%$ na Chapada Diamantina. Por outro lado, essas chuvas afetam com maior intensidade a costa leste nordestina, entre a Bahia e o Rio Grande do Norte e estão associadas principalmente à atuação da Alta Subtropical do Atlântico Sul (ASAS), chegando a representar $60 \%$ da precipitação no sul da Bahia, como visto, por exemplo, em Rao et al. (1993).

Ressalta-se um número menor de estudos encontrados na literatura acerca das precipitações que afetam o leste nordestino durante o inverno, em relação aos outros sistemas metereológicos aqui tratados. No entanto pouca ênfase será dada às chuvas desse período no presente trabalho, devido à baixa influência da ASAS nas médias anuais precipitação na Chapada Diamantina.

2.2.1. Relação entre os valores de $\delta D$ e $\delta^{18} \mathrm{O}$ em águas de gotejamento de cavernas $e$ precipitação na Chapada Diamantina

Pesquisas paleoclimáticas a partir de registros de $\delta^{18} \mathrm{O}$ em espeleotemas são somente possíveis se existir uma associação direta entre assinatura isotópica da água meteórica e dos gotejamentos que formam espeleotemas nas cavernas, quando a deposição de $\mathrm{CaCO}_{3}$ ocorre em equilíbrio isotópico (Hendy, 1971). Essa relação pode ser obtida através de monitoramentos de água de chuva e de gotejamento como, por exemplo, como realizado por Cruz et al. (2005b) nas cavernas Santana (Iporanga-SP) e Botuverá (Botuverá-SC). O monitoramento leva em conta a variação de $\delta^{18} \mathrm{O}$ das águas meteóricas ao longo do seu trajeto através do solo e rocha carbonática encaixante da caverna e também flutuações temporais na composição isotópica dessas águas, com objetivo de verificar a resposta da composição do gotejamento às condições ambientais, principalmente em relação às variações sazonais de pluviosidade (Cabbalero et al. 1996, Aylon et al. 1998).

Nesse sentido, foram trabalhados dados da composição isotópica de $\delta \mathrm{D}$ e $\delta^{18} \mathrm{O}$ da água de gotejamento e de chuvas obtidos através de monitoramentos hidrogeoquímicos realizados nas cavernas Fumaça, da região de Iraquara, e Paixão entre os meses de Julho de 2007 a Julho 
de 2008 (Ivo Karmann, dados inéditos). O procedimento metodológico do monitoramento consistiu na instalação de um pluviômetro remoto (de precipitação atmosférica) em duas estações externas para coleta de chuva e abaixo de um gotejamento em cada caverna, cuja precisão das medições correspondeu a $\pm 0,2 \mathrm{~mm}$ de chuva, registrando os eventos em Data Logger (registrador de dados) com capacidade de até 8000 registros. As estações ficaram localizadas a cerca de 200 e 100 m das entradas das cavernas Paixão e Fumaça, respectivamente. Os dados obtidos são relativamente limitados em comparação aos do monitoramento realizado no Sul e Sudeste do país (Cruz et al. 2005b), que devido ao curto período de amostragem, não possibilitou observar variações isotópicas temporais muito intensas, mas que de todo modo permitiu estabelecer associações com a composição isotópica da chuva.

A temperatura em ambas as cavernas é aproximadamente invariável ao longo do tempo, com médias de $22,1^{\circ} \mathrm{C}$ e $23,2^{\circ} \mathrm{C}$ observadas nas cavernas Paixão e Fumaça que, por sua vez, foram significativamente menores às médias registradas externamente nas duas cavernas de $31{ }^{\circ} \mathrm{C}$ e $26{ }^{\circ} \mathrm{C}$, respectivamente. A média mais baixa na segunda localidade ocorreu associada à localização da estação climática que foi instalada sob área parcialmente sombreada. Ambas as cavernas são invariavelmente saturadas em vapor d'água, sendo a umidade relativa sempre $100 \%$, o que demonstra clima internamente estável. Externamente tem-se umidade relativa média de aproximadamente $50 \%$ em ambos os sítios de monitoramento, como representado no gráfico da Figura 2.5 com os dados do monitoramento da área externa da caverna Fumaça.

Já os registros isotópicos da água da chuva nas duas áreas investigadas sugerem que os dados de $\delta^{18} \mathrm{O}$ e $\delta \mathrm{D}$ dos gotejamentos de ambas as cavernas estão relacionados à composição isotópica da água da chuva, pois todos os valores obtidos formaram aglomerações que se dispõem sobre ou bem próximas à linha meteórica global (GMWL, sigla em inglês do termo global meteoric water line) (Fig. 2.6). Essa é uma das principais evidências que suporta a utilização de registros isotópicos de espeleotemas de cavernas da Chapada Diamantina em estudos paleoclimáticos.

A GMWL, originalmente definida por Craig (1961), relaciona os valores de $\delta \mathrm{D}$ e $\delta^{18} \mathrm{O}$ das águas continentais, representada pela equação:

$$
\delta \mathrm{D}=8 \times \delta^{18} \mathrm{O}+10 \%(\mathrm{SMOW})
$$




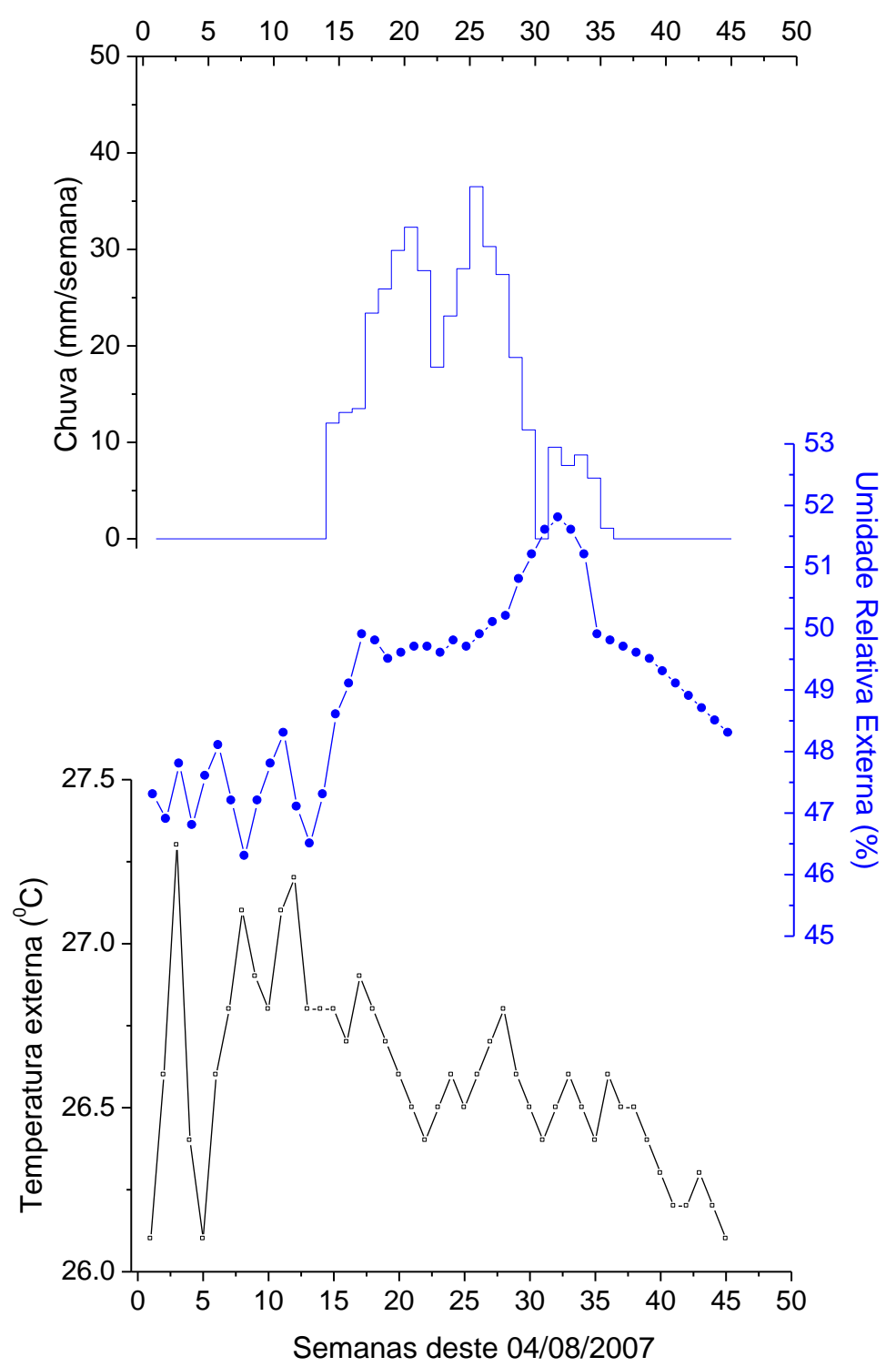

Figura 2.5 - Gráficos de quantidade de chuvas, temperatura e umidade relativa externa por semana da caverna Fumaça, Iraquara - BA.

A partir do monitoramento observou-se que os valores de $\delta^{18} \mathrm{O}$ dos gotejamentos oscilaram na caverna Paixão entre -2,62 e -3,48\%o (média= -2,62\%o) e na caverna da Fumaça entre $-0,58$ e $-3,88 \%$ o (média $=-2,73 \%$ ). Essa diferença na média, inferior a $0,5 \%$, é muito pequena em relação à precisão das análises isotópicas e não indicaram fortes alterações regionais da assinatura de $\delta^{18} \mathrm{O}$ do gotejamento entre as duas cavernas. Isso sugere associação direta com composição isotópica da chuva, corroborada por valores médios muito próximos de $\delta^{18} \mathrm{O}$ entre a chuva e gotejamento na caverna Fumaça e da Paixão. As médias obtidas são também semelhantes aos valores anuais de $\delta^{18} \mathrm{O}$ da precipitação sugeridos pelos dados de modelamentos de $\delta^{18} \mathrm{O}$ da precipitação reportados por Vuille et al. (2003). Além disso, a fraca correlação entre o $\delta^{18} \mathrm{O}$ e $\delta \mathrm{D}$ dos gotejamentos, observada nos gráficos de detalhe de ambas as 
cavernas, elimina a possibilidade de forte evaporação da água meteórica ao longo da percolação do solo até as cavernas (Fig. 2.6). Sob essas condições, observa-se que os fatores de fracionamento ocorridos na interface solo/caverna não tornaram as águas enriquecidas em ${ }^{18} \mathrm{O}$ e, por isso, não alteraram os valores de $\delta^{18} \mathrm{O}$ dos gotejamentos que formam os espeleotemas significativamente.

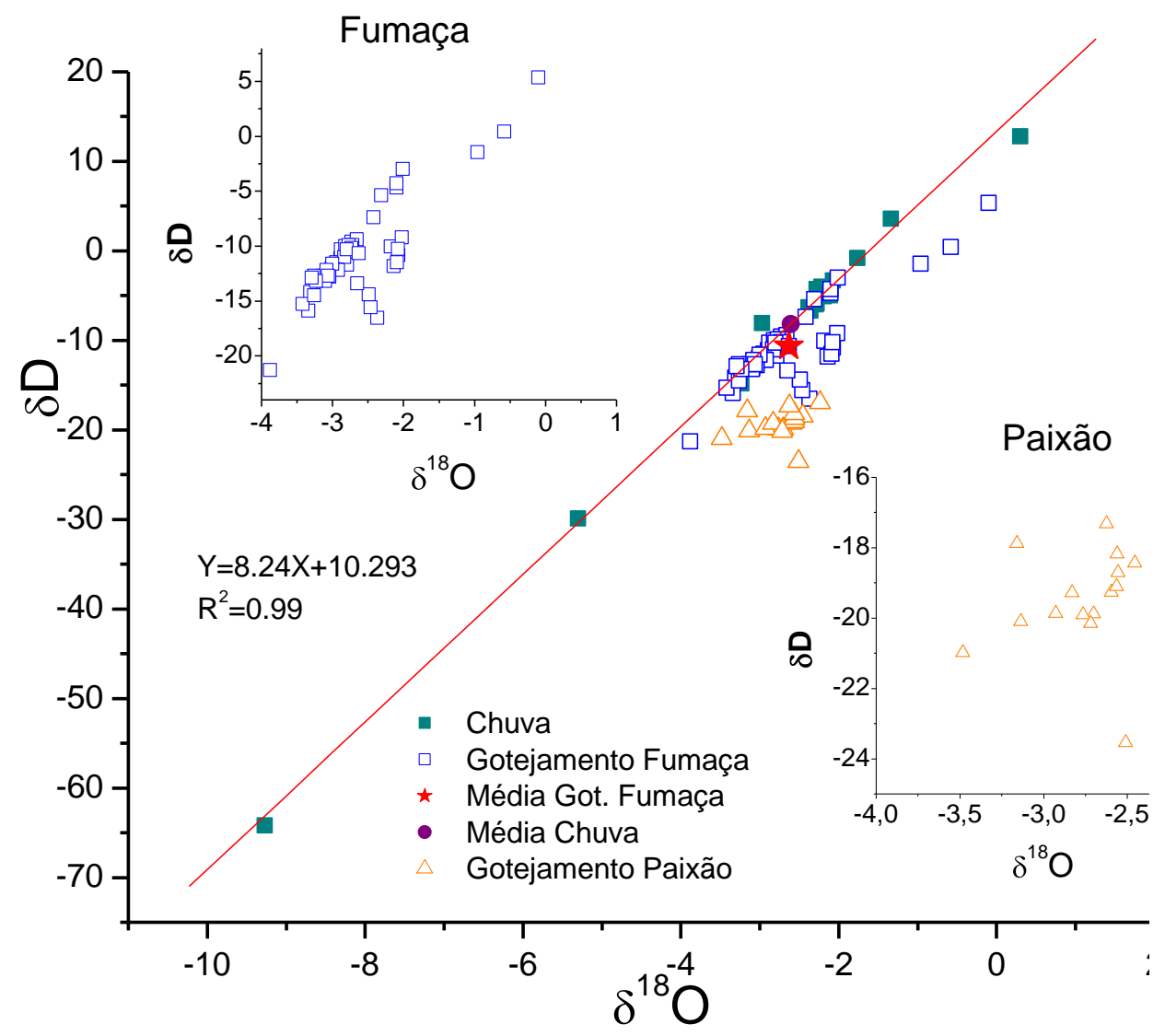

Figura 2.6 - Dados de $\delta^{18} \mathrm{O}$ e $\delta \mathrm{D}$ de gotejamentos das cavernas Paixão e Fumaça, localizadas nas áreas de Andaraí-BA e Iraquara-BA. Os dados das amostras de ambas as cavernas se aglomeram sobre a linha de água meteórica global e sugerem forte relação com a água da chuva. Em detalhe, nota-se a fraca correlação dos dados de $\delta^{18} \mathrm{O}$ e $\delta \mathrm{D}$ de gotejamentos, o que sugere pequena influência de processos evaporativos em superfície em ambas as cavernas.

Quanto à análise do volume de gotejamento na caverna Fumaça, notou-se o aumento gradual dos valores a partir da décima terceira semana de monitoramento, que por sua vez, foi concordante com o aumento da quantidade de chuva (Fig. 2.7). Já no monitoramento na caverna Paixão esta relação mostrou-se mais clara na vigésima quinta semana (Fig. 2.8). Em ambas as cavernas foi verificada também boa correlação entre o volume do gotejamento com os valores isotópicos de oxigênio. Valores mais altos de $\delta^{18} \mathrm{O}$ foram concordantes, na caverna da Fumaça, com a diminuição do volume de gotejamento na décima quarta semana (Fig. 2.7). 
Relação sutilmente inversa, representados pelos baixos valores de $\delta^{18} \mathrm{O}$ e aumento do volume gotejado indicando correlação negativa entre os dois parâmetros, mantiveram-se em grande parte dos meses de monitoramento.

A relação entre altos valores de $\delta^{18} \mathrm{O}$ e diminuição do volume de gotejamento, também esteve clara no monitoramento na caverna Paixão entre a quinta e décima semana (Fig. 2.8), mas que devido falta de obtenção de dados, não se pôde observar esta correlação no restante das semanas. De todo modo, em ambas as cavernas observou-se de forma clara, a boa resposta do volume gotejado com o aumento das chuvas, bem como relação direta entre os valores de $\delta^{18} \mathrm{O}$ do gotejamento e a quantidade de chuva.

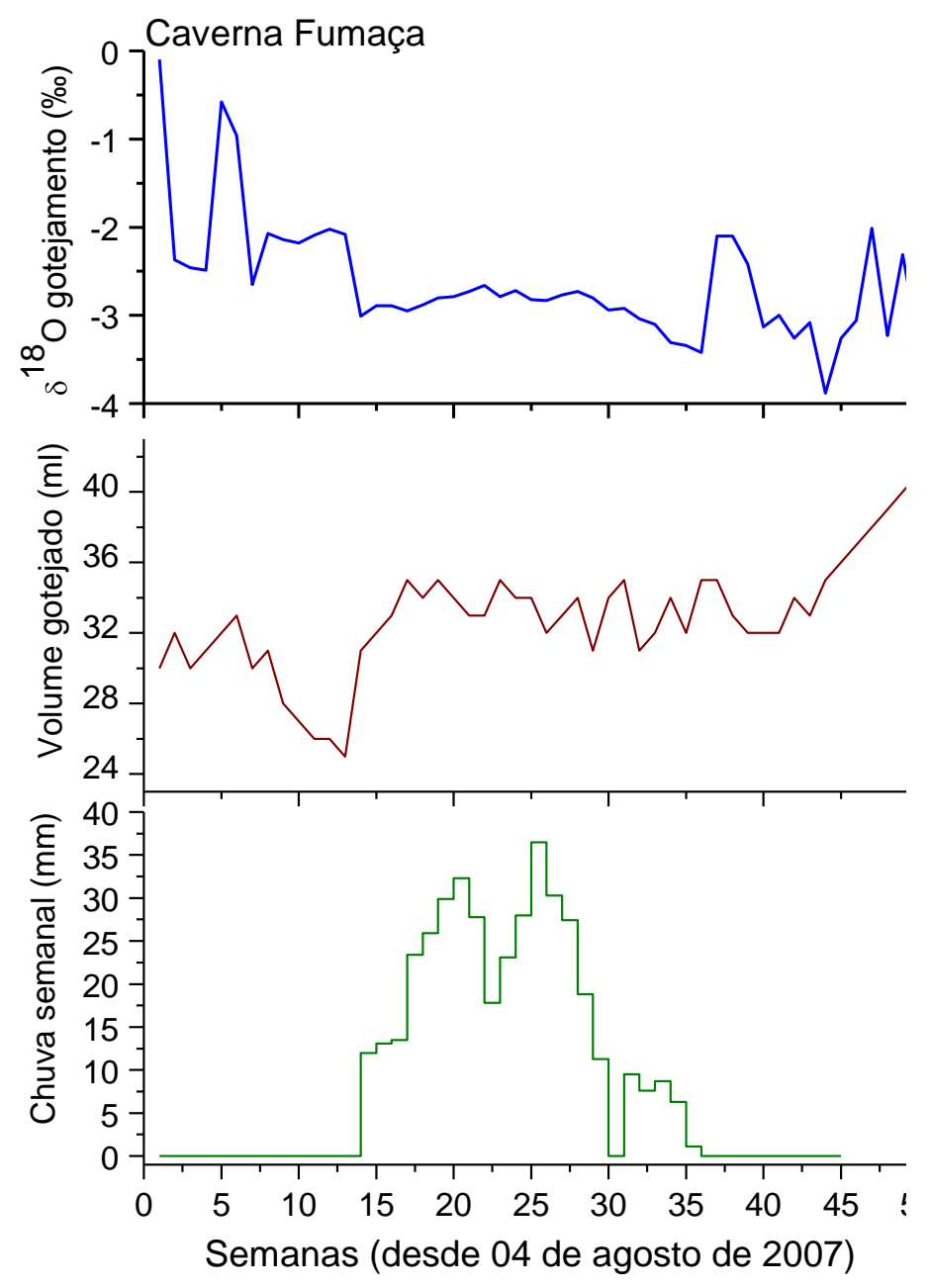

Figura 2.7 - Variação de $\delta^{18} \mathrm{O}$ versus vazão de gotejamento e pluviosidade na área da caverna Fumaça. 

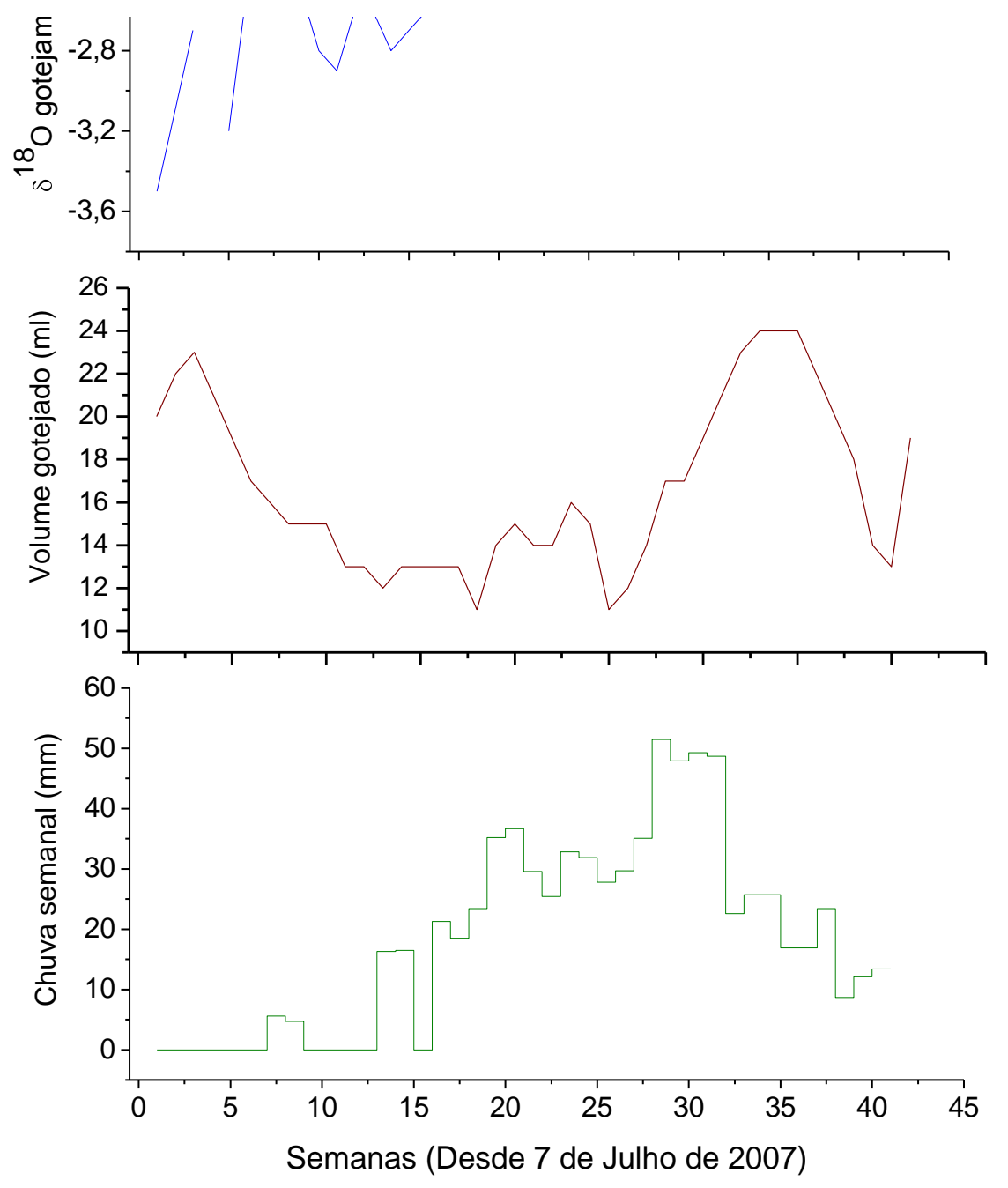

Figura 2.8 - Variação de $\delta^{18} \mathrm{O}$ versus vazão de gotejamento e pluviosidade na área da caverna Paixão.

2.2.2. Monitoramento pluviométrico da IAEA-GRIP: Análise da composição isotópica da chuva e controle isotópicos

Para avaliação de como a composição isotópica das chuvas estão relacionadas com mudanças na pluviosidade, foram analisadas estações pluviométricas da IAEA-GRIP mais próximas da Chapada Diamantina (www-naweb.iaea.org/napc/ih/IHS_resources_gnip.html), localizadas em Salvador (BA), Brasília (DF), Ceará Mirim (RN) e Fortaleza (CE). Os dados de pluviometria ( $\mathrm{mm} / \mathrm{mês})$ e as razões isotópicas de oxigênio mensal dessas estações de monitoramento foram tratados com a finalidade de analisar a influência dos três sistemas 
metereológicos, que atuam na distribuição das chuvas em Andaraí e Iraquara, na variação sazonal de $\delta^{18} \mathrm{O}$. As análises têm como objetivo discutir a consistência entre os valores de $\delta^{18} \mathrm{O}$ chuva e os fatores que controlam o fracionamento isotópico, como: quantidade de chuva, temperatura e fonte de umidade; considerados nas simulações de modelo climáticos (Vuille et al. 2003).

Ressalta-se que o levantamento isotópico realizado pela IAEA-GNIP variou entre 9 e 15 anos. Apesar de representar um intervalo relativamente curto para estabelecer médias climatológicas, geralmente calculadas a partir de dados com no mínimo em 30 anos, foi possível discutir a provável influência de cada sistema metereológico no $\delta^{18} \mathrm{O}$ chuva da região da Chapada Diamantina.

A análise representada no gráfico da Figura 2.9a teve como base os valores da média ponderada entre o $\delta^{18} \mathrm{O}_{\text {chuva }}$ e precipitação acumulada mensalmente $(\mathrm{mm})$ das estações de monitoramento, obtidas pela equação:

$$
\operatorname{Vr} \delta^{18} \mathbf{O}=\frac{\sum_{i=\mathbf{1}}^{n} \mathbf{P}_{\mathbf{i}} \boldsymbol{\delta}_{\mathbf{i}}^{\mathbf{1 8}} \mathbf{0}}{\sum_{i=\mathbf{1}}^{n} \mathbf{P}_{\mathbf{i}}}
$$

Onde P é o valor de precipitação em ( $\mathrm{mm} / \mathrm{mês})$ e $\delta^{18} \mathrm{O}$ é valor das razões isotópicas que compõem a chuva. Esse método atenua distorções causadas por dados isotópicos anômalos no cálculo da média do $\delta^{18} \mathrm{O}$ mensal, por exemplo, valores anomalamente baixos de $\delta^{18} \mathrm{O}$ em amostras correspondentes a pequenos volumes de chuva. Com isso, são calculados dados mais representativos da variação mensal de $\delta^{18} \mathrm{O}$ (Cruz et al. 2005b). A partir desses dados foi também possível realizar inferências das fontes de umidade que afetaram as chuvas das quatro estações de monitoramento em questão, o que pode ser relacionado com os resultados obtidos a partir das simulações do ECHAM-4 e GISS II (Vuille et al. 2003).

No gráfico da Figura 2.9b está representada a distribuição média de chuva mensal nos quatro municípios brasileiros monitorados, sendo a temperatura média mensal representada no gráfico 2.9c. A análise desses gráficos permitiu identificar mudanças sazonais na composição isotópica da água da chuva, caracterizadas por valores mais negativos de $\delta^{18} \mathrm{O}$ durante meses mais chuvosos. No entanto, uma maior amplitude de variação é observada em Brasília $(\Delta=-$ $6 \%$ ), no centro do país, do que nas estações de localidades dispostas na costa nordestina ( $\Delta=-$ $3 \%$ ). 


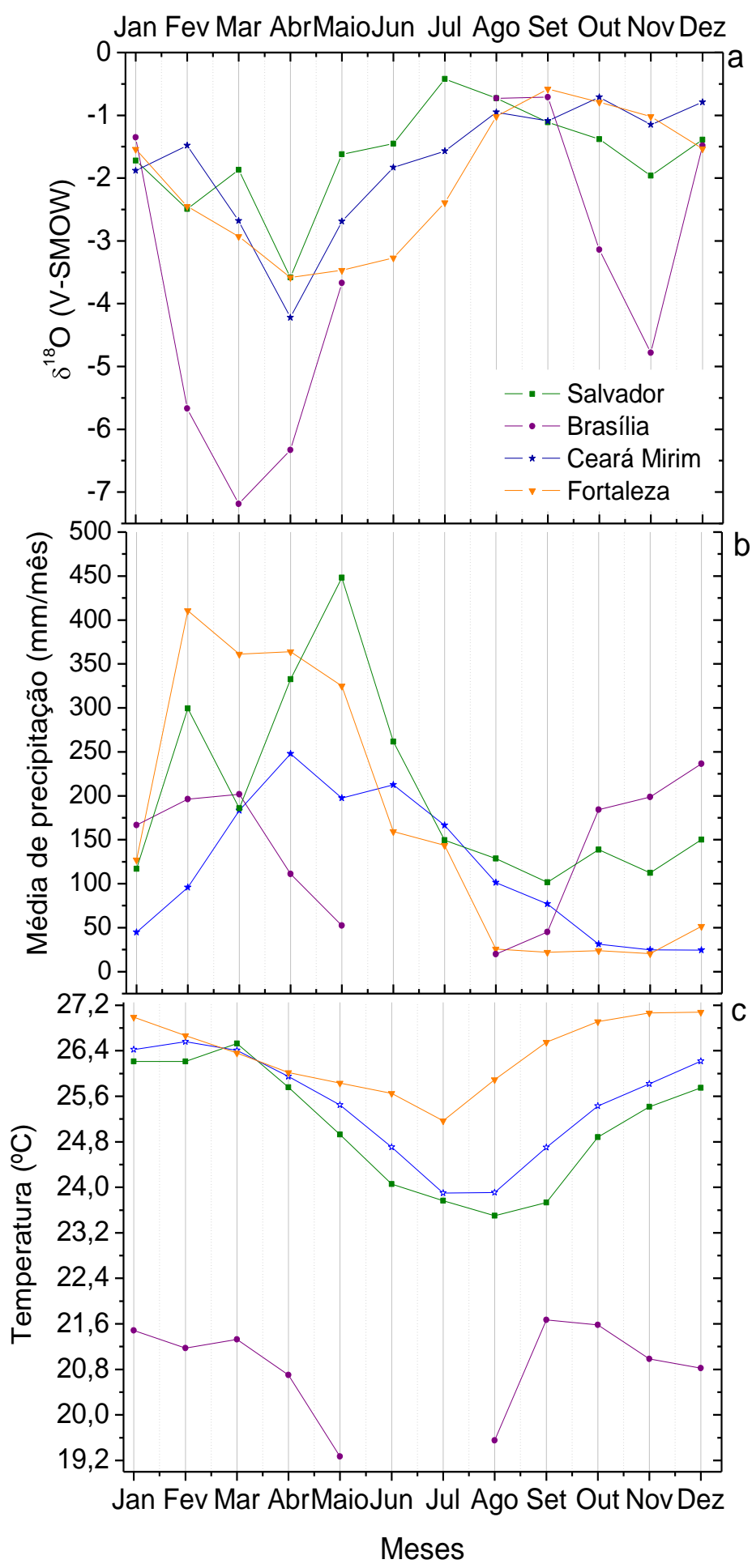

Figura 2.9 - Dados da média mensal de: (a) $\delta^{18} \mathrm{O}_{\text {chuva }}$, (b) pluviometria e (c) temperatura; das estações do IAEA em Salvador, Brasília, Ceará Mirim e Fortaleza.

Essa relação é confirmada estatisticamente por forte correlação negativa nas estações de Salvador, Fortaleza, Ceará Mirim, representada por coeficiente de determinação $\left(\mathrm{R}^{2}\right)$ igual 
a 0,58, 0,66 e 0,61 (Fig. 2.10). Exceção se faz a estação de Brasília onde foi obtido um valor baixo de $\mathrm{R}^{2}$ de 0,16 (Fig. 2.10), indicando que outros fatores não associados diretamente à quantidade de precipitação foram também significantes para variação da composição isotópica mensal da chuva.

O controle isotópico devido ao amount effect está associado à profunda convecção vertical ocorrida nas regiões tropicais (Vuille et al. 2003, Rise et al. 2008). Esse efeito ocorre a partir do processo de condensação, quando as moléculas de água enriquecidas por ${ }^{18} \mathrm{O}$ são preferencialmente removidas, tornando a composição isotópica do vapor residual gradativamente mais leve, ou seja, enriquecida em ${ }^{16} \mathrm{O}$ (Clark e Fritz, 1997; Lachniet et al. 2009). Esse processo resulta em uma composição isotópica da água mais empobrecida em isótopos em ${ }^{18} \mathrm{O}$, à medida que ocorre o incremento da precipitação e o prolongamento temporal desta. Em outras palavras, os valores de $\delta^{18} \mathrm{O}$ tornam-se gradativamente mais baixos associados ao aumento da quantidade de precipitação, o que foi claramente evidenciado nas estações do IAEA-GNIP (Fig. 2.9a, 2.9b) e nos resultados do modelo ECHAM-4 (Vuille et al. 2003).

A maior amplitude de variação nos dados de Brasília é atribuída ao efeito de continentalidade, o qual promove valores cada vez mais baixos de $\delta^{18} \mathrm{O}$ da chuva ao passo que se distancia da área fonte da umidade, no caso a Bacia Amazônica (Vuille et al. 2003). O mecanismo envolvido nesse processo considera que o vapor residual torna-se cada vez mais empobrecido em ${ }^{18} \mathrm{O}$ com o prolongamento das chuvas monçônicas, desde seu início em setembro/outubro até final da estação em março/abril da Bacia Amazônica para as outras regiões do Brasil (Vuille e Werner, 2005). Assim, o efeito continentalidade está associado ao fracionamento isotópico do vapor que ocorre na atmosfera, tipo destilação Rayleigh (Lachniet, 2009).

Portanto, é natural que as chuvas no final das monções, meses de fevereiro a abril sejam significativamente mais negativas do que nos meses antecedentes na mesma estação. Essa também é a razão para os valores muito baixos de $\delta^{18} \mathrm{O}$ observados em março em Brasília e para a fraca correlação estatística com os dados de pluviometria mensal nesta estação. Isso porque a quantidade de chuvas no mês de março ( 200 mm) são inferiores ao registrado em dezembro, durante o pico da estação (Fig. 2.9b). Por outro lado, a baixa amplitude dos valores isotópicos em estações do nordeste é devido à proximidade destas da área fonte de chuva, ou seja, ao oceano Atlântico. 

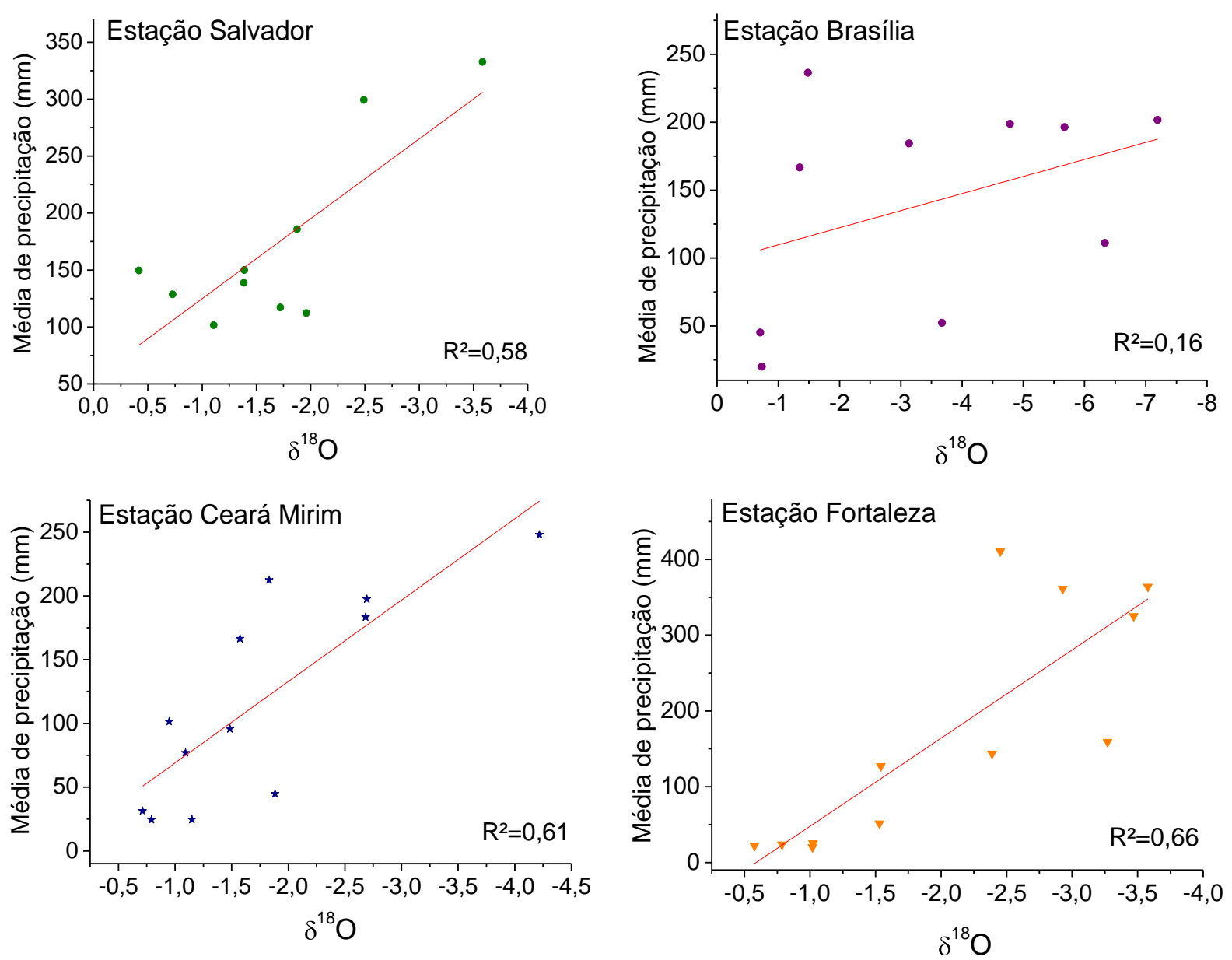

Figura 2.10 - Relação entre a média pluviométrica mensal e o $\delta^{18} \mathrm{O}_{\text {chuva }}$ nas estações da IAEA em Salvador, Brasília, Ceará Mirim e Fortaleza

As variações isotópicas de $\delta^{18} \mathrm{O}$ da precipitação amostradas são pouco relacionadas com a temperatura, como visualizado nas Figuras 2.9a e 2.9c. A amplitude de variação da temperatura média nas estações de interesse é pequena, cerca de $2{ }^{\circ} \mathrm{C}$ em Fortaleza e CearáMirim e $3{ }^{\circ} \mathrm{C}$ em Salvador e Brasília e, contrariamente ao esperado para um efeito significativo da temperatura (Clark e Fritz, 1997), os valores mais altos de $\delta^{18} \mathrm{O}$ são observados nos meses mais frios de inverno e mais baixos nos meses quentes de verão e outono. Além disso, as anomalias de temperatura coincidem com períodos mais secos de inverno e primavera na região de estudo, o que torna esse parâmetro menos relevante para variação de $\delta^{18} \mathrm{O}$ da água meteórica que forma os espeleotemas em cavernas da Chapada Diamantina.

Os dados das estações de monitoramento isotópico foram tratados trimestralmente (Fig. 2.11) com objetivo de melhor distinguir a contribuição de chuvas associadas com cada 
sistema metereológico que afeta a região da Chapada Diamantina, necessária para correlação regional com outros registros paleoclimáticos. Devido a certa sobreposição no período de atuação de cada sistema, considerou-se nessa análise o pico de atividade do sistema de monções (MSA) nos meses de dezembro, janeiro e fevereiro (Carvalho e Jones, 2009); do sistema da zona de convergência intertropical (ZCIT) em março, abril e maio (Melo et al. 2009) e de inverno nos meses de junho, julho e agosto (Rao et al. 1996).

Os gráficos na Figura 2.11 e o mapa da Figura 2.4 mostram que a ZCIT é o sistema mais atuante faixa costeira do NEB, com maiores índices pluviométricos observados em MAM em Salvador, Fortaleza e Ceará-Mirim, o que coincide com valores mínimos de $\delta^{18} \mathrm{O}$ nessas estações. Por outro lado, os valores são 1,5 a 2 \%o mais altos em JJA nas estações de Salvador e Ceará Mirim, onde as chuvas de invernos são significantes. Já em Brasília, os índices pluviométricos mais altos ocorrem durante o pico da MSA em DJF, mas os valores mais baixos de $\delta^{18} \mathrm{O}$ são observados em MAM, em virtude das chuvas de março e abril, o que corresponde ao final da estação MSA, como comentado anteriormente.
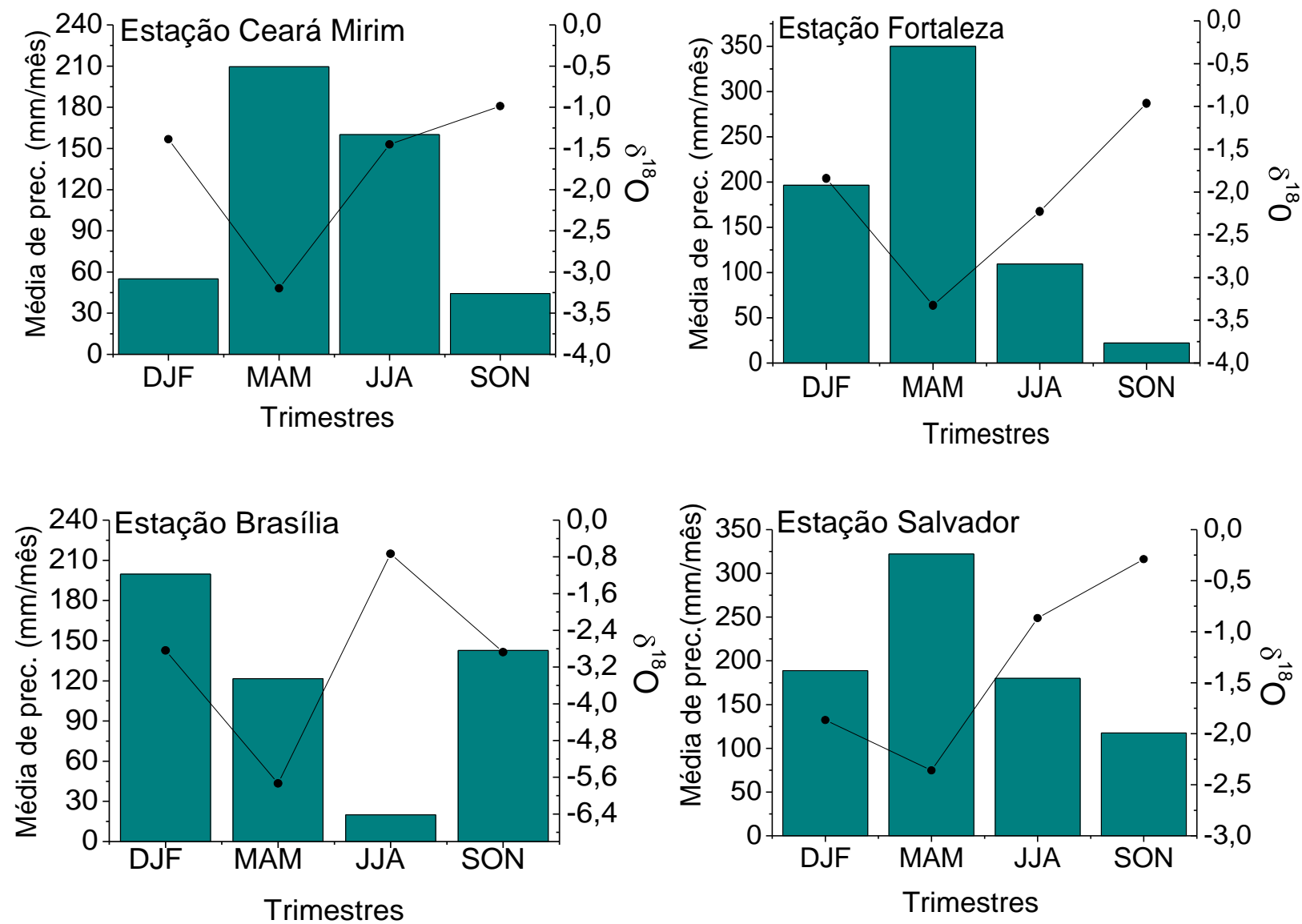

Figura 2.11 - Relação entre a média pluviométrica trimestral e os valores de $\delta^{18} \mathrm{O}_{\text {chuva }}$ nas estações da IAEA em Salvador, Brasília, Ceará Mirim e Fortaleza. 
Esses dados sugerem que tanto uma intensificação da MSA como da ZCIT poderiam resultar em uma diminuição de valores de $\delta^{18} \mathrm{O}$ das precipitações na região da Chapada Diamantina. Diferentemente, uma maior contribuição das chuvas de inverno causaria aumento nos valores de $\delta^{18} \mathrm{O}$, provavelmente devido à fonte de umidade mais proximal dessas chuvas, a costa sul da Bahia. Os resultados obtidos indicaram que, de modo geral, existe uma influência dominante da pluviosidade sobre as variações isotópicas, fator esse mais conhecido como amount effect (Clark e Fritz, 1997), e apresentaram-se consistentes com os resultados de simulações de modelos que analisam a variação de $\delta^{18} \mathrm{O}$ da precipitação (Vuille et al. 2003). No entanto, deve-se ser considerada a influência da área fonte de umidade.

Vuille et al. (2003), destacam três tipos de áreas fontes de umidade: continental, oceânica-equatorial e Atlântico sul, as quais são relativamente mais importantes nas chuvas associadas a MSA, ZCIT e de inverno, respectivamente. A contribuição relativa de cada fonte é discutida através de dados de experimentos de modelagem isotópica com a utilização do modelo ECHAM-4, obtidas e disponibilizadas pelo Prof. Dr. Mathias Vuille. Nota-se que a maior porcentagem de contribuição das chuvas para a região da Bahia está associada primeiramente à fonte Oceânica-equatorial, designada no gráfico de Tropical Atlantic, relacionada deste modo a atividade do sistema ZCIT (Fig. 2.12). Ainda a partir do mesmo gráfico, observa-se que a segunda maior contribuição está ligada à fonte continental sulamericana, denominada de South America, o que remete à influência da MSA na região. E por último, fica evidenciada a baixa contribuição da umidade proveniente do Atlântico Sul ( $S$. Atlantic), para as chuvas no interior da Bahia como observado claramente na Figura 2.12.

A composição isotópica da chuva associada à fonte de umidade também pôde ser analisada por meio da modelagem ECHAM-4. Os valores sazonais de $\delta^{18} \mathrm{O}_{\text {chuva }}$ modelados para cada área fonte de umidade são consistentes com dados das estações do GNIP-IAEA acima descritos, com exceção dos dados correspondentes a fonte continental sul-americana. Valores significativamente mais altos de $\delta^{18} \mathrm{O}_{\text {chuva }}$ em relação ao observado nas estações, devido a influência dessa última fonte, são atribuídos a um certo exagero do modelo ECHAN4 na estimativa de fracionamento pela evaporação da água sobre os continentes (Mathias Vuille, informação pessoal). Através da Figura 2.13 observa-se que os valores de $\delta^{18} \mathrm{O}_{\text {chuva }}$ proveniente da fonte oceânica-equatorial não apresentam grandes variações sazonais para a área correspondente a Bahia, durante os meses de verão e outono. Relação semelhante 
também foi observada entre os valores de $\delta^{18} \mathrm{O}_{\text {chuva }}$ e a fonte continental, durante o final da primavera e o verão. 

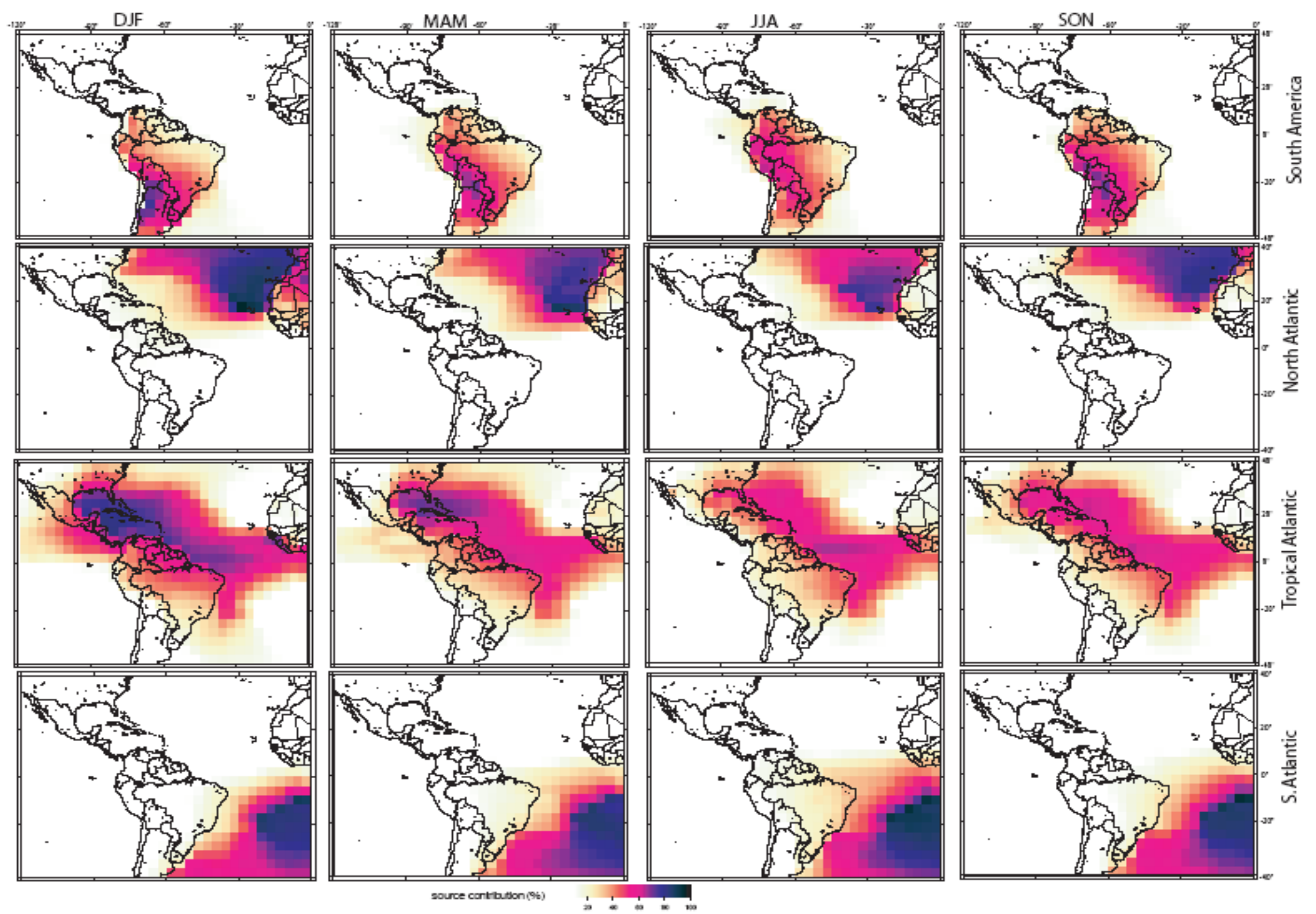

Figura 2.12 - Contribuição média anual (em porcentagem) das diferentes áreas fontes de umidade para a precipitação regional obtidas pela simulação através do modelo ECHAM-4. Dados modificados de Vuille et al. (2003). 

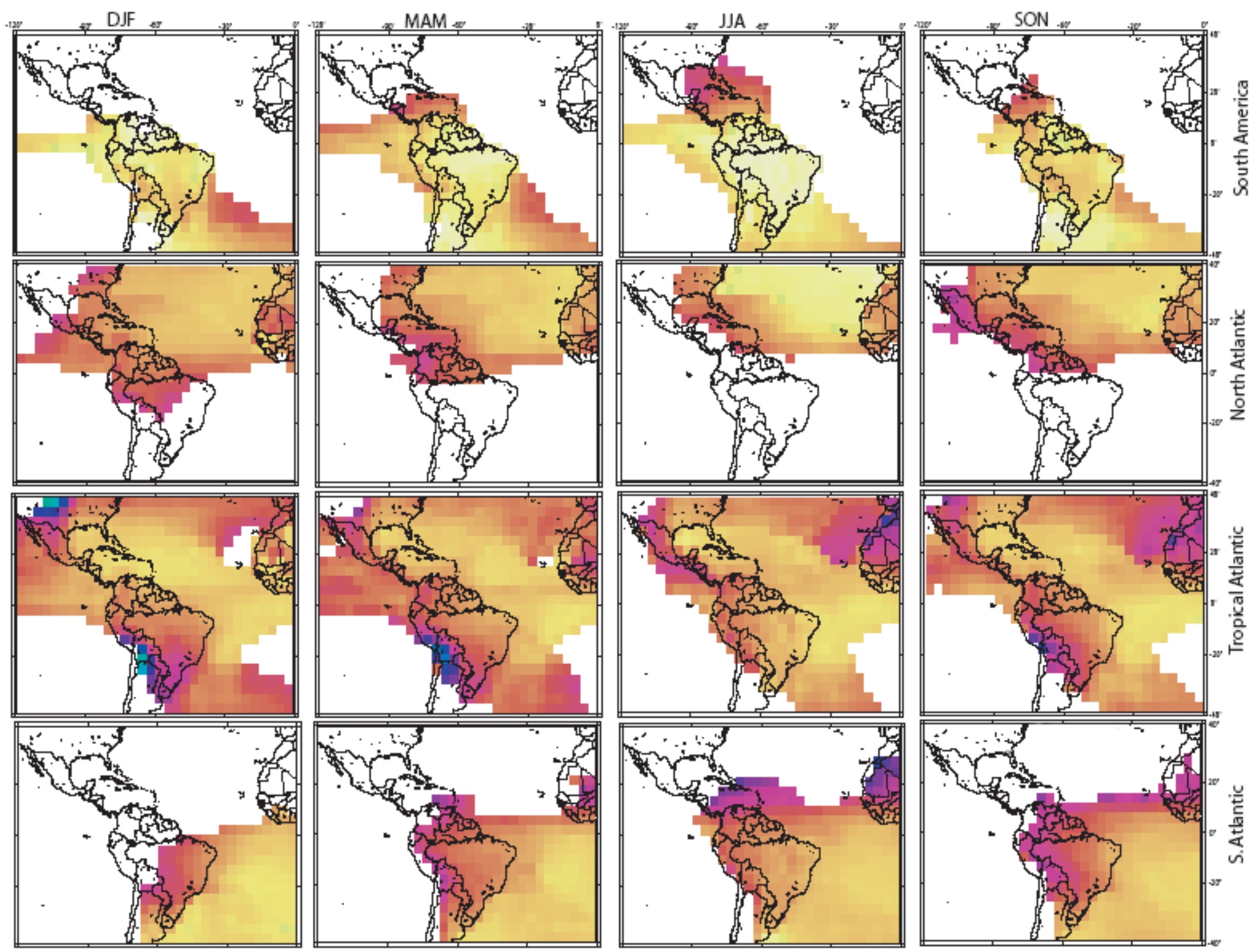

$\delta^{18} \mathrm{O}$ (permil)

Figura 2.13- Composição isotópica (valores de $\delta^{18} \mathrm{O}$ ) média das chuvas que afetam a América do Sul simulada através do ECHAM-4 com dados obtidos por estações da IAEA. . Dados modificados de Vuille et al. (2003). 


\section{PROCEDIMENTOS METOdOLÓGICOS APLICADOS À PESQUiSA PALEOCLIMÁTICA}

\subsection{Coleta das estalagmites}

As estalagmites coletadas nas cavernas Ioiô, Diva de Maura e Paixão, foram preferencialmente as do tipo cilíndricas, ideal para estudos paleoclimáticos, devido à estratigrafia relativamente simples (Fairchild et al. 2006). Por motivo de preservação ambiental, preferiu-se coletar quando possível, estalagmites já quebradas por depredações e dispostas ao longo no assoalho de salões e galerias. Já os locais de coleta das estalagmites se deram principalmente em galerias e salões isolados, ambientalmente caracterizados pela mínima circulação e alta umidade relativa de ar. Essas características estiveram bem marcadas nas três cavernas pesquisadas, considerando as dimensões quilométricas das mesmas e predominância de clima úmido e temperatura pouco variável em suas galerias.

A escolha do local de coleta dentro da caverna é um pré-requisito básico para evitar estalagmites que tenha sofrido efeitos de fracionamento cinético durante a precipitação do $\mathrm{CaCO}_{3}$ (Fairchild et al. 2006). Esse procedimento metodológico é de elevada importância no presente trabalho, uma vez que, para interpretação razões de isótopos estáveis, necessita-se que a precipitação do $\mathrm{CaCO}_{3}$ tenha ocorrido em equilíbrio isotópico, fator este que depende da ausência de processos evaporativos na caverna. Desse modo, o rigor no procedimento de coleta se constituiu como condição básica para que os valores de $\delta^{18} \mathrm{O}$ e $\delta^{13} \mathrm{C}$ do $\mathrm{CaCO}_{3}$ dos espeleotemas possam ser associados à composição da água meteórica e do carbono orgânico do solo e dessa forma às variações paleoclimáticas. Nesse contexto, foram evitadas as amostras depositadas próximas as entradas das cavernas, onde fatores ambientais externos fossem fortemente atuantes.

\subsection{Preparação de estalagmites para estudo paleoclimático}

A primeira etapa na preparação das estalagmites consiste na realização de cortes longitudinais ao longo de eixo de crescimento dessas formações. Em casos de espeleotemas com variações acentuadas do eixo de crescimento, por conta das migrações laterais de gotejamento durante o seu crescimento, foram feitos cortes adicionais para exposição tridimensional da estrutura das amostras. Para a realização deste procedimento utilizaram-se discos de corte com bordas diamantadas de espessura entre 1 e $2 \mathrm{~mm}$, acoplados a uma serra de corte. 
A segunda etapa consistiu no polimento das faces cortadas com a utilização de uma politriz adequada para polimento de rochas carbonáticas. $\mathrm{O}$ polimento das faces internas teve a finalidade de permitir visualização mais nítida das camadas de crescimento da estalagmite, imprescindível para identificar cavidades de redissolução, por vezes preenchidas por calcita reprecipitada. Essas feições de alteração foram evitadas nas estalagmites escolhidas para o estudo.

A terceira etapa consistiu na digitalização das faces polidas das estalagmites com a utilização de um digitalizador (scanner) convencional, com o intuito de permitir o planejamento das duas próximas fases metodológicas: a amostragem para geocronologia e as análises de isótopos estáveis de oxigênio e carbono. A partir das imagens, foram préselecionados os locais para extração de pó para datação U/Th (Fig. 3.1) e estimados o número de amostras para análise de isótopos estáveis em função da resolução temporal desejada no estudo de cada estalagmite.

\subsection{Geocronologia ${ }^{230} \mathrm{Th} /{ }^{234} \mathrm{U}$}

A amostragem geocronológica das estalagmites da Chapada Diamantina foi realizada a partir de camadas sem sinais de processos de dissolução e recristalização; evitando-se as camadas escuras com maior concentração de materiais terrígenos, fontes de ${ }^{230} \mathrm{Th}$ detrítico, causa dos maiores erros nas datações pelo método U/Th. Esses procedimentos tiveram como objetivo tornar a amostragem geocronológica mais confiável, ampliando sua exatidão e precisão das idades. Para cada camada amostrada extraiu-se cerca de 0,4 a 0,2 g de $\mathrm{CaCO}_{3}$ de calcita e 0,1 a $0,15 \mathrm{~g}$ de aragonita, a depender da concentração média de urânio de cada amostra.

O material carbonático das estalagmites foi datado pelo método ${ }^{230} \mathrm{U} /{ }^{234} \mathrm{Th}$ no laboratório de geocronologia da Universidade de Minnessota, nos Estados Unidos, com a utilização de espectrômetro de massa do tipo ICP-MS (Inductively coupled plasma mass spectrometry), modelos Finnigan Elements e Finnigan Neptune. Os procedimentos analíticos adotados na preparação e na análise das amostras seguiram os padrões estabelecidos pelo Isotope Laboratory do Departament of Geology and Geophysics da Universidade de Minnesota, descritos em Cheng et al. (2009).

Os cálculos das idades foram, de modo geral, são realizados com base nas razões isotópicas medidas e fatores de correção para eliminar efeitos de contaminação de Th detrítico 
(Edwards et al. 1986; Richards e Dorale, 2003). As precisões obtidas, na maior parte das datações, foi de $\sim 1 \%$ ou inferior, segundo estimativa $2 \sigma$.

Após obtenção dos dados geocronológicos, fez-se a seleção das estalagmites para as amostragens isotópicas, a partir da escolha do intervalo temporal de cada amostra de modo a obter um registro que fosse o mais contínuo possível. As distâncias entre camadas datadas foram medidas digitalmente sobre a imagem das estalagmites, com a utilização do programa Corel Draw, segundo perfis de amostragem que seguem aproximadamente o eixo de crescimento das estalagmites. Esses dados foram utilizados nos cálculos das taxas de crescimento, da resolução temporal de cada da amostragem para análise dos isótopos estáveis de $\mathrm{O}$ e $\mathrm{C}$.

\subsection{Estimativa da taxa de crescimento e resolução temporal}

As taxas de crescimento (TC) correspondem a razão entre as distâncias e a diferenças de idade entre dois pontos datados (Tab. 3.1). A representatividade dos valores de TC em termos de variação paleoclimáticas depende intrinsecamente do detalhamento geocronológico realizado em cada estalagmite

A escolha das estalagmites para amostragem isotópica considerou a continuidade no crescimento, melhor resolução temporal e o intervalo de tempo desejado para cada registro. Para a construção de um registro paleoclimático que envolvesse os últimos 100 mil anos A.P. foi necessária uma combinação de doze estalagmites: PX5, DV2, PX7, IO2, IO4, PX9, IO1, PX14, DV1, PX16, PX8 e PX13. O tamanho (comprimento) dessas amostras variou entre 25 cm a 2 metros. As estalagmites sob as denominações PX, DV e IO são provenientes respectivamente das cavernas Paixão, Diva de Maura e Ioiô da Chapada Diamantina.

Já a escolha da resolução temporal de amostragem levou em conta a duração dos eventos paleoclimáticos alvos do presente estudo. Para estalagmites depositadas durante o Holoceno e o deglacial, período em que almeja-se avaliar os impactos de variações climáticas abruptas milenares a seculares, foram realizadas amostragens com resolução de 30 a 2 anos. Para as estalagmites depositadas durante o glacial como um todo, foram realizadas amostragens de menor detalhe, entre 40 e 30 anos. Esses valores correspondem a intervalos de amostragem entre $0,4 \mathrm{~mm}$ e $6,0 \mathrm{~mm}$, sendo $0,4 \mathrm{~mm}$ o espaçamento mínimo entre cada amostra, o qual é limitado pelo diâmetro de $200 \mu$ da broca utilizada no microamostrador. 
Tabela 3.1. Exemplo de planilha de cálculo da resolução temporal da amostra IO2 para amostragem de pó destinada as análises isotópicas de $\mathrm{O}$ e $\mathrm{C}$.

\begin{tabular}{ccccccc}
\hline IO2 & $\begin{array}{c}\text { Prof. } \\
(\mathbf{m m})\end{array}$ & Idades & $\begin{array}{c}\text { Diferença - } \\
\text { Idade }\end{array}$ & $\begin{array}{c}\text { Distância do } \\
\text { topo }(\mathbf{m m})\end{array}$ & $\begin{array}{c}\text { Resolução 30 } \\
\text { anos (mm) }\end{array}$ & $\begin{array}{c}\text { Taxa de cresc. } \\
\text { (mm/ano) }\end{array}$ \\
\hline $\mathbf{T}$ & 25.19 & 19.074 & 19.085 & - & - & - \\
$\mathbf{1}$ & 88.41 & 20.044 & 970 & 63.22 & 0.7 & 0.0651 \\
$\mathbf{2}$ & 130.22 & 20.383 & 339 & 41.81 & 3.7 & 0.123 \\
$\mathbf{3}$ & 192.98 & 23.982 & 3.598 & 62.76 & 0.5 & 0.0174 \\
$\mathbf{4}$ & 282.06 & 24.476 & 494 & 89.08 & 5.4 & 0.180 \\
$\mathbf{5}$ & 373.48 & 26.480 & 2.004 & 91.42 & 1.4 & 0.045 \\
$\mathbf{6}$ & 469.36 & 29.389 & 2.910 & 95.88 & 1.0 & 0.032 \\
$\mathbf{7}$ & 581.83 & 30.278 & 889 & 112.47 & 3.8 & 0.126 \\
$\mathbf{8}$ & 659.58 & 30.470 & 192 & 77.75 & 6.2 & 0.405 \\
$\mathbf{9}$ & 730.47 & 36.645 & 6.175 & 70.89 & 0.3 & 0.011 \\
$\mathbf{1 0}$ & 782.55 & 40.562 & 3.916 & 52.08 & 0.4 & 0.013 \\
$\mathbf{B}$ & 834.05 & 41.896 & 1.334 & 51.5 & 1.2 & 0.038 \\
\hline
\end{tabular}

\subsection{Amostragem de calcita para análises das razões isotópicas de oxigênio e carbono}

As amostragens $\mathrm{CaCO}_{3}$ em pó, utilizadas para as análises isotópicas, foram extraídas ao longo do eixo de crescimento das doze estalagmites, como exemplificado na Figura 3.1. A aquisição das amostras foi feita com o uso de um microamostrador, modelo 5400 da Sherline, acoplado a um medidor digital de distância entre os pontos amostrados.

Através do microamostrador foram extraídas aproximadamente cerca de $0,2 \mathrm{mg}$ ou $200 \mu \mathrm{g}$ de amostra em pó com a utilização de uma broca de $0,2 \mathrm{~mm}$ de diâmetro. O pó extraído pela broca é depositado ao fundo de vials (ampolas) de vidro, com o auxílio de finas espátulas. Os vials contendo amostras são então levados para as análises de isótopos de oxigênio e carbono.

As amostras de calcita foram analisadas no laboratório de isótopos estáveis do Centro de Pesquisas Geocronológicas (LIE-CPGEO) do IGc/USP, com a utilização de um espectrômetro de massa de fonte gasosa, modelo Delta ${ }^{\text {Plus }}$ Advantage (Thermo Finningan). O princípio básico dos procedimentos analíticos para a obtenção das razões dos isótopos de $\mathrm{O}$ e $\mathrm{C}$ consiste na extração do dióxido de carbono $\left(\mathrm{CO}_{2}\right)$ contido na $\mathrm{CaCO}_{3}$ da calcita a partir da hidrólise ácida com $\mathrm{H}_{3} \mathrm{PO}_{4}$. A medição dos isótopos de $\mathrm{C}$ e $\mathrm{O}$ é realizada a partir do espectro de massas das moléculas de $\mathrm{CO}_{2}$.

A reação para produção de $\mathrm{CO}_{2}$ é iniciada logo após gotejamento de ácido fosfórico $\left(\mathrm{H}_{3} \mathrm{PO}_{4}\right)$ sobre amostras de $\mathrm{CaCO}_{3}$, num reator sob temperatura controlada a $72^{\circ} \mathrm{C}$. Após essa reação química, o dióxido de carbono é arrastado dos vials através de um fluxo de Hélio para 
o acessório tipo Finnigan Gas Bench, de onde é separado do vapor d'água dentre outros gases, por um sistema de cromatrografia gasosa, num sistema com operação automatizada.

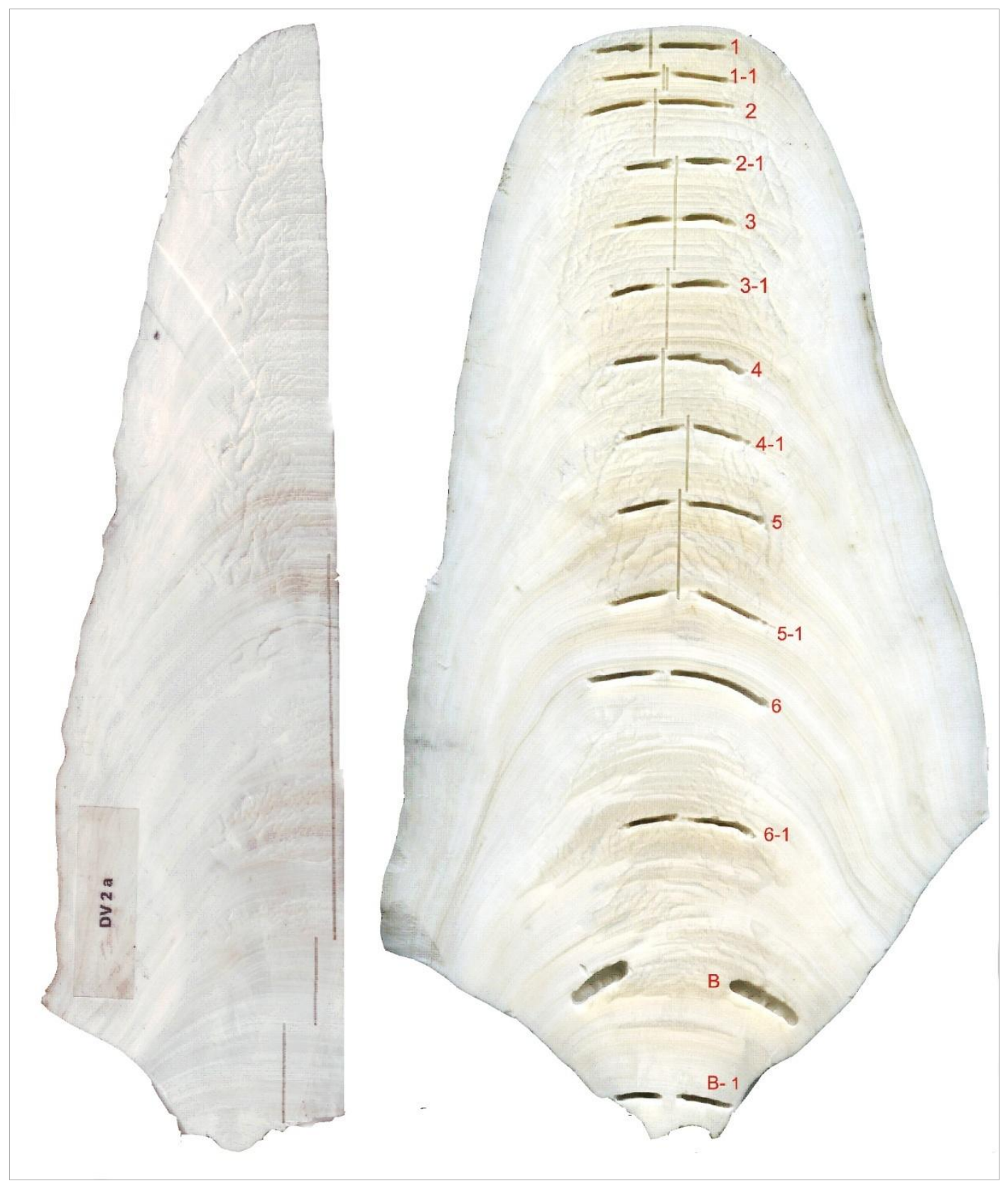

Figura 3.1 - Face polida e digitalizada da estalagmite DV2. Os furos realizados para geocronologia U/Th estão indicados pela numeração em vermelho. Os pequenos furos no eixo central da estalagmite foram realizados espaçamento de $0.4 \mathrm{~mm}$ entre amostras destinadas a análise isotópica. Esse é intervalo possível de ser obtida através do microamostrador do laboratório de Sistemas Cársticos do IGc-USP e adotado para amostragem de máxima resolução do Holoceno e período deglacial. 
Um sistema composto por triplo coletor de O/C realiza a determinação das razões isotópicas do $\mathrm{CO}_{2}$ já no espectrômetro, através de uma fonte iônica. Os resultados analíticos são baseados na análise de dez alíquotas sequenciais de cada amostra. A precisão analítica é melhor que $\pm 0.08 \%$ para os valores das razões isotópicas de ${ }^{13} \mathrm{C} /{ }^{12} \mathrm{C}$ e $\pm 0.1 \%$ para os valores de ${ }^{18} \mathrm{O} /{ }^{16} \mathrm{O}$ para as amostras contendo, no mínimo, $100 \mu \mathrm{g}$ de carbonato de cálcio.

As razões isotópicas são expressas através do termo delta $(\delta)$ e os valores obtidos são reportados em \%o relativos ao padrão VPDB (Vienna Pee Dee Belemnite), sendo este definido internacionalmente. Os valores $\delta^{18} \mathrm{O}$ e $\delta^{13} \mathrm{C}$ foram definidos, respectivamente, segundo as equações:

$$
\begin{aligned}
& \delta^{18} \mathrm{O}(\%)=\left[\left({ }^{18} \mathrm{O} /{ }^{16} \mathrm{O}_{\text {amostral }}{ }^{18} \mathrm{O} /{ }^{16} \mathrm{O}_{\text {padrão }}\right)-1\right] \times 1000 \\
& \delta^{13} \mathrm{C}(\%)=\left[\left({ }^{13} \mathrm{C} /{ }^{12} \mathrm{C}_{\text {amostra }} /{ }^{13} \mathrm{C} /{ }^{12} \mathrm{C}_{\text {padrão }}\right)-1\right] \times 1000
\end{aligned}
$$

\subsection{Interpolação de idades e cálculo de anomalias das razões isotópicas de $\delta^{18} \mathrm{O}$}

As idades de cada ponto analisado para isótopos estáveis foram obtidas através do procedimento de interpolação linear em função das datações U/Th, segundo incremento de profundidade conhecido. Ao criar uma linha de tendência que se ajusta perfeitamente ao conjunto de dados obtemos a expressão geral da linha reta assim:

$$
\mathrm{y}=m x-\mathrm{b}
$$

Onde y é o valor da profundidade (conhecido), m é a inclinação (constante), b é o intercepto no eixo y (constante), e x é a idade desconhecida de interesse. Isolando a incógnita x é obtida a seguinte expressão, utilizada para cálculos das idades interpoladas da amostra DV1, como exemplo:

$$
x=\frac{y+b}{m}=\frac{64,532+y}{0,1125}
$$

As interpretações paleoclimáticas foram, em alguns casos, baseadas nos valores de anomalias dos dados $\delta^{18} \mathrm{O}$, que teve como finalidade definir com maior clareza alguns eventos 
paleoclimáticos em escala regional, após remoção da tendência gerada por diferenças nos valores absolutos de $\delta^{18} \mathrm{O}$, observados entre registros sincrônicos de espeleotemas das áreas de Iraquara e Andaraí. Para isso foi utilizada a seguinte equação:

$$
\mathrm{A}=-1(M M-X)
$$

Onde $M M$ é o valor da média móvel dos valores de $\delta^{18} \mathrm{O}$, e $X$ é o valor médio obtido pela média móvel. Preferiu-se utilizar valores de MM para eliminar valores mais discrepantes, ou seja, o ruído na curva isotópica. No caso do tratamento aqui empregado, o sinal analítico foi dividido em intervalos de 5 pontos. 


\section{REGISTROS PALEOCLIMÁTICOS}

\subsection{Geocronologia pelo método ${ }^{230} \mathrm{Th} /{ }^{234} \mathrm{U}$ em estalagmites}

A cronologia das 12 estalagmites selecionadas para o presente estudo paleoclimático da Bahia está fundamentada na seleção de 79 datações, obtidas através do método ${ }^{230} \mathrm{Th} /{ }^{234} \mathrm{U}$ (Richards e Dorale, 2003). A amostragem total foi realizada em cinco cavernas da Bahia nos municípios de Iraquara e Palmeiras (Ioiô, Diva de Maura, Fumaça, Rosário e Torrinha) e três cavernas no distrito de Ubiraitá, município de Andaraí (Paixão, Marota e Abelhas), situadas, respectivamente, na porção oriental e ocidental da Chapada Diamantina (Fig. 4.1). Do conjunto amostrado, estão sendo utilizadas somente estalagmites coletadas das cavernas Ioiô e Diva de Maura e Paixão, as quais definem um registro de boa parte dos últimos 93 mil anos. Todas as idades obtidas estão apresentadas no Anexo 1, ordenadas de acordo com sua ordem estratigráfica.

As idades das estalagmites estão distribuídas em uma sequência cronoestratigráfica normal, por vezes interrompidas por hiatos, como observado no gráfico de distribuição de idades da amostra DV2 (Fig. 4.2a). O detalhamento geocronológico realizado variou de acordo com o período geológico de interesse e pela taxa de crescimento de cada estalagmite. Foi realizado maior refinamento geocronológico principalmente para as estalagmites depositadas no período Holoceno, assim como para as amostras DV2 e PX5 (Fig. 4.2a; Fig. 4.2b), pois através delas foram obtidos registros isotópicos de mais alta resolução temporal.

Para efeito descrição paleoclimatológica, o registro da Chapada Diamantina foi subdividido em três fases, durante os últimos 93 mil anos: glacial, deglacial e Holoceno. O período glacial é considerado aqui como o intervalo temporal que varia entre $\sim 93$ e 20 mil anos A.P. Esse período foi estudado através de dez estalagmites: PX8, PX13, PX16, DV1, PX14, IO1, PX9, IO4, IO2 e PX7. Nele, o intervalo de tempo entre as datações variou entre 1 e 5 mil anos e encontra-se menos detalhada em relação ao período deglacial e holocênico. Mesmo assim, a cronologia das amostras é considerada robusta o suficiente para permitir precisa delimitação de eventos milenares do tipo Heinrich e Dansgaard-Oescheger. O período glacial, por sua vez, foi aqui dividido em duas fases: 93-45 e 45-20 mil anos A.P, com objetivo de ressaltar tais eventos milenares em escala de maior detalhe. 


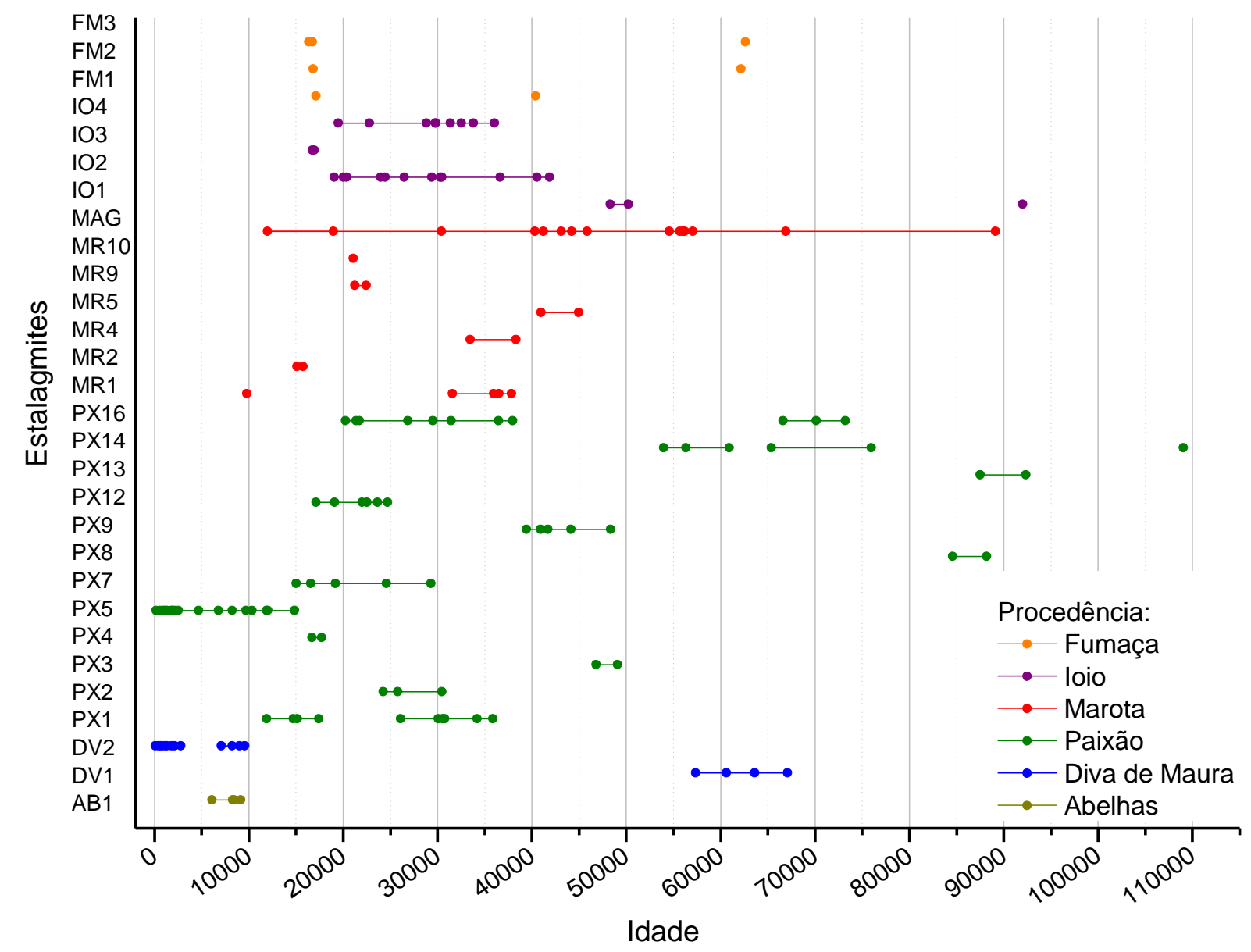

Figura 4.1- Intervalos de deposição de todas as estalagmites coletadas nas cavernas da Chapada Diamantina, situadas em Iraquara e Andaraí, porção central da Bahia. As idades U/Th estão destacadas para cada amostra de estalagmite plotada no eixo Y.

Para o período glacial que variou entre $~ 93-45$ mil anos A.P. foram utilizadas as seguintes estalagmites: PX13, PX8, PX16, DV1, PX14 e IO1. As amostras PX13, PX8, PX16 totalizaram 15 datações, que variaram respectivamente entre 92.364-87.527, 88.188-84.599 e 73.239-66.630 anos. Já as estalagmites DV1, PX14 e IO1, totalizaram 11 datações que oscilaram entre 67.109-57.360, 60.919-53.958 e 50.231-48.290 anos A.P. A média aritmética do erro de todas as datações do período glacial de 93-45 mil anos A.P foi de \pm 401,33 anos obtidas na maioria com a utilização do ICP-MS modelo Finnigan Element. Os dados detalhados de cada datação estão apresentados no Anexo 1, a exemplo dos erros de cada uma das seis estalagmites, como também de outras seis correspondentes aos outros períodos.

Para o período glacial entre 45-20 mil anos A.P foram utilizadas quatro estalagmites: PX9, IO2, IO4 e PX7. A cronologia das estalagmites PX9 e IO4 é definida através de 14 datações, enquanto para a IO2 foram utilizadas 12 datações U/Th (Fig. 4.2d), em um total de 
28 idades. As idades variaram respectivamente nestes três espeleotemas, entre: 44.1-39.5, 36.0-31.4, 41.9-19.1 anos A.P. O erro das idades das três estalagmites corresponde aritmeticamente $\mathrm{a} \pm 210$ anos.

a

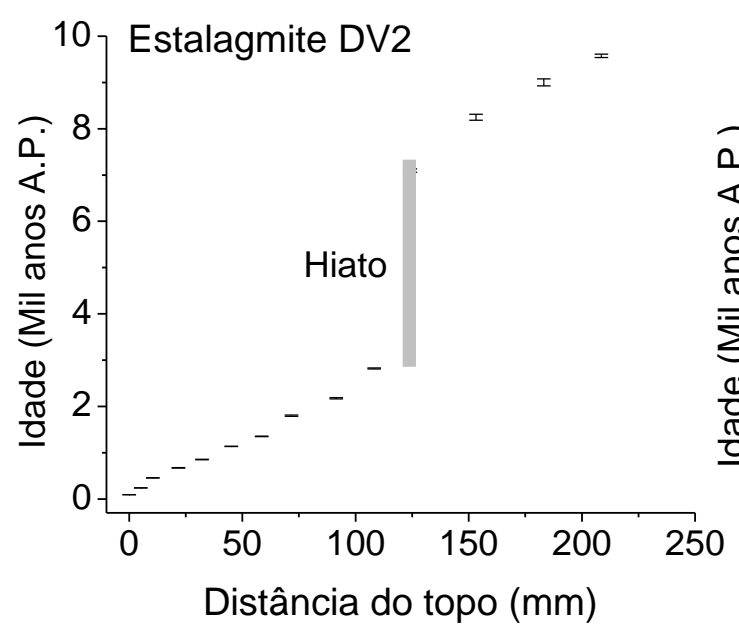

b

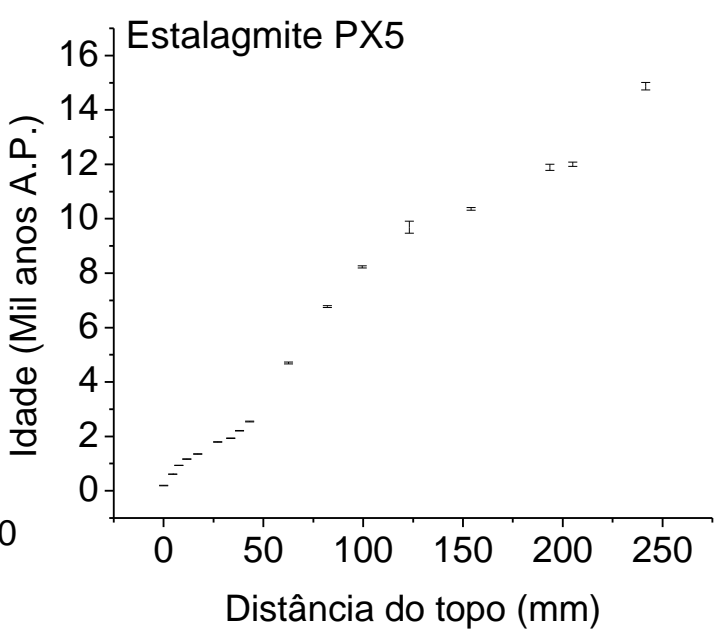

d

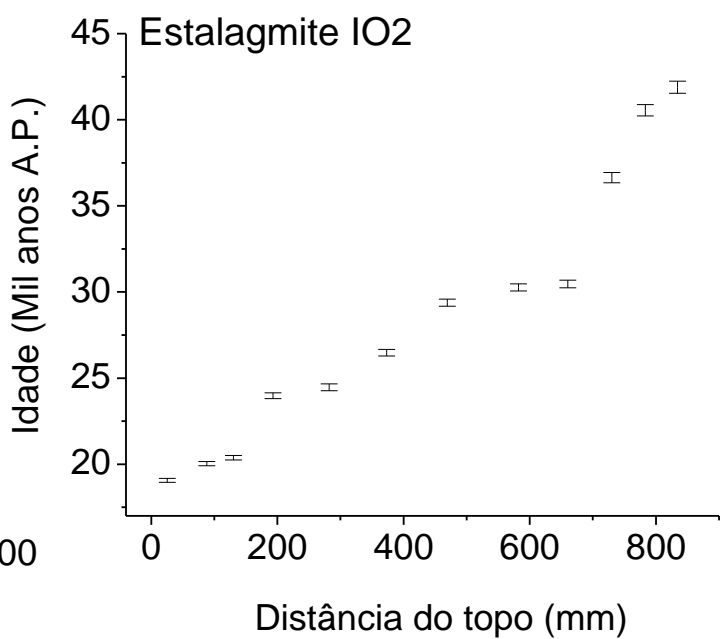

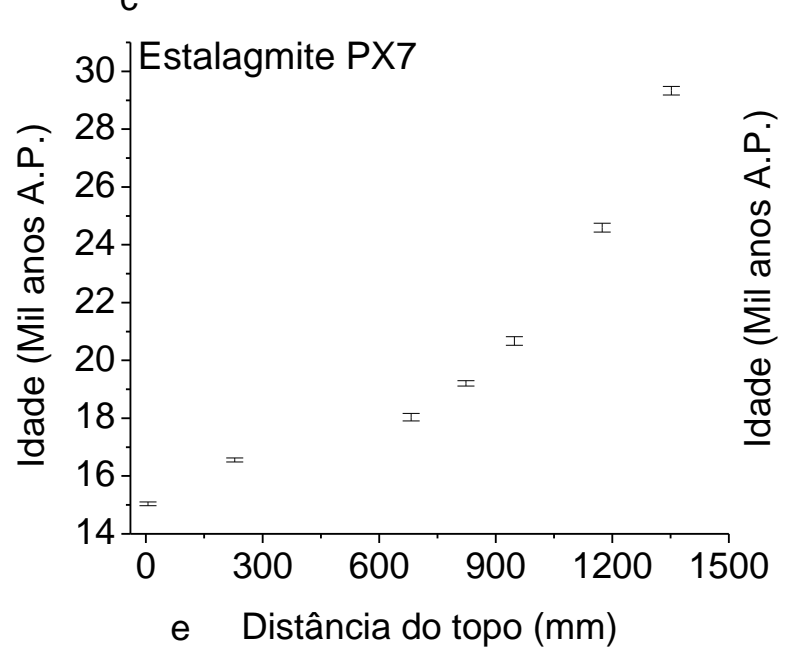

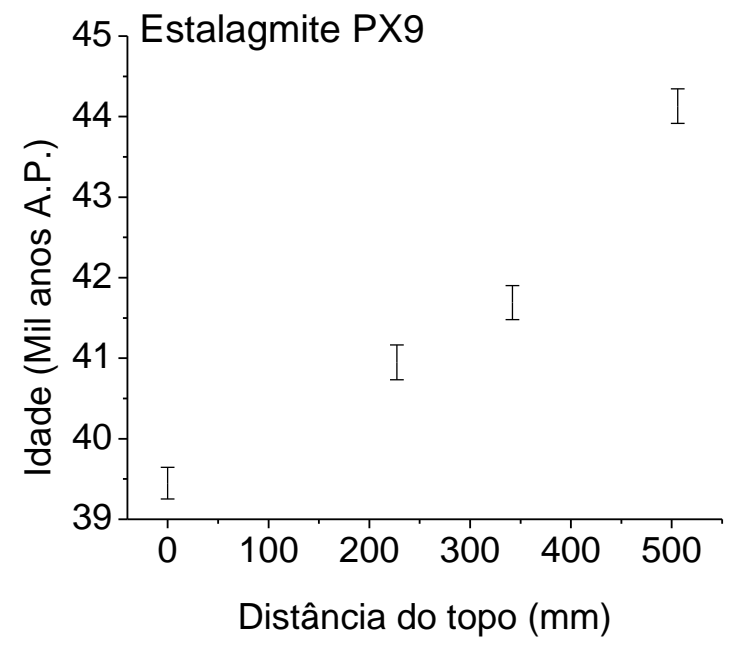


Figura 4.2 - Distribuição de idades U/Th versus profundidade (mm) das estalagmites DV2 (a); PX5(b); PX7(c); IO2 (d) e PX9(e). 
O período deglacial se iniciou com a finalização do Último Máximo Glacial (UMG) por volta de $20 \mathrm{ky}$ e terminou com aumento da temperatura global que define o início do Holoceno, cerca de 10 mil A.P. Esse período está bem representado pelos registros das estalagmites PX7 e PX5, as que se encontram mais bem datadas, através de 24 datações U/Th cujos intervalos temporais oscilam entre 1 a $2 \mathrm{ky}$. As duas estalagmites foram depositadas entre 29.331-15.051 anos A.P. e entre 14.875 A.P. ao presente, respectivamente (Fig. 4.2c, Fig. 4.2b). A média aritmética do erro de todas as idades das duas estalagmites foi de $\pm 66,90$ anos.

As estalagmites PX5 e DV2 foram selecionadas para o estudo de variações climáticas durante o Holoceno. Ao todo foram obtidas 14 idades para as amostras DV2 (erro de $\pm 20,09$ ) e 17 para a amostra PX5 (Fig. 4.4) ( \pm erro médio 34,94 anos), sendo a DV2 depositada entre 9.576 ao presente, mas com um hiato entre 2.822 e 7.097 A.P. (Fig. 4.2a). O número relativamente maior de datações, caracterizados por intervalos temporais entre aproximadamente 200 anos e 1 ky em geral, irá permitir estudos futuros de eventos climáticos de mais curta duração de tempo, de escala centenial ou de maior detalhe, que estão além do escopo desse trabalho. O detalhamento geocronológico para os períodos de deglaciação e do Holoceno foi motivado neste trabalho pela ampla abordagem aos eventos milenares ocorridos nessa faixa temporal, amplamente discutida na literatura, mas ainda pouco estudados no continente sul-americano.

Valores de taxas de crescimento (TC) foram calculados entre cada intervalo datado e correspondem à velocidade média de crescimento em cada trecho do espeleotema, representado neste trabalho em milímetros por ano. A resolução das variações das taxas de crescimento é, portanto, função do número de datações, ou seja, do detalhamento geocronológico realizado em cada estalagmite. Nesse sentido, valores de TC de estalagmites que possuem menos de três idades, como é o caso das amostras PX8, PX13, PX14, PX16, IO4 e IO1, são pouco representativos dos processos de deposição dessas formações.

A observação dos valores de TC é importante para se estabelecer possíveis relações da velocidade de deposição de cada espeleotema com períodos mais úmidos ou secos. As principais estalagmites utilizadas para esse fim foram PX5, DV2, PX7, IO2, DV1 e PX9, devido ao maior número de datações disponíveis (Fig. 4.3). No geral as amostras da Chapada Diamantina apresentam crescimento relativamente rápido, quando comparadas às estalagmites estudadas nos Estados de São Paulo e Santa Catarina, Sudeste/Sul brasileiro (Cruz et al. 2005a; 2006a). 
Nas seis estalagmites, mudanças abruptas da TC são visualizadas nas amostras PX5, DV2, PX7 e IO2, principalmente em intervalos mais detalhadamente datados, como é o caso dos últimos dois mil anos das estalagmites DV2 e PX5. Na estalagmite DV2 é observada gradual decréscimo da TC entre $\sim 9.5$ e 7 mil anos A.P e após hiato temporal entre $\sim 7$ e 3 mil anos A.P é observada a presença de quatro picos de crescimento abruptos, entre $\sim 3$ mil anos A.P. e o presente. Já na amostra PX5 observa-se crescimento gradual entre $\sim 9.5$ e 3.5 mil anos A.P., decrescendo drasticamente após este último período e crescendo abruptamente entre 2.3 e 1.8 mil anos A.P (Fig. 4.3).

Na estalagmite PX7 observa-se que a TC aumenta gradualmente a partir de $\sim 24.6 \mathrm{ky}$, com a presença de um pico abrupto de crescimento entre 18.1 e 16.7 mil anos A.P, intervalo de tempo correspondente ao evento milenar Heinrich 1 (H1). Com a amostra IO2 foram observados três picos abruptos de TC, localizados entre aproximadamente: 20.4-20, 24.4-24, 30.5-29.3 mil anos A.P., sendo o segundo intervalo coincidente ao evento $\mathrm{H} 2$. Na estalagmite PX9 observou-se decréscimo da TC entre $~ 41.3-40.9$ mil anos A.P e na amostra DV1 aumento abrupto de crescimento entre 63.7-61.9 mil anos A.P., o que coincide com intervalo do evento H6 registrado no Hemisfério Norte (Bond et al. 1992).
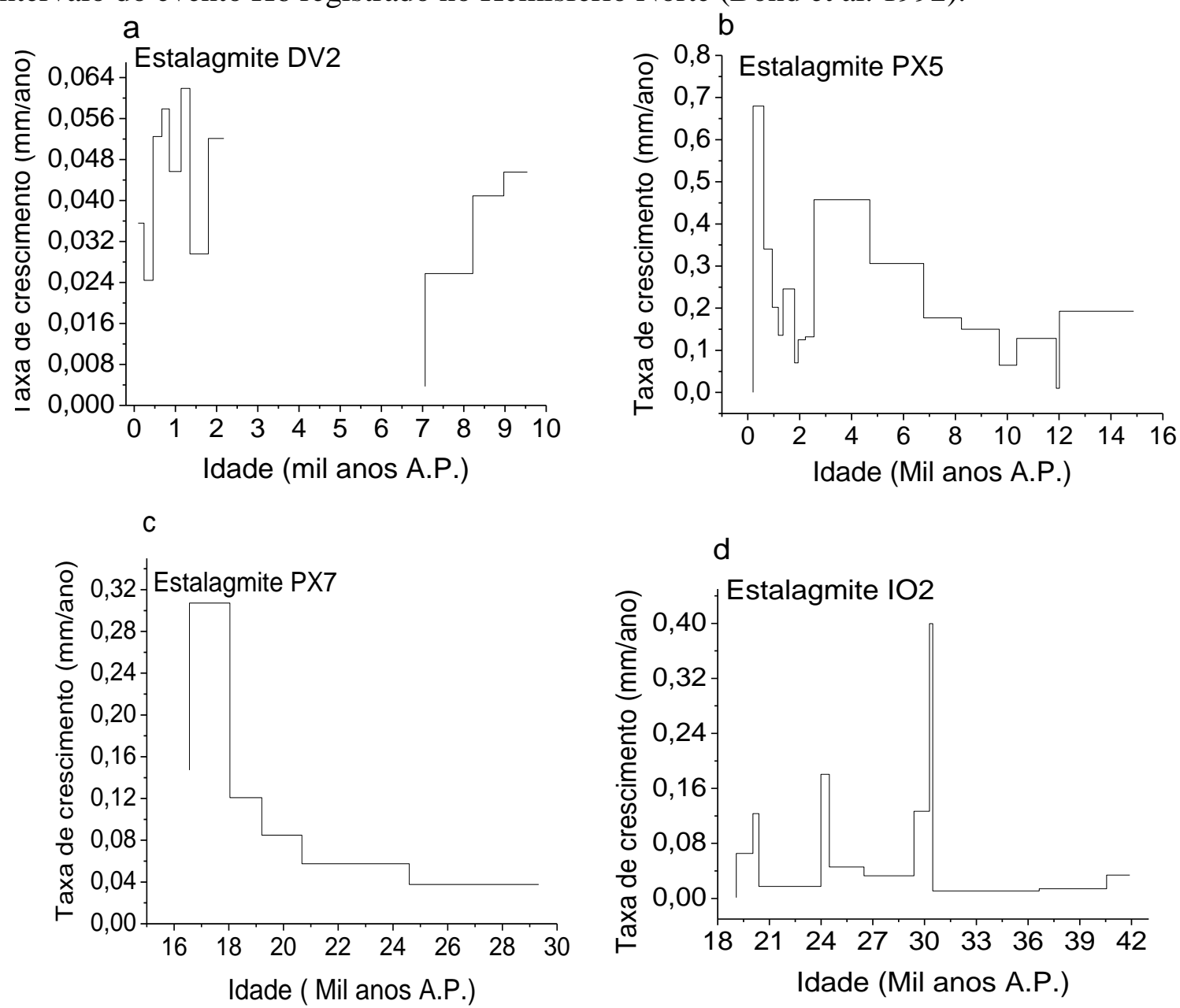

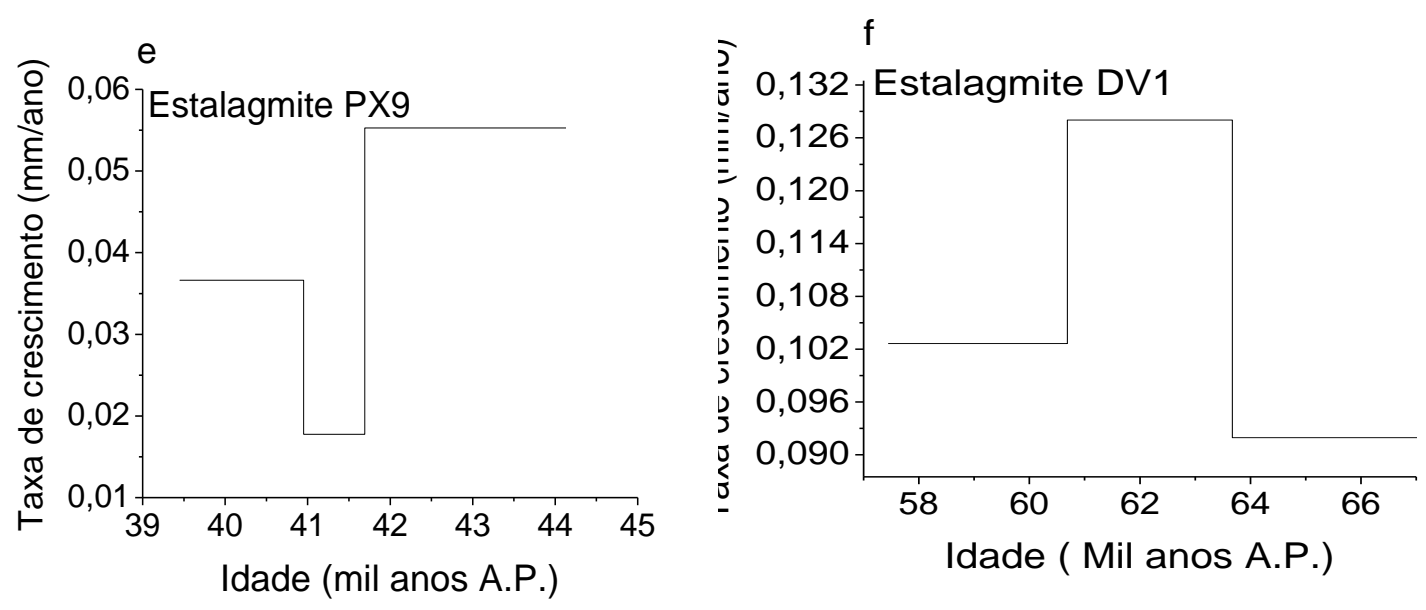

Figura 4.3 - Taxas de crescimento das estalagmites DV2 (a); PX5 (b); PX7 (c); IO2(d); PX9 (e) e DV1(f).

\subsection{Registros isotópicos de $\delta^{18} \mathrm{O}$ e $\delta^{13} \mathrm{C}$ em estalagmites}

Para reconstrução paleoclimática dos registros de espeleotemas baianos foram obtidas 4.647 análises isotópicas das razões isotópicas de oxigênio $\left(\delta^{18} \mathrm{O}\right)$ e carbono $\left(\delta^{13} \mathrm{C}\right)$, através da microamostragem de $\mathrm{CaCO}_{3}$ do conjunto das doze estalagmites. Essas amostragens permitiram compor perfis isotópicos de alta resolução dos últimos 93 mil anos A.P. Assim como nos dados geocronológicos, a resolução temporal aplicada às amostras variou de acordo com o período paleoclimático. Os valores de resolução foram fixados para cada espeleotema conforme interesse paleoclimático do período que ela representa (ver detalhes no Cap. 3).

Os perfis isotópicos de $\mathrm{O}$ e $\mathrm{C}$ de todas as estalagmites estão apresentadas na Figura 4.5. Neles, foi possível observar variações paleoclimáticas nas escalas orbitais (periodicidade de $\sim 23$ mil anos) e milenares ( 1.5 a 3 mil anos) para maior parte dos últimos $\sim 93$ mil anos. A exceção se faz aos intervalos 43-48, 52-55 e 73-84 ky, devido ausência de estalagmites que contemplassem estes períodos.

Para comparação dos dados das razões isotópicas de oxigênio com a curva de insolação de verão (Fig. 4.5) para a latitude $10^{\circ} \mathrm{S}$, foram utilizados os dados referentes ao mês de fevereiro (Berger e Loutre, 1991), os quais melhor representam a atividade das monções no Hemisfério Sul (Cruz et al. 2005a; Ruddiman, 2006). Já a discussão da influência dos eventos de escala milenar, do tipo Heinrich $(\mathrm{H})$ e Dansgaard-Oeschger (D-O) no clima do Nordeste, foi baseada na comparação com trabalhos clássicos da literatura (por exemplo: Bond et al. 1992; 1993; Dansgaard et al. 1993; Andersen et al. 2004). A correspondência entre os eventos de escala orbital e milenar também pôde ser observada a partir dos registros isotópicos de $\delta^{13} \mathrm{C}$, contudo de forma mais restrita quando comparado com as observações realizadas com os valores de $\delta^{18} \mathrm{O}$. 


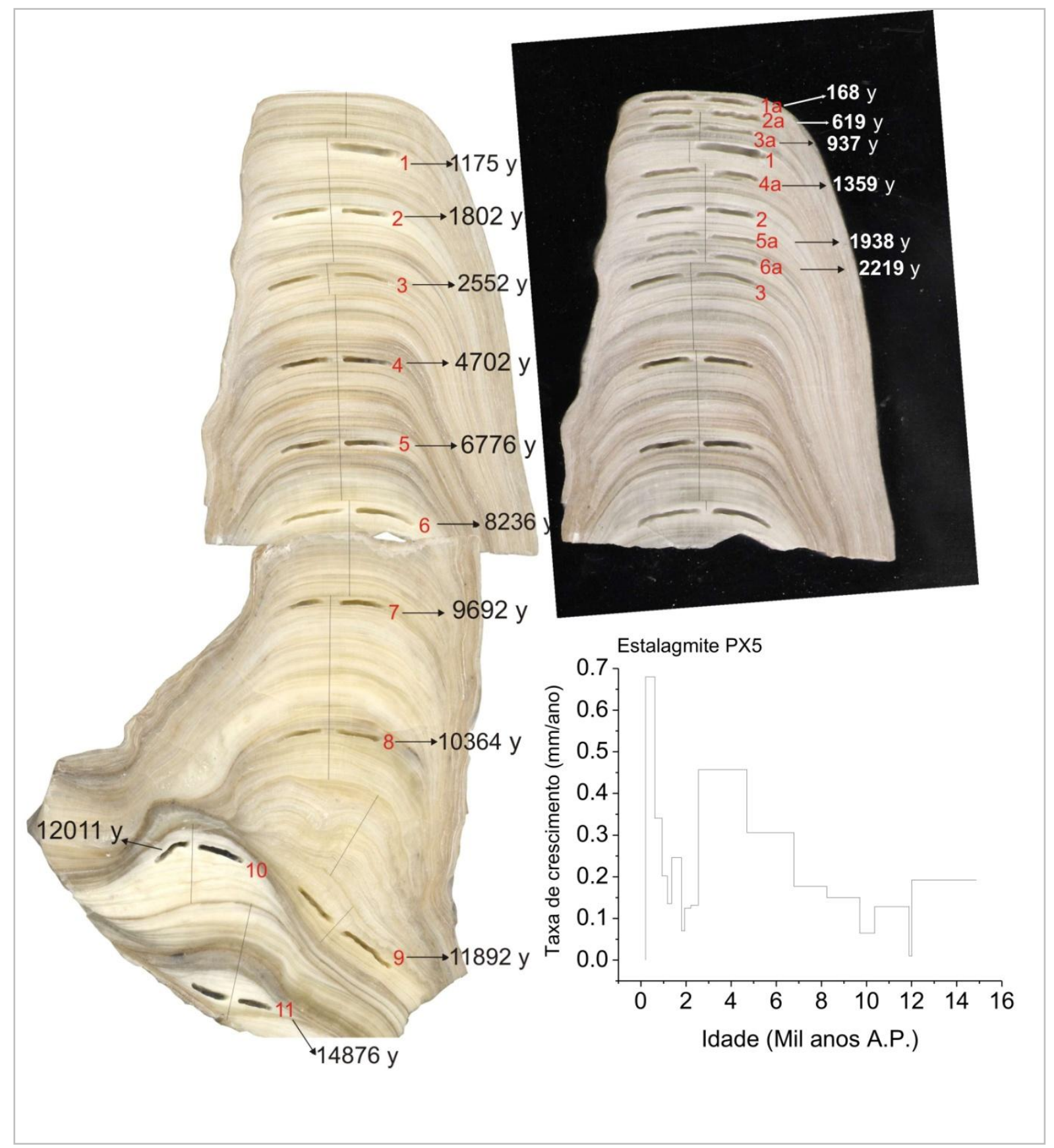

Figura 4.4 - Face da estalagmite PX5 amostrada para geocronologia U/Th. Os pontos datados estão indicados pela numeração em vermelho, com suas respectivas idades. O traçado preto central corresponde ao local onde se realizou as amostragens para isótopos estáveis. O gráfico ao lado da imagem corresponde à taxa de crescimento dos últimos 15 mil anos da estalagmite. 


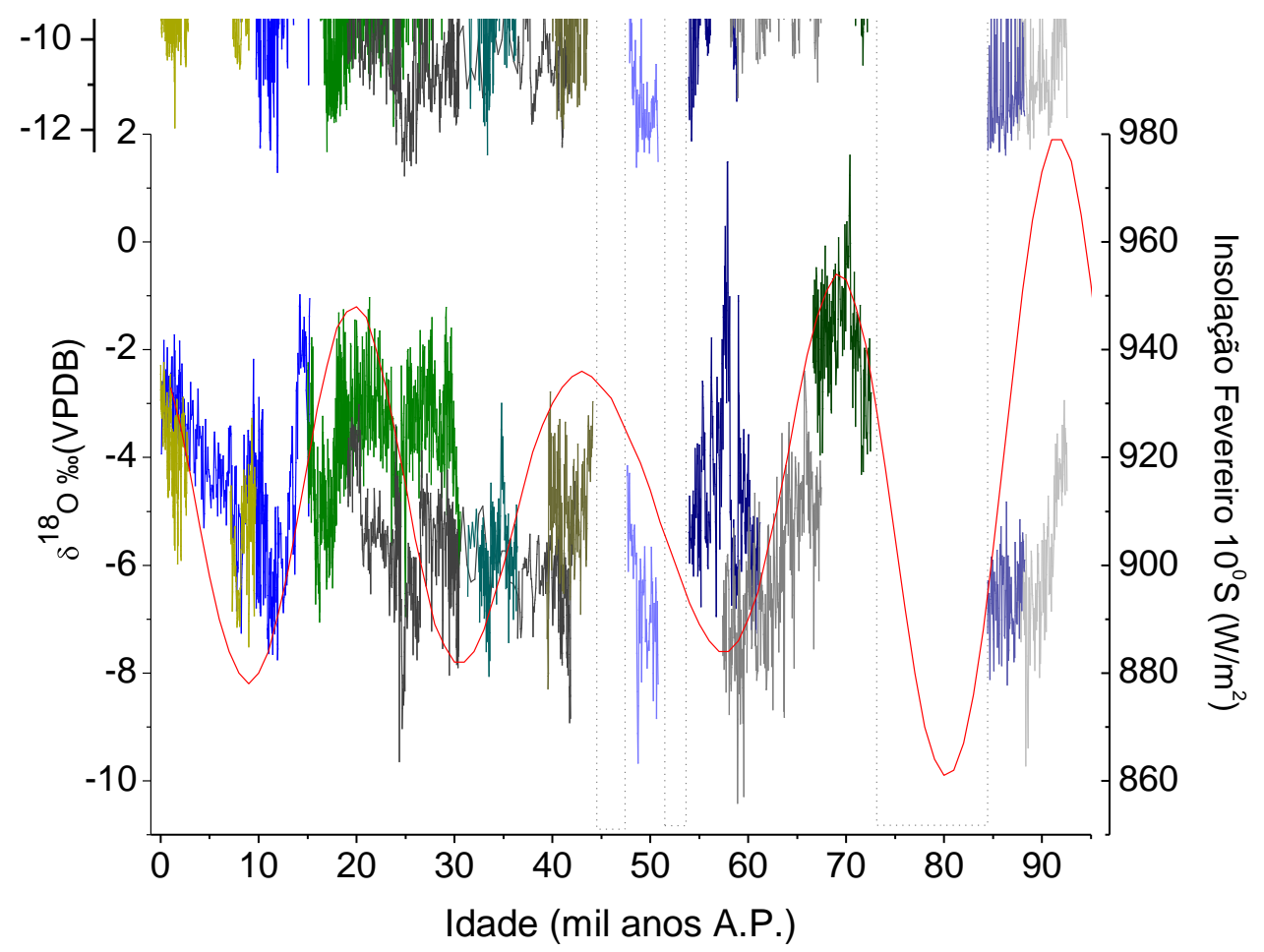

Figura 4.5 - Comparação entre as razões isotópicas de carbono e oxigênio das doze estalagmites utilizadas na pesquisa.

\subsubsection{Período glacial}

O período glacial foi compartimentado em dois gráficos correspondentes aos intervalos entre 93-48 e 44-20 mil anos A.P., com a finalidade de analisar variações de $\delta^{18} \mathrm{O}$ e $\delta^{13} \mathrm{C}$ com suficiente detalhe para discussão de eventos milenares. 


\subsubsection{Período glacial: 93-48 mil anos A.P.}

As amostras PX13 e PX8 correspondem aos registros mais antigos dentre as doze estalagmites analisadas, com idades entre 92.539-87.527 e 88.195-84.614 anos. As razões isotópicas de $\delta^{18} \mathrm{O}$ de PX13 e PX8 oscilaram respectivamente entre - 2,99 \%о e - 9,72 \%о; $4,82 \%$ e $-8,22 \%$ (média $=-5,93 \%$ e $-6,59 \%$, amplitude isotópica $(\Delta)=-6,78 \%$ e $-3,40$ \%o). Já os valores de $\delta^{13} \mathrm{C}$ da PX13 e PX8 variaram entre - 6,26 \%o e - 12,43\%; -6,39 \%о e 12,56 \% (média=-10,52 e -11,19; $\Delta=-6,17 \%$ e -6,17\%o). O valor do coeficiente de correlação (R) entre os valores de $\delta^{18} \mathrm{O}$ e $\delta^{13} \mathrm{C}$ foi respectivamente de 0,50 e 0,45 , indicando nível de correlação mediano entre as duas variáveis.

Duas hipóteses podem ser consideradas para explicar o coeficiente de correlação observada entre as razões isotópicas de $\mathrm{O}$ e $\mathrm{C}$ nessas estalagmites: falta de equilíbrio isotópico entre a água e a calcita durante a precipitação do espeleotema, o que denota fracionamento cinético (Hendy, 1971), admitindo significativa correlação entre $\delta^{18} \mathrm{O}$ e $\delta^{13} \mathrm{C}$, ou melhoria do clima regional. No primeiro caso, as variações isotópicas seriam controladas localmente pelas condições ambientais da caverna, não sendo possível reconstituir variações climáticas externamente a caverna. Já no segundo, valores mais baixos de $\delta^{18} \mathrm{O}$ e $\delta^{13} \mathrm{C}$ corresponderiam a um aumento na média de chuvas acumuladas, que resultou na aceleração de processos de produção biogênica de $\mathrm{CO}_{2}$ no solo (McDermott et al. 2005, Fairchild et al. 2006) e adensamento de florestas originalmente abertas com predomínio de plantas tipo $\mathrm{C}_{3}$, como descrito tanto em estudos com isotópicos em $\delta^{13} \mathrm{C}$ da matéria orgânica do solo (Pessenda et al. 2005) como de espeleotemas (Bar-Matthews e Ayalon, 1996; Dorale et al. 1998).

$\mathrm{O}$ perfil isotópico de $\delta^{18} \mathrm{O}$ das estalagmites PX13 e PX8 não seguiu perfeitamente a curva de insolação de verão $\left(10^{\circ} \mathrm{S}\right)$ em toda sua amplitude no período. Contudo, a amostra PX13 apresentou oscilação das razões isotópicas que acompanhou a diminuição da insolação, principalmente entre 93-90.5 ky, com valores de $\delta^{18} \mathrm{O}$ gradativamente mais negativos, ou seja, menos enriquecidos em isótopos $\mathrm{O}^{18}$ (Fig. 4.6). A estalagmite PX8 apresentou predominância de valores mais baixos de $\delta^{18} \mathrm{O}$, coincidentes com o período de insolação baixa. Já o perfil isotópico das razões isotópicas de $\delta^{13} \mathrm{C}$, tanto na amostra PX13 e PX8, apresenta oscilações em parte coincidentes com as de $\delta^{18} \mathrm{O}$, mas que visivelmente não seguem o ciclo de insolação.

As estalagmites PX16 e DV1 abrangeram o período entre 72.6-57.4 anos A.P., as quais possuem valores de $\delta^{18} \mathrm{O}$ que variaram respectivamente entre 1,61\%o e - 4,31\%o; e entre $2,39 \%$ e $-10,42 \%$, respectivamente (média=- $1,78 \%$ e $-6,16 \%$ o $\Delta=-5,92$ e $\Delta=-8,03$ ). 
Já as razões isotópicas de $\delta^{13} \mathrm{C}$ das duas estalagmites oscilaram entre -3,23 \%o e - 10,57 \%; $-1,20 \%$ e $-11,29$, respectivamente (média=-7,14 \%o e -8,47 \%, $\Delta=-7,34$ e -10,09, respectivamente) e perfazem intervalo total de aproximadamente 15.000 anos. As amplitudes de variações dos valores de $\delta^{18} \mathrm{O}$ e $\delta^{13} \mathrm{C}$ da amostra DV1 são bastante elevadas, enquanto em PX16, ocorre predomínio de valores altos de $\delta^{18} \mathrm{O}$. Já na amostra PX16 o valor de R entre esses dois parâmetros corresponde a 0,79 e em DV1 a 0,50, o que indica correlação positiva de média a alta entre oxigênio e carbono dessas estalagmites.

As curvas isotópicas de $\delta^{18} \mathrm{O}$ da DV1 e PX16 demonstram que os valores isotópicos seguem perfeitamente a amplitude do ciclo de precessão para o período (Fig. 4.6). Os valores mais altos de $\delta^{18} \mathrm{O}$ da amostra PX16 coincidem com o pico de alta insolação de verão por volta de 70 ky A.P, enquanto o perfil isotópico da estalagmite DV1 acompanha diminuição da insolação até alcançar os valores mais baixos do período, por volta de 63.7-61.9 mil anos A.P., os quais coincidem com o evento milenar Heinrich 6 (H6).

$\mathrm{Na}$ amostra DV1, a curva geral dos valores de $\delta^{13} \mathrm{C}$ é significativamente distinta à curva de $\delta^{18} \mathrm{O}$, no entanto são observados dois picos bem destacados no gráfico por valores positivos com amplitude isotópica de aproximadamente -7\% em 63.7-61.9 ky A.P., os quais são também visíveis na curva do $\delta^{18} \mathrm{O}$. Diferentemente da curva de $\delta^{18} \mathrm{O}$, a curva dos valores de $\delta^{13} \mathrm{C}$ é pouco consistente com a curva de insolação. Por outro lado, os eventos milenares estão bem marcados em ambos os registros isotópicos de $\mathrm{O}$ e C. A observação desses eventos, especificamente do H6, pôde ser mais bem observada por meio da relação entre a taxa de crescimento das estalagmites com os valores $\delta^{13} \mathrm{C}\left(\mathrm{TC} / \delta^{13} \mathrm{C}\right)$. Observou-se através dessa relação que os valores mais baixos de $\delta^{13} \mathrm{C}$ das estalagmites PX16 e DV1 coincidiram parcialmente com alta taxas de crescimento, respectivamente, nos intervalos que variaram entre 70-73 e 63-60 ky, servindo como indicador do aumento abrupto da paleoprecipitação. As ligeiras discrepâncias entre as variações abruptas dos valores de $\delta^{13} \mathrm{C}$ e das taxas de crescimentos são decorrentes do detalhamento geocronológico do período correspondente a cada evento.

Conectada aos registros PX16 e DV1 encontra-se o registro da estalagmite PX14, da qual se utilizou o trecho depositado no período de 60.919-53.932 anos (Fig. 4.6). Os valores isotópicos de $\delta^{18} \mathrm{O}$ variaram abruptamente entre 1,53\%o e - 7,26 \% (média=- 4,55, $\Delta=-8,79$ $\%$ ) e de $\delta^{13} \mathrm{C}$ entre $9,24 \%$ e $-12,25 \%$ (média=-7,46 \%o, $\Delta=-21,49$ ), num intervalo de tempo relativamente curto de 6.982 anos, sendo obtido alto valor de R $(0,89)$ entre as duas variáveis. 


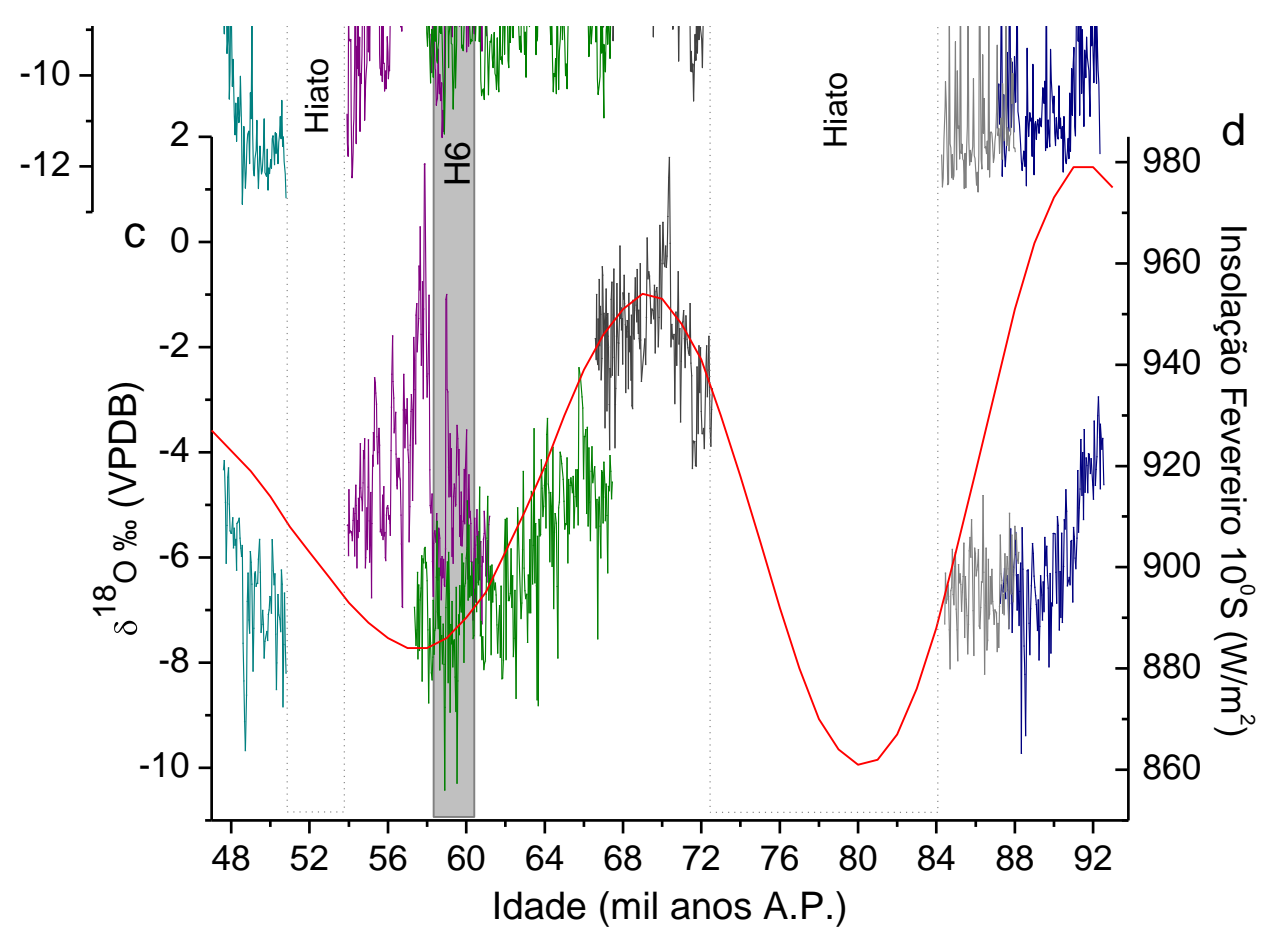

Figura 4.6 - Comparação entre: taxa de crescimento das estalagmites PX16 e DV1 (a); razões isotópicas de carbono (b) e oxigênio (c) das estalagmites IO1, PX14, DV1, PX16, PX8 e PX13; e a curva de insolação de verão $\left(10^{\circ} \mathrm{S}\right)(\mathrm{d})$. 
Diferentemente das estalagmites anteriores, tanto o perfil isotópico de $\delta^{18} \mathrm{O}$ como de $\delta^{13} \mathrm{C}$ da amostra PX14 são caracterizadas por valores anomalamente altos e se comportaram de forma inversa à tendência da curva de insolação para o período (Fig. 4.6). É possível que esse pico de $\delta^{18} \mathrm{O}$ e $\delta^{13} \mathrm{C}$ esteja associado à mudança climática abrupta em escala milenar, coincidente com o evento do tipo Dansgaard-Oeschger. Esses eventos, caracterizados por períodos mais quentes em alta latitude no Hemisfério Norte (Andersen et al. 2004), estão provavelmente associado a um clima mais seco na Bahia (Wang et al. 2007b) por volta de 14,5 ky A.P., durante o evento Bolling-Allerod (B-A), correspondente do evento D-O no período deglacial.

Entre a amostra PX14 e a IO1, a última estalagmite do intervalo 93-40 ky do período glacial, encontra-se um hiato temporal de 5.031 anos (Fig. 4.6). A estalagmite IO1, depositada no período 50.807-47.612 anos, apresentou variação nos valores de $\delta^{18} \mathrm{O}$ entre $-4,15 \%$ e 9,67\%o (média=-6,57 \%o, e $\Delta=-5,52 \%$ ) e de $\delta^{13} \mathrm{C}$ entre - 7,23\%o e - 12,83\%o (média=- 11,11 $\%$, e $\Delta=-5,6 \%$ ). Essa amplitude de valores considerada alta para o curto intervalo de 3.195 anos abrangido pela amostra. Já o valor de $\mathrm{R}$ foi de 0,60 , o que indica bom índice de correlação.

Diferentemente do que é observado nos registros isotópicos das estalagmites PX16 e DV1, a curva isotópica da IO1 não se sobrepôs diretamente na curva de insolação, contudo apresentou boa relação com as razões isotópicas do oxigênio, indicado pelo aumento de $\delta^{18} \mathrm{O}$ nos primeiros mil anos desse registro. No entanto, a presença de eventos milenares tipo D-O e $\mathrm{H}$ não é evidente nessa porção do registro. Da mesma forma do que foi descrito anteriormente, os registros isotópicos de $\delta^{13} \mathrm{C}$ não mostra relação tão evidente quando comparada com a curva de insolação.

\subsubsection{Período glacial: 45-20 mil anos A.P.}

O registro da estalagmite PX9 abrange o período entre 44.130 e 39.450 anos enquanto da amostra IO2 se estende principalmente através do intervalo 40-20 ky (Fig. 4.7). Os valores de $\delta^{18} \mathrm{O}$ da primeira oscilaram entre - 2,78 \%o e - 8,79 \%o (média=-5,02\%o, $\Delta=-5,51 \%$ ) e de $\delta^{13} \mathrm{C}$ entre $-2,26 \%$ e $-11,98 \%$ (média $=-8,40 \%$ \% $\Delta=-9,72 \%$ ), sendo o valor de $\mathrm{R}$ entre as duas variáveis de 0,53 , indicando correlação positiva mediana.

$\mathrm{O}$ perfil isotópico de $\delta^{18} \mathrm{O}$ da $\mathrm{PX} 9$ não segue a curva de precessão, assim como observado nas amostras PX16, DV1 e IO1 (Fig. 4.6). Observa-se que os valores das razões se 
mantêm relativamente altos mesmo durante períodos de baixa insolação. No entanto, existe uma significativa diminuição relativa das razões isotópicas entre 42-41.1 ky, a qual coincide temporalmente com o evento H4. A mesma tendência foi observada com os registros isotópicos de carbono, denotadas por amplitudes isotópicas ainda maiores. Esse evento está bem marcado também através da relação $\mathrm{TC} / \delta^{13} \mathrm{C}$ entre $\sim 44-42 \mathrm{ky}$, caracterizada por altos valores de TC e baixos valores de $\delta^{13} \mathrm{C}$.

O trecho da amostra IO4, depositado no período 36.430-31.370 anos, foi utilizado para complementar o registro da estalagmite IO2, por encontrar-se mais bem datado nesse período (Fig. 4.7). Os valores de $\delta^{18} \mathrm{O}$ de IO4 variaram entre $-2,99 \%$ e $-8,06 \%$ (média=-5,81\%o, $\Delta=-$ $5,07 \%$ ), enquanto os valores de $\delta^{13} \mathrm{C}$ entre $-1,78 \%$ e $-12,55 \%$, (média=-8,85\%o, $\Delta=-10,77$ $\%$ ). O valor de R da amostra IO4 foi de 0,77 , o que indica alta correlação positiva entre as razões isotópicas de $\delta^{18} \mathrm{O}$ e $\delta^{13} \mathrm{C}$.

O perfil isotópico da estalagmite IO4 não apresenta relação muito clara com a curva de insolação (Fig. 4.7), mantendo-se menos variável e com valores mais baixos de $\delta^{18} \mathrm{O}$ em comparação com os registros anteriormente descritos. Os valores isotópicos de $\delta^{13} \mathrm{C}$ apresentam a mesma tendência, contudo, com maior amplitude isotópica. Por outro lado, ainda são observadas variações abruptas de valores tanto no registro de $\delta^{18} \mathrm{O}$ como no de $\delta^{13} \mathrm{C}$, que são coincidentes ao evento de escala milenar $\mathrm{H} 3$, que ocorreram nos períodos de 31.7-29 ky. O evento $\mathrm{H} 3$ está marcado por uma diminuição em até $-2 \%$ de $\delta^{18} \mathrm{O}$, respectivamente, sendo o último evento também bem indicado pelos altos valores de TC e baixos valores de $\delta^{13} \mathrm{C}$ (Fig. 4.7).

A estalagmite IO2 abrange o final do período glacial entre 41.896 e 19.074 anos da área de Iraquara. As razões de $\delta^{18} \mathrm{O}$ variaram entre - 3,01 \%o e - 9,64\%o (média=-5,78 \%o, $\Delta=-$ 6,63 ) e de $\delta^{13} \mathrm{C}$ entre - 5,77 \%o e - 13,02\% (média=-10,32\%, $\Delta=-7,25 \%$ ). Já o valor de R para a amostra IO2 foi de 0,44 , o que indica certa correlação positiva entre os valores isotópicos de carbono e oxigênio, porém de mais baixa significância. 


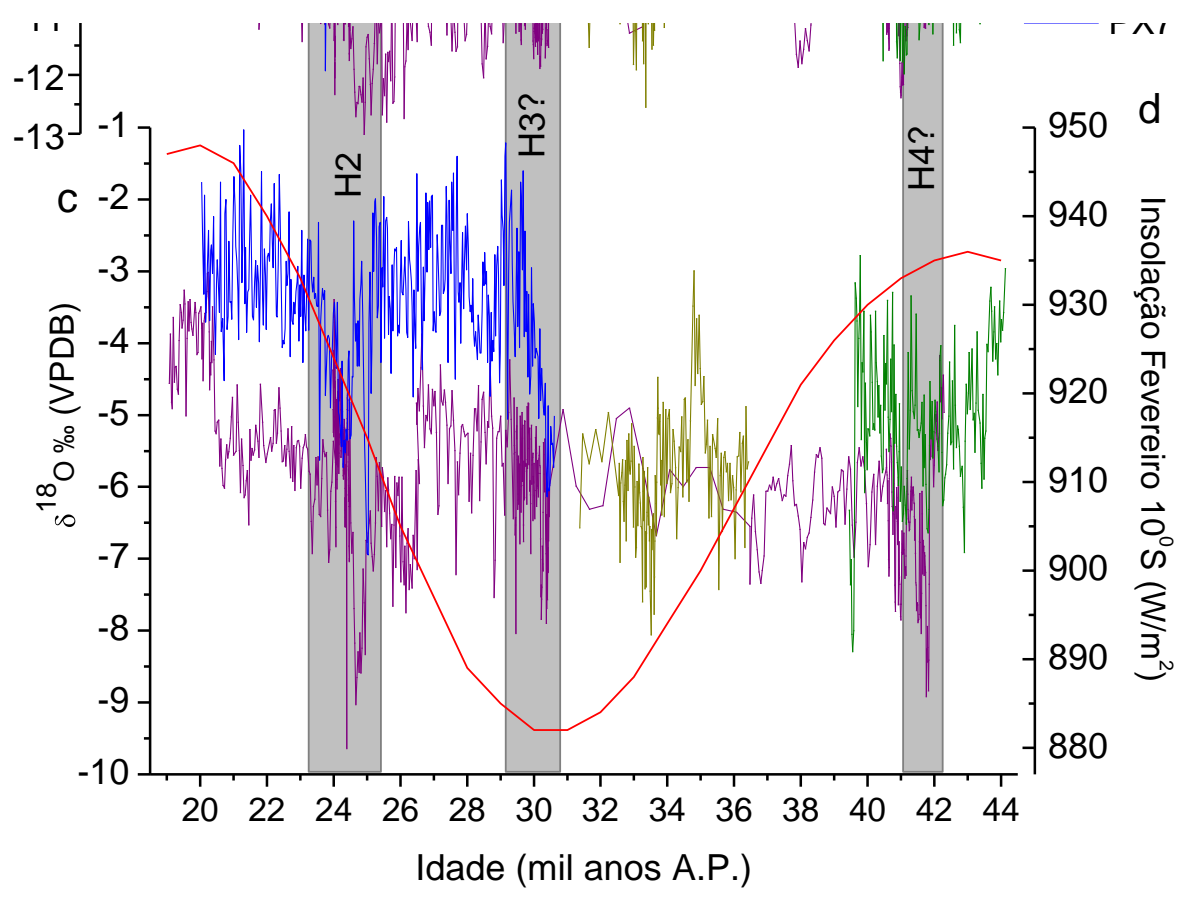

Figura 4.7 - Comparação entre: a taxa de crescimento das estalagmites PX9, IO4 e IO2 (a); razões isotópicas de carbono (b); razões isotópicas de oxigênio (c); e a curva de insolação de verão $\left(10^{\circ} \mathrm{S}\right)(\mathrm{d})$. 
Assim como na estalagmite $\mathrm{IO} 4$, os valores de $\delta^{18} \mathrm{O}$ da $\mathrm{IO} 2$ não indicaram boa similaridade com a curva de insolação para o período em Iraquara, no entanto foram observadas fortes oscilações nas curvas isotópica do oxigênio e carbono. No caso, os valores de $\delta^{18} \mathrm{O}$ estabelecem um patamar com média em torno de - 5,00\% entre $\sim 30$ e 26.5 mil anos A.P., que estão aproximadamente em continuidade com os valores médios de $\delta^{18} \mathrm{O}$ do registro IO4. No entanto, essa certa constância nos valores é quebrada entre 25.5 e 23.1 mil A.P., quando é observada forte diminuição dos valores de $\delta^{18} \mathrm{O}$ em $\mathrm{IO} 2$, que coincide temporalmente com o período correspondente ao evento H2. Uma outra evidência da influência desses eventos no clima da região é a e boa correspondência dos valores negativos de $\delta^{13} \mathrm{C}$ com altos valores de TC da amostra IO2 entre os períodos 30-29 e 25-24 ky, os quais são coincidentes com os eventos $\mathrm{H} 3$ e H2, respectivamente.

Para o período concomitante ao registro da amostra IO2, utilizou-se também a estalagmite PX7 que cobre o intervalo de 30.617-20.018 anos da outra área estuda no município de Andaraí, no lado leste da Chapada. Nesse período os valores de $\delta^{18} \mathrm{O}$ em PX7 oscilaram entre $-6,95 \%$ e $-1,03 \%$ (média $=-3,40 \%, \Delta=-5,92 \%$ ) e os de $\delta^{13} \mathrm{C}$ entre $-3,84 \%$ o e -11,93 \%o (média=-8,41, $\Delta=-8,09$ ). Já o valor de $\mathrm{R}$ correspondeu a 0,24 , indicando baixa correlação entre os valores de $\delta^{18} \mathrm{O}$ e $\delta^{13} \mathrm{C}$.

Da mesma forma que nas estalagmites IO4 e IO2, não foi observado boa associação entre os dados isotópico da estalagmite PX7 com a curva de insolação. Contudo, as curvas isotópicas de oxigênio dessas estalagmites são bem relacionadas, o que indica prováveis variações paleoclimáticas em escala regional. Flutuações isotópicas coincidentes com o evento $\mathrm{H} 2$ também foram identificadas na amostra PX7.

\subsubsection{Período deglacial: 20-10 mil anos A.P.}

A reconstituição paleoclimática do período deglacial é feita a partir da utilização das estalagmites PX7 e PX5, que quando combinadas recobrem por completo o período entre 2010 ky. Da amostra PX7, foi utilizado o trecho do intervalo 20.018-15.050 ky, enquanto da estalagmite PX5 o intervalo correspondente a 15-10 ky. Esse período é caracterizado por forte variação nos valores isotópicos, que são consistentes tanto com o ciclo orbital quanto com eventos mais curtos, em escala milenar.

Os valores de $\delta^{18} \mathrm{O}$ e $\delta^{13} \mathrm{C}$ de PX7 variaram para esse período entre -1,25 \%o e -7,05\% (média=- 4,30\%o, $\Delta=-5,80 \%$ ) e entre -3,18\% e -12,48 \%o (média=- 9,30\%o, $\Delta=-9,30 \%$ ), 
respectivamente, sendo valor de $\mathrm{R}=0,33$ indicativo de baixa correlação entre essas variáveis. Já o registro da estalagmite PX5 apresentou valores de $\delta^{18} \mathrm{O}$ que variaram entre - 0,98 \%o e 7,75\%o (média=-4,51\%o, $\Delta=-6,77 \%$ ) e de $\delta^{13} \mathrm{C}$ entre $-1,75 \%$ e $-12,94 \%$ (média $=-7,21 \%$, $\Delta=-11,19 \%$ ), havendo forte correlação entre essas variáveis $(\mathrm{R}=0,70)$. As curvas isotópicas dessas estalagmites, ambas procedentes da caverna Paixão, em Andaraí, demonstram boa coerência por volta de 15 mil anos A.P., durante período em que são contemporâneas.

A comparação realizada entre o perfil isotópico de $\delta^{18} \mathrm{O}$ de PX7 e PX5 mostra certa similaridade com a curva de insolação, denotada por valores isotópicos em parte consistentes com a diminuição de seus valores no período (Fig. 4.8). No entanto, essas variações de $\delta^{18} \mathrm{O}$ não são graduais, visto valores significativamente acima ou abaixo da tendência definida pela curva de insolação. Isso pode ser observado a partir de fortes oscilações positivas entre 18.917.8 ky A.P. e 15.6-13.8 ky A.P., intercaladas a oscilações dominantemente negativas 17.815.6 ky A.P. e 13.8-11.0 ky A.P. Essas variações abruptas dos valores de $\delta^{18} \mathrm{O}$, com amplitude entre 3 e $5 \%$, são coincidentes com a ocorrência de eventos milenares no final do último máximo glacial (UMG) e dos eventos Heinrich 1 (H1), Bolling-Allerod (B-A) e YoungerDryas (YD) (Fig. 4.8), amplamente discutidos na literatura. Os intervalos marcados por valores anomalamente negativos de $\delta^{18} \mathrm{O}(\mathrm{H} 1$ e YD), são temporalmente coincidentes com eventos úmidos descritos em outros estudos paleoclimáticos no Brasil e Andes, enquanto nos intervalos em que predominam valores positivos existe uma correspondência com eventos de clima mais secos nessas regiões.

Já a partir da relação $\mathrm{TC} / \delta^{13} \mathrm{C}$ da estalagmite PX7, foi observado que os valores mais baixos de $\delta^{13} \mathrm{C}$ coincidiram com as alta taxas de crescimento no período de $\sim 18$ a 16 ky A.P. (Fig. 4.8). Esta mesma relação foi observada na estalagmite PX5 no intervalo que variou entre 12-10 ky A.P., durante o período deglacial. Essas variações abruptas de TC e $\delta^{13} \mathrm{C}$ são estão aqui associadas à ocorrência dos eventos H1 e YD. 


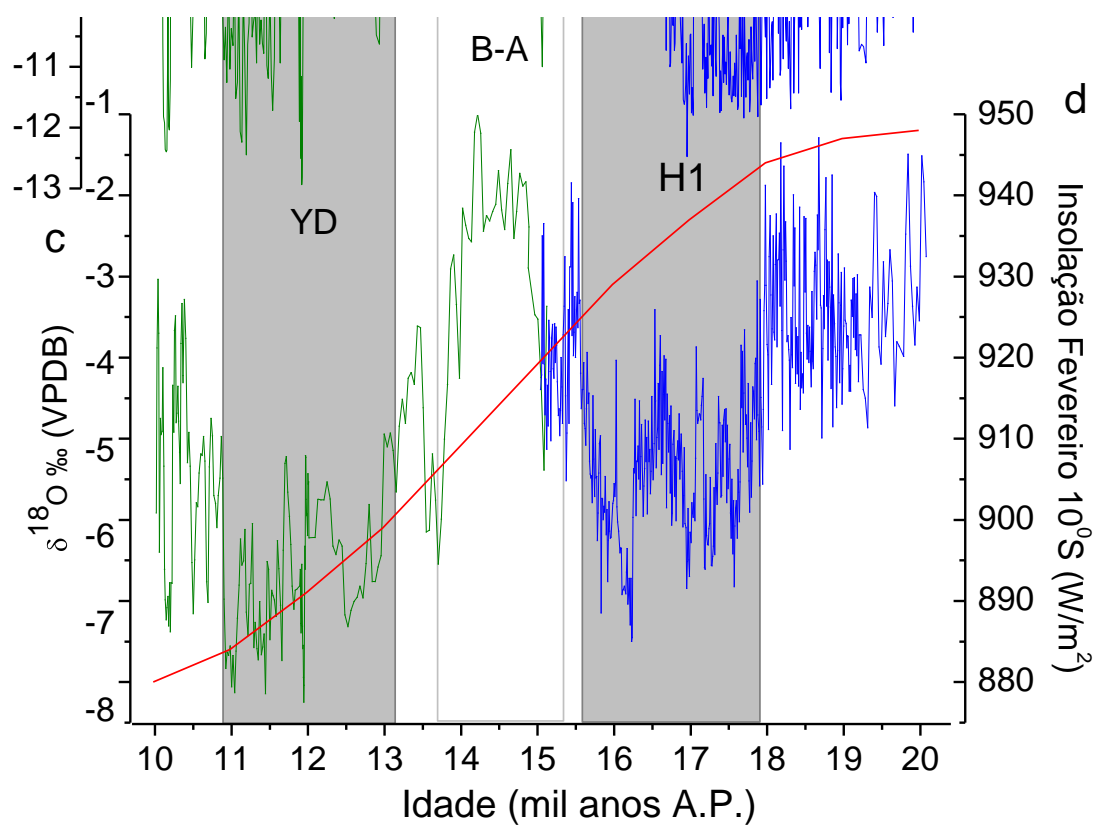

Figura 4.8 - Comparação entre taxa de crescimento das estalagmites PX5 e PX7 (a); razões isotópicas de carbono (b); razões isotópicas de oxigênio (c); e a curva de insolação de verão $\left(10^{\circ} \mathrm{S}\right)(\mathrm{d})$. 


\subsubsection{Período Holoceno: a partir de 10 mil anos até a atualidade}

O período holocênico foi estudado a partir das estalagmites, PX5 e DV2, que juntamente recobriram os últimos $10 \mathrm{ky}$. Os valores isotópicos de $\delta^{18} \mathrm{O}$ dos últimos $10 \mathrm{mil}$ anos da estalagmite PX5 variaram entre $-0,98 \%$ e - -7,75 \%o (média=-5,14\%, $\Delta=-6,77 \%$ ) e de $\delta^{13} \mathrm{C}$ entre $-2,74 \%$ e $-12,94 \%$ (média $=-8,19 \%$, $\Delta=-10,2 \%$ ). Já o valor de R entre $\delta^{18} \mathrm{O}$ e $\delta^{13} \mathrm{C}$ para esse período foi de 0,42 , índice considerado relativamente baixo.

O perfil isotópico do oxigênio da amostra PX5 seguiu a curva de insolação durante maior parte do Holoceno, apresentando valores isotópicos mais baixos entre 8 e 4 ky A.P., e mais altos nos últimos 4 mil anos A.P. (Fig. 4.9). Contudo, a mesma correspondência não foi tão visível com os valores de $\delta^{13} \mathrm{C}$, que se mantiveram mais altos entre 10 e 6 ky A.P. e mais baixos entre 6 e 2.5 ky A.P. Somente nos últimos 2.5 ky A.P. é que ocorre acréscimo nos valores de $\delta^{13} \mathrm{C}$, concomitante com o aumento nos valores de insolação (Fig. 4.9).

O registro da estalagmite DV2, coletada na Caverna Diva de Maura, Iraquara, abrangeu o período entre 9.622-7.097 e 2.822 anos até o recente. Apesar desse registro ser segmentado por hiato deposicional de 4.275 anos, ele é importante para efeito de comparação de mudanças paleoclimáticas ocorridas na porção leste (Andaraí) e oeste da Chapada Diamantina (Iraquara). Os valores de $\delta^{18} \mathrm{O}$ da amostra DV2 oscilaram entre - 2,23 \%o e - 7,51 $\%$ (média $=-4,14 \%, \Delta=-5,28 \%$ ) e de $\delta^{13} \mathrm{C}$ entre - 6,87 \%o e -10,93\% (média=-9,04\%o, $\Delta=-$ $6,98 \%$ ). O coeficiente de correlação entre $\mathrm{O}$ e $\mathrm{C}$ foi de 0,25 indicando baixa correlação entre as duas variáveis, que apesar da boa similaridade observada em alguns trechos.

Existe uma relação aparente entre os dados de $\delta^{18} \mathrm{O}$ e $\delta^{13} \mathrm{C}$ de DV2 e PX5, demonstrada pela tendência similar de aumento de valores nos últimos 3 mil anos, como também pela predominância de valores relativamente mais altos entre 9.5-8.5 ky A.P., que decaem abruptamente em até 1.5\%o entre 8.5-7.5 ky A.P. (Fig. 4.9). Esse último intervalo coincide com evento já bem conhecido no Hemisfério Norte como 8.2 ky cooling event (Fig. 4.8), o qual foi recentemente descrito como período mais úmido na região, com base na utilização do registro PX5 (Cheng et al. 2009).

É importante notar que, apesar da boa concordância entre registros, os dados da DV2 apresentaram valores de $\delta^{18} \mathrm{O}$ mais negativos em relação à amostra PX5, fator que pode estar associado a pequenas diferenças regionais nos valores de $\delta^{18} \mathrm{O}$ da chuva de acordo a com a localização das cavernas Diva de Maura e Paixão, como exposto anteriormente no capítulo 2. Já a relação entre $\mathrm{TC} / \delta^{13} \mathrm{C}$ na estalagmite $\mathrm{DV} 2$ não ocorreu de forma muito clara, 


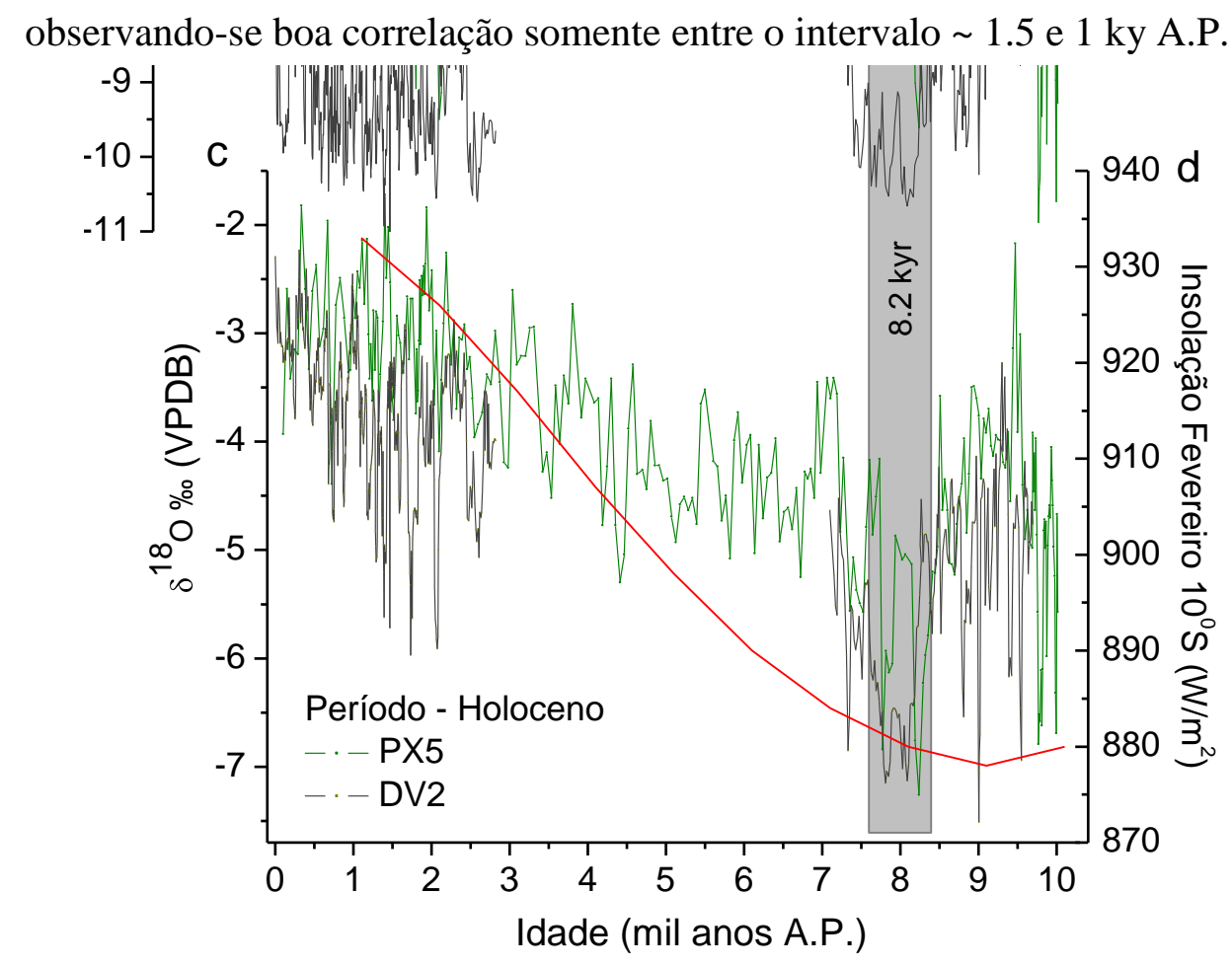

Figura 4.9 - Comparação entre a taxa de crescimento das estalagmites PX5 e DV2 (a); as razões isotópicas de carbono (b) e oxigênio (c); e a curva de insolação de verão $\left(10^{\circ} \mathrm{S}\right)(\mathrm{d})$. 


\title{
5. RECONSTITUIÇÃo PALEOCLIMÁTICA A PARTIR DOS REGISTROS ISOTÓPICOS DE $\delta^{18} O$ DE ESPELEOTEMAS
}

\author{
5.1. Significado paleoclimático das razões isotópicas do oxigênio em estalagmites da \\ Chapada Diamantina
}

Valores de $\delta^{18} \mathrm{O}$ dos registros de estalagmites da Chapada Diamantina foram interpretados como indicativos de variação de paleopluviosidade. Para a realização desse estudo paleoclimático, considerou-se a interação de fatores ambientais locais e regionais na composição da água meteórica e, por conseguinte, dos espeleotemas por ela formados.

Condições ambientais para deposição de espeleotemas em equilíbrio isotópico foram discutidas com base na composição isotópica da água de gotejamento nas cavernas estudadas e através da correlação entre os valores de $\delta^{18} \mathrm{O}$ e $\delta^{13} \mathrm{C}$ de todas as doze estalagmites estudadas. A partir do monitoramento da composição isotópica do gotejamento nas cavernas Paixão e Fumaça, observou-se que os valores de $\delta^{18} \mathrm{O}$ estão diretamente associados com a composição isotópica da chuva, visto a disposição deles sobre a linha meteórica global (Ver capítulo 2).

A partir dessa observação, considerou-se que condições evaporativas, associadas à baixa umidade relativa do ar, não ocorreram de forma significativa no ambiente das cavernas da Chapada Diamantina, como também durante percolação da água da chuva através do perfil solo/epicarste/caverna. Esses fatores favoreceram o estabelecimento de uma forte relação entre composição isotópica da água de gotejamento e os valores de $\delta^{18} \mathrm{O}$ da chuva, condições ideais para fracionamento em equilíbrio isotópico entre o $\mathrm{CaCO}_{3}$ e a água da solução de percolação durante a precipitação do espeleotema. A baixa correlação entre as razões isotópicas de $\mathrm{O}$ e $\mathrm{C}$ observados em algumas estalagmites sugere que, condições de fracionamento cinético não preponderaram nas variações das razões isotópicas dos espeleotemas, como originalmente proposto por Hendy (1971). Já os altos coeficientes de correlação entre os valores de $\delta^{18} \mathrm{O}$ e $\delta^{13} \mathrm{C}$, observados em alguns espeleotemas estudados (Ver capítulo 4), podem ser perfeitamente explicados pela variação simultânea desses parâmetros associada com mudanças climáticas. Isso é amplamente discutido por Lachniet (2009), em artigo de revisão sobre emprego de registros de $\delta^{18} \mathrm{O}$ e $\delta^{13} \mathrm{C}$ em estudos paleoclimáticos.

A boa correlação entre registros isotópicos das duas áreas estudadas na Chapada Diamantina é um forte critério para sugerir condições de precipitação de estalagmites em 
equilíbrio isotópico (ou quasi-equilíbrio) com a água. Outra evidência da forte relação entre os valores de $\delta^{18} \mathrm{O}$ e mudanças de pluviosidade é também a boa correlação dos registros da Chapada com de outros registros de espeleotemas do Nordeste e do restante do Brasil, tanto durante os ciclos orbitais quanto durante os eventos milenares.

Propõem-se, portanto, que valores mais baixos (altos) de $\delta^{18} \mathrm{O}$ estejam associados a períodos mais úmidos (secos). Para aquelas estalagmites que apresentam altos coeficientes de correlação entre os valores de $\delta^{18} \mathrm{O}$ e $\delta^{13} \mathrm{C}$ (Ver capítulo 4), é provável que a diminuição das razões isotópicas de carbono esteja relacionada com variação de chuva, pois isso otimizaria tanto a produção de $\mathrm{CO}_{2}$ biogênico no solo (Cruz et al. 2006a), quanto aumento na proporção de plantas C3, predominantemente árvores, durante a expansão de florestas sobre campos (Pessenda et al. 2004). Assim, a maior contribuição de $\mathrm{CO}_{2}$ empobrecido em ${ }^{13} \mathrm{C}$ biogênico, produto da respiração de plantas e microorganismos (Baldini et al. 2005) e também da decomposição de plantas $C_{3}$ (Dorale et al. 1998), tendem a produzir valores de $\delta^{13} \mathrm{C}$ mais baixos de espeleotemas.

A discussão das variações de $\delta^{18} \mathrm{O}$ das estalagmites da Chapada Diamantina leva em conta a análise da composição isotópica da água da chuva face a pluviometria. A análise considera os dados tratados de composição da chuva da IAEA-GNIP (wwwnaweb.iaea.org/napc/ih/IHS_resources_gnip.html) de quatro estações no Brasil e também das simulações das variações do $\delta^{18} \mathrm{O}$ da chuva, através do modelo climático ECHAM-4 (Vuille et al. 2003). Essas informações foram relacionadas aos dados pluviométricos de estações metereológicas nas áreas de Andaraí e Iraquara.

Com isso, foi possível identificar os principais fatores de condicionamento isotópicos da chuva que formam os espeleotemas em tempos modernos, sendo eles: o amount effect, a fonte de umidade e o efeito continentalidade. Observou-se que o amount effect, produz correlação negativa entre valores de $\delta^{18} \mathrm{O}_{\text {chuva }}$ e a quantidade de precipitação, evidente nos dados isotópicos da estações pluviométricas do Nordeste, assim como também nos resultados da modelagem ECHAM-4. Sugere-se a partir do amount effect que os baixos (altos) valores de $\delta^{18} \mathrm{O}_{\text {chuva }}$, associados ao aumento (diminuição) da pluviosidade, é dominante na composição isotópica da chuva da Chapada Diamantina, que afeta a região principalmente nas estações de verão e outono.

Nesse estudo, a relação tipo amount effect foi extrapolada para o passado, como fator responsável pela maior parte da variação composição isotópica dos espeleotemas da Chapada Diamantina e dessa forma interpreta-se que os valores mais baixos de $\delta^{18} \mathrm{O}$ das estalagmites 
indicam o aumento da paleoprecipitação e vice-versa. Em segundo plano, também se deve considerar o possível efeito as três áreas fontes de umidade na composição isotópica das precipitações sazonais na Chapada Diamantina, aqui tratadas como: continental, Atlânticoequatorial e Atlântico-Sul.

Além do que foi discutido nos dados das estações de monitoramento de $\delta^{18} \mathrm{O}$ da chuva discutidos no capítulo 2, as expressivas amplitudes de variação do $\delta^{18} \mathrm{O}$ nos espeleotemas da Bahia, que durante o período glacial foi de $\sim-8 \%$, e no deglacial e Holoceno correspondeu, respectivamente, a -7 e -6 \%, indicam baixa relevância da temperatura da caverna no fracionamento isotópico dos espeleotemas. Isso porque o gradiente isotópico devido à variação de temperatura é de apenas $0,24 \%{ }^{\circ}{ }^{\circ} \mathrm{C}$, (Mühlinghaus et al. 2009), ou seja, muito baixo para explicar as grandes amplitudes de variação de $\delta^{18} \mathrm{O}$ observadas. Do mesmo modo, ao contrário do esperado se caso a temperatura fosse um fator muito significante para o fracionamento isotópico, existe uma coincidência dos altos valores de $\delta^{18} \mathrm{O}$ dos espeleotemas estudados com baixas temperaturas médias globais, que caracterizam o último máximo glacial (UMG), período entre 30 e $20 \mathrm{ky}$.

Portanto, um aumento ou diminuição da atividade no sistema de monções sulamericanas ou da zona de convergência intertropical, pode resultar num excedente ou déficit na pluviosidade média da regional. No entanto, muita cautela é necessária na avaliação da diferenças entre valores absolutos de $\delta^{18} \mathrm{O}$ em espeleotemas, devido à complexa interação de chuvas relacionadas com diferentes trajetórias de umidade na Chapada Diamantina. Por exemplo, diferenças nos valores absolutos de $\delta^{18} \mathrm{O}$ de espeleotemas de cavernas em Andaraí ou Iraquara podem está mais relacionadas à maior ou menor contribuição de chuvas de determinada estação/área fonte de umidade, do que diferenças na pluviosidade média local. Deste modo, é possível inferir que um determinado evento climático afetou ou não paleopluviosidade regional, mas é difícil concluir que numa área choveu mais do que em outra.

\subsection{Variações paleoclimáticas em longas escalas temporais}

Os registros da Chapada Diamantina permitiram fazer reconstituições paleoclimáticas mais completas acerca das variações a longo-prazo, em escala de várias centenas a milhares de anos, durante o último período glacial. Até então, algumas das discussões paleoclimáticas mais aprofundadas no Nordeste brasileiro através de registros continentais contínuos, se 
deram principalmente por meio de análises de geoquímica orgânica, mineralogia (Sifeddine et al. 2003; Jacob et al. 2006) e polínicas em sedimentos lacustres (Ledru et al. 2005), juntamente com os registros isotópicos em matéria orgânica de solos (Pessenda et al. 2004; 2005). Esses estudos fazem inferências de mudanças de vegetação e paleopluviosidade da região de Barreirinhas, litoral do Maranhão, e envolvem menor intervalo de tempo, os últimos 20 mil anos A.P.

Reconstituições paleoambientais realizadas numa escala maior de tempo foram realizadas através de registros isotópicos de foraminíferos e da aplicação de vários métodos da geoquímica orgânica e inorgânica em sedimentos marinhos, depositados na plataforma continental adjacente ao Ceará e Rio Grande no Norte durante os últimos 85 mil anos (Arz et al. 1998; Jennerjahn et al. 2004; Weldeab et al. 2006; Jaeschke et al. 2007; Dupont et al. 2009). A partir destes registros foram conhecidos dados da variação da temperatura da superfície do oceano e do aporte de sedimentos continentais transportados por rios, parâmetros esses muito importantes para estudo de paleoclima continental.

O registro paleoclimático de espeleotemas do norte da Bahia, cuja deposição ocorreu a partir de 210 mil anos A.P., são os mais longos do Nordeste (Wang et al. 2004). O estudo foi realizado com base em dados geocronológicos obtidos pelo método U/Th, os quais permitiram mapear as fases de crescimento de espeleotemas da caverna Toca da Boa Vista e de tufas depositadas nas margens dos principais rios da região, onde atualmente não ocorrem condições de deposição dessas formações, devido aridez climática. Portanto, as fases de crescimento dos espeleotemas e tufas representam períodos de melhoria climática, num cenário em que condições de umidade estavam bem acima do observado nos tempos modernos.

Indicadores da subida de nível de água, como calcitas depositadas nas margens de lagos em cavernas (“jangadas”), também datadas pelo método U/Th, sugerem clima muito úmido durante o período correspondente ao último máximo glacial (Auler, 1999; Auler e Smart, 2001). As interpretações paleoambientais desses trabalhos foram somadas a de outros estudos realizados na Bahia, que também inferem condições de alta umidade, sugeridas pela expansão de florestas úmidas dada a abundância de macrofósseis de folhas de plantas comuns a Mata Atlântica e Amazônia em tufas (Cristalli, 2003; Wang et al. 2004; Auler et al. 2004). Essas folhas estão bem preservadas nas tufas depositadas nas margens do rio Salitre, um dos principais afluentes do rio São Francisco. Outras observações climáticas do Pleistoceno tardio foram feitas a partir de métodos de análises mais indiretos, através da tafonomia de fósseis de 
vertebrados (Auler et al. 2006), e da análise de sedimentação clástica de cavernas da Bahia (Auler et al. 2009). Contudo, o maior problema desses registros é falta de continuidade, o que em geral, impossibilita correlações com variações de umidade de ciclos climáticos longos, como os orbitais.

Registros continentais em alta resolução, que permitissem reconstituições mais robustas das condições paleoprecipitação e da circulação atmosférica no Nordeste durante o Pleistoceno Tardio, segundo o ciclo de precessão, estão restritos aos registros isotópicos de $\delta^{18} \mathrm{O}$ em espeleotemas do Rio Grande do Norte (Cruz et al. 2009a). Através deste registro foi possível interpretar as variações das condições de umidade correlacionadas ao ciclo de precessão nos últimos 26 mil anos, os quais estão mais bem definidos no Holoceno. Contudo, associado à limitação temporal desses indicadores, não foi possível realizar investigação mais ampla de como a insolação de verão afetou a paleopluviosidade do Nordeste brasileiro, em estágios mais antigos do último período glacial, assim como feito em estudo dos registros de espeleotemas do Sul e Sudeste do Brasil (Cruz et al. 2005a; 2006b). No presente estudo, registros de alta resolução da Chapada Diamantina são utilizados para preencher lacunas na discussão de como insolação de verão afetou o clima da Bahia e da região Nordeste como um todo, com base na definição de um padrão de variação entre pluviosidade e razões isotópicas de oxigênio e carbono em espeleotemas.

\subsubsection{Variações climáticas ocorridas entre 93 e 47 mil anos A.P.}

O intervalo entre 93 e 47 mil anos A.P. do último período glacial, aqui adotado como primeira fase da glaciação, se caracterizou por maior consistência entre valores de $\delta^{18} \mathrm{O}$ dos espeleotemas da Chapada Diamantina com a curva da insolação de verão $\left(10^{\circ} \mathrm{S}\right)$, que segue o ciclo precessão ( periodicidade de 23 mil anos) durante o Pleistoceno Tardio (Berger e Loutre, 1991). Isso indica que a insolação é a principal forçante das variações de paleoprecipitação durante este período, sendo que os altos (baixos) valores de $\delta^{18} \mathrm{O}$ ocorrem durante fases de maior aumento (diminuição) da insolação de fevereiro em $10^{\circ} \mathrm{S}$ e correspondem, portanto, a períodos mais secos (úmidos) na porção central da Bahia. As fases de clima relativamente mais úmido estão bem marcadas nos períodos entre 93-82 e 68-57

ky, por diminuição geral dos valores de $\delta^{18} \mathrm{O}$ (Fig. 5.1). Já o inverso, predominância de condições mais secas, foi verificado entre 80-69 e 57-47 ky, quando existe uma subida geral nos valores de $\delta^{18} \mathrm{O}$, coincidente com períodos de alta insolação de verão. 
A fim de obter uma visão mais ampla do significado climático dos arquivos de espeleotemas da Chapada Diamantina, utilizou-se registros longos e com resolução suficientemente alta para definir padrões mudanças climáticas inter-regionais e até mesmo inter-hemisféricos, segundo o ciclo orbital. Para isso, foram feitas comparações com registros de espeleotemas das cavernas Santana e Botuverá, localizadas no Sudeste/Sul brasileiro (Cruz et al. 2005a; 2006b), e das cavernas Hulu, Sanbao e Dongee, situadas na porção centromeridional da China (Wang et al. 2001; 2008).

Durante as fases de alta insolação observou-se que os altos valores $\delta^{18} \mathrm{O}$ das estalagmites da Chapada Diamantina coincidem com valores mais baixos de $\delta^{18} \mathrm{O}$ dos espeleotemas Bt2 e St8 (Cruz et al. 2005a; 2006b), entre os intervalos 93-90 e 50-47 ky (Fig. 5.1). Nesse caso, a diminuição das chuvas na região ocorre durante a intensificação das chuvas associadas ao sistema de monções de verão no Sul e Sudeste do país. Tal relação é confirmada através dos registros das razões $\mathrm{Sr} / \mathrm{Ca}$ e $\mathrm{Mg} / \mathrm{Ca}$ no espeleotema Bt2 (Cruz et al. 2007), os quais são indicadores mais diretos de mudanças hidrológicas, pois não são sensíveis a área fonte de umidade como as razões de $\delta^{18} \mathrm{O}$. O inverso é também observado durante fases de baixa insolação entre 73-67 ky, em que condições mais secas na Chapada Diamantina ocorrem concomitantemente aos aumentos da paleoprecipitação em Santa Catarina e São Paulo.

Os registros de espeleotemas dos subtrópicos brasileiros tornaram-se populares por demonstrarem relação antifásica com registros da China (Cruz et al. 2005a; Wang et al. 2006a; Cruz et al. 2006b; Wang et al. 2007; Cruz et al. 2009b). Contudo, uma relação em fase é claramente observada entre os registros paleoclimáticos da Chapada Diamantina e da China Wang et al. (2001; 2008), nos intervalos de 93-90 e 73-70 ky, sendo os altos valores de $\delta^{18} \mathrm{O}$ coincidentes com períodos de alta insolação de verão no Hemisfério Sul (Fig. 5.1). A boa correspondência entre os registros dos espeleotemas da Chapada Diamantina e da China permitiu interpretar que condições mais secas ocorreram de modo sincrônico em ambas as regiões e são coincidentes com as fases de alta insolação. O contrário também é válido, ou seja, um aumento gradativo da umidade em ambas as regiões para períodos de baixa insolação entre $\sim 92-89$ e $\sim 60-57$ ky. No entanto, no caso dos registros da China, não se observou de forma tão clara uma correspondência entre os valores de $\delta^{18} \mathrm{O}$ com a variação de insolação no intervalo 70-60 ky, como observado com os registros da Chapada Diamantina. Portanto, de modo geral, as variações de $\delta^{18} \mathrm{O}$ na primeira fase da glaciação estão positivamente correlacionadas aos registros da China e negativamente correlacionadas aos registros do Sul 
brasileiro. Esse resultado é o oposto do que foi proposto por Wang et al. (2004), entretanto, vale lembrar que o registro desses autores não é contínuo o suficiente para estabelecer uma relação robusta-êntreco clima e inssollaçăo."

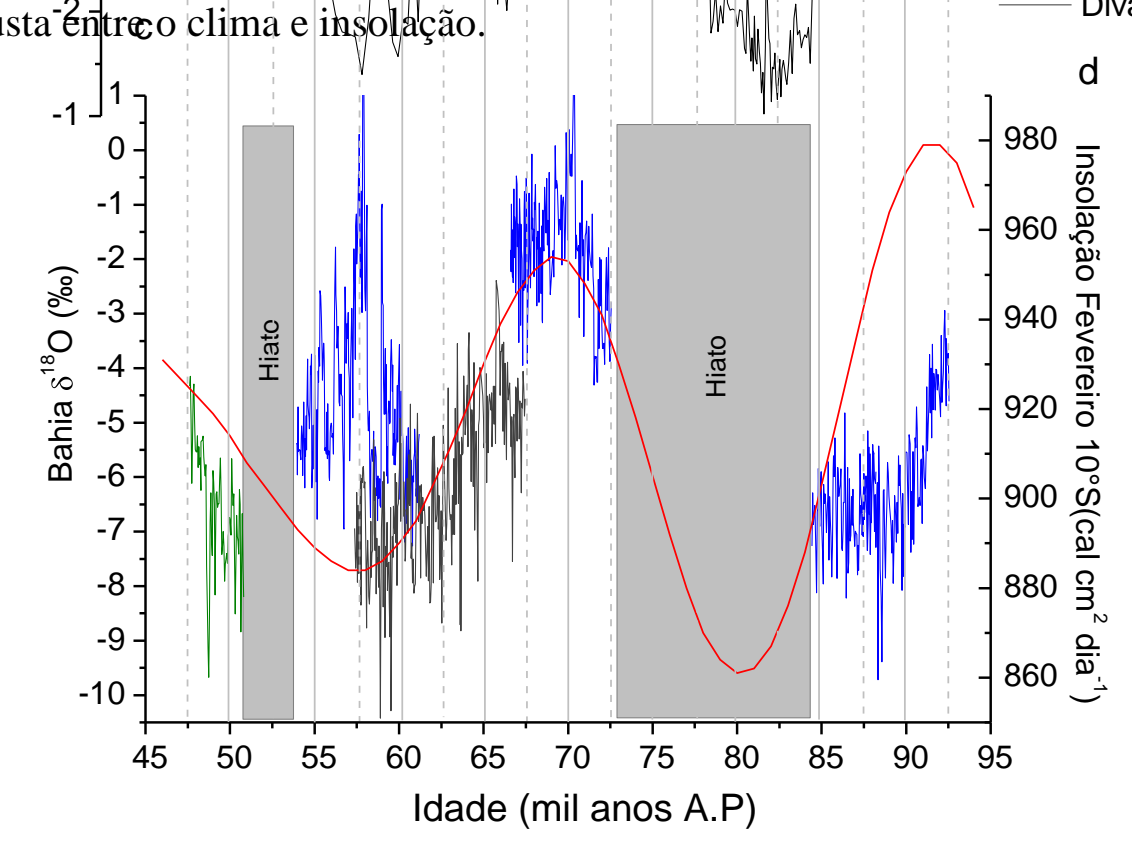

Diva de Maura

崖

Figura 5.1. Comparação entre registros paleoclimáticos de $\delta^{18} \mathrm{O}$ de espeleotemas entre 93 e 47 mil anos A.P. (a) registros da China (Wang et al. 2001; 2008); (b) registros das cavernas Santana (St8) e Botuverá (Bt2) localizadas nos Estados de São Paulo e Santa Catarina (Cruz et al. 2005a), (c) registros da Chapada Diamantina das cavernas Ioio (verde), Paixão (azul) e Diva de Maura (cinza); (d) registros da curva de insolação de verão $\left(10^{\circ} \mathrm{S}\right)$. 
O padrão antifásico de paleoprecipitação entre o Nordeste e Sul/Sudeste brasileiro foi primeiramente descrito por Cruz et al. (2009b) para o período holocênico, através da correlação entre os registros dos espeleotemas do Rio Grande do Norte com os do Sul/Sudeste, de forma semelhante ao que foi observado por meio dos registros da Chapada Diamantina. Essa relação pode ser explicada a partir da influência das Monções sulamericanas de verão (MSA) sobre a circulação zonal ou de direção oeste-leste na América do Sul. Isso porque a variação da MSA, ao centro do continente, influencia substancialmente a circulação atmosférica em baixos e altos níveis próximo a faixa equatorial (Rodwell e Hoskins, 2001).

O aumento das chuvas ao longo do centro de atividade da MSA causaria intensificação do anticiclone subtropical do Atlântico de baixos níveis e do cavado do Nordeste em altos níveis (Lenters e Cook, 1997; Rodwell e Hoskins, 2001). O primeiro processo intensificaria os ventos de SE na costa do Nordeste em baixos níveis e, por conseguinte, esfriaria as águas do Atlântico Sul em relação ao Atlântico Norte. Já o segundo favoreceria subsidência de ar frio e seco em altos níveis que causa aumento da pressão atmosférica próxima a superfície. Atuação desses processos leva ao posicionamento preferencial da ZCIT no Hemisfério Norte e a predominância de condições mais secas no Nordeste. Estas condições podem ter gerado distribuições de chuvas mais irregulares no Nordeste, concomitante com chuvas mais intensas na Amazônia, durante períodos de insolação mais alta, assim como observado por Cruz et al. (2009a) durante parte do Holoceno. Esses novos registros da Bahia indicam que esse processo é também durante o período glacial.

O desencadeamento dos mecanismos climáticos associados principalmente ao sistema monçônico durante os períodos de alta e baixa insolação, justificaria o padrão antifásico observados entre as regiões Nordeste e Sul/Sudeste do Brasil. Neste sentido, Cruz et al. (2005a; 2006b) e Cruz et al. (2007), a partir das razões dos elementos traços $\mathrm{Mg} / \mathrm{Ca}$ e $\mathrm{Sr} / \mathrm{Ca}$ na estalagmite $\mathrm{Bt} 2$, consideraram que o aumento (diminuição) da paleoprecipitação em Santa Catarina e em São Paulo, durante as fases de alta (baixa) insolação no último período glacial, estaria associado à intensificação (desintensificação) das monções de verão na América do Sul. Com base dessas observações, sugere-se que o deslocamento do eixo central das atividades monçônicas para sul/sudoeste durante os períodos de alta insolação teria desencadeado o aumento de precipitação das regiões Sul/Sudeste, e a diminuição da umidade na Chapada Diamantina, assim como em todo semi-árido nordestino, durante grande parte do último glacial. 
De modo geral, a insolação teria afetado o clima através da sua influência no gradiente de temperatura entre o continente e oceano, sendo o aumento do gradiente observado em fases de insolação mais altas e vice-versa. Por sua vez, a diminuição do gradiente teria inibido a convergência de umidade para a região amazônica e, por conseguinte, de chuvas na área afetada pela MSA. A diminuição das atividades convectivas sobre a Amazônia enfraquece a circulação de oeste para leste ou de Walker e afeta substancialmente o clima nordestino, pois pode favorecer a convergência de umidade para região da Chapada Diamantina tanto de oeste, da Amazônia, durante o verão, como de leste, do oceano, durante o outono. Isso porque nesses períodos de circulação zonal enfraquecida, o cavado do nordeste, feição típica da climatologia do verão brasileiro que envolve condições de baixa pressão em altos níveis e alta pressão próxima a superfície (Kayano e Andreoli, 2009), estaria menos desenvolvido proporcionando anomalias positivas de precipitação em escala orbital.

Já as correlações paleoclimáticas em escala continental foi dificultada durante a primeira fase do período glacial, devido à falta de registros que apresentem boa relação com os ciclos de insolação, por exemplo, os registros geoquímicos e de refletância em testemunhos marinhos da Venezuela (Peterson et al. 2000); as variações das razões Ti/Ca e Fe/Ca em sedimentos da costa nordestina brasileira (Arz et al. 2001; Jennerjahn et al. 2004); e os registros lacustres da região andina tropical (Baker et al. 2001; Fritz et al. 2004; 2007). Contudo, alguns desses trabalhos são referências clássicas para discussão de eventos climáticos de mais curta duração em escala sub-orbital, tais como os eventos milenares.

\subsubsection{Variações climáticas dos últimos 45 mil anos A.P.}

A segunda fase da glaciação, ocorrida entre 45 e $20 \mathrm{ky}$, caracterizou-se por apresentar relações menos consistentes entre os valores de $\delta^{18} \mathrm{O}$ e o ciclo de insolação, quando comparado ao período glacial anteriormente descrito. Isso implica na atuação de outras forçantes climáticas, em conjunto com a própria insolação de verão.

Nas estalagmites que recobriram esses intervalos, foram observadas diferenças entre os valores absolutos de $\delta^{18} \mathrm{O}$ entre estalagmites das regiões de Iraquara e Andaraí, sendo elas IO2/IO4 e PX9/PX7, respectivamente (Fig. 5.2). Com objetivo de avaliar similaridades e diferenças nas variações regionais de $\delta^{18} \mathrm{O}$, foi calculada valores de anomalia do $\delta^{18} \mathrm{O}$ (Fig. 5.3). Dessa forma, foi possível observar boa sobreposição das curvas isotópicas das 
estalagmites provenientes da borda leste e oeste da Chapada Diamantina, o que indica consistência no padrão de variação do $\delta^{18} \mathrm{O}$ e, por conseguinte, da pluviosidade na região.

Duas hipóteses podem ser sugeridas para explicar diferenças entre os valores absolutos de $\delta^{18} \mathrm{O}$ das estalagmites de Andaraí e Iraquara: diferenças no processo de fracionamento isotópico durante deposição de espeleotemas nas cavernas e/ou efeito da área fonte umidade, na diferenciação da composição isotópica entre os registros das quatro estalagmites estudadas nesse período. No entanto, como o regime de chuva é muito semelhante entre as duas áreas, é pouco provável que alterações nas contribuições de diferentes áreas fontes possa explicar diferenças entre 2 e $3 \%$, observadas entre as duas áreas estudadas. Portanto, é provável que diferenças nas condições climáticas das cavernas sejam o principal fator para tais distinções observadas. Por esse motivo, estão sendo utilizadas as variações de anomalias de $\delta^{18} \mathrm{O}$ dos espeleotemas, de modo evitar interpretações duvidosas sobre mudanças climáticas somente com base em valores absolutos de $\delta^{18} \mathrm{O}$.

As anomalias de $\delta^{18} \mathrm{O}$ durante o intervalo de $\sim 45-20 \mathrm{ky}$, ou até a transição do último máximo glacial (UMG) para o período deglacial, são dominantemente mais altos do que observados durante os intervalos 17.5-15.5 ky e de 13.0-3.0 ky (Fig. 5.3), o que envolve parte do período deglacial e todo o Holoceno inferior e médio da região. Esse resultado sugere que o final do período glacial foi relativamente seco na região, nos intervalos coincidentes aos estágios isotópicos marinhos 3 e 2 (MIS) (Wrigth, 1999). Esses estágios são caracterizados por ampla expansão de geleiras para latitudes mais baixas nos mares e continentes o que teria proporcionado consequentemente abaixamento das temperaturas oceânicas (Shackleton, 1967; Cutler et al. 2003).

Os registros de Andaraí (PX9/PX7/PX5) foram adotados como referência na discussão das mudanças paleoclimáticas entre o período glacial e Holoceno. Isso porque as estalagmites de Andaraí são provenientes do mesmo local, caverna Paixão, e desse modo eventuais problemas de interpretação paleoclimática, relacionados a valores significativamente mais baixos de $\delta^{18} \mathrm{O}$ das estalagmites de Iraquara, podem ser assim minimizados. Já os registros de Iraquara (IO2/IO4/DV2) são compostos por estalagmites coletadas em duas cavernas diferentes, Ioiô e Diva de Maura.

O clima durante o final do último período glacial, na segunda fase da glaciação aqui descrita, contrasta fortemente com condições mais úmidas observadas em grande parte do deglacial e durante o Holoceno inferior e médio, nos intervalos aproximadamente entre 17-15 e 13-5 ky, caracterizadas por valores mais baixos de $\delta^{18} \mathrm{O}$ (Fig. 5.2; Fig. 5.3). Após esses 
intervalos observou-se o retorno de condições climáticas mais secas a partir de 5 mil anos A.P., que perdura até os dias atuais. Nota-se que, a partir da semelhança de valores de $\delta^{18} \mathrm{O}$, que o clima da região da Chapada Diamantina durante o Holoceno superior foi tão seco quanto durante o UMG. Esse padrão de variações de precipitação em escala orbital durante parte do UMG, a deglaciação e o Holoceno são consistentes ao observado por Cruz et al. (2009a) através dos registros isotópicos dos espeleotemas do Rio Grande no Norte (Fig. 5.4).

Condições climáticas semelhantes entre 21-17.5 ky foram também indicadas, por análises polínicas, mineralógicas e das concentrações de carbono total em sedimentos da lagoa Caçó, no Maranhão (Sifeddine et al. 2003). Já no período deglacial, condições mais úmidas entre $\sim 17.5-12$ ky foram apontadas nessa mesma região através do estudo de registros polínicos (Ledru et al. 2006), da variação de $\delta^{13} \mathrm{C}$ e conteúdo de carvão em solos (Pessenda et al. 2004; 2005) e da geoquímica e mineralogia de sedimentos lacustres (Sifeddine et al. 2003). Esses dados são coerentes com os estudos paleoclimáticos em espeleotemas nordestinos.

Auler e Smart (2001) por meio da utilização de travertinos fósseis e espeleotemas subaquosos como indicadores de paleoníveis da recarga hídrica da caverna Toca da Boa Vista (TBV), localizada a norte da Bahia, sugeriram aumento de umidade durante maior parte do intervalo de 21-9 ky, envolvendo parte do UMG. No entanto, as inferências paleoclimáticas realizadas a partir desses registros não são tão confiáveis, devido a imprecisões nos dados geocronológicos U/Th dos espeleotemas e travertinos, obtidos pelo método de contagens alfa (Dr. Augusto Auler, informação verbal). Isso pode ter resultado em um deslocamento temporal das idades dos eventos úmidos do período deglacial para o glacial, ou seja, a fase úmida descrita no UMG pode na verdade ter acontecido durante o evento Heinrich 1 entre 17.5 e 15.0 ky A.P.

Através de registros polínicos do vale do rio Icatu, drenagem tributária do rio São Francisco, no norte da Bahia, foi descrita uma transição de vegetação indicativo da passagem de condições mais úmidas para mais secas de Holoceno médio para o Holoceno superior (De Oliveira et al. 1999). Essa transição climática foi definida pela mudança do predomínio de plantas arbóreas, típica de matas de veredas, ricas em palmeiras do tipo Mauritia (popularmente conhecidas como Buritis), para vegetação mais secas, com maior abundância de plantas típicas da caatinga e cerrado. O ápice do declínio das florestas mais úmidas de galerias e predomínio da vegetação de caatinga é observado por volta de cal. 4200 anos A.P., o qual marca o estabelecimento de condições semi-áridas na Bahia durante o Holoceno tardio na região. Tal mudança de vegetação é plenamente concordante com o cenário paleoclimático 
apontado na porção central da Bahia pelos registros de espeleotemas. É bem provável que a expansão de florestas mais abertas de caatinga ou cerrado, relativamente ricas em plantas $\mathrm{C}_{4}$, esteja refletida nos valores mais altos de $\delta^{13} \mathrm{C}$ inicialmente observados entre 5 e 3 mil anos A.P., tanto no Rio Grande do Norte quanto na Bahia.

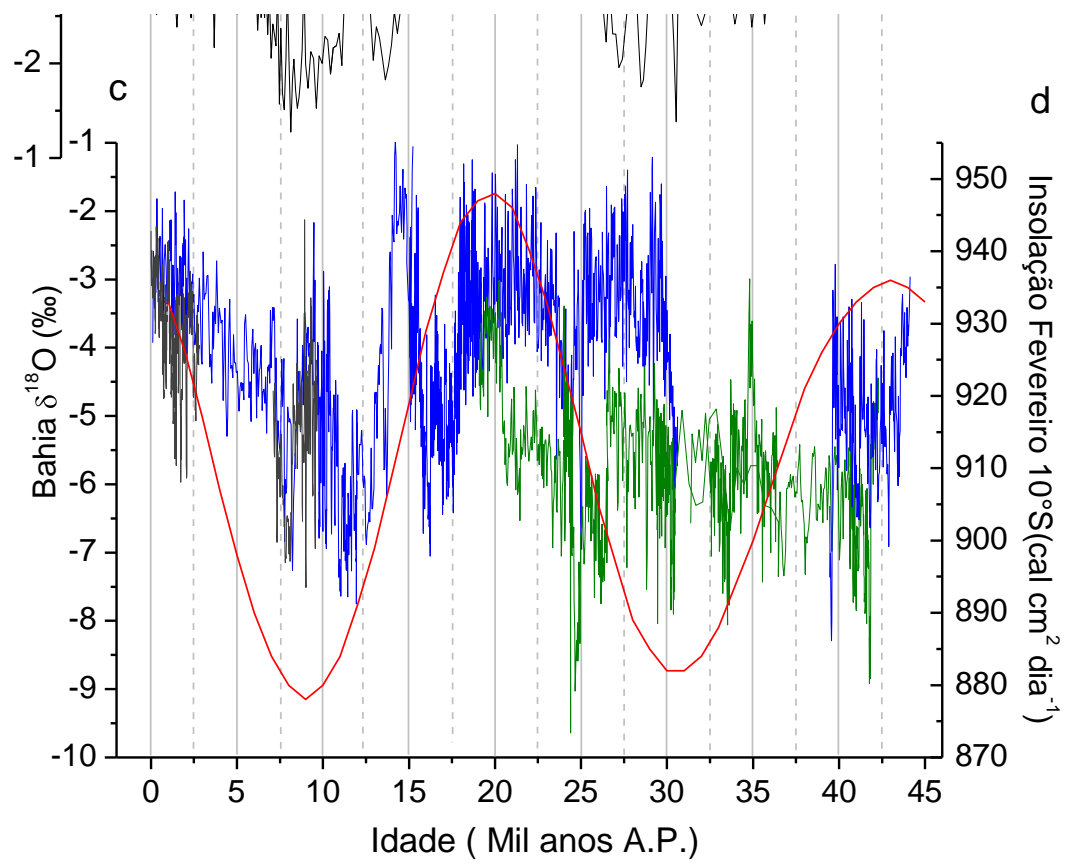

Figura 5.2 - Comparação entre registros de $\delta^{18} \mathrm{O}$ de espeleotemas durante os últimos 45 mil anos A.P. da China (Wang et al. 2001; 2008) (a), das cavernas Santana (St8) e Botuverá (Bt2) (Cruz et al. 2005a) (b), das cavernas Ioiô, Paixão e Diva de Maura na Chapada Diamantina (c); com a curva de insolação de fevereiro (10 $\left.{ }^{\circ} \mathrm{S}\right)(\mathrm{d})$. 


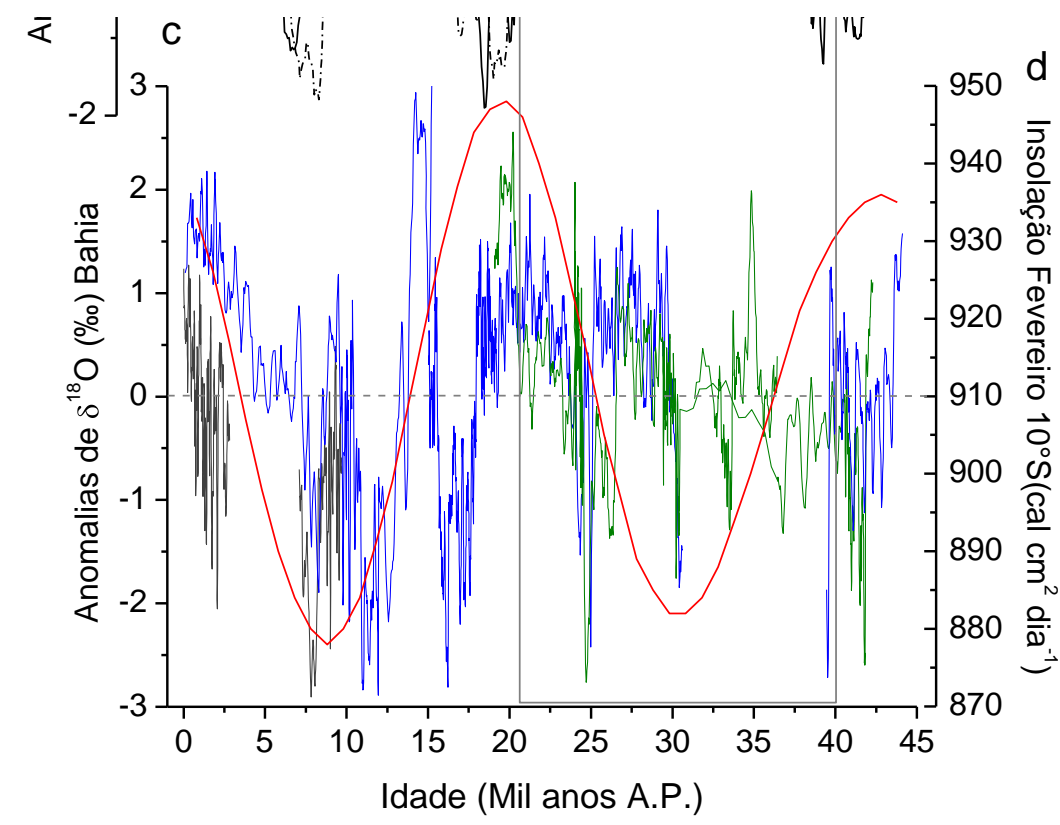

Figura 5.3 - Como na comparação da figura anterior, mas com utilização dos valores de anomalias de $\delta^{18} \mathrm{O}$ dos espeleotemas. O retângulo destaca o período cujos valores de $\delta^{18} \mathrm{O}$ das estalagmites da Chapada Diamantina não acompanham a curva de insolação durante o intervalo coincidente ao MIS-3/MIS-2 e ao UMG. 
Por outro lado, o quadro de variação paleoambiental não parece ser muito claro no Maranhão durante o Holoceno, porque enquanto os trabalhos com $\delta^{13} \mathrm{C}$ em solos apontam para um clima mais úmido no Holoceno Tardio, devido à maior contribuição de plantas C3 (Pessenda et al. 2004; 2005). Já os registros palinológicos existentes não sugerem variação significativa no percentual de polens arbóreos nesse período (Ledru et al. 2006). Fortes contrastes climáticos durante o Holoceno, também não são evidenciados nos registros de mineralogia e geoquímica orgânica de sedimentos da lagoa Caçó (Siffedine et al. 2003).

Correlações positivas são bem visíveis, na comparação em escala global dos registros da Chapada Diamantina e dos espeleotemas chineses (Wang et al. 2001; 2008) nos últimos 45 mil anos A.P (Fig. 5.2; Fig. 5.3). A correlação entre os dois registros é boa tanto nos períodos em que as curvas isotópicas são fortemente coerentes com a variação de insolação de verão, ou mesmo em períodos quando elas não são, como na segunda fase do período glacial, 45-20 ky A.P.

Do mesmo modo, correlações positivas foram observadas entre registros geoquímicos de titânio (Fig. 5.4), envolvendo os últimos 14 mil anos A.P. dos testemunhos marinhos da Bacia de Cariaco (Haug et al. 2001), na Venezuela $\left(\sim 10^{\circ} \mathrm{N}\right)$. No caso, a diminuição das concentrações de Ti nos sedimentos marinhos nas proximidades da costa venezuelana durante os últimos 4 ky, foram associados à menor descarga fluvial na bacia do Cariaco, devido ao aumento de aridez na porção norte da América do Sul. O contrário ocorreu durante o Holoceno inferior e médio, as maiores concentrações de Ti nos sedimentos marinhos, são atribuídas ao maior aporte de sedimentos terrígenos de origem continental, devido a condições mais úmidas no continente. Essa variação de condições mais úmidas para mais secas por volta de 4 ky descrita nos trabalhos da China (Wang et al. 2001; 2008), de Cariaco (Peterson et al. 2000; Haug et al. 2001), oeste da África (Gasse, 2000) e América Central (Lachniet et al. 2004), foi associada a um deslocamento mais a sul da ZCIT o que causaria, em teoria, aumento de umidade em todo o Brasil. O mesmo mecanismo vem sendo largamente utilizado para explicar condições mais úmidas durante fases de insolação mais alta nos subtrópicos brasileiros (Cruz et al. 2005a; 2006b), nos Andes (Baker et al. 2001a; 2001b; Seltzer et al., 2002), que ocorrem em oposição ao clima dos trópicos do Hemisfério Norte.

O ponto mais importante de toda a discussão sobre o padrão de variação paleoclimática acima definido em escala orbital, é que o mesmo não se encaixa nos padrões de precipitação estabelecidos para a região Nordeste, através dos trabalhos mais clássicos de climatologia moderna (Moura e Shukla, 1981; Hastenrath e Lamb, 2004). Isso porque a 
porção mais norte do Nordeste é tida referência mundial no estudo da atividade da ZCIT, pois a maior parte do seu acumulado anual de chuvas ocorre nos meses de outono (MAM), quando a ZCIT está localizada mais a sul da sua posição média. Tal posicionamento da ZCIT é favorecido por águas relativamente mais quentes no oceano Atlântico, logo a sul do Equador (Chang et al. 2003). Esse padrão de deslocamento meridional devido ao gradiente de temperatura na faixa tropical do Atlântico Norte e Sul é muito bem definido em escala subdecadal a decadal, no entanto é pouco conhecido para escalas mais longas de tempo.

No entanto, ao contrário do esperado, as variações há mais longo prazo, que seguem o ciclo de precessão durante o Holoceno, estão em fase com registros paleoclimáticos do Hemisfério Norte e são assim antifásicos com os registros da espeleotemas do Sul e Sudeste do Brasil (Cruz et al. 2005a; 2006b; 2007) e de lagos/espeleotemas dos Andes (Baker et al. 2001a; 2001b; Seltzer et al. 2002; van Breukelen, 2008). Portanto, os dados aqui apresentados confirmam que o padrão antifásico de paleoprecipitação entre o Nordeste e Sul/Sudeste brasileiro proposto por Cruz et al. (2009), que passa agora a possuir caráter regional e atinge maior parte do Nordeste, do Rio Grande do Norte a Bahia.

O padrão antifásico das chuvas do Hemisfério Sul durante o Holoceno, assim como descrito para alguns trechos da última glaciação, pode ser explicado a partir da influência das Monções sul-americana sobre a circulação zonal dentro do continente, intensificada durante os períodos de insolação mais alta. Sugere-se que o aumento da radiação solar no topo da atmosfera teria aquecido o continente sul-americano em relação a superfície marinha, e que resultou numa maior convergência de umidade do oceano Atlântico tropical para a Bacia Amazônica. Esse processo intensificou o sistema monçônico e aprofundou o cavado do Nordeste, feição responsável pelas condições de baixa (alta) pressão em altos (baixos) níveis da região durante o verão, que gerou condições mais secas no Nordeste brasileiro e mais úmidas no restante do país. 


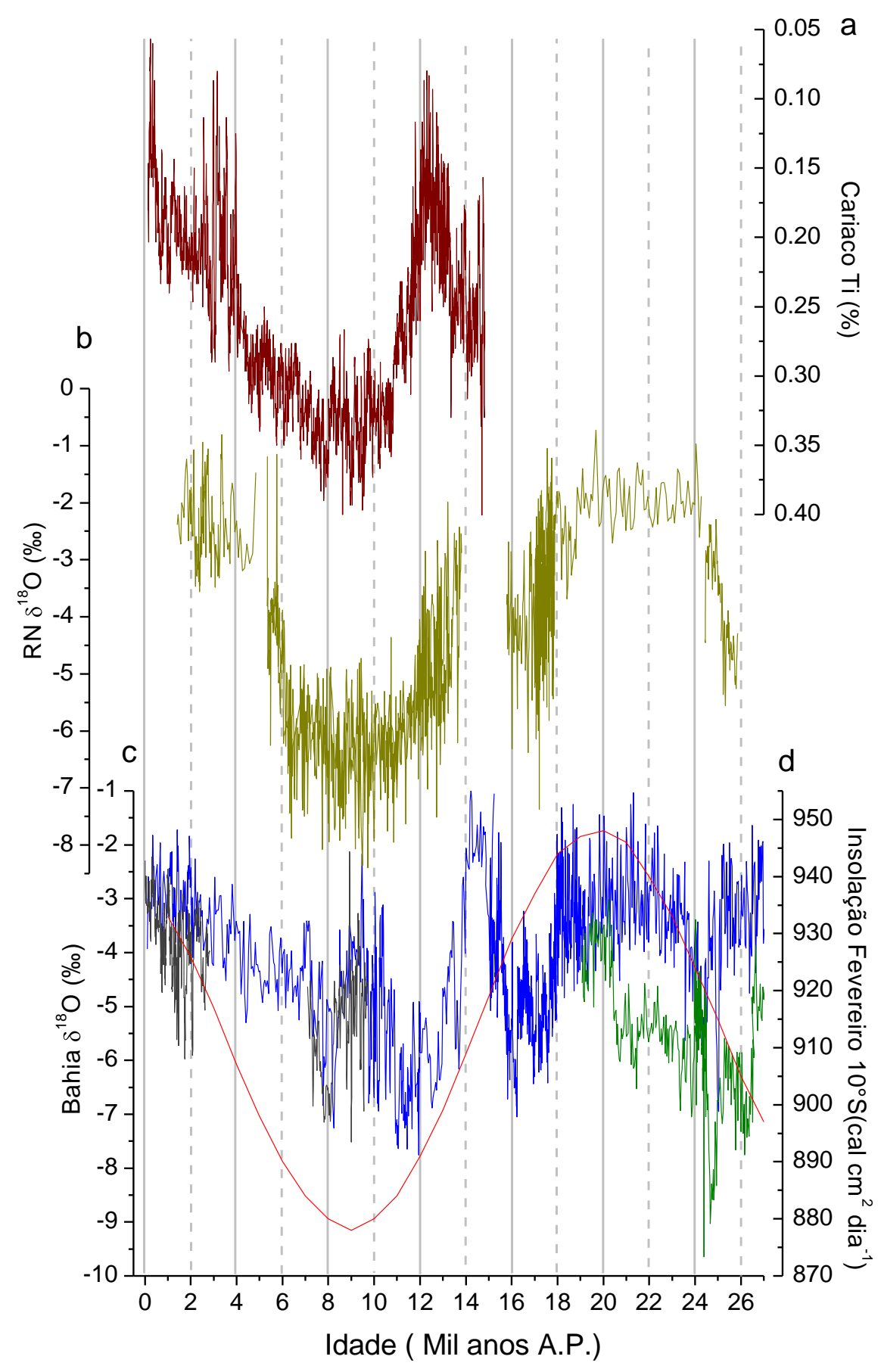

Figura 5.4 - Comparação entre registros paleoclimáticos durante os últimos 45 mil anos A.P. Concentração de Ti em sedimentos da Bacia do Cariaco, Venezuela (Haug et al. 2003) (a); Valores de $\delta^{18} \mathrm{O}$ de espeleotemas do Rio Grande do Norte (Cruz et al. 2009) (b); e de espeleotemas da Chapada Diamantina, das cavernas Ioiô (verde), Paixão (azul) e Diva de Maura (cinza) (c); e a curva de insolação de verão $\left(10^{\circ} \mathrm{S}\right)(\mathrm{d})$. 
Em resumo, o sistema de monções torna-se mais intensificado (enfraquecido) no Holoceno superior (últimos quatro mil anos A.P.) no Hemisfério Sul (Norte), o que pode ser representado por mais chuvas de verão no Sul/Sudeste do Brasil e nos Andes centrais e menos chuvas na China. O padrão em fase observado entre a China e o Nordeste é associado, portanto, com a influência que as monções sul-americanas na circulação no continente, a qual provoca clima mais seco nessa última, ao contrário do restante da região da América do Sul. Já o clima da China (Wang et al. 2001; 2008) entre outras áreas na Ásia, oriente médio (BarMatthews et al. 1997; 2000) e norte do continente (Haug et al. 2001) é antifásico com o Sul/Sudeste do Brasil e Andes, porque a ZCIT é deslocada para sul durante as fases de maior insolação no Hemisfério Sul, o que compreende as fases de menor insolação no Hemisfério Norte. Assim, resta discutir, portanto o por quê das variações climáticas em fase com a China e antifásica com o sul/sudeste do Brasil entre 45 e 20 mil anos A.P., quando as variações de $\delta^{18} \mathrm{O}$ não parecem seguir tão claramente a insolação (Fig. 5.2; Fig. 5.3).

Valores anomalamente mais baixos de $\delta^{18} \mathrm{O}$ dos espeleotemas do Sul/Sudeste brasileiro, especificamente durante o UMG, foram interpretados em função das condições de contorno associadas à expansão de geleiras no mar e continentes do Hemisfério Norte (Cruz et al. 2006b), que por sua vez teriam propiciado maior umidade na área sob influência da MSA. Essas condições de mais alta precipitação puderam ser mais bem definidas através das análises das razões $\mathrm{Sr} / \mathrm{Ca}$ e $\mathrm{Mg} / \mathrm{Ca}$ na estalagmite $\mathrm{Bt} 2$ (Cruz et al. 2007). Essas razões elementares foram aplicadas como indicadores da taxa de infiltração da água meteórica na zona vadosa da caverna, a qual está diretamente relacionada com a pluviosidade. Através desses registros, foi confirmada a predominância de condições mais úmidas no intervalo de 70-17ky, entre o MIS-4, 3 e 2, durante o último período glacial. Tais dados são consistentes com resultados de estudos paleoclimáticos através de isótopos estáveis de carbono e palinologia em turfeiras da Serra do Mar, Estado de São Paulo (Pessenda et al. 2009), o qual aponta a ocorrência de florestas úmidas, de clima tipicamente mais frio.

Com os novos registros obtidos com espeleotemas da Chapada Diamantina é possível sugerir que tanto áreas do Nordeste brasileiro quanto da China estiveram mais secas durante longos intervalos de tempo em que a MSA esteve intensificada na última glaciação. No entanto, esse padrão de mudanças no intervalo entre 45-20 ky, que coincide com o MIS-3 e o MIS-2, deve ser atribuída a uma outra forçante climática que atua em conjunto com insolação.

Nessa questão, alguns trabalhos se destacam nas simulações dos mecanismos climáticos relacionados a mudanças de clima do Nordeste durante o último máximo glacial, 
por exemplo: Chiang et al. (2003); Chiang e Bitz (2005) e Lee et al. (2009). Esses autores analisaram variações do posicionamento da ZCIT no Atlântico tropical durante o UMG através das simulações por modelos climáticos dos possíveis efeitos das concentrações de $\mathrm{CO}_{2}$, das oscilações de insolação e da cobertura de geleiras continentais e oceânicas. Os mesmos elegeram o último fator como preponderante no deslocamento da ZCIT para posições médias mais a sul. Eles sugerem que o aumento de albedo relacionado com a expansão do gelo nórdico levou a intensificação dos ventos de NE (associado às atividades da alta subtropical do Açores) sobre o Atlântico Norte, provocando aumento do fluxo do calor latente e diminuição progressiva da temperatura da superfície marinha (TSM) da região subtropical a tropical do Atlântico Norte. Essas condições teriam proporcionado um gradiente de temperatura entre os Atlânticos equatoriais do Norte e do Sul, que resultou variações no posicionamento da ZCIT mais ao sul do Equador, o que em teoria produz um clima mais úmido na maior parte do Brasil, inclusive no Nordeste. Essas condições são também inferidas por simulações da variação de $\delta^{18} \mathrm{O}$ das chuvas nesse mesmo período (Lee et al. 2009).

Esses dados são consistentes com as anomalias positivas de precipitação apontadas pelos registros de geoquímica elementar da caverna Botuverá, localizada em Santa Catarina, pois o deslocamento mais a sul da ZCIT tende a intensificar a MSA, tornando o clima mais úmido nos subtrópicos brasileiros. No entanto, através desses mesmos mecanismos, consagrados nos trabalhos de climatologia moderna (Vera et al. 2006) e do paleoclima do Nordeste (Chiang e Koutavas, 2004), se esperaria mais chuvas no Nordeste durante o UMG, como apontam os estudos com modelos climáticos (Chiang et al. 2003; Chiang e Bitz, 2005; Lee et al. 2009). No entanto, não é esse o resultado indicado pelos registros de espeleotemas da Chapada Diamantina e do Rio Grande do Norte (Cruz et al. 2009a), que evidenciam clima muito seco durante o UMG.

Isso demonstra que as simulações através de modelos climáticos do passado, a exemplo do ECHAM-4, que consideram a influência da MSA sobre alterações na circulação zonal são mais coerentes com os dados de espeleotemas (Cruz et al. 2009a). O ECHAM-4 reproduz muito bem, condições atmosféricas favoráveis para convergência de umidade oceânica e formação de chuvas no Nordeste durante o Holoceno médio no Nordeste em relação ao Holoceno inferior. Esses experimentos também apontam valores de $\delta^{18} \mathrm{O}$ mais negativos durante o período mais chuvoso. 


\subsection{Eventos paleoclimáticos de escala milenar}

A alta resolução temporal obtida nos registros da Chapada Diamantina permitiu discutir variações climáticas de eventos na escala milenar durante o último período glacial. A ocorrência desses eventos pôde ser evidenciada através de oscilações abruptas dos valores de $\delta^{18} \mathrm{O}$ das estalagmites, indicando que significativas mudanças na paleoprecipitação, cuja duração oscilou entre 1.5 a 3 mil anos, foram iniciadas em curtos intervalos de tempo, de poucas décadas.

Oscilações abruptas para valores mais baixos de $\delta^{18} \mathrm{O}$ foram interpretadas como indícios de aumento de paleoprecipitação, bem marcados principalmente durante a segunda fase da glaciação e no período deglacial, entre os intervalos de 25.5-24, 17.9-15.5 e 13.510.9 ky (Fig. 5.6; Fig. 5.8). Esses períodos foram caracterizados por elevadas amplitudes das oscilações isotópicas em até $~ 4 \%$, o que indica forte intensidade desses eventos climáticos. Todos esses intervalos, marcados por grandes variações dos registros isotópicos da Chapada Diamantina, coincidem com a ocorrência de eventos frios típicos do Hemisfério Norte (Heinrich, 1988; Bond et al. 1992; 1993; 1995), e correspondem respectivamente aos eventos Heinrich, sendo eles: $\mathrm{H} 2, \mathrm{H} 1$, e ao $\mathrm{H}_{0}$; este último também designado de Younger Dryas (YD). Esses eventos compõem ciclos de ocorrência quasi-periódica que durante o período deglacial na Bahia estão intercalados com um grande evento seco que ocorreu entre 15.5 e $13.5 \mathrm{ky}$.

Outras variações abruptas dos valores de $\delta^{18} \mathrm{O}$ e, portanto, da paleopluviosidade foram observadas durante o período glacial, contudo de forma não tão evidente como durante o período deglacial. Essas bruscas variações climáticas foram observadas nos intervalos de 63.7-61.9, 40.1-42 e 34-32.5 ky (Fig. 5.5; Fig. 5.6; Fig. 5.7), cuja a amplitude isotópica também oscilou entre 3 e 4 \%, coincidindo com a ocorrência dos eventos H6, H4 e H3, respectivamente.

A consistência acerca das variações das condições de umidade ocorridas na Bahia com os eventos Heinrich foi também evidenciada a partir da comparação entre taxa de crescimento e oscilações dos valores de $\delta^{13} \mathrm{C}$ das estalagmites, como observado nas figuras do capítulo 4 . As taxas de crescimento das estalagmites, quando analisadas conjuntamente com as razões $\delta^{13} \mathrm{C}$ podem ser bons indicadores paleoambientais, uma vez que podem ser relacionadas com a recarga hídrica da caverna e com a acidez da água de percolação no processo de precipitação de $\mathrm{CaCO}_{3}$ no ambiente da caverna (Fairchild et al. 2006a). O suprimento de água 
está diretamente relacionado à pluviosidade, devido a recarga de água na superfície para o sistema cárstico. Já as concentrações de dióxido de carbono $\left(\mathrm{CO}_{2}\right)$ podem ser associadas com a atividade biológica do solo, que por sua vez sofre influência das condições climáticas como mudanças de temperatura e umidade (McDermott et al. 2005; McDermott et al. 2004).

Em regiões tropicais, como a Bahia, espera-se que o aumento de umidade produza condições favoráveis para aumento na produção de $\mathrm{CO}_{2}$ biogênico no solo e consequentemente de ácido carbônico $\left(\mathrm{H}_{2} \mathrm{CO}_{3}\right)$ dissolvido na água através do perfil de infiltração solo-caverna. $\mathrm{O}$ aumento dos níveis de acidez da água de percolação irá resultar numa maior dissolução do pacote de rocha carbonática sobre a caverna, no aumento da saturação da água em carbonato de cálcio e consequentemente na taxa de deposição de espeleotemas. Já o aumento de $\mathrm{CO}_{2}$ biogênico, produzido pela respiração de raízes e microorganismos ( $\delta^{13} \mathrm{C}$ entre -27 e $-14 \%$, Amundson et al. 1998) ou aumento na proporção de plantas C3 durante expansão de florestas em clima mais úmido (Gouveia, 2001), implicam em valores significativamente menores das razões dos isótopos de carbono de espeleotemas (Dorale et al. 1998; Genty et al. 2006). Isso porque a fonte inorgânica, o calcário encaixante da caverna possui valores de $\delta^{13} \mathrm{C}$ significativamente mais elevados $\left(\delta^{13} \mathrm{C}\right.$ aproximadamente 0 \%). Portanto, um período úmido pode ser caracterizado por altas taxas de crescimento e valores mais baixos de $\delta^{13} \mathrm{C}$ e $\delta^{18} \mathrm{O}$.

Nesse sentido, explica-se que a relação entre as baixas razões isotópicas de $\delta^{13} \mathrm{C}$ e as elevadas taxas de crescimento, indica incremento das atividades biológicas no solo associado a clima mais úmido. Elevadas taxas de crescimento, quando correlacionadas aos valores mais baixos de $\delta^{13} \mathrm{C}$, podem permitir identificar com mais clareza as variações paleoclimáticas tropicais ocorridas durantes os eventos $\mathrm{H}$ no Hemisfério Norte. A exceção se faz ao evento H4, onde esta relação não está tão bem estabelecida.

Já as variações abruptas dos registros isotópicos da Chapada Diamantina para valores mais altos de $\delta^{18} \mathrm{O}$, foram interpretadas como correspondentes aos períodos caracterizados por bruscas diminuições da umidade. Porém, a observação dessas oscilações em relação aos ciclos úmidos de escala milenar se deu de forma mais restrita, sendo verificadas somente nos intervalos de $~ 57.5-56$ e 15-13.6 ky (Fig. 5.5; Fig. 5.8), que da mesma forma, caracterizaramse por elevadas amplitudes de oscilações isotópicas entre -5 e -4\%, ocorridas em curto espaço de tempo. Essas oscilações climáticas abruptas, que resultam em condições mais secas na Chapada Diamantina, são temporalmente coincidentes com a ocorrência de eventos climáticos quentes identificados no Hemisfério Norte (Dansgaard et al. 1993; Andersen et al. 
2004). Estes eventos são denominados de Dansgaard-Oeschger (D-O), e de Bølling-Allerød (B-A), sendo este último ocorrido durante a deglaciação, e está mais bem marcado em todo o registro isotópico.

Essas alterações climáticas coincidentes com os eventos Heinrich foram descritas através do registro da Toca da Boa Vista (TBV) por Wang et al. (2004), os quais atribuíram a condições de maior umidade em curto períodos de tempo, através da identificação de fases de crescimento de espeleotemas e travertinos da porção centro-norte da Bahia, precisamente datados por geocronologia U/Th. Essas fases de crescimento possuem duração de algumas centenas a poucos milhares de anos e estão separados por períodos de longa aridez no norte da Bahia.

Em suma, tanto as fases de crescimento do norte da Bahia quanto valores anomalamente baixos de $\delta^{18} \mathrm{O}$ dos espeleotemas da Chapada Diamantina indicam a ocorrência de períodos de maior umidade no Estado. Esses períodos mais úmidos, por sua vez, são temporalmente coincidentes com os eventos $\mathrm{H} 6, \mathrm{H} 5, \mathrm{H} 4$ e $\mathrm{H} 1$ e refletem mudanças na distribuição da umidade nos trópicos em decorrência de eventos frios no Hemisfério Norte (Fig. 5.5; Fig.5.6; Fig. 5.8) Essa comparação entre registros exclui os eventos H5, H3 e H2 da discussão, pois o evento H5 ocorrido por volta de 48 ky (H5), encontra-se ausente no registro da $\mathrm{CD}$, enquanto os eventos $\mathrm{H} 3$ e $\mathrm{H} 2$ estão ausentes no registro da $\mathrm{TBV}$, devido à falta de estalagmites depositadas nesse período.

A correlação de períodos secos e úmidos com os eventos B-A e YD, respectivamente, foram pioneiramente sugeridas por Wang et al. (2007b), através de registros de $\delta^{18} \mathrm{O}$ em espeleotemas da Gruta do Padre, localizada no oeste do Estado. Wang et al. (2007b; 2009) atribuíram o aumento (diminuição) abrupta dos valores de $\delta^{18} \mathrm{O}$, à diminuição (aumento) da paleopluviosidade nos intervalos de 14.6-12.8 e 12.7-11.6 ky, como resposta aos eventos BA e YD no Hemisfério Norte, respectivamente. As interpretações dos dados isotópicos realizadas por estes autores são as mesmas adotadas no presente trabalho, as quais são bastante coerentes com os registros da Chapada Diamantina. Assim, por meio desses registros mais contínuos do período deglacial, foi possível obter mais clareza na identificação de eventos paleoclimáticas de natureza abrupta em escala milenar ocorridos na Bahia, em relação ao registro previamente apresentado por Wang et al. (2004). 


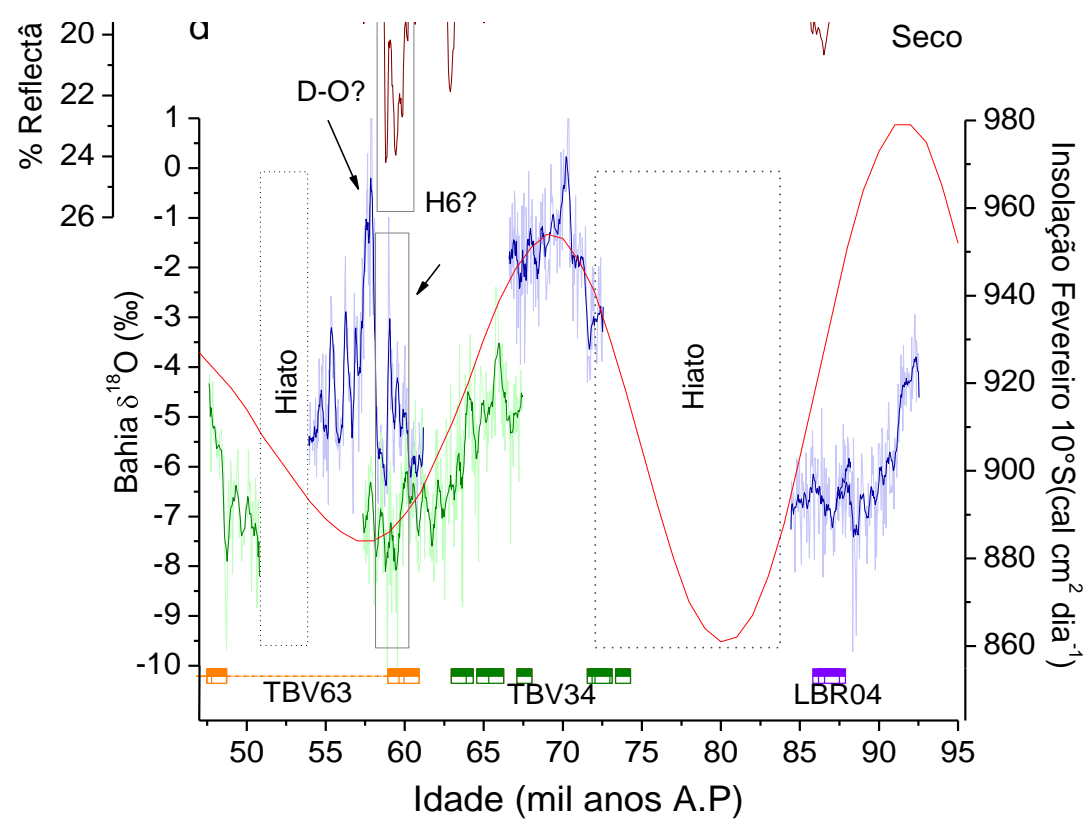

Figura 5.5 - Comparação entre registros paleoclimáticos de $\delta^{18} \mathrm{O}$ de espeleotemas da China (Wang et al. 2001; 2008) (a) ; de Botuverá-SC (Bt2, Cruz et al. 2005) e Iporanga-SP (St8, Cruz et al. 2006) (b); de refletância em sedimentos da Bacia do Cariaco, Venezuela (Peterson et al. 2000) (c); Registros de $\delta^{18} \mathrm{O}$ dos espeleotemas das cavernas Ioio (verde) e Paixão (azul) - BA (d). Os pontos localizados abaixo dos registros isotópicos da Bahia correspondem às datações realizadas nos espeleotemas Toca da Boa Vista (TBV) e Lapa dos Brejões (LBR) (Wang et al. 2004). 
Variações da paleopluviosidade puderam ser reconstituídas mais recentemente através de registros isotópicos de espeleotemas potiguares dos últimos 26 mil anos A.P. (Cruz et al. 2009a). Oscilações abruptas para valores mais baixos de $\delta^{18} \mathrm{O}$ dos espeleotemas do Rio Grande do Norte, cujas amplitudes isotópicas chegaram alcançar cerca de 4 \% num intervalo temporal inferior a $2 \mathrm{ky}$, indicam aumento brusco da paleopluviosidade, coincidentes com os eventos H2 e H1. Esses eventos são aproximadamente sincrônicos com as anomalias positivas da precipitação, interpretadas através dos registros da Chapada Diamantina nos intervalos de 25.3-24 e 17.9-15.8 ky (Fig. 5.7; Fig. 5.8). Devido a boa correlação entre dados de $\delta^{18} \mathrm{O}$ de espeleotemas observados do Nordeste ao Sul do Brasil é possível demonstrar o caráter continental que esses eventos imprimem sobre a pluviosidade tanto em regiões influências pelo MSA, quanto pela ZCIT.

A exceção se faz à variação de pluviosidade durante o evento YD, 12.7-11.6 ky no Rio Grande do Norte. Nesses intervalos as oscilações de $\delta^{18} \mathrm{O}$ dos espeleotemas potiguares não demonstraram variações climáticas abruptas (Cruz et al. 2009a), assim como verificado através dos registros em testemunhos marinhos da costa nordestina (Arz et al. 1998; Jennerjahn et al. 2004; Jaeschke et al. 2007). Por outro lado, condições mais áridas durante o evento B-A foram evidenciadas através de hiatos deposicionais sistemáticos observados em vários espeleotemas potiguares (Cruz et al. 2009a), o que é também bastante coerente com os altos valores de $\delta^{18} \mathrm{O}$ observados em estalagmites da Gruta do Padre (Wang et al. 2007b; 2009) e agora da Chapada Diamantina.

Também nessa mesma direção, os registros da lagoa Caçó, no norte do Nordeste brasileiro, apontaram aumento abrupto da umidade concomitante com evento Heinrich 1 . $\mathrm{O}$ qual é inferido através do aumento da sedimentação orgânica por volta de $~ 17.0 \mathrm{ky}$ (Sifeddine et al. 2003) e dos valores mais negativos de $\delta \mathrm{D}$ de moléculas em resíduos de plantas aquáticas e terrestres, entre 17.3-16.8 ky (Jacob et al. 2007). A partir dos mesmos registros foram inferidas condições mais secas durante o evento YD em relação ao H1, por volta de $\sim 12 \mathrm{ky}$, o que está em consonância com os registros potiguares. Ocorreu ainda uma provável expansão da floresta pluvial na mesma região, interpretada através da ampla ocorrência de espécies de plantas indicativas de clima úmido, como Podocarpus e Myrtaceae entre 17 e 12.8 ky. (Ledru et al. 2001 e Ledru et al. 2006). Contudo, é importante notar que discrepâncias entre as interpretações de Ledru et al. (2006) e os registros supracitados ocorrem principalmente entre 15-13.5 ky e são coincidentes com os eventos B-A. 
Uma das questões mais relevantes a ser aqui discutida é a ocorrência sincrônica do aumento da paleoprecipitação tanto no Sul/Sudeste brasileiro (Cruz et al. 2006b; Wang et al. 2007a; 2007b) como no norte do Nordeste do país, durante os intervalos de tempo coincidentes com os eventos Heinrich, o que permite estabelecer um padrão em fase da pluviosidade em meso-escala na porção a sul do continente. Essas anomalias positivas de precipitação estão bem marcadas principalmente no período deglacial em outros registros do continente sul-americano, a exemplo e da região dos Altiplanos boliviano e peruano (Baker et al. 2001a; Baker et al. 2001b).

As causas das variações climáticas durante os eventos de escala milenar têm sido geralmente atribuídas a fortes mudanças ocorridas na circulação oceânica do Atlântico (Clark et al. 1999; Broecker, 2000, Clark et al. 2002; Cortijo et al. 2005), as quais são responsáveis por estabelecimento de um padrão de variação antifásica da temperatura da superfície no oceano Atlântico, a sul e a norte da linha do equador (Barker et al. 2009). Nesse caso, considera-se que mudanças no padrão de circulação através de um processo de interação oceano-atmosfera teriam impactado o clima, em escala global (Broecker, 2000).

Mudanças das condições oceânicas durante os eventos de escala milenar, principalmente os do tipo Heinrich, puderam ser bem evidenciadas através de registros marinhos da costa norte do Nordeste brasileiro. Através deles, foram descritas significativas variações de parâmetros oceanográficos, tais como a TSM, a salinidade e paleoprodutividade, discutidas principalmente por meio de registros isotópicos e geoquímicos em foraminíferos planctônicos. Um dos estudos pioneiros nessa linha de pesquisa foram realizados por Arz et al. (1998), com base no variação de $\delta^{18} \mathrm{O}$ dos foraminíferos planctônicos das espécies Globigerinoides sacculifer e Globigerinoides ruber (pink) da costa cearense $\left(\sim 5^{\circ} \mathrm{S}\right)$, que envolveu os últimos 85 mil anos. O mesmo descreve grandes diferenças na superfície hidrográfica da água (envolvendo as condições de TSM e salinidade) durante o período glacial e o Holoceno, no entanto isso não é tão evidente durante os eventos na escala milenar.

Mudanças na circulação oceânica ao longo da costa nordestina, durante o período deglacial, foram investigadas através das razões de valores de $\delta^{18} \mathrm{O}$ e razões geoquímica de $\mathrm{Mg} / \mathrm{Ca}$ (Arz et al. 1999; Weldeab et al. 2006). Esses estudos apontaram aumento abrupto de temperatura e salinidade das camadas oceânicas superiores em consequência dos eventos $\mathrm{H} 1 \mathrm{e}$ YD $\left(\sim 0,5^{\circ} \mathrm{C}\right.$ de acordo com Weldeab et al. 2006). Tais variações paleoceonográficas ocorridas em curtas escalas temporais são tidas como resposta às largas mudanças da 
circulação oceânicas processadas durante o resfriamento do Atlântico Norte, fenômeno característico dos eventos Heinrich.

As análises em alquenonas nos mesmos testemunhos da costa cearense, indicam o inverso para os eventos Heinrich ocorridos durante período glacial, ou seja, a TSM do oceano Atlântico tropical teria passado por abruptos e rápidos resfriamentos, na ordem de $\sim 1{ }^{\circ}-2^{\circ} \mathrm{C}$, nos intervalos coincidentes aos eventos H6-H2 (Jaeschke et al. 2007). No entanto análise das alquenonas não indicou variações significativas de TSM durante H1 e YD.

Variações abruptas de temperatura oceânica também foram observadas no Atlântico Sul, na costa sul brasileira por Chiessi et al. (2008) durante os eventos milenares ocorridos durante o período deglacial, o que torna consistente a observação de largas mudanças sincrônicas dos parâmetros oceanográficos em toda a costa brasileira. Nesse estudo, registros em alta resolução de temperatura e da composição isotópica oceânica $\left(\delta^{18} \mathrm{O}\right)$, obtidos por meio de análises em foraminíferos bentônicos (Uvigerina bifurcata) e planctônicos (Globorotalia inflata), indicaram variações abruptas de temperatura de $\sim 6.5$ e $3.5^{\circ} \mathrm{C}$ na termoclina e na camada de águas de profundidade intermediária, na transição entre os eventos H1 e B-A, respectivamente.

Registros da intensidade de Ti e Fe (\%) (Arz et al. 1998) e das razões de Ti/Ca (Jennerjahn et al. 2004; Jaeschke et al. 2007) e Fe/Ca (Jennerjahn et al. 2004) nos sedimentos marinhos da costa nordestina, foram utilizados para recompor os pulsos de sedimentação de material de origem terrígena continental depositado no oceano durante o último glacial e a deglaciação. Nesses registros foram observados que os maiores picos de sedimentação ocorreram durante os eventos Heinrich, que são assim considerados períodos de aumento abrupto de precipitação, devido às maiores taxas de erosão e de transporte de material terrígeno para a plataforma continental (Arz et al. 1998; Jennerjahn et al. 2004; Jaeschke et al. 2007). Essas condições hidrológicas são confirmadas através de valores de $\delta^{13} \mathrm{C}_{\text {org }}$ e $\delta^{15} \mathrm{~N}$ nos testemunhos marinhos nordestinos, os quais serviram como indicadores da contribuição de matéria orgânica terrestre no processo de sedimentação marinha e, por conseguinte, como indicadores das condições erosivas continentais (Jennerjahn et al. 2004) e das razões C/N (Dupont et al. 2009).

No gráfico das Figuras 5.7 e 5.9, as correlações diretas entre as razões de Ti/Ca (Arz et al. 1998) com os registros da Chapada Diamantina, sugerem boa consistência temporal principalmente com ocorrência dos eventos $\mathrm{H} 2, \mathrm{H} 1$ e YD, sendo este último mais discreto nos registros marinhos. Já os eventos H3 e H4 foram mais bem mais marcados nos indicadores 
oceânicos em relação aos valores de $\delta^{18} \mathrm{O}$ dos espeleotemas (Fig. 5.6). Por outro lado, a ocorrência deles como anomalias de pluviosidade nos trópicos são bem evidentes através da correlação entre altas taxas de crescimento e baixos valores de $\delta^{13} \mathrm{C}$ das estalagmites baianas. De todo modo, essas intercomparações permitiram inferir que variações sincrônicas de paleopluviosidade de norte a sul do Nordeste brasileiro são coincidentes aos eventos Heinrich, o que dá suporte ao padrão de precipitação estabelecido na escala intra-regional inferido por meio dos registros isotópicos em espeleotemas da Bahia e do Rio Grande do Norte.

Por fim, condições mais úmidas durante os eventos $\mathrm{H}$ também foram discutidas com base no aumento de fluxos polínicos de vegetações do Nordeste para o mar, no período glacial e deglacial (Behling et al. 2000; Jennerjahn et al. 2004; Dupont et al. 2009). O aporte de material polínico no mar acontece principalmente por transporte fluvial, o que permite realizar interpretações tanto acerca das condições de umidade continental, como também de mudanças vegetacionais ocorridas no continente. A partir desses indicadores observaram-se que altas concentrações de pólens e de esporos de pteridófitas (Selaginella) associadas às elevadas razões de $\mathrm{Fe} / \mathrm{Ca}$ e Ti/Ca, indicaram expansão de vegetação típica de clima mais úmido em relação a atualidade durante os intervalos coincidentes aos eventos Heinrich 5, 4, 3 e 2 (Behling et al. 2000; Jennerjahn et al. 2004) e no H1 (Jennerjahn et al. 2004; Dupont et al. 2009).

A hipótese de variações antifásicas de pluviosidade entre as regiões tropicais a sul e norte do Equador durante eventos abruptos em escala milenar, associadas às fortes alterações da circulação oceânica é suportada pela comparação entre registros paleoclimáticos do Brasil com os registros de sedimentos marinhos da Bacia do Cariaco, Venezuela $\left(10^{\circ} \mathrm{N}\right)$ (Peterson et al. 2000; Haug et al. 2001; Lea et al. 2003). Nesse contexto, Lea et al. (2003) através das razões de $\mathrm{Mg} / \mathrm{Ca}$ em foraminíferos planctônicos da espécie G. ruber (white) obtidos a partir de sedimentos marinhos venezuelanos, inferiram condições de paleotemperatura da superfície oceânica durante os últimos 25 mil anos A.P. Contudo, diferentemente ao que foi observado na costa do Nordeste brasileiro, as condições da TSM portaram-se de forma inversa durante os intervalos coincidentes aos eventos milenares. No período deglacial, Lea et al. (2003) estimaram valores da TSM mais baixos durante os eventos $\mathrm{H} 1\left(23.4-24.7^{\circ} \pm 0.5^{\circ} \mathrm{C}\right)$ e YD $\left(23.4-24.3^{\circ} \pm 0.4^{\circ} \mathrm{C}\right)$ em relação ao presente, sendo que em média, a TSM foi similar à observada durante o UMG. 


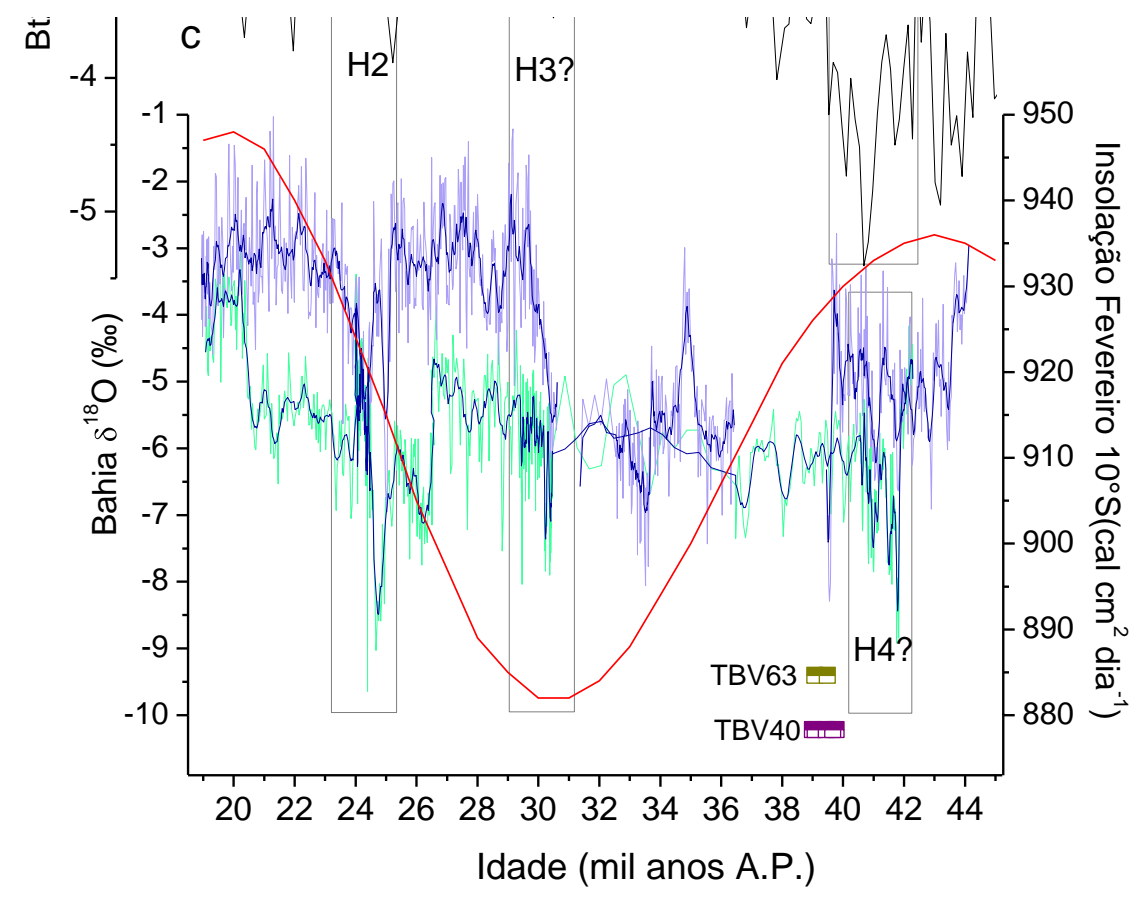

Figura 5.6 - Comparação entre as razões isotópicas de $\delta^{18} \mathrm{O}$ dos espeleotemas da China (Wang et al. 2001; 2008) (a), da estalagmite Bt2 - SC (Cruz et al. 2005a; 2006) (b) e dos espeleotemas das cavernas Paixão (azul) e Ioio (verde) (c). Os pontos localizados abaixo dos registros isotópicos da Bahia correspondem às datações realizadas em espeleotemas Toca da Boa Vista (TBV) e Lapa dos Brejões (LBR) (Wang et al. 2004). 


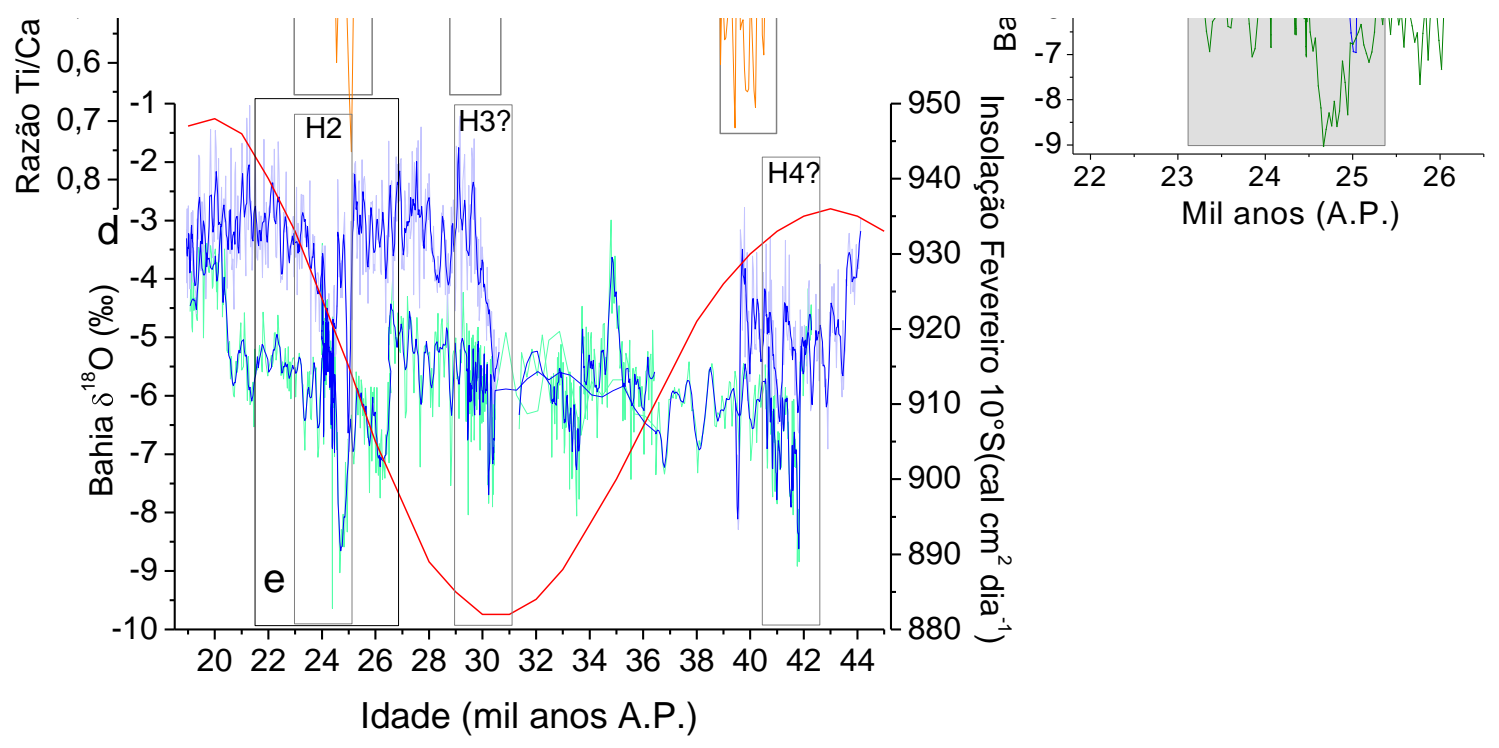

Figura 5.7 - Comparação entre os registros paleoclimáticos: de refletância e concentração de Ti e em sedimentos da Bacia do Cariaco, Venezuela (Haug et al. 2001; Peterson et al. 2000) (a,b); razões de Ti/Ca do testemunho marinho GeoB 3910-2 da costa nordestina (Arz et al. 2007) (c); valores de $\delta^{18} \mathrm{O}$ das estalagmites da caverna Paixão e Ioio - BA e do Rio Grande do Norte (d,e). 
Ainda na Bacia do Cariaco, foi possível inferir as condições de umidade e hidrológicas nos intervalos coincidentes aos eventos de escala milenar, observados através de registros de refletância (Peterson et al. 2000) e da geoquímica elementar (Peterson et al. 2000; Haug et al. 2001). Dados de refletância dos sedimentos da Bacia do Cariaco (Peterson et al. 2000) foram aplicados como indicadores do aumento (diminuição) da composição orgânica marinha, associados a fases de diminuição (aumento) da precipitação, identificadas por sua vez, através das tonalidades mais claras ou mais reflectantes (escuras) dos sedimentos. Já as concentrações de Ti e Fe, em Cariaco (Peterson et al. 2000; Haug et al. 2001), permitiu inferir que o maior incremento de material terrígeno ("mais escuro"), está associado a aumentos da precipitação continental e da descarga fluvial para a bacia e vice-versa.

Do mesmo modo ao que foi observado através da relação entre as TSM's da costa venezuelana e nordestina do Brasil, verificou-se relação inversa nas variações interhemisféricas de paleopluviosidade na América do Sul, obtidas por meio das intercomparações entre registros marinhos e continentais dessas duas regiões. No entanto, devem ser consideradas nessa intercomparação algumas pequenas discrepâncias na cronologia entre os registros de $\delta^{18} \mathrm{O}$ da Chapada Diamantina e Rio Grande do Norte e de Ti/Ca da costa nordestina, que são no geral inferiores a 1000 anos.

A relação antifásica entre as duas regiões durante os eventos Heinrich é definida por altos valores de refletância e baixa concentração de Ti nos sedimentos da Bacia do Cariaco, os quais indicam que condições de menor umidade ocorreram na Venezuela. Em contraste, condições mais úmidas no Nordeste brasileiro, indicadas através dos baixos valores de $\delta^{18} \mathrm{O}$ dos registros Chapada Diamantina e do Rio Grande do Norte e as altas razões de Ti/Ca dos sedimentos da costa cearense (Fig. 5.5; Fig. 5.7; Fig. 5.9). Já durante os eventos quentes do Atlântico tropical norte caracterizados por TSM mais elevada, a exemplo do B-A, bem marcado nos espeleotemas da Chapada por valores mais altos de $\delta^{18} \mathrm{O}$ no intervalo de $\sim 15-13$ ky (Fig. 5.9), a relação climática é invertida. Isso significa que anomalias positivas de chuva estão localizadas no lado venezuelano, visto altas concentrações de Ti medidas nos sedimentos de Cariaco. No entanto, os demais períodos quentes de TSM a norte do equador não estão claramente correlacionados com eventos climáticos no nordeste ou mesmo em outras áreas do Brasil (Cruz et al. 2009b). Portanto, os eventos frios do Hemisfério Norte, tipo Heinrich, tem um impacto mais regular e intenso sobre o clima passado do Brasil do que os eventos quentes, tipo D-O. 


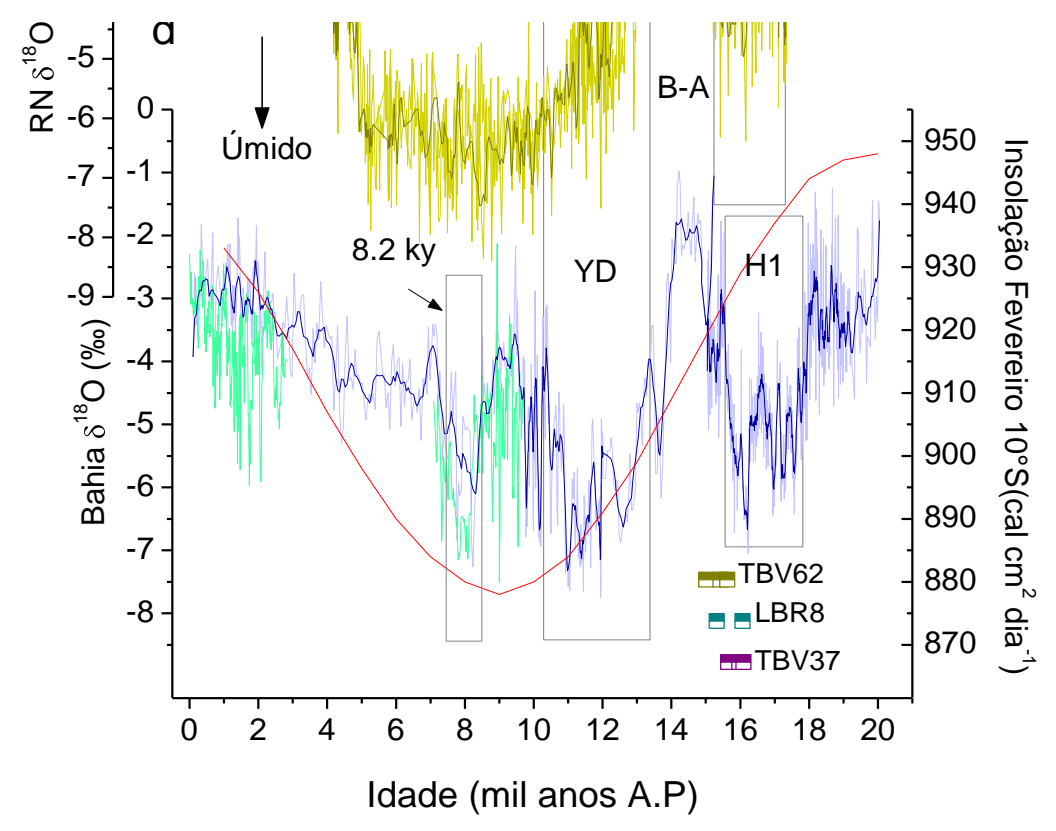

Figura 5.8 - Comparação entre os registros de $\delta^{18} \mathrm{O}$ de espeleotemas da China (Wang et al. 2001, 2008) (a) e de Botuverá - SC (Cruz et al. 2005a) (b); $\delta^{18} \mathrm{O}$ das estalagmites das cavernas do Rio Grande do Norte e Paixão (azul) e Diva de Maura (verde) - BA (c,d). Os pontos localizados abaixo dos registros isotópicos da Bahia correspondem às datações realizadas nos espeleotemas Toca da Boa Vista (TBV) e Lapa dos Brejões (LBR) (Wang et al. 2004). 


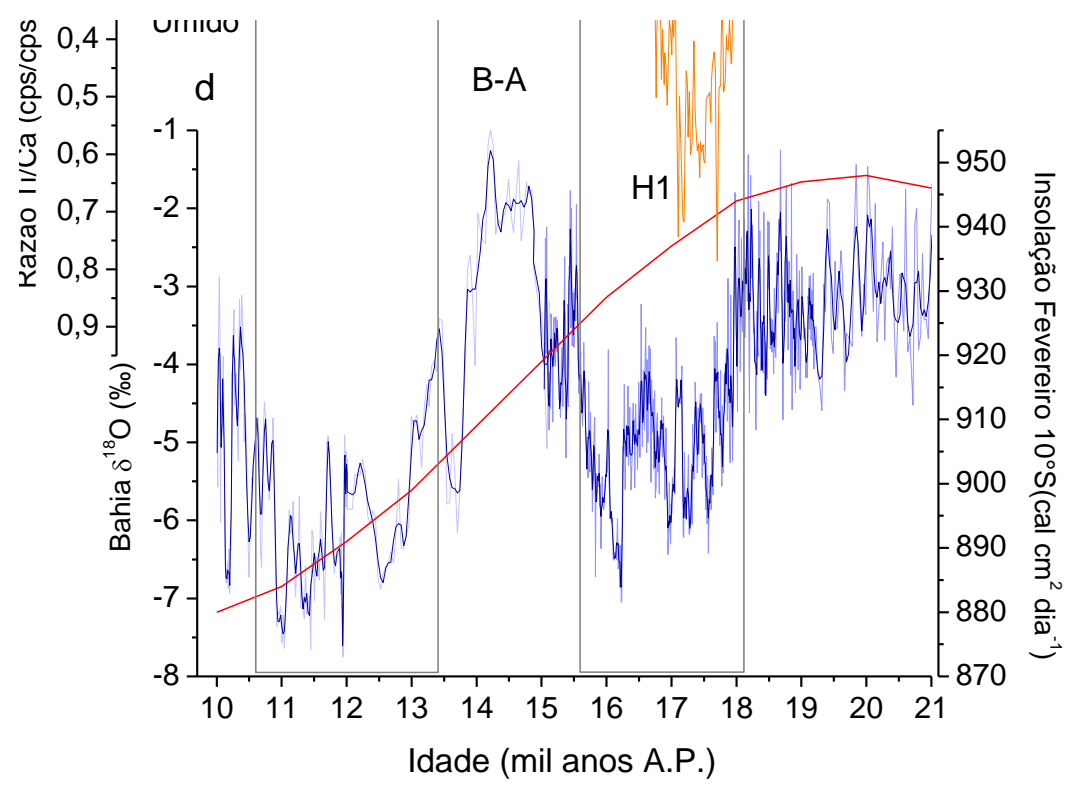

Figura 5.9 - Comparação entre os registros da concentração de Ti e refletância em sedimentos da Bacia do 
Cariaco, Venezuela (Haug et al. 2001; Peterson et al. 2000) (a,b); razões de Ti/Ca do testemunho marinho GeoB 3910-2 da costa nordestina (Arz et al. 1998) (c); valores de $\delta^{18} \mathrm{O}$ das estalagmites da caverna Paixão - BA (d).

Em resumo, fortes variações da paleopluviosidade em escala milenar ocorreram de modo sincrônico e antifásico entre o Nordeste brasileiro e a Venezuela durante os eventos Heinrich e YD, que por sua vez, foi bem corroborado com variações ocorridas nos parâmetros oceânicos das duas áreas. Essa relação permite considerar que as variações da umidade teriam resultado de uma ampla interação entre o oceano e a atmosfera. Sugere-se que mudanças climáticas como essas registradas no Nordeste brasileiro, estejam conectadas às fortes variações da circulação oceânica ocorridas no Atlântico Norte, principal forçante das mudanças climáticas ocorridas em escala milenar, como vêm sendo largamente postulado na literatura científica nas últimas décadas.

As ocorrências dessas transições bruscas no clima foram inicialmente evidenciadas através da concentração de sedimentos líticos típicos de transporte por icebergs, designados de IRD (Sigla do termo Ice-rafted debris) e de assembléias de foraminíferos planctônicos em testemunhos marinhos do Atlântico Norte (Heinrich, 1988; Bond et al. 1992; De Abreu et al. 2004). Tais variações também puderam ser bem estabelecidas através de valores de $\delta^{18} \mathrm{O}$ no testemunho de gelo GRIP Summit (Dansgaard et al. 1993) e mais recentemente nos registros do NGRIP (Andersen et al. 2004), ambos da Groelândia, que servem como bons indicadores da paleotemperatura e da composição química atmosférica do passado.

Bond et al. (1992) formulou a hipótese de que as seis camadas de IRD, originalmente identificadas por Heinrich (1988) no intervalo de 70-14 ky, são evidências da diminuição da TSM e salinidade no Atlântico Norte, em decorrência de elevadas descargas de água doce do derretimento de icebergs. Esses icebergs, provavelmente, teriam sido provenientes das capas de gelo de Laurentide, no Canadá, e da Fenoscândia/Groelândia (Cortijo et al. 2000; Hemming, 2004).

A ampliação das capas de gelo sobre o Atlântico Norte proporcionou maior transporte de sedimentos desde fontes distais até latitudes tão baixas chegando a alcançar a península Ibérica $\left(\sim 40^{\circ} \mathrm{N}\right)$ (Lebreiro et al. 1997; Thouveny et al. 2000), onde há registros da existência de IRD. Nessa região os registros de IRD são vastos e estão associados com a presença de foraminíferos planctônicos polares (Neogloboquadrina pachyderma)(De Abreu et al. 2004).

Mesmo com as incertezas na origem desses eventos frios (Broecker, 2006), sabe-se que este fenômeno teria propiciado mudanças na circulação oceânica e, por conseguinte, da transferência de calor em escala inter-hemisférica que ocorre entre os dois oceanos Atlântico, a sul e norte do equador. Essas descargas de água doce reduziriam a circulação termohalina 
(THC) no oceano Atlântico, o que implica na diminuição das condições de transporte de calor dos trópicos para os pólos, proporcionando condições mais frias e aumento da cobertura de gelo no Atlântico Norte.

De modo geral e simplificado, a circulação oceânica no Atlântico corresponde a uma forma de forçante termal dominada pela circulação de água superficial pouco salina proveniente do Atlântico Sul. Essa circulação dirige-se para norte e através de um processo de profundo arrefecimento que ocorre na região do mar Nórdico e Labrador, no Atlântico Norte, engatilha o processo de formação da corrente termohalina (THC) denominada North Atlantic Deep Water (NADW) (Clark et al. 2002). Por outro lado, a NADW depois de formada dirigese para o Hemisfério Sul em grandes profundidades (entre 3000-2000m), e que juntamente com a circulação gerada pela corrente superficial e quente supracitada, constitui o sistema de circulação em larga escala do Atlântico denominada de Atlantic Meridional Overturning Circulation (AMOC). Alterações desse sistema de circulação são especificamente relacionadas às variações de TSM durante os eventos Heinrich (Broecker, 2000; Clark et al. 2002; Alley et al. 2003; Rahmstorf, 2002) sendo consideradas as principais responsáveis pela redistribuição de umidade nos próximos ocorridos em escala milenar.

De acordo com Clark et al. (2002), o processo de formação da corrente NADW durante os eventos Heinrich teria estado sob condições de profunda redução ou até mesmo de completa estagnação, o que ele denominou de "modo de circulação Heinrich", associado ao largo processo de degelo dos icebergs. O colapso da circulação oceânica NADW, por sua vez, teria desencadeado forte resfriamento e expansão de gelo no Atlântico Norte e causado em contra partida aquecimento relativo no Hemisfério Sul (Clark et al. 1999), pois as águas frias de altas latitudes do Hemisfério Norte não chegaram a cruzar com muita intensidade a linha do Equador. Isso produziu um efeito inter-hemisférico tipo dipolo nas variações da TSM entre o Atlântico Norte e Sul, melhor conhecido como seesaw ("efeito balança"), como designado por Stocker (1998).

Esses eventos frios do Hemisfério Norte teriam afetado o clima no Hemisfério Sul, através da interação oceano-atmosfera por meio de mudanças nas células atmosféricas meridionais ou de Hadley. Tais mudanças induzem reposicionamento da Zona de Convergência Intertropical (ZCIT) para posições mais ao sul, associado a um gradiente de TSM das águas superficiais tropicais (Jaeschke et al. 2007). Na climatologia moderna, a diferença entre a temperatura da superfície do lado sul e norte do Atlântico tropical, denominado de dipolo do Atlântico, conduzem a fenômenos anômalos de precipitação em 
escala decadal no Nordeste brasileiro (Moura e Shukla, 1981), e estão relacionados diretamente ao posicionamento da ZCIT.

De acordo com Chang et al. (1997), através da ocorrência anômala do gradiente de TSM equatorial é gerada uma circulação atmosférica de escala local, termicamente forçada, que por sua vez, conduz a anomalias de direção e intensidade dos ventos. Intensificação anômala de ventos de NE ocorre quando o Atlântico Norte encontra-se menos aquecido em relação ao Atlântico Sul, e conduzem em contra partida a "intensificação" dos ventos de NE, deslocando a zona de convergência dos alísios (ZCA) e condicionando, do mesmo modo, a posição da ZCIT mais para sul. Estas condições proporcionam anomalias positivas de precipitação nos trópicos do Hemisfério Sul. Em contrapartida, quando os ventos de SE encontram-se intensificados devido a condições mais frias no Atlântico Sul em relação ao Norte, ocorre o oposto, ou seja, o deslocamento para norte da ZCA e da ZCIT, o que proporciona anomalias positivas de precipitação no Nordeste brasileiro.

Dessa forma, a relação entre o posicionamento da ZCIT em relação ao equador e o aumento da pluviosidade do Nordeste em tempos modernos tem sido largamente considerada na literatura e por isso utilizada como guia para interpretações paleoclimáticas através dos registros marinhos e continentais do Nordeste e de outras áreas da América do Sul. Vale lembrar que vários trabalhos de paleoclimatologia consideram que a redução da AMOC, durante os eventos Heinrich, teria induzido posicionamento mais a sul da ZCIT (Hessler et al. 2009), que resultam em condições mais secas na Venezuela (Peterson et al. 2000; Haug et al., 2001. Lea et al. 2004) e mais úmidas da costa norte nordestina (Jaeschke et al. 2007; Jennerjahn et al. 2004) e no norte da região (Cruz et al. 2009). Assim como no presente, esse posicionamento mais para sul da ZCIT teria, por sua vez, sido condicionada pela intensificação dos alísios de NE, o que implicaria, por conseguinte, no aumento da precipitação tanto na costa (Arz et al. 1998) quanto no interior do Nordeste (Wang et al. 2004).

O aumento da pluviosidade no sertão baiano durante os eventos Heinrich é também observado através dos registros da Chapada Diamantina. Desse modo, o padrão anti-fásico de pluviosidade inter-hemisférica nos trópicos, proposto por Wang et al. (2004), é aqui confirmado.

Contudo, os registros de espeleotemas da Chapada Diamantina e da gruta do Padre (Wang et al. 2007b), indicam intensificação também das chuvas associadas à precipitação proveniente das atividades da Monções Sul-Americana (MSA) e das ZCAS, sistema que afeta 
mais diretamente a pluviosidade das porções centro-oeste da Bahia. Esses resultados mostram que a MSA esteve intensificada desde o Nordeste até a região Sul do Brasil (Cruz et al. 2006; 2009b) e os Andes Centrais (Baker et al. 2001b, Baker et al. 2001a), regiões fortemente afetadas pelas chuvas monçônicas.

Oscilações abruptas para valores mais baixos de $\delta^{18} \mathrm{O}$, com amplitudes isotópicas que variaram de 1.5 até $2.8 \%$, também estiveram bem marcados nos registros da Bt2 de Botuverá-SC (Cruz et al. 2006b), as quais foram interpretadas como variações climáticas abruptas para condições de maior umidade durante o verão. Esses registros foram bem correlacionados com os valores de $\delta^{18} \mathrm{O}$ dos espeleotemas da Bahia principalmente durante os eventos H6, H1 e YD (Fig. 5.5 e 5.8), muito embora, tenha-se observado neste primeiro evento pequenas discrepâncias temporais entre os dois registros. Já os eventos H3 e H4 foram mais bem observados através dos registros de Bt2 (Fig. 5.6), mas ainda são identificados no registro da Chapada Diamantina, a partir de pequenas variações dos valores de $\delta^{18} \mathrm{O}$ dos espeleotemas. No entanto, o impacto desses eventos na pluviosidade do Nordeste é, contudo, reforçado pelas altas taxas de crescimento e os baixos valores de $\delta^{13} \mathrm{C}$ observadas durante os eventos H (Fig. 4.7).

Anomalias positivas na pluviosidade nas regiões Sul/Sudeste durante os eventos Heinrich, de acordo com Cruz et al. (2006b) e Wang et al. (2006), teriam ocorrido através de mecanismos climáticos semelhantes ao observado no Último Máximo Glacial (UMG). Segundo esses autores, o aumento do volume de gelo e a diminuição das temperaturas no Hemisfério Norte, teriam favorecido o aumento das chuvas de verão, devido à influência da posição da ZCIT na atividade da ZCAS, proporcionando assim condições na maior parte do Brasil. Tais mecanismos climáticos, do mesmo modo, justificariam a ocorrência sincrônica do aumento da paleoprecipitação tanto entre o Nordeste, Sul/Sudeste brasileiro como em outras áreas afetadas pelo sistema monçônico como o Peru durante o YD (Van Breukelen et al. 2008) e a Bolívia (Baker et al. 2001a; 2001b). O efeito dos eventos Heinrich sobre a pluviosidade dos Andes centrais é amplamente discutido por Fritz et al. (2010), através dos registros lacustres de Titicaca e de Salar Uyuni, durante os últimos 25 e 50 mil anos A.P.

Baker et al. (2001a), a partir dos registros do lago Titicaca, interpretaram que períodos de mudanças no fluxo de deposição e de aumento do nível lacustre, teriam estado associados à episódios de aumento da paleoprecipitação coincidentes aos eventos H e YD nos intervalos de 26-15 e 13-11.5 ky, como também ao intervalo de diminuição de chuvas durante o deglacial correspondente ao evento B-A. Já a partir dos registros dos testemunhos do Salar Uyuni, 
Baker et al. (2001b) interpretaram a ocorrência respectivamente de períodos úmidos (H2, H1,YD) e secos (B-A), a partir da abundância de diatomáceas de águas mais doces e da deposição de halita $(\mathrm{NaCl})$ e gipsita $\left(\mathrm{CaSO}_{4} \cdot 2 \mathrm{H}_{2} \mathrm{O}\right)$, respectivamente. Esses trabalhos, um dos primeiros a associar eventos abruptos de aumento de umidade com as condições da TSM no Atlântico Norte equatorial, sugerem que tais condições teriam modulado as condições de umidade na bacia Amazônica, favorecendo ocorrência das chuvas de verão nos Andes.

Relações entre variações da paleopluviosidade e atividades monçônicas também foram interpretadas por Wang et al. $(2001 ; 2008)$ através de valores de $\delta^{18} \mathrm{O}$ em espeleotemas da China, que do mesmo modo indicaram a ocorrência de variações abruptas da precipitação conectadas aos intervalos coincidentes aos ciclos milenares (Fig. 5.5; Fig. 5.6; Fig.5.8). Contudo, no caso do Hemisfério Norte, existe uma boa correlação entre eventos secos na China com os períodos frios (estadiais) registrados nos dados isotópicos de testemunhos de gelo da Groelândia, os quais ocorrem num processo conjunto com os eventos Heinrich no Atlântico Norte (Bond et al. 2003). Esses períodos secos na China foram associados a mudanças nas atividades monçônicas que atuam no leste asiático, também conhecidos como Chinese intervals (Wang et al. 2008).

Correlações diretas entre os registros da Chapada Diamantina e os valores de $\delta^{18} \mathrm{O}$ dos espeleotemas chineses (Wang et al. 2001; 2008) são consistentes com as variações de pluviosidade ocorridas de modo sincrônico em escala inter-hemisférica, mas as mesmas possuem relação anti-fásica com as variações de pluviosidade no Brasil e Andes como por exemplo durante os eventos milenares H1, B-A e YD (Fig. 5.5; Fig. 5.6; Fig. 5.8). Na China, estes eventos $\mathrm{H}$ são bem marcados por variações abruptas dos valores de $\delta^{18} \mathrm{O}$ dos espeleotemas, cujas amplitudes isotópicas variaram de 4 a $2.5 \%$, e são coincidentes com os intervalos do eventos H4 a YD (Fig. 5.5 e Fig. 5.6), com exceção do H6 que não foi apresentado de forma clara. Contudo, a comparação entre registros de espeleotemas mostrou também ligeiras discordâncias temporais, o que pode estar associado principalmente ao detalhamento geocronológico de cada um deles.

Por tudo acima exposto, fica evidente que o registro da Chapada Diamantina constituise em um importante marco para reconstituição paleoclimática da região Nordeste, por se tratar de um registro relativamente bem datado e muito mais completo do que os outros registros de espeleotemas da região, anteriormente publicados. A partir dele fica evidente a atuação dominante da forçante oceânica no estabelecimento da relação em fase entre as variações da paleoprecipitação em escala milenar ocorridas entre o Nordeste brasileiro e o 
continente sul-americano e anti-fásica na escala inter-hemisférica na faixa (sub)subtropical, assim como proposto por Wang et al. 2004. Por outro lado, isso não pode ser corroborado para ciclos mais longos que os milenares, pelo menos da forma como descrita por Wang e coautores.

Os registros de $\delta^{18} \mathrm{O}$ de espeleotemas da Chapada estão em fase com registros de espeleotemas da China, entre outros do Hemisfério Norte, o que descarta uma associação direta com mudanças de pluviosidade devido ao deslocamento meridional da ZCIT segundo ciclo orbital. Portanto, é mais provável que as variação de pluviosidade segundo o ciclo orbital estejam relacionadas com alterações na circulação oeste-leste ou de Walker, por sua vez diretamente influenciadas pela atividade das MSA no centro do continente (Cruz et al. 2009a). 


\section{CONSIDERAÇÕES FINAIS}

Os registros paleoclimáticos obtidos na Chapada Diamantina, Bahia, permitiram ampliar o conhecimento sobre a paleopluviosidade do Nordeste brasileiro durante os últimos 93 mil anos A.P., tanto em escalas mais longas de tempo, segundo o ciclo de insolação, quanto devido ao impacto de eventos abruptos tipicamente registrados no Hemisfério Norte, em escala de tempo milenar. Essas variações temporais dos registros isotópicos de oxigênio e carbono estão precisamente delimitadas nos espeleotemas estudados por um grande número de datações obtidas pelo método U/Th. O bom controle geocronológico obtido permite compor interpretações paleoclimáticas robustas acerca das variações da precipitação ocorridas no último período glacial e Holoceno.

Observou-se, por meio dos valores de $\delta^{18} \mathrm{O}$ das estalagmites, em parte da última glaciação e durante todo período deglacial e Holoceno, que as condições de paleopluviosidade na porção central da Bahia estiveram condicionadas primariamente às fases de alta (baixa) insolação de verão. Mudanças graduais na insolação de verão conduzem à diminuição (aumento) da paleoprecipitação na região, com exceção do período entre 40 e 20 ky A.P., quando houve predomínio de condições mais secas. Essas variações de paleoprecipitação ocorreram de modo fásico e sincrônico com o registro de espeleotemas do Rio Grande do Norte e permite, portanto, concluir que a insolação exerce um forte controle sobre as mudanças de pluviosidade, de maneira semelhante em toda a região Nordeste.

Esse resultado não poderia ser explicado simplesmente pela variação meridional na posição média da Zona de Convergência Intertropical, como apontado em estudos anteriores com espeleotemas do norte da Bahia. Primeiro porque as variações de pluviosidade indicadas pelos registros de espeleotemas da Chapada Diamantina estão em fase com registros clássicos da paleoclimatologia dos trópicos do Hemisfério Norte, da China e Venezuela. Segundo porque, a comparação entre registros paleoclimáticos indica que o padrão climático estabelecido no Nordeste, a partir dos registros isotópicos de espeleotemas, apresenta uma relação anti-fásica com as variações de pluviosidade do Sul/Sudeste brasileiro e a região (sub) tropical andina.

Propõe-se que esse cenário paleoclimático esteve associado principalmente à ação do sistema de Monção Sul-Americana (MSA) sobre a circulação atmosférica zonal em escala orbital, que afeta o clima do Nordeste durante o verão. O fortalecimento da MSA durante as fases de alta (baixa) insolação na América do Sul está associado a intensificação da circulação atmosférica zonal, do tipo Walker, que influencia substancialmente a circulação atmosférica 
em baixos e altos níveis, e resulta na formação do cavado do Nordeste em altos níveis, próximo a faixa equatorial. Essas alterações da circulação oeste-leste, induzidas pelo aumento das chuvas na região de origem da MSA na Bacia Amazônica, produz ao mesmo tempo déficits na pluviosidade no Nordeste e excedentes no Sul/Sudeste e Andes Centrais. O mesmo processo de alteração da circulação atmosférica/clima pode ser utilizado também para explicar as o predomínio das condições secas ocorridas no Nordeste brasileiro entre 40 e 20 ky A.P. Esta hipótese leva em conta com o posicionamento médio da zona de convergência intertropical mais para sul e uma forte intensificação das chuvas de verão na região de atuação do sistema de monções da América do Sul, todavia não pelo controle da insolação, mas sim pela expansão de gelo nos mares e continentes para latitudes mais baixos, ocorridos em parte dos estágios isotópicos marinho 3 e 2 .

Os eventos úmidos em escala milenar foram observados através de oscilações abruptas das razões isotópicas, caracterizadas por valores mais baixos de $\delta^{18} \mathrm{O}$ e $\delta^{13} \mathrm{C}$, os quais mantêm uma relação com altas taxas de crescimento nos registros dos espeleotemas. Intercomparações entre os registros da Chapada Diamantina, do Norte do Nordeste, do Sul/Sudeste brasileiro e dos altiplanos boliviano e peruano, demonstraram que durante os intervalos coincidentes aos eventos Heinrich, anomalias positivas de precipitação teriam ocorrido de modo sincrônico entre todas estas regiões, caracterizando assim um padrão de precipitação em fase, mais claramente observado durante o período deglacial. Já as comparações entre os valores de $\delta^{18} \mathrm{O}$ dos registros da Chapada Diamantina com os registros paleoclimáticos da Venezuela e da China, indicaram que o padrão inter-hemisférico de paleoprecipitação teria ocorrido de modo antifásico entre as distintas regiões.

Variações abruptas da paleoprecipitação na América do Sul (sub)tropical temporalmente coincidentes aos eventos Heinrich ocorridas, estão provavelmente associados principalmente a fortes mudanças ocorridas da North Atlantic Deep Water e, por conseguinte da Atlantic Meridional Overturning Circulation. Em um processo de interação oceanoatmosfera, estas condições teriam influído nos regimes de chuva tanto devido ao posicionamento latitudinal da ZCIT quanto pela alteração na atividade da MSA e da Zona de Convergência do Atlântico Sul. Nesse sentido, sugere-se que as anomalias positivas da paleoprecipitação ocorridas durante esses eventos milenares tanto no Nordeste brasileiro como na região subtropical da América do Sul, estiveram relacionadas às mudanças no padrão de circulação atmosférica meridional, associados a mudanças no gradiente de temperatura da superfície do mar no oceano Atlântico tropical. 


\section{REFERÊNCIAS BIBLIOGRÁFICAS}

ABREU, L.; SHACKLETON, N.J.; SCHÖNFELD, J.; HALL, M.; CHAPMAN, M. Millennial-scale oceanic climate variability on the Western Iberian margin during the last two glacial periods. Marine Geology, v.196, p.1-20, 2003.

ALLEY, R.B.; MEESE, D.A.; SCHUMAN, C.A.; GOW, A.J.; TAYLOR, K.C.; GROOTES, P.M.; WHITE, J.W.; RAM, M.; WADDINGTON, E.D.; MAYEWSKI, P.A.; ZIELINSKI, G.A. Abrupt increase in Greenland snow accumulation at the end of the Younger Dryas event. Nature, v. 362, p. 527-529, 1993.

AMUNDSON, R., STERN, L.; BAISDEN, T.; WANG, Y. The composition of soil and soilrespired $\mathrm{CO}_{2}$. Geoderma, n. 82, p. 83-114, 1998.

ANDERSEN et al. High resolution record of Northern Hemisphere climate extending into the last interglacial period. Nature, v. 431, p. 147-151, 2004.

ARZ, H. W.; PÄTZOLD, J.; WEFER, G. Correlated millennial-scale changes in surface hydrography and terrigenous sediment yield inferred from last glacial marine deposits off northeastern Brazil. Quaternary Research, v. 50, p. 157-166, 1998.

ARZ, H.W.; PÄTZOLD, J.; WEFER, G. The deglacial history of the western tropical Atlantic as inferred from high resolution stable isotope records off northeastern Brazil. Earth and Planetary Science Letters, v.167 p. 105-117, 1999.

ARZ, H.W.; GERHARDT, S.; PÄTZOLD, J.; RÖHL, U. Millennial-scale changes of surface and deep-water flow in the western tropical Atlantic linked to Northern Hemisphere highlatitude climate during the Holocene. Geology, v. 29(3), p.239-242, 2001.

AULER, A. S. Karst Evolution and palaeoclimate in Eastern Brazil. Tese (Doutorado). University of Bristol, Bristol, 1999.

AULER, A.S.; SMART, P.L. Late Quaternary paleoclimate in semiarid Northeastern Brazil from U-series dating of travertine and water-table speleothems. Quaternary Research, v. 55, p. 159-167, 2001.

AULER, A.S.; WANG, X.; EDWARDS, R.L.; CHENG, H.; CRISTALLI, P.S.; SMART. P.L.; RICHARDS, D.A. Quaternary ecological and geomorphic changes associated with rainfall events in presently semi-arid northeastern Brazil. Journal of Quaternary Science, v.19, p. 693-701, 2004.

AULER, A.S.; PILÓ, L.B.; SMART, P.L.; WANG, X.; HOFFMANN, D.; RICHARDS, D.A.; R.L.; EDWARDS, NEVES, W.A.; CHENG, H. U-series dating and taphonomy of Quaternary vertebrates from Brazilian caves. Palaeogeography, Palaeoclimatology, Palaeoecology, v.19, p. 508-522, 2006.

AULER, A.S.; SMART, P.L.; WANG, X.; PILÓ, L.B.; EDWARDS,R.L.; CHENG,H. Cyclic sedimentation in Brazilian caves: Mechanisms and palaeoenvironmental significance. Geomorphology, v.106, p. 142-153, 2009. 
AMBRIZZI, T.; SOUZA, E.B.; PULWARTY, R.S. The Hadley and Walker regional circulations and associated ENSO impacts on South American seasonal rainfall. In: DIAZ H.F.; BRADLEY R.S. (Eds.). The Hadley circulation: present, past and future. Amsterdã: Kluwer Publishers, Capítulo 7, p. 203-235, 2004.

AYALON, A.; BAR-MATTHEWS, M.; SASS, E. Rainfall-recharge relationships within a karstic terrain in the Eastern Mediterranean semi-arid region, Israel: $\delta^{18} \mathrm{O}$ and $\delta \mathrm{D}$ characteristics. Journal of Hydrology, v. 207, p. 18-31, 1998.

BAKER, P.A.; RIGSBY, C.A.; SELTZER, G.O.; FRITZ, S.C.; LOWENSTEINK, T.K.; BACHER, N.P.; VELIZ, C. Tropical climate changes at millennial and orbital timescales on the Bolivian Altiplano. Nature, v. 409, p. 698-701, 2001a.

BAKER, P.A.; SELTZER, G.O.; FRITZ, S.C.; DUNBAR, R.B.; GROVE, M.J.; TAPIA, P.M.; CROSS, S.L.; ROWE, H.D.; BRODA, J.P. The history of South American tropical precipitation for the past 25,000 years. Science, v. 291, p. 640-643, $2001 \mathrm{~b}$.

BAKER, A.; ASRAT, A.; FAIRCHILD, I.J.; LENG, M.J.; WYNN, P.M.; BRYANT, C., GENTY, D. UMER, M. Analysis of the climate signal contained within $\delta^{18} \mathrm{O}$ and growth rate parameters in two Ethiopian stalagmites. Geochimica Cosmochimica Acta, v. 71, p. 29752988, 2007.

BARKER, S.; DIZ, P.; VAUTRAVERS, M.J.; PIKE, J.; KNORR, GREGOR.; HALL, I.R.; BROECKER, W.S. Interhemispheric Atlantic seesaw response during the last deglaciation. Nature, v. 457, p. 1097-1102, 2009.

BALDINI, J.U.L. ; MCDERMOTT, F.; BAKER, A.; BALDINI, Z.L.M.; MATTEY, D.P.; RAILSBACK, L.B. Biomass effects on stalagmite growth and isotope ratios: A 20th century analogue from Wiltshire, England. Earth and Planetary Science Letters, v. 240, p. 486-494, 2005.

BARBOSA, J. F.; DOMINGUEZ, J. M. L. (Eds.). Geologia da Bahia. Texto explicativo para o mapa geológico ao milionésimo. Salvador: UFBA, p. 295, 1995.

BAR-MATTHEWS, M.; AYALON, A. Late Quaternary paleoclimate in the Eastern Mediterranean Region from stable isotope analysis of speleothems at Soreq Cave, Israel. Quaternary Research, v. 47, p. 155-168, 1997.

BAR-MATTHEWS, M.; AYALON, A; KAUFMAN, A. Timing and hydrological conditions of Sapropel events in the Eastern Mediterranean, as evident from speleothems, Soreq Cave, Israel. Chemical Geology, v. 169, p. 145-156, 2000.

BEHLING, H.; ARZ, H.W.; PÄTZOLD, J.; WEFER, G. Late Quaternary vegetational and climate dynamics in northeastern Brazil, inferences from marine core GeoB 3104-1. Quaternary Science Reviews, v. 19, p. 981-994, 2000.

BERGER, A.; LOUTRE, M. F. Insolation values for the climate of the last 10 million years. Quaternary Science Reviews, v. 10, p. 297-317. 1991. 
BIASUTTI, M.; BATTISTI, D. S.; SARACHIK, E. S. Mechanisms controlling the annual cycle of precipitation in the Tropical Atlantic sector in an atmospheric GCM. Journal of climate, v. 17, p. 4708-4723, 2004.

BROECKER, W.S. Abrupt climate change: causal constraints provided by the paleoclimate record. Earth-Science Reviews, v. 51, p. 137-154, 2000.

BROECKER, W. B. Abrupt climate change revisited. Global and Planetary Change, v. 54, p. 211-215, 2006.

BOMBARDI, R.J.; CARVALHO, L.M.V. Variabilidade do regime de monções sobre o Brasil: o clima presente e projeções para um cenário com $2 \mathrm{xCO}_{2}$ usando o modelo MIROC. Revista Brasileira de Meteorologia, v.23, p. 58-72, 2008.

BOND, G.; HEINRICH, H.; BROECKER, W.; LABEYRIE, L.; MCMANUS, J.; ANDREWS, J.; HUON, S.; JANTSCHIK, R.; CLASEN, S.; SIMET, C.; TEDESCO, K.; KLAS, M.; BONANI, G.; IVY,S. Evidence for massive discharges of icebergs into the North Atlantic ocean during the last glacial period. Nature, v. 360, p. 245-249, 1992.

BOND, G.; BROECKER, W.; JEHNSEN, S.; MCMANUS, J.; LABEYRIE, L.; JOUZEL, J.; BONANI, G. Correlations between climate records from north Atlantic sediments and Greenland ice. Nature, v. 365, p. 143-147, 1993.

BOND, G.C.; LOTTI, R. Icebergs discharges into the North Atlantic on millennial time scale during the last glaciation. Science, v. 267, p. 1005-1010, 1995.

BURNS, S.J.; FLEITMANN, D.; MUDELSEE, M.; NEFF, U.; MATTER, A.; MANGINI, A. A 780-year annually resolved record of Indian Ocean monsoon precipitation from a speleothem from South Oman. Journal of Geophysical Research, v. 107, n. D20, p. 4434, 2002.

CABBALERO, E.; JIMENEZ, C.; REYES, E. A stable isotope study of cave seepage waters. Applied Geochemistry, v.11, p. 583-587, 1996.

CARVALHO, L.M.V.; JONES, C. Zona de Convergência do Atlântico Sul. In. CAVALCANTI, I.F.A. et al. (Eds). Tempo e Clima no Brasil. São Paulo: Oficina de textos, 2009, 464 p.

CERQUEIRA, E.O.; POPP, R.J.; KUBOTA, L.T. Utilização de filtro de transformada de fourier para a minimização de ruído em sinais analíticos. Química nova, v. 23, n. 5, p. 690$698,2000$.

CHANG, P.; JI, L.; LI, H. A decadal climate variation in the tropical Atlantic Ocean from thermodynamic air-sea interactions. Nature, v. 385, p. 516-518, 1997.

CHENG, H.; FLEITMANN, D.; EDWARDS, R.L.; WANG, X.; CRUZ, F.W.; AULER, A.S. AUGUSTO MANGINI, A.; WANG, Y.; KONG, X.; BURNS, S.J.; MATTER, A. Timing and structure of the $8.2 \mathrm{kyr}$ B.P. event inferred from $\delta^{18} \mathrm{O}$ records of stalagmites from China, Oman, and Brazil. Geology, v. 37, n. 11, p. 1007-1010, 2009. 
CHIANG, J.C.H.; BIASUTTI, M.; BATTISTI, D.S. Sensitivity of the Atlantic Intertropical Convergence Zone to the last glacial maximum boundary conditions. Paleoceanography, v. 18, p. 1094-1112, 2003.

CHIANG, J.C.; BITZ, C.M. Influence of high latitude ice cover on the marine Intertropical Convergence Zone. Climate Dynamics, v. 25, p. 477-496, 2005.

CHIANG, J.C.H.; KOUTAVAS, A. Tropical flip-flop connections. Nature, v. 432, p. 684$685,2004$.

CHIESSI, C. M.; MULITZA, S.; PAUL, A.; PÄTZOLD, J.; GROENEVELD, J.; WEFER, G. South Atlantic interocean exchange as the trigger for the Bolling warm event. Geology, v. 36, p. 919-922, 2008.

CLARK, I.; P. FRITZ. Environmental Isotopes in Hydrology. CRC Press, Boca Raton, 1997, $328 \mathrm{p}$.

CLARK, P.U.; ALLEY, R.B.; POLLARD, D. Northern Hemisphere ice-sheet influences on global climate change. Science, v. 286, p.1104-1111, 1999.

CLARK, P.U.; PISIAS, N. G.; STOCKER, T. F.; WEAVER, A. J. The role of the thermohaline circulation in abrupt climate change. Nature, v. 415, p. 863-869, 2002.

CLEMENT, A.C.; PETERSON, L.C. Mechanism of abrupt climate change of the last glacial period. Reviews of Geophysics, v.46, p. 1-39, 2008.

CORTIJO, E.; LABEYRIE, L.; ELLIOT, M.; BALBON, E.; TISNERAT, N. Rapid climatic variability of the North Atlantic Ocean and global climate: a focus of the IMAGES program. Quaternary Science Reviews, v. 19, p. 227-241, 2000.

CORTIJO, E.; DUPLESSY, J.C.; LABEYRIE, L.; DUPRAT, J.; PAILLARD, D. External geophysics, climate and environment (climate) Heinrich events: hydrological impact. Comptes Rendus Geoscience, v. 337, p. 897-907, 2005.

CRAIG, H. Isotopic variations in meteoric waters. Science, v. 133, p. 1703-1703, 1961.

CRISTALLI, P.S. Macrofitofósseis em tufos calcários quaternários do norte da Bahia como indicadores paleoclimáticos. Tese (Doutorado) - Instituto de Geociências, Universidade de São Paulo, São Paulo, 2006.

CRUZ Jr., F.W. Aspectos geomorfológicos e geoespeleologia do carste da região de Iraquara, Centro-norte da Chapada Diamantina, estado da Bahia. Dissertação (mestrado) - Instituto de Geociências, Universidade de São Paulo, 1998.

CRUZ Jr., F.W. Estudo paleoclimático e paleoambiental a partir de registros geoquímicos quaternários em espeleotemas das regiões de Iporanga (SP) e Botuverá (SC). Tese (Doutorado) - Instituto de Geociências, Universidade de São Paulo, São Paulo, 2003.

CRUZ Jr., F.W.; BURNS, S.J.; KARMANN, I.; SHARP, W.D.; VUILLE, M.; CARDOSO, A.O.; FERRARI, J.A.; SILVA DIAS, P.L.; VIANA Jr., O. Insolation-driven changes in 
atmospheric circulation over the past $116 \mathrm{ky}$ in subtropical Brazil. Nature, v. 434, p. 63-66, 2005a.

CRUZ Jr., F.W.; KARMANN, I.; VIANA Jr., O.; BURNS, S.J.; FERRARI, J.A.; VUILLE, M.; MOREIRA, M.Z.; SIAL, A.N. Stable isotope study of cave percolation waters in subtropical Brazil: implications for paleoclimate inferences from speleothems. Chemical Geology, v. 220, p. 245-262, 2005b.

CRUZ Jr., F.W.; BURNS, S.J.; KARMANN, I.; SHARP, W.D.; VUILLE, M.; FERRARI, J.A. A stalagmite record of changes in atmospheric circulation and soil processes in the Brazilian subtropics during the Late Pleistocene. Quaternary Science Reviews, v. 25, p. 27492761, 2006a.

CRUZ Jr., F.W.; BURNS, S.J.; KARMANN, I.; SHARP, W.D.; VUILLE, M. Reconstruction of regional atmospheric circulation features during the Late Pleistocene in subtropical Brazil from oxygen isotope composition of speleothems. Earth Planetary Science Letters, v. 248, p. 494-506, 2006b.

CRUZ Jr., F.W.; BARNS, S.; JERCINOVIC, M.; KARMANN, I.; SHARP, W.D.; VUILLE, $M$. Evidence of rainfall variations in southern Brazil from trace element ratios $(\mathrm{Mg} / \mathrm{Ca}$ and $\mathrm{Sr} / \mathrm{Ca}$ ) in a Late Pleistocene stalagmite. Geochimica et Cosmochimica Acta, n.71, p. 22502263, 2007.

CRUZ Jr., F.W.; VUILLE, M.; BURNS, S.J.; WANG, X.; CHENG, H.; WERNER, M.; EDWARDS, R.L.; KARMANN, I.; AULER, A.S.; NGUYEN, H. Orbitally driven east-west antiphasing of South American precipitation. Nature geosciences, v. 2, p. 1-5, 2009a.

CRUZ Jr., F.W. WANG, X.; AULER. A.; VUILLE. M.; BURNS.; S.J.; EDWARDS, L.R.; KARMANN, I.; CHENG, H. Orbital and millennial-scale precipitation changes in Brazil from speleothem records. In FRANCOISE, V. et al. (Eds.). Past Climate Variability in South America and Surrounding Regions. Paris: Springer, $2009 \mathrm{~b}$.

CUTLER, K.B.; EDWARDS, R.L.; TAYLOR, F.W.; CHENG, H.; ADKINS, J.; GALLUP, C.D.; CUTLER, P.M.; BURR, G.S.; BLOOM, A.L. Rapid sea-level fall and deep-ocean temperature change since the last interglacial period. Earth and Planetary Science Letters, v. 206, p. 253-271, 2003.

DANSGAARD, W.; JOHNSEN, S.J.; CLAUSEN, H.B.; JENSEN, D.D.; GUNDESTRUP, N.S; HAMMER, C.U.; HVIDBERG, C.S.; STEFFENSEN, J.P.; SVEINBÖRNSDOTTR, A.E.; JOUZEL, J.; BOND,G. Evidence for general instability of past climate from a 250-kyr ice-core record. Nature, v. 364, p. 218-220, 1993.

DE OLIVEIRA, P.E.; BARRETO, A.M.; SUGUIO, K. Late Pleistocene/Holocene climatic and vegetational history of the Brazilian caatinga: the fossil dunes of the middle São Francisco River. Palaeogeography, Palaeoclimatology, Palaeoecology, v. 152, p. 319-337, 1999.

DORALE, A.J; EDWARDS, R. L.; ITO, E; GONZALEZ, L.A. Climate and vegetation history of the midcontinent from 75 to $25 \mathrm{ka}$ : A speleothem record from Crevice Cave, Missouri, USA. Science, v. 282, p. 1871-1874, 1998. 
DUPONT, L.M.; SCHLÜTZ, F.; EWAH, C.T.; JENNERJAHN, T.C.; PAUL, A.; BEHLING, H. Two-step vegetation response to enhanced precipitation in Northeast Brazil during Heinrich event 1. Global Change Biology, v. 15, p. 1-14, 2009.

EDWARDS, R.L.; CHEN, J.H.; WASSERBURH, G.J. ${ }^{238} \mathrm{U}-{ }^{234} \mathrm{U}-{ }^{230} \mathrm{Th}-{ }^{232} \mathrm{Th}$ systemtics and the precise measurement of time over the past 500.000 years. Earth Planetary Science Letters, v. 81, p. 175-192, 1986.

FAIRCHILD, I.J.; SMITH, C.L.; BAKER, A.; FULLER, L.; SPÖTL, C.; MATTEY, D.; MCDERMOTT, F.; E.I.M.F. Modification and preservation of environmental signals in speleothems. Earth-Science Reviews, v. 75, p. 105-153, 2006.

FAIRCHILD, I.J.; TREBLE, P.C. Trace elements in speleothems as recorders of environmental change. Quaternary Science Reviews, v. 28 (5-6), p. 381-576, 2009.

FLEITMANN, D.; BURNS, S.J.; NEFD, U.; MUDELSEE, M.; MANGINI, A.; MATTER, A. Palaeoclimatic interpretation of high-resolution oxygen isotope profiles derived from annually laminated speleothems from Southern Oman. Quaternary Science Reviews, v. 23 (7-8), p. 935-945, 2004.

FRITZ, S.C.; BAKER, P.A.; LOWENSTEIN, T.K.; SELTZER, G.O.; RIGSBY, C.A.; DWYER, G.S.; TAPIA, P.M.; ARNOLD, K.K.; KU, T.L.; LUO, S. Hydrologic variation during the last 170,000 years in the southern hemisphere tropics of South America. Quaternary Research, v. 61, p. 95-104, 2004.

FRITZ, S.C.; BAKER, P.A.; SELTZER, G.O.; BALLANTYNE, A.; TAPIA, P.; CHENG, H.; EDWARDS, R.L. Quaternary glaciation and hydrologic variation in the South American tropics as reconstructed from the Lake Titicaca drilling project. Quaternary Research, v. 68, p. 410-420, 2007.

FRITZ, S.C.; BAKER, P.A.; EKDAHL E.; SELTZER, G.O.; STEVENS L.R. Millennialscale climate variability during the Last Glacial period in the tropical Andes. Quaternary Science Reviews, v. 29, p.1017-1024, 2010.

GASSE, F. Hydrological changes in the African tropics since the Last Glacial Maximum. Quaternary Science Reviews, v. 19 (1-5), p. 189-211, 2000.

GENTY, D.; BAKER, A.; VOKAL, B. Intra- and inter-annual growth rate of modern stalagmites. Chemical Geology, v. 176 (1-4), p. 191-212, 2001.

GENTY, D.; BLAMART, D.; GHALE, B.; PLAGNES, V.; CAUSSE, CH.; BAKALOWICZ, M.; ZOUARIF, K.; CHKIR, N.; HELLSTROM, J.; WAINER, K.; BOURGES, F. Timing and dynamics of the last deglaciation from European and North African $\delta^{13} \mathrm{C}$ stalagmite profiles comparison with Chinese and South Hemisphere stalagmites. Quaternary Science Reviews, v. 25 , p. 2118-2142, 2006.

GOUVEIA, S.E.M. Isótopos do carbono na avaliação do remonte biológico de Latossolos e Podzólicos e de eventos paleoclimáticos em distintas localidades do Brasil. Tese (Doutorado) - Centro de Energia Nuclear, Universidade de São Paulo, 2001. 
GUERRA, A.M. Processos de carstificação de hidrogeologia do grupo Bambuí na região de Irecê - Bahia. Tese (Doutorado) - Instituto de Geociências, Universidade de São Paulo, 1986.

HASTENRATH, S.; HELLER L. Dynamics of climatic hazards in northeast Brazil. Quarterly Journal of the Royal Meteorological Society, v. 103, p. 77-92, 1977.

HASTENRATH, S.; LAMB, P. J. Climate dynamics of atmosphere and ocean in the equatorial zone: A synthesis. International Journal of Climatology, v. 24 (13), p.1601-1612, 2004

HASTENRATH, S. Circulation and teleconnection mechanisms of Northeast Brazil droughts. Progress in Oceanography, v. 70, p.407-415, 2006.

HAUG, G.H.; HUGHEN, K.A.; SIGMAN, D.M.; PETERSON, L.C.; RÖHL, U. Southward migration of the intertropical convergence zone through the Holocene. Science, v. 293, p. 1304-1308, 2001.

HEINRICH, H. Origin and consequences of cyclic ice rafting in the Northeast Atlantic Ocean during the past 130,000 years. Quaternary Research, v. 29, p. 142-152, 1988.

HEMMING, S. R. Heinrich events: Massive late pleistocene detritus layers of the North Atlantic and their global climate imprint, Reviews of Geophysics, v. 42, RG1005, 2004.

HENDERSON, G.M. Caving un to new chronologies. Science, v. 313, p. 620-622, 2006.

HENDY, C.H., The isotopic geochemistry of speleothems-I. The calculation of the effects of different modes of formation on the isotopic composition of speleothems and their applicability as paleoclimatic indicators. Geochimica et Cosmochimica Acta, v. 35, p. 801824, 1971.

HESSLER, I.; DUPONT, L.; BONNEFILLE, R.; BEHLING, H.; GONZÁLEZ, C.; HELMENS, K.F.; HOOGHIEMSTRA, H.; LEBAMBA, J.; LEDRU, M.P.; LÉZINE, A.M.; MALEY, J.; MARRET, F.; VINCENS, A. Millennial-scale changes in vegetation records from tropical Africa and South America during the last glacial. Quaternary Science Reviews, v. 29 p. 1-18, 2009.

INDA, H.A.V.; BARBOSA, J.F. Texto Explicativo para o Mapa Geológico do Estado da Bahia. Escala 1.1.000.000. Salvador: SME/CPM, p. 122, 1978.

JACOB， J.; HUANG， H.; DISNAR， J.R.; SIFEDDINE， A.; BOUSSAFIR, M.; ALBUQUERQUE, A.L.; TURCQ, B. Paleohydrological changes during the last deglaciation in Northern Brazil. Quaternary Science Reviews, v. 26, p. 1004-1015. 2007.

JAESCHKE, A.; RÜHLEMANN, C.; ARZ, H.; HEIL, G.; LOHMANN, G. Coupling of millennial-scale changes in sea surface temperature and precipitation off northeastern Brazil with high-latitude climate shifts during the last glacial period. Paleoceanography. v. 22, PA4206, 2007. 
JENNERJAHN, T.C.; VENUGOPALAN I.; ARZ, H.W.; BEHLING, H.; PATZOLD, J.; WEFER, G. Asynchronous terrestrial and marine signals of climate change during Heinrich Events. Science, v. 306, p. 2236-2239, 2004.

KARMANN, I.; SÁNCHEZ, L.E. Distribuição das rochas carbonáticas e províncias espeleológicas do Brasil. Espeleo-Tema, v. 13, p. 105-167, 1979

KING L.C. A geomorfologia do Brasil Oriental. Revista Brasileira de Geografia, v. 18, p. 147-265, 1956.

KOYANO, M.T.; ANDREOLI, R.V. Clima da Região Nordeste do Brasil. In. CAVALCANTI, I.F.A. et al. (Eds). Tempo e Clima no Brasil. São Paulo: Oficina de textos, 2009, 464 p.

KOUSKY, V.E. Frontal influences on Northeast Brazil. Monthly Weather Review, v. 107, p. 1140-1153, 1979.

LACHNIET, M. S.; BURNS, S.J.; PIPERNO, D.R.; ASMEROM ,Y.; POLYAK, V.J.; MOY, C.; CHRISTENSON, K. A. A 1500 year El Niño-Southern Oscillation and rainfall history for the Isthmus of Panama from speleothem calcite. Journal of Geophysical Research, v. 109, n. D20117, 2004.

LACHNIET, M.L. Climatic and environmental controls on speleothem oxygen-isotope values. Quaternary Science Reviews, v. 28, p. 412-432, 2009.

LAUREANO, F. V. O registro sedimentar clástico associado aos sistemas de cavernas Lapa Doce e Torrinha, município de Iraquara, Chapada Diamantina (BA). Dissertação (mestrado) Instituto de Geociência, Universidade de São Paulo, São Paulo, 1998.

LAUREANO, F.; CRUZ Jr, F.W. Grutas de Iraquara (Iraquara, Seabra e Palmeiras), BA: Um dos principais sítios espeleológicos do Brasil, SIGEP 18. In: SCHOBBENHAUS, C. et al. (Org.). Sítios geológicos e paleontológicos do Brasil. $1^{\text {a }}$ edição. Brasília: DNPM, v. 1, p. 461468, 2003.

LEA, D.W.; PAK, D.K. PETERSON, L.C.; HUGHEN, K.A. Synchroneity of tropical and high-latitude Atlantic temperatures over the Last Glacial Termination. Science, v. 301, n 5638, p. 1361-1364, 2003.

LEBREIRO, S.M.; MORENO, J.C.; MCCAVE, I.N.; WEAVER, P.P.E.; Evidence for Heinrich layers off Portugal (Tore Seamount: $39^{\circ} \mathrm{N}, 12^{\circ} \mathrm{W}$ ). Marine Geology, v. 131, p. 47-56, 1996.

LEDRU, M.P, CORDEIRO, R.; CAMPELLO, D.; DOMINGEZ, J.M..; MARTIN, L.; MOURGUIART, P.; SIFEDDINE, A.; TURCQ B. Late-Glacial Cooling in Amazonia Inferred from Pollen at Lagoa do Caçó, Northern Brazil. Quaternary Research, v. 55, p. 47$56,2001$.

LEDRU, M.P.; ROUSSEAU, D.D.; CRUZ JR., F.W.; RICCOMINI, C.; KARMANN, I.; MARTIN, L. Paleoclimate changes during the last 100,000 yr from a record in the Brazilian 
Atlantic rainforest region and interhemispheric comparison. Quaternary Research, v. 64, p. 444-450, 2005.

LEDRU, M.P.; CECCANTINI, G.; GOUVEIA, S.E.M.; LÓPEZ-SÁEZ, J.A.; PESSENDA, L. C.R.; RIBEIRO, A.S. Millenial-scale climatic and vegetation changes in a northern Cerrado (Northeast, Brazil) since the Last Glacial Maximum. Quaternary Science Reviews, v. 25, p. 1110-1126, 2006.

LEE, J.E.; JOHNSON, K.; FUNG, I. Precipitation over South America during the Last Glacial Maximum: An analysis of the "amount effect"' with a water isotope-enabled general circulation model. Geophysical research letters, v. 36, p. 1-5, 2009.

LENTERS, J. D.; COOK, K. H. On the origin of the Bolivian High and related circulation features of the South American climate. Journal of the Atmosphere Science. v. 54, p. 656-677, 1997.

IMBRIE, J.; IMBRIE, J.Z. Modeling the climatic response to orbital variations. Sience, v. 29, p. 943-953, 1980.

McDERMOTT, F. Palaeo-climate reconstruction from stable isotope variations in speleothems: a review. Quaternary Science Reviews, v. 23, p. 901-918, 2004.

McDERMOTT, F.; SCHWARCZ, H.; ROWE, P. J. Isotopes in speleothems. In: LENG, M.J (Ed). Isotopes in palaeoenvironmental research, p. 185-225, 2005.

MECHOSO, C.R.; ROBERTSON, A. W.; ROPELEWSKI, C. F.; GRIMM, A. M. The American Monsoon Systems: an introduction. In: CHANG, B. et al. (Eds.). The Global Monsoon System: Research and Forecast. WMO/TD, n. 1266 (TMRP Report n. 70), p. 197206, 2005.

MELO, A.B.C.; CAVALCANTI, I.F.A.; SOUZA, P.P. Zona de Convergência Intertropical do Atlântico. In. CAVALCANTI, I.F.A. et al. (Eds.). Tempo e Clima no Brasil. São Paulo: Oficina de textos, 2009, $464 \mathrm{p}$.

MISI, A.; SILVA, M. Chapada Diamantina Oriental, Bahia. Geologia e recursos minerais. Superintendência de Geologia e Recursos minerais/Universidade Federal da Bahia, p. 194, 1996.

MOLION, L.C. B.; BERNARDO, S.O. Dinâmica das chuvas no Nordeste brasileiro. In Congresso Brasileiro de Meteorologia, 11, Fortaleza: SBM, p. 561-572, 2000.

MOURA, A.D.; SHUKLA, J.; On the dynamics of droughts in Northeast Brazil: observations, theory and numerical experiments with a general circulation model. American Meteorological Society, v. 38, p. 2653-2675, 1981.

MÜHLINGHAUS, C.; SCHOLZ, D.; MANGINI, A. Modelling fractionation of stable isotopes in stalagmites. Geochimica et Cosmochimica Acta, v. 73, p. 7275-7289, 2009.

NOBRE, P.; SHUKLA, J. Variations of sea surface temperature, wind stress, and rainfall over the tropical Atlantic and South America. Journal of Climate, v. 9, p. 2464-2479, 1996. 
PEDREIRA DA SILVA, A. J. O Supergrupo Espinhaço na Chapada Diamantina centrooriental, Bahia: sedimentologia, estratigrafia e tectônica. 1994. Tese (Doutorado) - Instituto de Geociências, Universidade de São Paulo, São Paulo, 1994.

PEREIRA, R.G.F. de A. Caracterização geomorfológica e geoespeleológica do carste da bacia do Rio Una, borda leste da Chapada Diamantina (Município de Itaetê, estado da Bahia). Dissertação (mestrado) - Instituto de Geociências, Universidade de São Paulo, São Paulo, 1998.

PESSENDA, L.C.R.; ADAUTO, S.R.; MARQUES, E.G.; ARAVENA, R.; BOULET, R.; BENDASOLLI, A. Vegetation dynamics during the late Pleistocene in the Barreirinhas region Maranhão State, Northeastern Brazil, based on carbon isotopes in soil organic matter. Quaternary Research, v. 62 (2), p. 183-193, 2004.

PESSENDA, L.C.R.; LEDRU, M.P.; GOUVEIA, S.E.M.; ARAVENA, R.; RIBEIRO, A.S.; BENDASSOLLI, J.A.; BOULET, R. Holocene palaeoenvironmental reconstruction in northeastern Brazil inferred from pollen, charcoal and carbon isotope records. The Holocene, v. 15(6), p. 812-820, 2005.

PESSENDA, L.C.R.; OLIVEIRA, P.E.; MOFATTO, M.; MEDEIROS, V.B.; GARCIA, R.J.F.; ARAVENA, R.; BENDASSOLI, J.A.; LEITE, A.Z.; SAAD, A.R.; ETCHEBEHERE, M.L. The evolution of a tropical rainforest/grassland mosaic in southeastern Brazil since $28,000{ }^{14} \mathrm{C}$ yr BP based on carbon isotopes and pollen records. Quaternary research, v. 71, n.3, p.437-452, 2009.

PETERSON, L.C.; HAUG, GERALD H.; HUGHEN, K.A.; RÖHL, U. Rapid changes in the hydrologic cycle of the Tropical Atlantic during the Last Glacial. Science, v. 290, n 5498, p. 1947-1951, 2000.

RAHMSTORF, S. Ocean circulation and climate during the past 120,000 years. Nature, v. 419, p. 207-214, 2002.

RAO, V.B.; HADA, K. Characteristics of rainfall over Brazil: Annual variations and connections with the Southern Oscillation. Theoretical and Applied Climatology, v. 42, p. 8191, 1990.

RAO, V.B.; LIMA, M.C.; FRANCHITO, S.H. Seasonal and interannual variations of rainfall over Eastern Northeast Brazil. Journal of Climate, v. 6, p. 1754-1763, 1993.

RAO, V.B.; CAVALCANTI, I. F. A.; HADA, K. Annual variation of rainfall over Brazil and water vapor characteristics over South America. Journal of geophysical research, v. 101, p. 26,539-26,551, 1996.

RICHARD, D.A.; DORALE, J.A., 2003. Uranium-series chronology and environmental applications of speleothem. In: BOURDON, B. et al. (Eds.), Uranium-series Geochemistry. Reviews in Mineralogy and Geochemistry, v. 52, p. 407-460, 2003.

RISE, C.; BONY, S.; VIMEUX, F. Influence of convective processes on the isotopic composition $\left(\delta^{18} \mathrm{O}\right.$ and $\left.\delta \mathrm{D}\right)$ of precipitation and water vapor in the tropics: 2. Physical interpretation of the amount effect. Journal of geophysical research, v.113, p. 1-12, 2008. 
RODWELL, M.J.; HOSKINS, B.J. Subtropical anticyclones and summer monsoons. Journal of Climate, v. 14, p. 3192-3211, 2001.

RUDDIMAN, W.F. Orbital changes and climate. Quaternary Science Reviews, v. 25 (23-24), p. 3092-3112, 2006.

RUDDIMAN, W.F. Earth's climate: past and future. $2^{\mathrm{a}}$ edição. Nova Iorque: W.H. Freeman. 2008, $465 \mathrm{p}$.

SELTZER, G.; RODBELL, D.; BURNS, S. Isotopic evidence for late Quaternary climatic change in tropical South America. Geology, v. 28, n. 1, p. 35-38, 2000.

SELTZER, G.O.; RODBELL, D.T.; BAKER, P.A.; FRITZ, S.C.; TAPIA, P.M.; ROWE, H.D.; DUNBAR, R.B. Early warming of tropical South America at the last glacial-interglacial transition, Science, v. 296, p.1685-1686, 2002.

SIFEDDINE, A.; ALBUQUERQUE, A.L.S.; LEDRU, M-P.L.; TURCQ, B.; KNOPPERS, B., MARTIN; L., MELLO, W.Z.; PASSENAU, H.; DOMINGUEZ, J.M.L.; CORDEIRO, R.C.; ABRÃO, J.J.; BITTENCOURT, A.C.S.P. A 21000 cal years paleoclimatic record from Caço Lake, Northern, Brazil: Evidence from sedimentary and pollen analyses. Palaeogeography, Palaeoclimatology, Palaeoecology, v. 189, p. 25-34, 2003.

SHACKLETON, N. Oxygen isotope analyses and Pleistocene temperatures re-assessed. Nature, v.215, p.15-17, 1967.

SOUZA, S.L.; BRITO, P.C.R.; SILVA, R.W.S. Estratigrafia, Sedimentologia e Recursos Minerais da Formação Salitre na Bacia de Irecê, Bahia. Integração e SÍNTESE por Augusto J. Pedreira. Salvador: CBPM, p. 34, 1993.

STOCKER, T.F. The seesaw effect. Science, v. 282, p. 61-62. 1998.

THOUVENY, N.; MORENO, E.; DELANGHE,D.; CANDON, L.; LANCELOT,Y.; SHACKLETON, N.Y. Rock magnetic detection of distal ice-rafted debries: clue for the identification of Heinrich layers on the Portuguese margin. Earth and Planetary Science Letters, v. 180, p. 61-75, 2000.

VAN BREUKELEN, M.R.; VONHOF, H.B.; HELLSTROM, J.C.; WESTER, W.C.G.; KROON, D. Fossil dripwater in stalagmites reveals Holocene temperature and rainfall variation in Amazonia. Earth Planet. Science Letters, v. 275, p. 54-60, 2008.

VERA, C.; HIGGINS, W.; AMADOR, J.; AMBRIZZI, T.; GARREAUD, R.; GOCHIS, D.; GUTZLER, D.; LETTENMAIER, D.; MARENGO, J.; MECHOSO, C.R.; NOGUESPAEGLE, J.; SILVA DIAS, P.L.; ZHANG, C. Toward a unified view of the American Monsoon Systems. American Meteorological Society, v. 19, p. 4977-5000, 2006.

VUILLE, M.; BRADLEY, R.S.; WERNER, M.; HEALY, R.; KEIMIG, F., Modeling $\delta^{18} \mathrm{O}$ in precipitation over the tropical Americas: 1. Interannual variability and climatic controls. Journal of Geophysical Research, v.108, p. 4174, 2003 
VUILLE, M.; WERNER, M. Stable isotopes in precipitation recording South American summer monsoon and ENSO variability observations and model results. Climate Dynamic, v. 25, p. 401-413, 2005.

XIE, S.H.; CARTON, J.A. Tropical Atlantic variability: patterns, mechanisms, and impacts. Geophysical monograph, v. 147, p. 121-142, 2004.

ZHOU, J.; W. LAU, K.-M. Does a monsoon climate exist over South America?. Journal Climate, v. 11, p. 1020-1040, 1998.

WANG, Y. J.; CHENG, H.; EDWARDS, R. L.; AN, Z. S.; WU, J. Y.; SHEN, C.C.; DORALE, J. A. A high-resolution absolute-dated late Pleistocene monsoon record from Hulu Cave, China. Science, v. 294, p. 2345-2348, 2001.

WANG, X.; AULER, A.S.; EDWARDS, R.L.; CHENG, H.; CRISTALLI, P.S.; SMART, P.; RICHARDS, D.A.; SHEN, C. Wet periods in northeastern Brazil over the past 210 kyr linked to distant climate anomalies. Nature, v. 432, p. 740-743, 2004.

WANG, X.; AULER, A.S.; EDWARDS, R. L.; HAI, C.; ITO, E.; MANIKO, S.; Interhemispheric anti-phasing of rainfall during the last glacial period. Quaternary Science Reviews, v. 25, p. 3391-3403. 2006.

WANG, X.; AULER, A. S.; EDWARDS, R. L.; CHENG, H.; ITO, E.; WANG, Y. J.; KONG, X.G.; SOLHEID, M. Millennial-scale precipitation changes in southern Brazil over the past 90,000 years. Geophysics Research Letters, v. 241, p. 699-706, 2007a.

WANG, X.; EDWARDS, R. L.; AULER, A. S.; CHENG, H.; ITO, E. Millennial-scale interhemispheric asymmetry of low-latitude precipitation: Speleothem evidence and possible high-latitude forcing. Geophysical Monography Ser. p. 173, 279-293, 2007 b.

WANG, Y.; CHENG, H.; EDWARDS, R.L.; KONG, X.; SHAO, X.; CHEN, S.; WU, J.; JIANG, X.; WANG, X.; AN, Z. Millennial- and orbital-scale changes in the East Asian monsoon over the past 224,000 years. Nature, v. 452, p. 1090-1093, 2008.

WANG, X; EDWARDS, R.L.; AULER, A.; KONG, X.; CRUZ, F.W.; CHENG, H.; WANG, Y.; BROECKER, W.S. Termination I in Brazilian speleothems. Eos, Transactions AGU, v. 90(52), 2009.

WELDEAB, S.; SCHNEIDER, R.R.; KÖLLING, M. Deglacial sea surface temperature and salinity increase in the western tropical Atlantic in synchrony with high latitude climate instabilities. Earth and Planetary Science Letters, v. 241, p. 699-706, 2006.

WRIGHT, J.D., Global climate change in marine stable isotope records, In NOLLER, J.S. et al. (Eds.). Quaternary Geochronology: Applications in Quaternary Geology, p. 671-682, 1999. 
ANEXOS 
Anexo 1. Tabelas com composição de Th e U das estalagmites da Bahia obtidas a partir de ICP-MS.

\begin{tabular}{|c|c|c|c|c|c|c|c|c|c|c|c|}
\hline \multicolumn{12}{|c|}{$\begin{array}{l}\text { Uranium and thorium isotopic compositions and }{ }^{230} \mathrm{Th} \text { age } \text { for } \mathrm{NE} \text { Brazil samples by ICP-MS } \\
\text { (alagmite }\end{array}$} \\
\hline Sampiple & We tight & $16 \mathrm{Bg}_{\mathbf{U}} \pm 5$ & 222929 & $8^{26107,9} \pm 4,5$ & 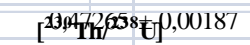 & {$\left[{ }^{230} \mathrm{Th}{ }^{5200} \mathrm{Th}\right]$} & $\pm 18,0$ & $\operatorname{Alge}^{051,8}$ & $\pm 66,0$ & Ade. 1540,8 & $8 \pm 66,2$ \\
\hline PXI-4 & 0,6169 & $11960 \pm 4$ & $76 p^{8} \pm 2$ & measured 27325 & $0,5,537]^{ \pm 0,00210}$ & 13141,3 & $\pm 48,3$ & uncorrected & $\pm 72,2$ & \multicolumn{2}{|c|}{$\frac{\text { Age }}{16.558,3} \pm 72,2$} \\
\hline 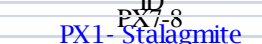 & 0,5590 & $2332 \pm 13$ & $258 \pm 2$ & $2495,3 \pm 10,4$ & $0,54193 \pm \pm 0,00329$ & pon & $\pm 500,6$ & $18.037,8$ & \pm 130.4 & \multicolumn{2}{|c|}{$\begin{array}{c}\text { corrected dite } \\
18.030,9 \pm 130,4\end{array}$} \\
\hline $\begin{array}{l}\text { PX1- Stalagmite } \\
\text { PXX1-1 }\end{array}$ & 0,5693 & $90,92 \pm \pm 0,2$ & $82 \pm \pm 1$ & $1558847 \pm 6 \pm 4,5,4$ & 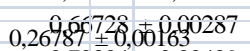 & 49050901 & $\pm 0000,7$ & $11.920 \pm \pm 292,2$ & $\pm 92, i$ & \multicolumn{2}{|c|}{$11.910 \stackrel{19.801,5 \pm 92,6}{1}$} \\
\hline$P x-10$ & $0,6060^{\circ}$ & $104,8 \pm \pm 0,31$ & 222019 & $11944,9 \pm 6,511,9$ & 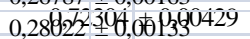 & $2184 \pm 108$ & $\pm 566,7$ & $14.744^{0} \pm 68,7$ & \pm 147.1 & \multirow{2}{*}{\multicolumn{2}{|c|}{$14.714-\frac{10}{95} \cdot 80,9 \pm 147,1$}} \\
\hline PPXI & (1),f5335 & $922,4 \pm \pm 7,4$ & 9983 童本 1 & $1317,2,23 \pm 1 \geq, 4,8$ & 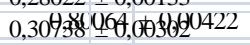 & 478369.7 & $\pm 341,2$ & $15.305^{2+99887}$ & \pm 149.4 & & \\
\hline PPX $1 \frac{15}{3}$ & 0,48441 & $1 \phi 1,94 \pm, 5,8$ & $395^{23} \pm 1$ & $1636,2 \pm \pm 41 \theta, 8,9$ & $0,39882866 \theta$,由 & $1852^{4+7029}$ & \pm 328 & 17.4772923023 & \pm 146 & \multirow{2}{*}{\multicolumn{2}{|c|}{$17.439 \pm 290329 \pm 146$}} \\
\hline 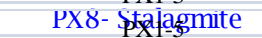 & 0,4416 & $86,9 \pm 0,2$ & $486 \pm 2$ & $1436,5 \pm 5,4$ & $0.53143 \pm 0,00360$ & $1565 \pm 12$ & & $26.169 \pm 206$ & & & \\
\hline $8 \times 8=6$ & Q),5554 & $67,8 \pm \oplus, 1$ & 104423 & $1302,3445,511,8$ & 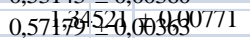 & $6 \mathrm{~d} \Phi 128,7$ & $\pm 182,9$ & $30.272^{4}+61444_{1}$ & \pm 917.9 & \multicolumn{2}{|c|}{$30.085^{34.289} .7 \pm 917,7$} \\
\hline$P X 8=8$ & 0,43048 & $86,99 \pm \oplus, 9$ & $28+29 \geq 2$ & $1525,364 \pm 4,64,1$ & $0,63 \div 8+954$, & 31807258 & $\pm 432,5$ & $30.80 \$ 3 \pm 2528$ & \pm 546.0 & $30.76538 .288,0$ & $0 \pm 545,9$ \\
\hline PX9- Stagmite & 0,5319 & $196,3 \pm 0,3$ & $155 \pm 1$ & $1706,6 \pm 3,4$ & $0,67960 \pm 0,00291$ & $14214 \pm 140$ & & $30.554 \pm 153$ & & \multicolumn{2}{|c|}{$30546+153$} \\
\hline PXQ=10 & 0,503312 & $89,6) \pm \oplus, Q$ & $4463 \pm 2 \geq 2$ & $1345184+65,3,8$ & $0,650288488,0 A 4080406$ & $2159837 \mathrm{~d}$ & $\pm 28,7$ & $34.2639 \pm 4283^{7}$ & \pm 196.5 & \multicolumn{2}{|c|}{$34.20739 .26 \Phi, 7 \pm 196,8$} \\
\hline PXQ-B & 0,30049 & $6297 \pm \pm, 3$ & $415742 \pm 1$ & $1222288+43 \pm \pm 91,5$ & $0,641906809,0 \oplus 000462$ & 18325896 & $\pm 2899,5$ & $35.9740 \pm \$ 8005$ & \pm 2164 & \multicolumn{2}{|c|}{$35.8894+1.849,9 \pm 216,4$} \\
\hline PX2-13latgmite & 0,7697 & $1293,5 \pm 3,3$ & $215 \pm 1$ & $2255,4 \pm 5,3$ & $1,07454 \pm 0,00432$ & 106671 & \pm 690 & 41.692 & \pm 211 & \multirow{2}{*}{\multicolumn{2}{|c|}{ 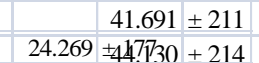 }} \\
\hline$P \times 2=-8$ & (0) 576886 & $1+8,1, j \pm 0,2,3$ & 1023441 & $1482283+0+4,64,2$ & $0,50 \uparrow 843950,0939,80446$ & 90339458635 & $5 \pm 10516$ & $24.279 \$ 41130$ & \pm 214 & & \\
\hline$B \times 3=-10 a$ & Q. $6690 \%$ & $18428+ \pm, 4$ & $324 \div \leq 1$ & $164219+0+4+3.7$ & $0,5698,16 \neq 998,092), 80408$ & 53348579.8 & \pm 496.8 & $25.8148 \div 34392$ & \pm 220.8 & \multicolumn{2}{|c|}{25.798 4.359. $9 \pm 220.7$} \\
\hline PX12-BX?támite & 0,4571 & $110,5 \pm 0,2$ & $943 \pm 3$ & $1285,5 \pm 4,7$ & $0,57266 \pm 0,00383$ & $1105 \pm 8$ & & $30.579 \pm 241$ & & $30.475 \pm 246$ & \\
\hline PX3 pxtadagmite & 0,6938 & $357 \pm 1$ & $110 \pm 1$ & $2345,6 \pm 5,5$ & $0,49,448 \pm 0,00262$ & 26449,2 & $\pm 281,7$ & $17.113,0$ & \pm 1011 & \multicolumn{2}{|c|}{$171104+101,1$} \\
\hline $\mathrm{P} P \mathrm{P}-\mathrm{3}-\mathrm{k}$ & 0,55608 & $213901+1,8$ & $66386 \frac{1}{5}$ & $99279 \div \geq 1245,5$ & $0,203.58_{1}+x_{1} Q, 00=3180238$ & 1078 南1, & $\pm 123,7$ & $11.64 \phi_{0}+2391$ & $\pm 83,2$ & \multicolumn{2}{|c|}{$11.603-1-24991 \pm 83,2$} \\
\hline 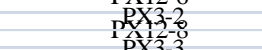 & 0.1420 & $355,8 \pm 0,7$ & $4133,5,132$ & $\begin{aligned} 12858 & +4,7 \\
026 & +7,7\end{aligned} 6,7$ & $0,119253=0,001610374$ & 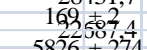 & $\pm 80,4$ & $\begin{aligned} 5.809,+56,4 \\
46843+863\end{aligned}$ & \pm 1309 & \multicolumn{2}{|c|}{$5.663,+109,5 \pm 130,8$} \\
\hline 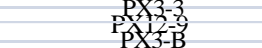 & $\begin{array}{l}0,2945 \\
3,106 \\
07062\end{array}$ & $\begin{array}{r}27,0 \pm 0,1 \\
663.51 \frac{1}{6}+14\end{array}$ & $\begin{aligned} 53 & \pm 2 \\
164 & \pm 1\end{aligned}$ & $\begin{array}{l}926,6 \pm 9,4 \\
692 \frac{1}{2} \pm 26,0\end{array}$ & 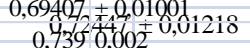 & $\begin{array}{r}5826+274 \\
491853301\end{array}$ & $\pm 122,2$ & $\begin{array}{l}46.843, \pm 863 \\
49.070212,0\end{array}$ & \pm 433.2 & \multicolumn{2}{|c|}{$\begin{array}{l}46.815, \pm 8.863 \\
49.066 .000312 \pm 433,2\end{array}$} \\
\hline 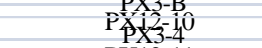 & $\begin{array}{l}0,3062 \\
0,3586\end{array}$ & $\begin{array}{r}663,6,6 \\
1765,7 \pm \pm \frac{1}{5}, 3\end{array}$ & $\begin{array}{l}164 \\
568 \pm \frac{1}{3}+1\end{array}$ & $8613 \pm 2,5$ & $\begin{array}{l}0,7390,002 \\
1,51949 \pm 000 \\
1,006080423\end{array}$ & $\begin{array}{l}49185336 \\
77720909 \\
7700\end{array}$ & $0 \pm 452,6$ & $\begin{array}{r}49.070 .212 \\
150.9840 .37519\end{array}$ & \pm 150.5 & \multirow{2}{*}{\multicolumn{2}{|c|}{$\begin{array}{r}49.066 \\
150.980 \pm 0.932155^{3} \pm 150,5 \\
24.705,0 \pm 119,6\end{array}$}} \\
\hline PX4 4 Statdimite & 0,4861 & $994 \pm 3$ & $608 \pm 2$ & $2764,8 \pm 5,4$ & $0,78327 \pm 0,00328$ & 18943,4 & $\pm 71,2$ & $24.710,0$ & \pm 119.6 & & \\
\hline PX13-pxalagmite & 0,4995 & $37 \pm 0$ & $96 \pm 1$ & $1568,0 \pm 12,2$ & $0,37073 \pm 0,00503$ & $2342,4 \pm 46,7$ & & $16.727,4 \pm 256$ & & $16.698,7 \pm 256,6$ & \\
\hline PXX13+b & (0),59429 & $45,8,3 \pm \oplus, 0,3$ & 10999 是 $\# 1$ & $1673365489 ; \pm 4,0$ & $0,408288636,0 \oplus 8760532$ & 280139879 & \pm 511 & $17.750 \$ 71583$ & \pm 521 & $17.725 \pm 878527$ & $7 \pm 521$ \\
\hline PX5-PSX hæasmite & 0,4678 & $2103,0 \pm 5,4$ & $321 \pm 2$ & $1430,2 \pm 3,9$ & $1,48677 \pm 0,00568$ & 160722 & \pm 1021 & 92.366 & \pm 554 & 92.364 & $4 \pm 554$ \\
\hline PX14PX6allagmite & 0,0882 & $2304,6 \pm 9,0$ & $4929 \pm 25$ & $1484,8 \pm 9,8$ & $0,00507 \pm 0,00013$ & $39 \pm 1$ & & $223 \pm 6$ & & $198 \pm 14$ & \\
\hline PX\$ $42 \mathrm{a}$ & (1), 60220 & $27011 \oplus \div \pm \pm, 0$ & $19160 \pm \nVdash 2$ & $141448+63,84,8$ & $0,018,94+400,00090447$ & 322848,7 & $\pm 14,2$ & $6284+622,0$ & \pm 324.7 & $61953.958,8$ & $8 \pm 325,9$ \\
\hline$P \times P_{4} 39$ & Q).89334 & $22441 \pm \pm 0$ & $521_{8 \oplus \notin 1}$ & $145648+\div 5.44 .5$ & $0,021,994 \neq 49,09(9), 80524$ & 1499267563 & $3 \pm 342,8$ & $940,36 \div 348.6$ & \pm 373.6 & $937,956.340,9$ & $9 \pm 373,6$ \\
\hline$p R \times 5-6$ & Q,23867 & $267 k_{0} \pm \pm 0$ & $3601<\frac{1}{4} \pm 1$ & $144336 \pm \pm 2.859$ & $0,02 \% 682 \pm 18,009160490$ & $325,0,7 \rightarrow 0.4$ & $\pm 25,1$ & $1.191,80,0789$ & \pm 4220 & $1.175,1,106999$ & $9 \pm 422,4$ \\
\hline $\begin{array}{l}\text { PXY } \\
\text { PXI } 4 \text { a }\end{array}$ & $\begin{array}{l}0,159 \\
0,12\end{array}$ & $\begin{array}{l}2753+7 \\
27,+0\end{array}$ & $916, \pm \frac{1}{6}+2$ & $14297 \pm 4,4,7$ & $0,03018+0,00014$ & $1497,5 \pm 114$ & $4 \pm 15,0$ & $1.363,4= \pm, 69$ & \pm 518.5 & $1.359,4+7.28$ & $6 \pm 519,1$ \\
\hline 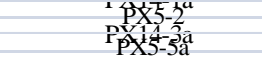 & $\begin{array}{l}0,2586 \\
0,0572 \\
0,0572\end{array}$ & $\begin{array}{l}2246, \pm 8 \\
26+4^{7} \pm \frac{1}{9}\end{array}$ & $\begin{array}{l}806 \pm+4 \\
568=0\end{array}$ & $\begin{array}{l}146,0 \pm 3,7, i \\
143,1 \pm 7,6,8\end{array}$ & 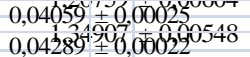 & 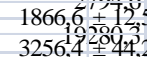 & $\begin{array}{l}5 \pm 15,6 \\
2 \pm 126,3\end{array}$ & $\begin{array}{l}1.806,2,1104 \\
1.940,7 \geq 91,5\end{array}$ & $\pm 506,2$ & $\begin{array}{l}1.802,0,0.1,606 \\
1.938,1 \pm .71,5^{6}\end{array}$ & $6 \pm 506,2$ \\
\hline$P \times 4=6 a$ & $0,0856^{4}$ & $2283_{ \pm} \dot{L}^{0} 00$ & 14849992 & $1436,44^{2} 65,97,1$ & 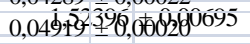 & $1247,4048,5$ & $\pm 22,2$ & $2.222,9^{9} \pm 990 ; 9$ & \pm 963.6 & 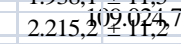 & $7 \pm 963,4$ \\
\hline PX16-px3liagmite & 0,1883 & $2043,2 \pm 5,0$ & $370 \pm 4$ & $1429,5 \pm 3,6$ & $0,05629 \pm 0,00030$ & $5130 \pm 60$ & & $2.554 \pm 14$ & & $2.552 \pm 14$ & \\
\hline$P \times 6=4$ & 0,26586 & $18884 \pm 1$ & $331099 \pm 2$ & $14836955_{1} 04, \theta 9,4$ & $0,104942469,0 \oplus 0630263$ & $984,853 \theta_{3}, 8$ & $\pm 113,8$ & $4.722,40 \pm 2609,8$ & \pm 108.2 & $4.702,120.35,35$ & $5 \pm 108,2$ \\
\hline$P X X 6-2$ & 0,253462 & $273601 \pm \# 11$ & $16756 \pm \pm 1$ & $1440534+24,88,0$ & $0,148,54964, \oplus \oplus 0,00258$ & 400164077 & $2 \pm 1294,6$ & $6.783,9 \mid \pm 395,9$ & \pm 1057 & $6.776,824.39,4,5$ & $5 \pm 105,7$ \\
\hline PXX6-6 & (10,28921 & $23091(\bar{x}) \pm 5,2$ & $9588 \pm 1$ & $1402604 \div 24 \pm 9,0$ & 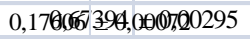 & 70421883,99 & $9 \mathbb{Z} 313,9$ & $8.232 ! \pm 38,1$ & $\pm 118,2$ & $8.2362+.387,2$ & $2 \pm 118,2$ \\
\hline PQXXX-D & (1),63809 & $97219, \pm \pm, 8$ & $5022 \pm \uplus 1$ & $127846 \div ; 84+28,8$ & 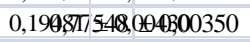 & 6218150,0 & $9 \pm 79,2$ & 9.6986188834 & \pm 1534 & $9.692: 26.826,2$ & $2 \pm 153,4$ \\
\hline PRXE-68 & (1),36851 & $97314 \geq \pm \pm 26$ & $396(0) 434$ & $1402438 \div 84,27,6$ & $0,210,983872,0969,90321$ & 8898800,52 & $\pm 221,7$ & 10.3629 与 499,0 & \pm 145.9 & $10.36429 .593,2$ & $2 \pm 145,9$ \\
\hline PRXY & Q), $487 \overline{7}$ & $14624+3 \pm A$ & $119 p 8 \neq 5 \pm 2$ & $144248 \pm \pm 6,94,6$ & $0,256,396609,0929080274$ & 518164,7 & $\pm 147,5$ & $11.9831 \pm 48047$ & \pm 117.3 & $11.892 .3+.474 .5$ & $5 \pm 117,3$ \\
\hline PXP 716 & Q), 32884 & $19237 \pm \underline{0,4}$ & 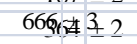 & $1480305,04,99,1$ & $0,268,35 ;$ स $19,096,560489$ & 1295 क 9,4 & $\pm 89,6$ & $12.053\left(c_{4}^{+} 774,8\right.$ & \pm 2397 & $12.011_{37} .486,4$ & $4 \pm 239,7$ \\
\hline PXXF-16 & $8,1,4855$ & $145_{25}, \pm \pm, 4$ & $9946 \frac{1}{4} \pm 2$ & $145829+7,6 \pm 7,5$ & $0,319200339,0924400410$ & 7624839,1 & $\pm 268,2$ & $14.9547 \div 988,4$ & $\pm 205,0$ & $14.875,7$. $.882,9$ & $9 \pm 205,0$ \\
\hline PX16-12 & 0,4481 & $660 \pm 3$ & $1783 \pm 7$ & $2446,8 \pm 9,1$ & $1,67518 \pm 0,00822$ & 10239,0 & $\pm 51,9$ & $66.650,5$ & $\pm 477,1$ & $66.630,6$ & $6 \pm 477,0$ \\
\hline PX16-13 & 0,5166 & $900 \pm 4$ & $3730 \pm 13$ & $2395,1 \pm 9,6$ & $1,71649 \pm 0,00853$ & 6835,8 & $\pm 31,2$ & $70.155,6$ & $\pm 523,3$ & $70.124,8$ & $8 \pm 523,3$ \\
\hline PX16-14 & 0,7154 & $525 \pm 2$ & $2516 \pm 44$ & $2039,9 \pm 7,0$ & $1,58407 \pm 0,00711$ & 5453,5 & $\pm 97,5$ & $73.279,1$ & $\pm 489,5$ & $73.239,3$ & $3 \pm 489,6$ \\
\hline
\end{tabular}


Uranium and thorium is o to pic compositions and ${ }^{230} \mathrm{Th}$ age s for NE Brazil samples by ICP-MS

\begin{tabular}{|c|c|c|c|c|c|c|c|c|c|c|c|c|c|c|c|}
\hline & & & & & & & & & & \multirow{2}{*}{\multicolumn{2}{|c|}{$\left[{ }^{230} \mathrm{Th} /{ }^{232} \mathrm{Th}\right]$}} & \multirow{2}{*}{\multicolumn{2}{|c|}{ Age }} & \multirow{2}{*}{\multicolumn{2}{|c|}{ Age }} \\
\hline \multirow{3}{*}{$\begin{array}{c}\text { Sample } \\
\text { ID } \\
\text { DV1 stalagmite }\end{array}$} & \multirow{3}{*}{$\begin{array}{c}\text { Weight } \\
\mathrm{g}\end{array}$} & \multicolumn{2}{|c|}{${ }^{238} \mathrm{U}$} & \multicolumn{2}{|c|}{${ }^{232} \mathrm{Th}$} & \multicolumn{2}{|c|}{$\delta^{234} \mathbf{U}$} & \multicolumn{2}{|c|}{$\left[{ }^{230} \mathrm{Th} /{ }^{238} \mathrm{U}\right]$} & & & & & & \\
\hline & & \multicolumn{2}{|c|}{ ppb } & \multicolumn{2}{|c|}{ ppt } & \multicolumn{2}{|c|}{ measured $^{a}$} & \multicolumn{2}{|c|}{ activity $^{c}$} & \multicolumn{2}{|c|}{$\mathbf{p p m}^{d}$} & \multicolumn{2}{|c|}{ uncorrected } & \multicolumn{2}{|r|}{ corrected $^{c, e}$} \\
\hline & & & & & & & & & & & & & & & \\
\hline DV1-T & 0,6264 & 62,7 & $\pm 0,1$ & $433=$ & \pm 1 & 1149,3 & $\pm 4,6$ & 0,91752 & $\pm 0,00409$ & 2188 & \pm 12 & 57.446 & \pm 358 & 57.360 & \pm 361 \\
\hline DV2-2 & 0,5695 & 46,4 & $\pm 0,1$ & $207=$ & \pm 1 & 1158,5 & $\pm 5,1$ & 0,96091 & $\pm 0,00608$ & 3559 & \pm 32 & 60.686 & \pm 522 & $60.631=$ & \pm 522 \\
\hline DV1-B & 0,5868 & 58,5 & $\pm 0,1$ & $241=$ & \pm 1 & 1212,2 & $\pm 4,1$ & 1,02528 & $\pm 0,00426$ & 4106 & \pm 27 & 63.673 & \pm 374 & 63.624 & \pm 375 \\
\hline DV2-6 & 0,4005 & 100,3 & $\pm 0,2$ & $63=$ & \pm 2 & 1417,6 & $\pm 4,8$ & 1,16890 & $\pm 0,00424$ & 30757 & \pm 859 & 67.109 & \pm 362 & $67.102=$ & \pm 362 \\
\hline \multicolumn{16}{|l|}{ DV2 stalagmite } \\
\hline DV2-1 & 0,1125 & 7939,2 & $\pm 28,0$ & $128=$ & \pm 6 & 2345,1 & $\pm 4,5$ & 0,00290 & $\pm 0,00004$ & 2956 & \pm 148 & & \pm 1 & & \pm 1 \\
\hline DV2-1 & 0,0842 & 11362,0 & $\pm 27,1$ & $171=$ & \pm 8 & 2179,8 & $\pm 3,1$ & 0,00698 & $\pm 0,00005$ & 7677 & \pm 377 & 240 & \pm 2 & & \pm 2 \\
\hline DV2-2 & 0,1294 & 4779,8 & $\pm 12,3$ & $110=$ & \pm 5 & 2351,1 & $\pm 3,4$ & 0,01405 & $\pm 0,00011$ & 10088 & \pm 501 & 458 & \pm 4 & & \pm 4 \\
\hline DV2-2-1 & 0,1061 & 43112,9 & $\pm 291,3$ & $739=$ & \pm 8 & 2390,2 & $\pm 12,1$ & 0,02084 & $\pm 0,00016$ & 20060 & \pm 216 & 673 & \pm 6 & & \pm 6 \\
\hline DV2-3 & 0,1181 & 10133,0 & $\pm 41,8$ & $42=$ & \pm 6 & 2532,6 & $\pm 5,4$ & 0,02754 & $\pm 0,00015$ & 108970 & \pm 15239 & 852 & \pm 5 & & \pm 5 \\
\hline DV2-3-1 & 0,1271 & 18425,8 & $\pm 46,4$ & $93=$ & \pm 5 & 2351,0 & $\pm 4,8$ & 0,03472 & $\pm 0,00014$ & 113635 & \pm 6719 & 1.136 & \pm 5 & 1.136 & \pm 5 \\
\hline DV2-4 & 0,1308 & 7188,8 & $\pm 24,8$ & $67=$ & \pm 5 & 2444,5 & $\pm 4,5$ & 0,04253 & $\pm 0,00021$ & 75385 & \pm 6015 & 1.352 & \pm 7 & $1.352=$ & \pm 7 \\
\hline DV2-4-1 & 0,1073 & 16447,1 & $\pm 98,5$ & $148=$ & \pm 7 & 2129,6 & $\pm 10,6$ & 0,05125 & $\pm 0,00034$ & 93968 & \pm 4144 & 1.800 & \pm 13 & 1.800 & \pm 13 \\
\hline DV2-5 & 0,1572 & 8710,6 & $5 \pm 41,6$ & $100=$ & \pm 4 & 2359,9 & $\pm 6,0$ & 0,06666 & $\pm 0,00037$ & 96021 & \pm 4285 & 2.179 & \pm 13 & 2.178 & \pm 13 \\
\hline DV2-5-1 & 0,0852 & 10828,4 & $\pm 23,8$ & $135=$ & \pm 8 & 2485,9 & $\pm 5,5$ & 0,08918 & $\pm 0,00032$ & 117840 & \pm 7135 & 2.822 & \pm 11 & $2.822=$ & \pm 11 \\
\hline DV2-6 & 0,1889 & 4690,0 & $\pm 17,7$ & $82=$ & \pm 4 & 2108,3 & $\pm 4,6$ & 0,19736 & $\pm 0,00090$ & 186611 & \pm 8451 & 7.097 & \pm 35 & $7.097=$ & \pm 35 \\
\hline DV2-6-1 & 0,1529 & 27304 & $4 \pm 166$ & $514=$ & \pm 5 & 2210,3 & $\pm 12,0$ & 0,23548 & $\pm 0,00160$ & 206527,3 & $\pm 2195,3$ & $8.250,5$ & $\pm 66,0$ & $8.250=$ & $\pm 66,0$ \\
\hline DV2-B & 0,5161 & 7046,5 & $5 \pm 49,2$ & $293=$ & \pm 2 & 2157,6 & $\pm 7,8$ & 0,25263 & $\pm 0,00197$ & 100060 & \pm 674 & 9.004 & \pm 76 & $9.004=$ & \pm 76 \\
\hline DV2-B-1 & 0,1400 & 4161,2 & $\pm 7,8$ & $306=$ & \pm 5 & 1961,4 & $\pm 4,9$ & 0,25087 & $\pm 0,00085$ & 56315 & \pm 945 & 9.576 & \pm 37 & $9.576=$ & \pm 37 \\
\hline
\end{tabular}

Uranium and thorium iso topic compositions and ${ }^{230} \mathrm{Th}$ ages for NE Brazil samples by ICP-MS

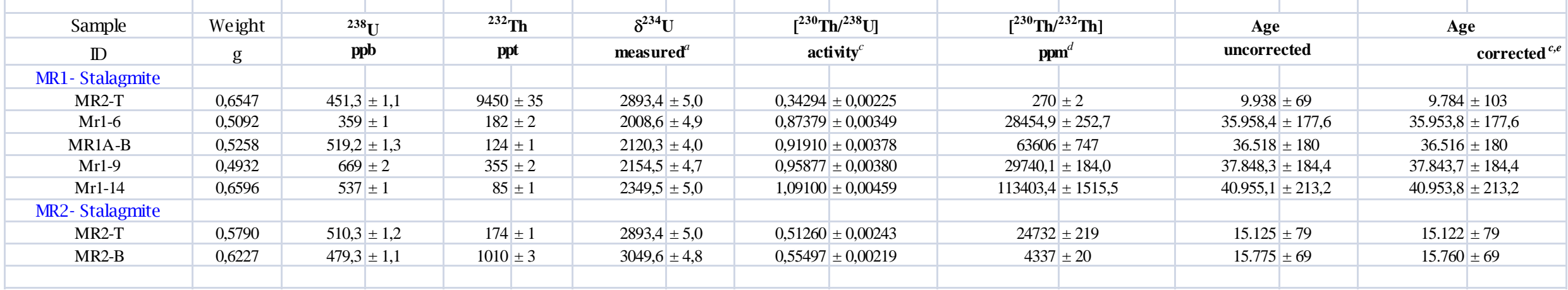


Uranium and thorium isotopic compositions and ${ }^{230} \mathrm{Th}$ ages for NE Brazil samples by ICP-MS

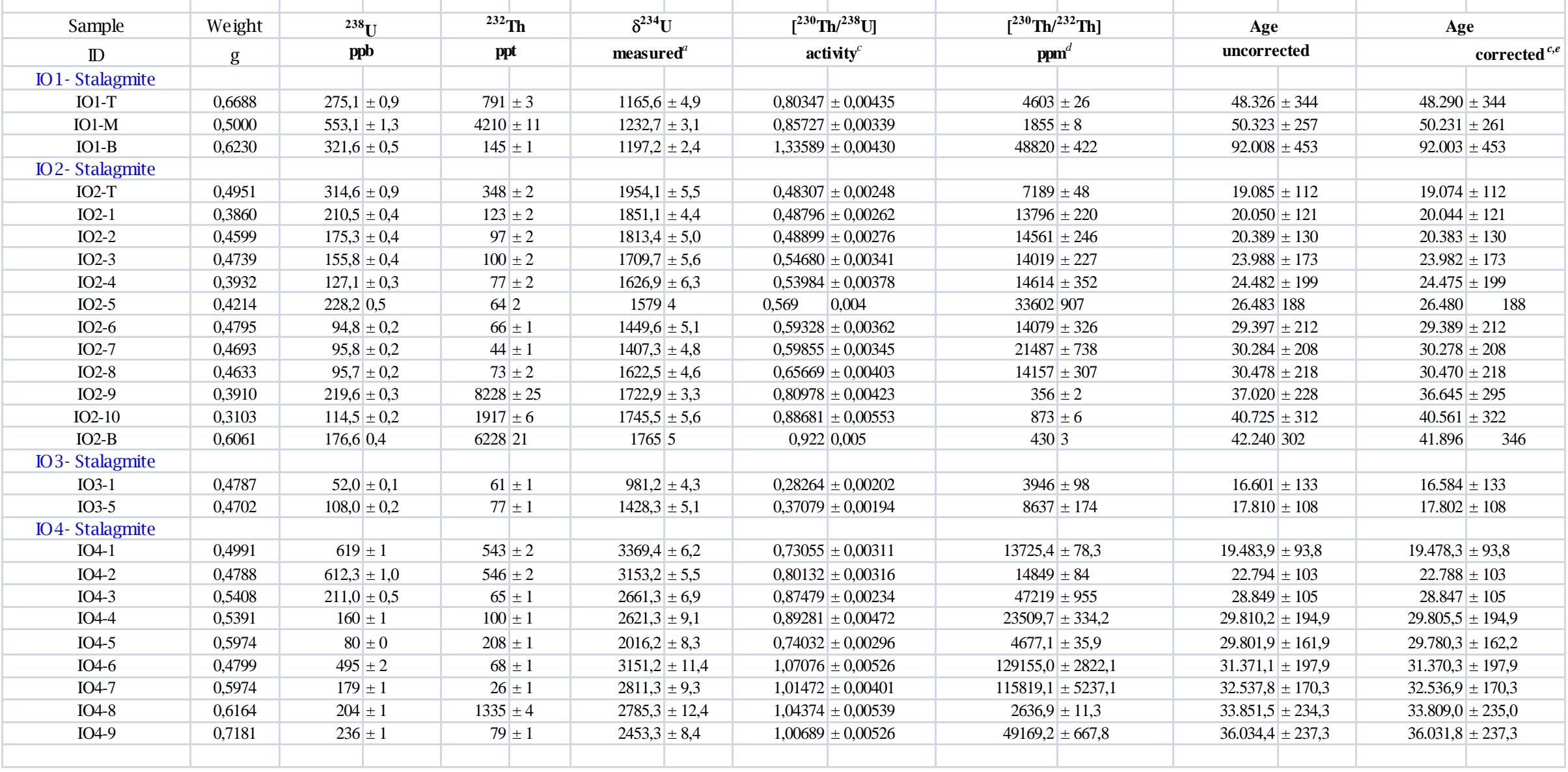




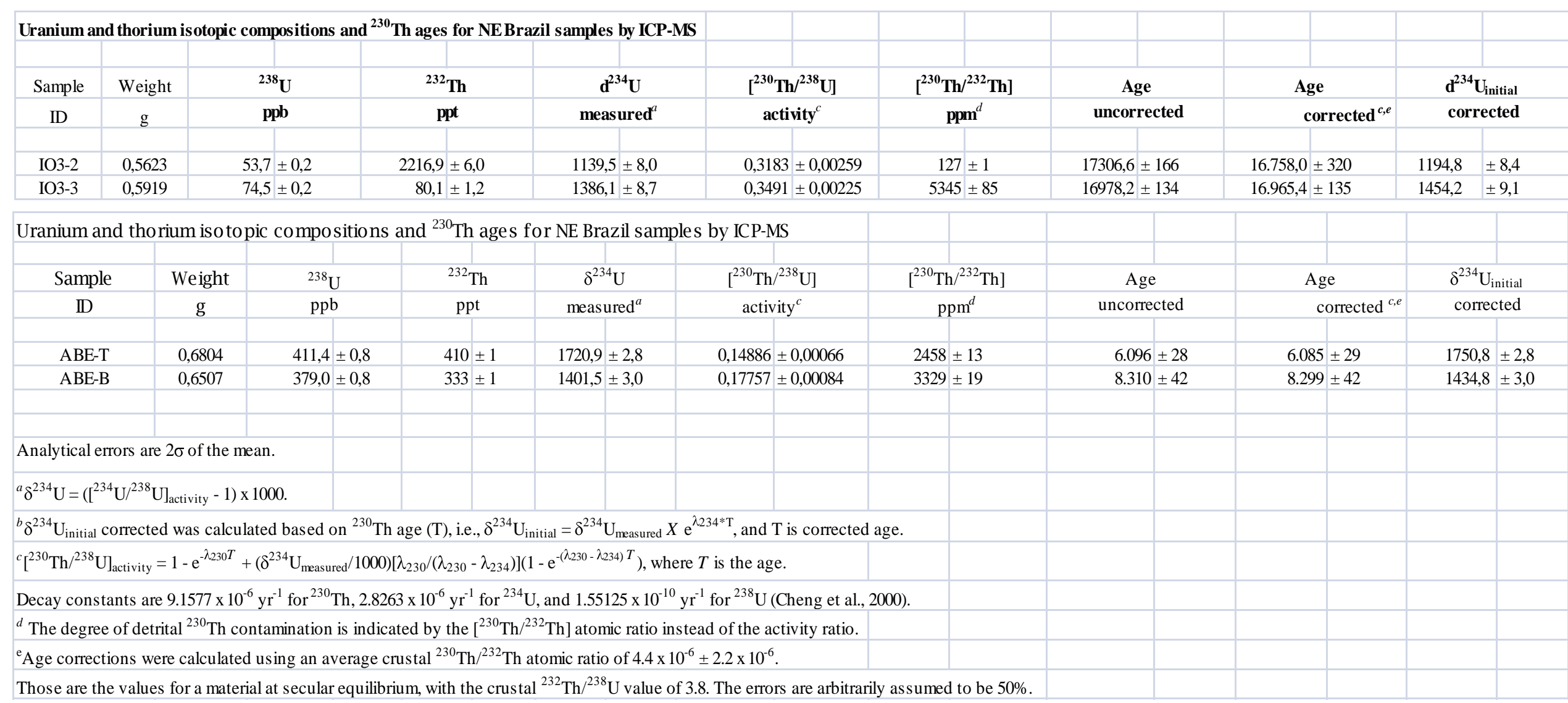

\begin{tabular}{|c|c|c|c|c|c|c|c|c|c|c|}
\hline \multicolumn{11}{|c|}{ Uranium and thorium isotopic compositions and ${ }^{230} \mathrm{Th}$ ages for NE Brazil samples by ICP-MS } \\
\hline Sample & Weight & ${ }^{238} \mathrm{U}$ & ${ }^{232} \mathrm{Th}$ & $d^{234} U$ & {$\left[{ }^{230} \mathrm{Th} /{ }^{238} \mathrm{U}\right]$} & {$\left[{ }^{230} \mathrm{Th} /{ }^{232} \mathrm{Th}\right]$} & Age & Age & \multicolumn{2}{|c|}{$d^{234} U_{\text {initial }}$} \\
\hline ID & $\mathrm{g}$ & ppb & ppt & measured $^{a}$ & activity $^{c}$ & $\mathbf{p p m}^{d}$ & uncorrected & corrected $^{c, e}$ & \multicolumn{2}{|c|}{ corrected } \\
\hline AB-1 & 0,5627 & $671,7 \pm 2,6$ & $729 \pm 18$ & $1430,2 \pm 4,8$ & $0,18308 \pm 0,00773$ & $2779 \pm 135$ & $8.471 \pm 370$ & $8.459 \pm 370$ & 1464.8 & \pm 5.1 \\
\hline AB-2 & 0,6316 & $405,9 \pm 1,7$ & $1358 \pm 4$ & $1519,7 \pm 6,6$ & $0,20552 \pm 0,00132$ & $1012 \pm 6$ & $9.195 \pm 66$ & $9.157 \pm 69$ & 1559,6 & $\pm 6,8$ \\
\hline
\end{tabular}


Uranium and thorium isotopic compositions and ${ }^{230} \mathrm{Th}$ ages for NE Brazil samples by ICP-MS

\begin{tabular}{|c|c|c|c|c|c|c|c|c|c|}
\hline Sample & Weight & ${ }^{238} \mathbf{U}$ & ${ }^{232} \mathrm{Th}$ & $\delta^{234} \mathbf{U}$ & {$\left[{ }^{230} \mathrm{Th} /{ }^{238} \mathrm{U}\right]$} & {$\left[{ }^{230} \mathrm{Th} /{ }^{232} \mathrm{Th}\right]$} & Age & Age & $\delta^{234} \mathbf{U}_{\text {initial }}$ \\
\hline ID & g & ppb & ppt & measured $^{a}$ & activity $^{c}$ & $\mathbf{p p m}^{d}$ & uncorrected & corrected $^{c, e}$ & corrected \\
\hline MR1 - 3 & 0,6138 & $241,6 \pm 0,9$ & $2324,33 \pm 14,3$ & $2132,1 \pm 8,1$ & $0,813393 \pm 0,00706$ & $1393 \pm 14$ & $31657,6 \pm 323$ & $31574 \pm 325$ & $2331,1 \pm 9,1$ \\
\hline MR4 - 1 & 0,5241 & $285,2 \pm 1,4$ & $1481,39 \pm 5,4$ & $1766,4 \pm 10,1$ & $0,754092 \pm 0,00491$ & $2392 \pm 13$ & $33506,9 \pm 285$ & $33455 \pm 285$ & $1941,6 \pm 11,2$ \\
\hline MR4 - 4 & 0,4626 & $475,1 \pm 2,7$ & $898,39 \pm 4,1$ & $1816,1 \pm 9,8$ & $0,863704 \pm 0,00632$ & $7523 \pm 49$ & $38331,0 \pm 359$ & $38313 \pm 359$ & $2023,8 \pm 11,1$ \\
\hline MR5 - 1 & 0,4142 & $222,2 \pm 1,1$ & $5497,02 \pm 23,7$ & $1818,4 \pm 11,6$ & $0,920024 \pm 0,00709$ & $613 \pm 4$ & $41205,1 \pm 423$ & $40968 \pm 437$ & $2041,7 \pm 13,3$ \\
\hline MR5 - 4 & 0,6816 & $1047,8 \pm 4,2$ & $61,33 \pm 1,1$ & $2429,4 \pm 5,2$ & $1,210444 \pm 0,00724$ & $340627 \pm 6074$ & $44969,2 \pm 327$ & $44969 \pm 327$ & $2758,7 \pm 6,4$ \\
\hline MR9 - 1 & 0,3967 & $219,4 \pm 0,6$ & $175,42 \pm 1,8$ & $1787,5 \pm 6,0$ & $0,503748 \pm 0,00231$ & $10377 \pm 116$ & $21267,9 \pm 117$ & $21260 \pm 117$ & $1898,2 \pm 6,4$ \\
\hline MR9 - 3 & 0,3967 & $166,8 \pm 0,5$ & $856,84 \pm 2,9$ & $1766,6 \pm 7,0$ & $0,526671 \pm 0,00259$ & $1689 \pm 9$ & $22505,1 \pm 136$ & $22453 \pm 138$ & $1882,4 \pm 7,5$ \\
\hline MR10 - 1 & 0,3275 & $414,4 \pm 2,2$ & $562,08 \pm 2,8$ & $1892,1 \pm 11,2$ & $0,518886 \pm 0,00344$ & $6302 \pm 41$ & $21093,7 \pm 176$ & $21081 \pm 176$ & $2008,3 \pm 11,9$ \\
\hline MAG - 1 & & $227,0 \pm 0,5$ & $12229 \pm 245$ & $2168,1 \pm 14,3$ & $0,5275 \pm 0,0015$ & $161,5 \pm 3,3$ & $19464 \pm 113$ & $18986 \pm 356$ & $2287 \pm 15$ \\
\hline MAG - 12 & & $298,7 \pm 0,6$ & $196 \pm 4$ & $2060,4 \pm 3,9$ & $0,3219 \pm 0,0009$ & $8090,7 \pm 164,1$ & $11976 \pm 40$ & $11970 \pm 40$ & $2131 \pm 4$ \\
\hline MAG - 18 & & $449,0 \pm 0,9$ & $298 \pm 6$ & $2202,1 \pm 3,8$ & $0,8025 \pm 0,0024$ & $19904 \pm 403$ & $30436 \pm 109$ & $30431 \pm 109$ & $2400 \pm 4$ \\
\hline MAG - 24 & & $403,6 \pm 0,8$ & $185 \pm 4$ & $2259,8 \pm 3,8$ & $1,0466 \pm 0,0030$ & $37651 \pm 763$ & $40334 \pm 144$ & $40330 \pm 144$ & $2532 \pm 4$ \\
\hline MAG - 26 & & $677,7 \pm 1,3$ & $731 \pm 15$ & $2366,3 \pm 4,1$ & $1,1018 \pm 0,0029$ & $16852 \pm 340$ & $41220 \pm 140$ & $41212 \pm 140$ & $2658 \pm 5$ \\
\hline MAG - 30 & & $597,6 \pm 1,2$ & $2323 \pm 47$ & $2297,5 \pm 4,6$ & $1,1220 \pm 0,0032$ & $4759 \pm 96$ & $43151 \pm 160$ & $43119 \pm 161$ & $2595 \pm 5$ \\
\hline MAG - 32 & & $670,2 \pm 1,2$ & $384 \pm 8$ & $2315,4 \pm 4,0$ & $1,1526 \pm 0,0029$ & $33194 \pm 670$ & $44247 \pm 145$ & $44243 \pm 145$ & $2623 \pm 5$ \\
\hline MAG - 34 & & $985,7 \pm 2,1$ & $269 \pm 5$ & $2287,0 \pm 4,3$ & $1,1780 \pm 0,0035$ & $71270 \pm 1443$ & $45869 \pm 175$ & $45867 \pm 175$ & $2603 \pm 5$ \\
\hline MAG - 36 & & $296,0 \pm 0,5$ & $127 \pm 3$ & $1889,0 \pm 3,5$ & $1,1928 \pm 0,0031$ & $45918 \pm 933$ & $54576 \pm 193$ & $54572 \pm 193$ & $2204 \pm 4$ \\
\hline MAG - 37 & & $899,2 \pm 1,7$ & $1035 \pm 21$ & $2030,2 \pm 3,5$ & $1,2734 \pm 0,0034$ & $18232 \pm 368$ & $55696 \pm 203$ & $55686 \pm 203$ & $2376 \pm 4$ \\
\hline MAG - 40 R & EPLICA & $1133,5 \pm 2,1$ & $1067 \pm 21$ & $1863,6 \pm 3,9$ & $1,2259 \pm 0,0032$ & $21472 \pm 433$ & $57087 \pm 209$ & $57078 \pm 209$ & $2189 \pm 5$ \\
\hline MAG - 40 & & $1959,1 \pm 3,0$ & $1064 \pm 21$ & $1867,9 \pm 3,6$ & $1,2271 \pm 0,0027$ & $37242 \pm 750$ & $57043 \pm 181$ & $57038 \pm 181$ & $2194 \pm 4$ \\
\hline MAG - 38 & & $522,3 \pm 1,2$ & $415 \pm 8$ & $1899,1 \pm 4,3$ & $1,2226 \pm 0,0037$ & $25349 \pm 513$ & $56010 \pm 237$ & $56002 \pm 237$ & $2224 \pm 5$ \\
\hline MAG - 39 & & $444,7 \pm 0,7$ & $534 \pm 11$ & $1758,6 \pm 3,4$ & $1,1655 \pm 0,0023$ & $15992 \pm 322$ & $56230 \pm 166$ & $56218 \pm 166$ & $2061 \pm 4$ \\
\hline MAG - 43 & & $210,2 \pm 0,3$ & $354 \pm 7$ & $2060,0 \pm 3,2$ & $1,4888 \pm 0,0030$ & $14591 \pm 294$ & $66932 \pm 199$ & $66918 \pm 199$ & $2488 \pm 4$ \\
\hline MAG - 46 & & $1039,2 \pm 2,5$ & $602 \pm 12$ & $2199,3 \pm 4,1$ & $1,9311 \pm 0,0065$ & $54917 \pm 1114$ & $89123 \pm 448$ & $89118 \pm 448$ & $2828 \pm 6$ \\
\hline
\end{tabular}


Uranium and thorium isotopic compositions and ${ }^{230} \mathrm{Th}$ age s for NE Brazil samples by ICP-MS

\begin{tabular}{|c|c|c|c|c|c|c|c|c|c|c|c|c|c|c|c|c|c|}
\hline Sample & Weight & \multicolumn{2}{|c|}{${ }^{238} \mathrm{U}$} & \multicolumn{2}{|c|}{${ }^{232} \mathrm{Th}$} & \multicolumn{2}{|c|}{$\delta^{234} \mathrm{U}$} & \multicolumn{2}{|c|}{$\left[{ }^{230} \mathrm{Th} /{ }^{238} \mathrm{U}\right]$} & \multicolumn{2}{|c|}{$\left[{ }^{230} \mathrm{Th} /{ }^{232} \mathrm{Th}\right]$} & \multicolumn{2}{|c|}{ Age } & \multicolumn{2}{|c|}{ Age } & \multicolumn{2}{|c|}{$\delta^{234} U_{\text {initial }}$} \\
\hline ID & g & \multicolumn{2}{|c|}{ ppb } & \multicolumn{2}{|c|}{ ppt } & \multicolumn{2}{|c|}{ measured $^{a}$} & \multicolumn{2}{|c|}{ activity $^{c}$} & \multicolumn{2}{|c|}{$\mathbf{p p m}^{d}$} & \multicolumn{2}{|c|}{ uncorrected } & \multicolumn{2}{|r|}{ corrected $^{c, e}$} & \multicolumn{2}{|c|}{ corrected } \\
\hline \multicolumn{2}{|c|}{ Espeleotema FM 1} & & & & & & & & & & & & & & & & \\
\hline FM1-A & 0,7544 & 72,78555 & $\pm 0,2$ & 116,0302 & $\pm 1,0$ & 774,1997 & $\pm 6,4$ & 0,261252 & $\pm 0,00156$ & 2700 & \pm 26 & 17159,4 & \pm 129 & $17.133,8$ & \pm 129 & 812,6131 & $\pm 6,7$ \\
\hline FM1-B & 0,6129 & 256,145 & $\pm 0,8$ & 171,6423 & $\pm 1,3$ & 758,7097 & $\pm 4,1$ & 0,5581 & $\pm 0,00275$ & 13720 & \pm 114 & 40410,5 & \pm 261 & $40.400,0$ & \pm 261 & 850,4807 & $\pm 4,6$ \\
\hline \multicolumn{18}{|c|}{ Espeleotema FM 2} \\
\hline FM-1 & 0,5673 & 531,7 & $\pm 2,1$ & 228,2 & $\pm 1,4$ & 828,2 & $\pm 5,4$ & 0,2646 & $\pm 0,00140$ & 10157 & \pm 71 & 16836,1 & \pm 109 & $16.829,5$ & \pm 109 & 868,6 & $\pm 5,6$ \\
\hline FM-2 & 0,6518 & 811,6 & $\pm 2,8$ & 40,8 & $\pm 1,1$ & 754,2 & $\pm 3,0$ & 0,7901 & $\pm 0,00396$ & 259044 & \pm 6924 & 62142,4 & \pm 427 & $62.141,6$ & \pm 427 & 899,0 & $\pm 3,8$ \\
\hline \multicolumn{18}{|c|}{ Espeleotema FM 3} \\
\hline FM - 3 & 0,5669 & 2212,6 & $\pm 6,8$ & 88,2 & $\pm 1,3$ & 741,1 & $\pm 2,6$ & 0,7886 & $\pm 0,00389$ & 325928 & \pm 4899 & 62621,5 & \pm 419 & $62.620,9$ & \pm 419 & 884,6 & $\pm 3,3$ \\
\hline FM - 4 & 0,6283 & 1264,7 & $\pm 6,1$ & 49,5 & $\pm 1,1$ & 804,3 & $\pm 4,8$ & 0,2544 & $\pm 0,00158$ & 107118 & \pm 2469 & 16377,7 & \pm 118 & $16.377,1$ & \pm 118 & 842,5 & $\pm 5,0$ \\
\hline FM - 5 & 0,5639 & 1017,9 & $\pm 4,7$ & 100,1 & $\pm 1,3$ & 816,2 & $\pm 5,5$ & 0,2617 & $\pm 0,00163$ & 43827 & \pm 591 & 16759,0 & \pm 124 & $16.757,5$ & \pm 124 & 855,8 & $\pm 5,7$ \\
\hline & & & & & & & & & & & & & & & & & \\
\hline & & & & & & & & & & & & & & & & & \\
\hline \multicolumn{18}{|c|}{$\left.* \delta^{234} \mathrm{U}=\left({ }^{234} \mathrm{U} /^{238} \mathrm{U}\right]_{\text {activity }}-1\right) \times 1000 . * * \delta^{234} \mathrm{U}_{\text {initial }}$ was calculated based on ${ }^{230} \mathrm{Th}$ age $(\mathrm{T})$, i.e., $\delta^{234} \mathrm{U}_{\text {initial }}=\delta^{234} \mathrm{U}_{\text {measured }} \mathrm{xe} \mathrm{e}^{\lambda 234 \times \mathrm{T}}$} \\
\hline \multicolumn{18}{|c|}{ Corrected ${ }^{230} \mathrm{Th}$ ages assume the initial ${ }^{230} \mathrm{Th} /{ }^{232} \mathrm{Th}$ atomic ratio of $4.4 \pm 2.2 \times 10^{-6}$. Those are the values for a material at secular } \\
\hline equilibriun & , with the by & alk earth ${ }^{232} \mathrm{Tl}$ & $\mathrm{Th} /{ }^{238} \mathrm{U}$ & e of 3.8. The & e errors & arbitrarily ass & sumed $\mathrm{t}$ & $50 \%$. & & & & & & & & & \\
\hline
\end{tabular}

